Bruno Henrique Martins

\title{
Aspectos químicos e potencial de sequestro de carbono em áreas sob diferentes manejos de solo
}

Tese apresentada ao Instituto de Química de São Carlos, da Universidade de São Paulo, como parte dos requisitos para obtenção do título de doutor em ciências.

Área de concentração: Química Analítica e Inorgânica

Orientador: Dr. Ladislau Martin-Neto

Exemplar revisado

$\mathrm{O}$ exemplar original encontra-se em acervo reservado na biblioteca do IQSC-USP

São Carlos

2013 
DEDICO E OFEREÇO

À memória de meus avôs Lucírio, Luzia e Benedicto, E à minha avó Lola, por terem me dado o maior presente de todos: MEUS PAIS 
"Se você não aceita o conselho, te respeito

Resolveu seguir, ir atrás, cara e coragem Só que você sai em desvantagem se você não tem fé Se você não tem fé Te mostro um trecho, uma passagem de um livro antigo

Pra te provar e mostrar que a vida é linda Dura, sofrida, carente em qualquer continente Mas boa de se viver em qualquer lugar".

O Rappa-Anjos (Pra quem tem Fé)

We believe in one God, the Father, the Almighty maker of heaven and earth, of all that is seen and unseen. We believe in one Lord, Jesus Christ, the only Son of God, eternally begotten of the Father; God from God, Light from Light, true God from true God, Begotten, not made, of one Being with the Father. Through Him all things were made. For us and for our salvation. He came down from heaven: by the power of the Holy Spirit, He became incarnate from the Virgin Mary, and was made man.

For our sake he was crucified under Pontius Pilate; He suffered death and was buried.

On the third day he rose again in accordance with the Scriptures; He ascended into heaven and is seated at the right hand of the Father. He will come again in glory to judge the living and the dead, And His kingdom will have no end.

We believe in the Holy Spirit, the Lord, the giver of Life, Who proceeds from the Father and the Son. With the Father and the Son he is worshipped and glorified.

He has spoken through the Prophets.

We believe in one holy catholic and apostolic church.

We acknowledge one baptism for the forgiveness of sins. We look for the resurrection of the dead and the life of the world to come. Amen. 


\section{AGRADECIMENTOS}

A Deus, Todo Poderoso, Jesus Cristo, Pai de Misericórdia, e Sua legião de Anjos da Guarda, pelas vitórias e derrotas, pela fé e perseverança, apontando-me as direções a serem seguidas em todos os momentos da vida;

A meus pais, Silvio e Neusa, por todo seu esforço em tornar-me uma pessoa melhor a cada dia que passa através de seu exemplo, seu carinho e amor inestimáveis, levando-me a transpor todos os obstáculos que possam aparecer. Nada disso seria realizado sem a presença destes dois anjos;

Ao Dr. Ladislau Martin-Neto por todos os anos de orientação, oportunidades, preocupações com bem estar, reuniões, amizade, apoio, sábias palavras e descontração. Meus mais sinceros e profundos agradecimentos;

Ao Dr. Wilson Tadeu Lopes da Silva e Dra. Débora M. B. P. Milori pela colaboração e pelas sempre oportunas colocações e sugestões;

Ao Sérgio Gaiad e Tania Almeida, pelo auxílio durante as atividades em campo experimental brasileiro;

Ao Dr. Michel A. Cavigelli, pela oportunidade de trabalho e supervisão durante o período de doutorado sanduíche;

Ao Drs. Jude E. Maul, Jeffrey S. Buyer e James Reeves III, pela colaboração na realização das medidas experimentais no período de estudo realizado no exterior;

À Anh Le, Chris Rasmann, Anne Conklin, Betty Marose e estagiários, pelo suporte nas atividades em campo experimental norte-americano;

Ao Dr. Ednaldo J. Ferreira, pelo auxílio nas análises estatísticas;

À minha noiva Thalita, por todos os anos de carinho e companheirismo;

À Silviane Hubinger, pelo apoio nas atividades no laboratório da Embrapa Instrumentação;

À Kate White, pelo apoio nas atividades no laboratório do ARS/USDA;

Ao Valentim e Daniel, pelo incansável auxílio nas impressões de trabalhos;

Aos funcionários do Serviço de Pós-Graduação do IQSC, Silvia Plepis, Andréia Moraes e Gustavo Costa, pelo auxílio com documentações e bolsas;

Às bibliotecárias do IQSC, pelo auxílio nas correções bibliográficas;

À Elena Pereira, por gentilmente abrir as portas de sua casa e me acolher tão carinhosamente no período de doutorado sanduíche;

Ao Felippe (Tinko) Boeira, Elayne Boeira, aos meninos Erik e Kayo, Osmar (Mazinho) Rosa, Katia Bautista, as meninas Stephanie e Nicole, Kenia, Yathan, por me acolherem e tratarem como membro de suas famílias em todos os momentos; 
A todos os novos amigos de Beltsville, College Park e redondezas, em especial a Magnus Teixeira e Alexandre Ricardo Silva;

Aos amigos de trabalho: Cleber, Lívia, Lilian, Camila, Guto, Anielle, Renan, Aline, pelas horas de descontração, viagens, discussões em grupo, sugestões e pontos de vista.

Ao sempre presente irmão por escolha Matheus Postigo, pelas longas conversas e risos sempre propícios em todas as horas;

Ao IQSC, Embrapa Instrumentação e Beltsville Agricultural Research Center (BARC), pelas inigualáveis infraestruturas utilizadas para a realização deste trabalho;

À Embrapa-Labex, pela oportunidade de realização de doutorado sanduíche;

À CAPES e ao CNPq pelas bolsas concedidas durante o período de doutorado no Brasil e nos Estados Unidos, respectivamente;

A todos os demais que direta e indiretamente contribuíram para a realização deste trabalho. 


\section{SUMÁRIO}

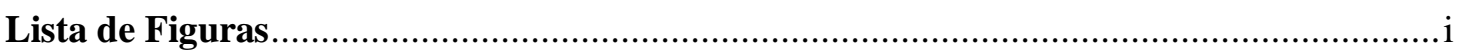

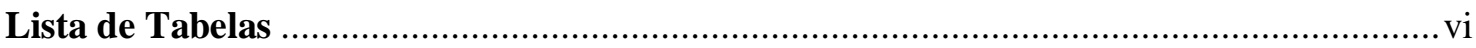

Lista de Siglas e Abreviaturas ....................................................................................... vii

Resumo

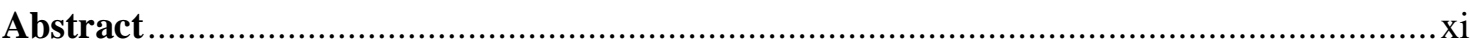

1 - Introdução

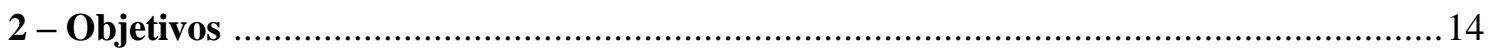

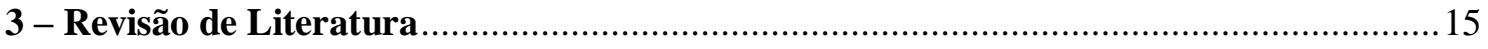

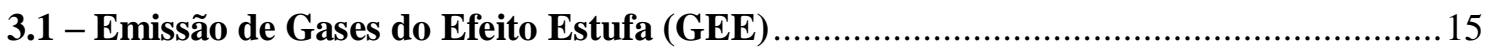

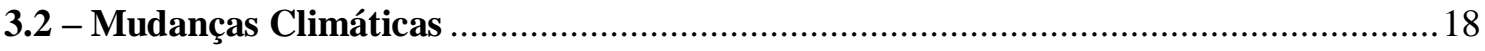

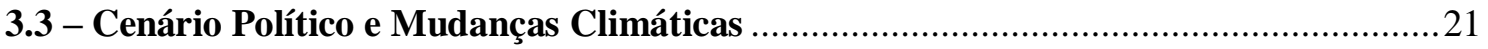

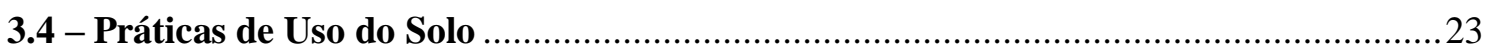

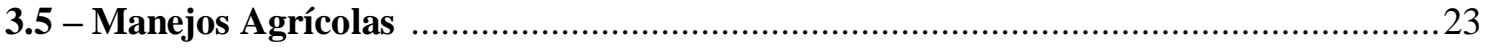

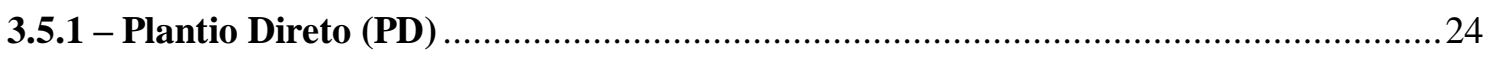

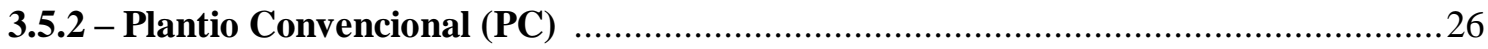

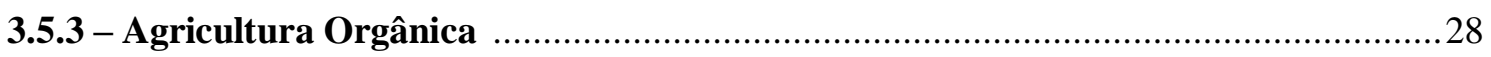

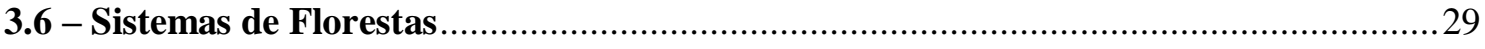

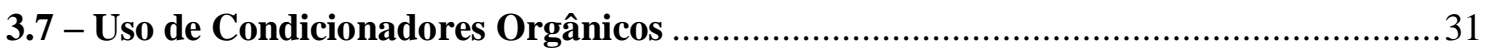

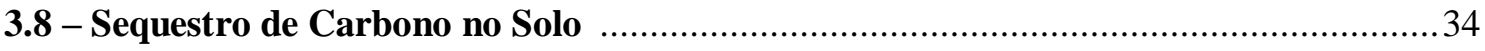

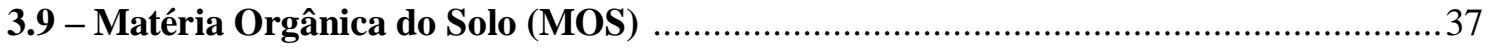

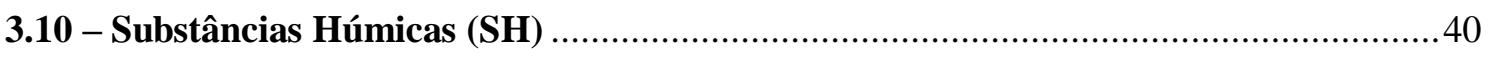

3.11 - Técnicas Analíticas e Espectroscópicas …............................................................. 44

3.11.1 - Pirólise Acoplada a Cromatografia a Gás/Espectrometria de Massas (PY-GC/MS)

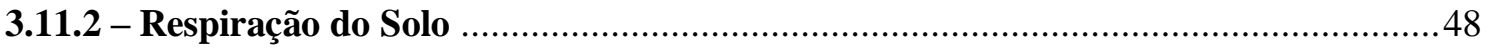

3.11.3 - Espectroscopia de Absorção na Região do Infravermelho ....................................49

3.11.4 - Espectroscopia de Absorção na Região do Ultravioleta e Visível (UV-Vis) ...........51

3.11.5 - Espectroscopia de Fluorescência de Luz UV - Vis ............................................53 
3.11.6 - Espectroscopia de Fluorescência Induzida por Laser (FIL) ...................................57

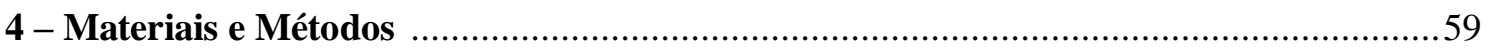

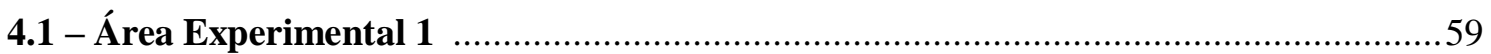

4.1.1 - Fracionamento Físico - Área Experimental 1 ....................................................6 61

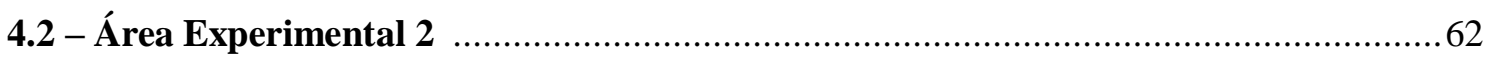

4.2.1 - Fracionamento Químico - Área Experimental 2 …..................................................63

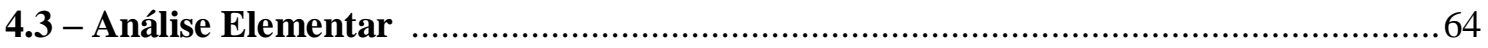

4.4 - Espectroscopia de Fluorescência Induzida por Laser (FIL) …................................65

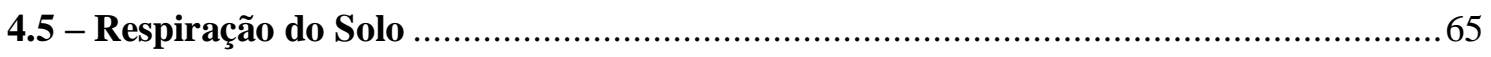

4.6 - Espectroscopia de Absorção na Região do Infravermelho ..........................................65

4.7 - Pirólise Acoplada a Cromatografia a Gás/Espectrometria de Massas (PY - GC/MS)

4.8 - Espectroscopia de Absorção na Região do Ultravioleta e Visível (UV-Vis) ..............66

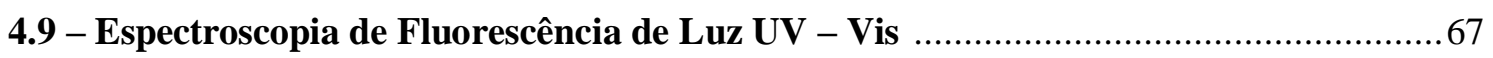

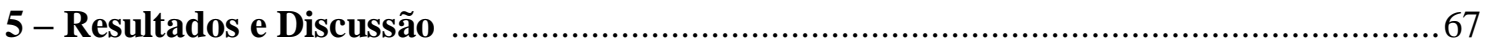

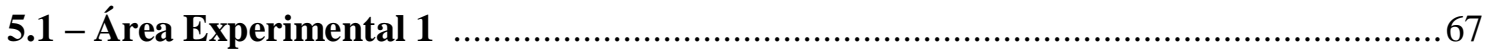

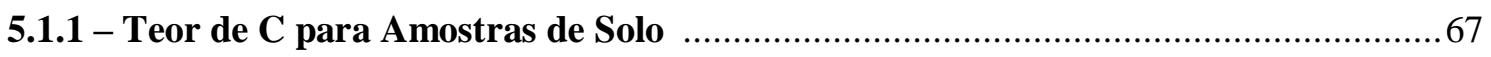

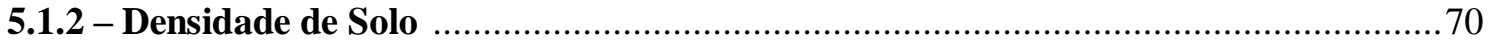

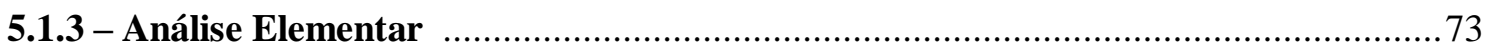

5.1.3.1 - Matéria Orgânica Particulada Livre (MOPI) ….............................................. 73

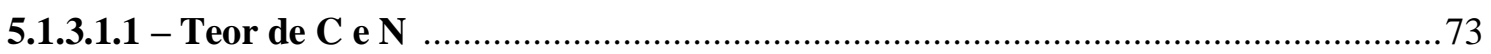

5.1.3.2 - Matéria Orgânica Particulada Oclusa (MOPo) ...................................................75

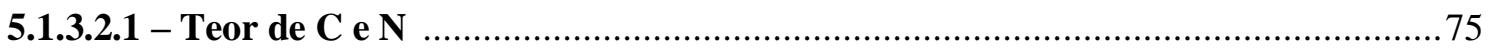

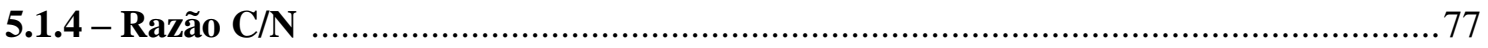

5.1.5 - Espectroscopia de Absorção na Região do Infravermelho ……............................78

5.1.6 - Pirólise Acoplada a Cromatografia a Gás/Espectrometria de Massas (PY - GC/MS)

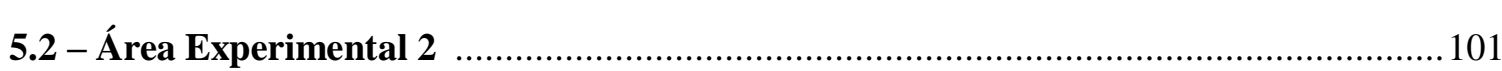

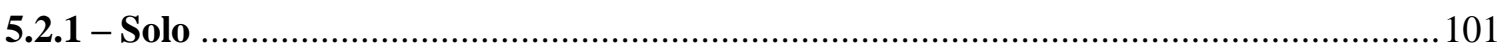

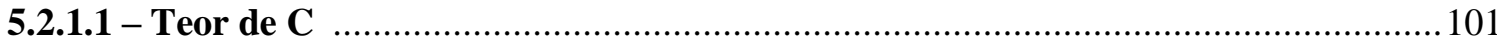

5.2.1.2 - Espectroscopia de Fluorescência Induzida por Laser (FIL) ................................. 104

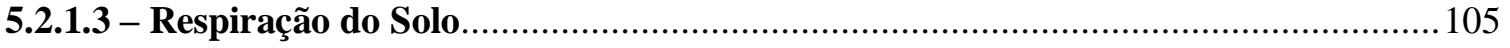


5.2.2.1 - Espectroscopia de Absorção na Região do Infravermelho .................................. 108

5.2.2.2 - Espectroscopia de Absorção na Região do Ultravioleta e Visível (UV-Vis) ........111

5.2.2.3 - Espectroscopia de Fluorescência de Luz UV - Vis .............................................113

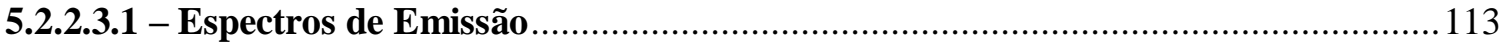

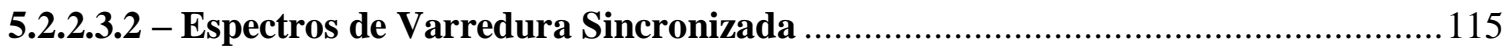

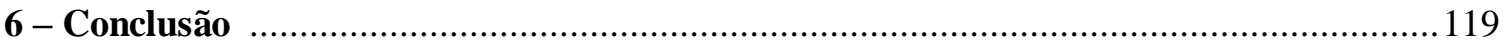

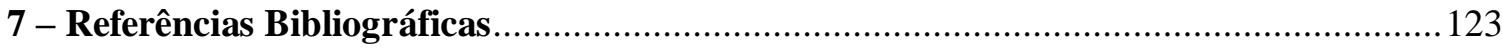




\section{LISTA DE FIGURAS}

Fig. 1 - Níveis de concentração de $\mathrm{CO}_{2}$ atmosférico através dos anos (adaptado de VijayaVengataRaman, et al., 2012).

Fig. 2 - Ilustração de mecanismo de efeito estufa (adaptado de Schahzenski e Hill, 2009). Radiação solar atravessa a camada natural de gases atmosféricos. Alguns raios solares incidentes no planeta são absorvidos e transformados em calor (1), levando ao aquecimento da superfície. A superfície, por sua vez, reemite a radiação para a atmosfera (2), sendo esta parcialmente absorvida pelos GEE (3), que por sua vez a "devolve" à superfície terrestre (4). O montante não absorvido pelos GEE é retornado ao espaço (5). Atividades humanas que levam à emissão adicional de GEE para a atmosfera (6) aumentam a quantidade de radiação que é absorvida, antes de ser reemitida para o espaço, assim aumentando o efeito estufa e levando, consequentemente, ao aquecimento global

Fig. 3 - Variação de temperatura global (adaptado de VijayaVengataRaman, et al., 2012).......

Fig. 4 - Variação de nível do mar (adaptado de VijayaVengataRaman, et al., 2012).

Fig. 5 - Representação esquemática dos efeitos da aplicação de condicionadores orgânicos na emissão de gases do efeito estufa $\left(\mathrm{CO}_{2}, \mathrm{CH}_{4}\right.$ e $\left.\mathrm{N}_{2} \mathrm{O}\right)$ (Adaptado de Thangarajan, et al., 2013).

Fig. 6 - Representação esquemática de fatores que influenciam diretamente no potencial de sequestro de carbono no solo (adaptado de Nair et al., 2009).

Fig. 7 - Frações fisicamente separadas da MOS (Adaptado de Plaza, et al., 2013).

Fig. 8 - Modelo macromolecular de ácidos húmicos proposto por Schulten e Schnitzer (1993)

Fig. 9 - Comparativo entre os modelos de estruturas de substâncias húmicas propostas por Simpson. et al., (2002). Em (A) observa-se a proposta de que as SH sejam uma única macromolécula. Em (B) observa-se a proposta de que as SH sejam um agregado de molécula com menor massa molecular (> $2.000 \mathrm{Da}$ ). Em vermelho representam-se cátions metálicos, em marrom, fragmentos de lignina, em azul, polipeptídeos, em preto, polissacarídeos e em verde, cadeias alifáticas.

Fig. 10 - Representação esquemática de pirolizador (Adaptado de Moldoveanu, 2005).

Fig. 11 - Representação esquemática do processo de respiração (Adaptado de material de aula do Prof. Dr. Carlos E. P. Cerri).

Fig. 12 - Representação de espectro eletromagnético (Adaptado de Rossell, et al., (2006)) ......

Fig. 13 - Representação esquemática de transições eletrônicas possíveis entre orbitais (Adaptado de Skoog, et al., (2002))

Fig. 14 - Diagrama de Jablonski (Adaptado de Sotomayor, et al., (2008))

Fig. 15 - Comparativo entre instrumentações de FIL de bancada (a) e portátil (b). Em (a): (1) laser de Argônio, (2) prisma, $(3,4,5)$ espelhos planos, (6) lente convergente, (7) modulador (optical chopper), (8) filtro, (9) monocromador, (10) fotomultiplicadora, (11) amplificador lock-in e (12) aquisição de dados (Milori et al., (2012)). 
Fig. 16 - Delineamento experimental do FSP. As diferentes cores representam as localizações dos sistemas analisados e as numerações ilustram identificação logística de campo. As letras apresentadas representam as culturas em cada parcela, sendo: A1,A2,A3 - alfafa de $1^{\circ}, 2^{\circ}$ e $3^{\circ}$ ano, respectivamente; $\mathrm{C}$ - milho, SB - soja; W/SB - trigo/soja; W/F - trigo/baga; r,v - plantas de cobertura. Em destaque, as parcelas de onde foram coletadas as amostras de solo.

Fig. 17 - Gráfico de valores de teor de C para amostras de solo para os diferentes sistemas analisados, onde PC - plantio convencional com manejo mínimo, ORG2 - agricultura orgânica de 2 anos, ORG3 - agricultura orgânica de 3 anos, ORG6 - agricultura orgânica de 6 anos e PD - plantio direto sem manejo.

68

Fig. 18 - Gráfico de valores de densidade de solo para amostras de solo intacto para os diferentes sistemas analisados, onde PC - plantio convencional com manejo mínimo, ORG2 - agricultura orgânica de 2 anos, ORG3 - agricultura orgânica de 3 anos, ORG6 - agricultura orgânica de 6 anos e $\mathrm{PD}$ - plantio direto sem manejo.

Fig. 19 - Gráfico de valores de teores de $\mathrm{C}$ e $\mathrm{N}$ para amostras de matéria organica livre particulada (MOPl) para o diferentes sistemas analisados, onde PC - plantio convencional com manejo mínimo, ORG2 - agricultura orgânica de 2 anos, ORG3 - agricultura orgânica de 3 anos, ORG6 - agricultura orgânica de 6 anos e PD - plantio direto sem manejo

Fig. 20 - Gráfico de valores de teores de $\mathrm{C}$ e $\mathrm{N}$ para amostras de matéria organica particulada oclusa (MOPo) para os diferentes sistemas analisados, onde PC - plantio convencional com manejo mínimo, ORG2 - agricultura orgânica de 2 anos, ORG3 - agricultura orgânica de 3 anos, ORG6 - agricultura orgânica de 6 anos e PD - plantio direto sem manejo

Fig. 21 - Gráfico de valores de razão C/N para amostras de matéria orgânica particulada livre (MOPl), à direita, e oclusa (MOPo), à esquerda, para os diferentes sistemas analisados, onde PC - plantio convencional com manejo mínimo, ORG2 - agricultura orgânica de 2 anos, ORG3 - agricultura orgânica de 3 anos, ORG6 - agricultura orgânica de 6 anos e PD - plantio direto sem manejo.

Fig. 22 - Espectros de infravermelho para amostras de matéria orgânica particulada livre (MOPl), à esquerda, e oclusa (MOPo), à direita, para o sistema PD - plantio direto sem manejo, sendo (a) 0-5, (b) 5-10, (c) 10-20, (d) 20-25 e (e) 25-30 cm. Nos espectros estão representados os picos mais relevantes.

Fig. 23 - Espectros de infravermelho para amostras de matéria orgânica particulada livre (MOPl), à esquerda, e oclusa (MOPo), à direita, para o sistema PC - plantio convencional com manejo mínimo, sendo (a) 0-5, (b) 5-10, (c) 10-20, (d) 20-25 e (e) 25-30 cm. Nos espectros estão representados os picos mais relevantes.

Fig. 24- Espectros de infravermelho para amostras de matéria orgânica particulada livre (MOPl), à esquerda, e oclusa (MOPo), à direita, para o sistema ORG2 - Agricultura Orgânica de 2 anos, sendo (a) 0-5, (b) 5-10, (c) 10-20, (d) 20-25 e (e) $25-30 \mathrm{~cm}$. Nos espectros estão representados os picos mais relevantes.....

Fig. 25 - Espectros de infravermelho para amostras de matéria orgânica particulada livre (MOPl), à esquerda, e oclusa (MOPo), à direita, para o sistema ORG3 - Agricultura Orgânica de 3 anos, sendo (a) 0-5, (b) 5-10, (c) 10-20, (d) 20-25 e (e) 25-30 cm. Nos espectros estão representados os picos mais relevantes. 
Fig. 26 - Espectros de infravermelho para amostras de matéria orgânica particulada livre (MOPl), à esquerda, e oclusa (MOPo), à direita, para o sistema ORG6 - Agricultura Orgânica de 6 anos, sendo (a) 0-5, (b) 5-10, (c) 10-20, (d) 20-25 e (e) 25-30 cm. Nos espectros estão representados os picos mais relevantes.

Fig. 27 - Cromatograma para amostras de matéria orgânica particulada livre (MOPl), na profundidade 5-10 cm, para o sistema PD - plantio direto sem manejo. Ao lado estão identificados os picos e seus respectivos tempos de retenção (RT).

Fig. 28 - Cromatograma para amostras de matéria orgânica particulada livre (MOPl), na profundidade 5-10 cm, para o sistema PC - plantio convencional com manejo mínimo. Ao lado estão identificados os picos e seus respectivos tempos de retenção (RT).

Fig. 29 - Cromatograma para amostras de matéria orgânica particulada livre (MOPl), na profundidade 5-10 cm, para o sistema ORG2 - agricultura orgânica de 2 anos. Ao lado estão identificados os picos e seus respectivos tempos de retenção $(\mathrm{RT})$.

Fig. 30 - Cromatograma para amostras de matéria orgânica particulada livre (MOPl), na profundidade 5-10 cm, para o sistema ORG3 - agricultura orgânica de 3 anos. Ao lado estão identificados os picos e seus respectivos tempos de retenção (RT).

Fig. 31 - Cromatograma para amostras de matéria orgânica particulada livre (MOPl), na profundidade 5-10 cm, para o sistema ORG6 - agricultura orgânica de 6 anos. Ao lado estão identificados os picos e seus respectivos tempos de retenção (RT).

Fig. 32 - Cromatograma para amostras de matéria orgânica particulada oclusa (MOPo), na profundidade 5-10 cm, para o sistema PD - plantio direto sem manejo. Ao lado estão identificados os picos e seus respectivos tempos de retenção (RT).

Fig. 33 - Cromatograma para amostras de matéria orgânica particulada oclusa (MOPo), na profundidade 5-10 cm, para o sistema PC - plantio convencional com manejo mínimo. Ao lado estão identificados os picos e seus respectivos tempos de retenção (RT).

Fig. 34 - Cromatograma para amostras de matéria orgânica particulada oclusa (MOPo), na profundidade 5-10 cm, para o sistema ORG2 - agricultura orgânica de 2 anos. Ao lado estão identificados os picos e seus respectivos tempos de retenção (RT).

Fig. 35 - Cromatograma para amostras de matéria orgânica particulada oclusa (MOPo), na profundidade 5-10 cm, para o sistema ORG3 - agricultura orgânica de 3 anos. Ao lado estão identificados os picos e seus respectivos tempos de retenção (RT).

Fig. 36 - Cromatograma para amostras de matéria orgânica particulada oclusa (MOPo), na profundidade 5-10 cm, para o sistema ORG6 - agricultura orgânica de 6 anos. Ao lado estão identificados os picos e seus respectivos tempos de retenção (RT).

Fig. 37 - Gráficos de teor de $\mathrm{C}$ obtidos para amostras de solo inteiro das áreas analisadas, sendo: AN SEM - fazenda Areona sem adição de biossólido; AN LODO - fazenda Areona com adição de biossólido; ER SEM - fazenda Entre Rios sem adição de biossólido; ER LODO - fazenda Entre Rios com adição de biossólido. 
Fig. 38 - Gráficos valores de grau de humificação obtidos por Fluorescência Induzida por Laser $\left(\mathrm{H}_{\mathrm{FIL}}\right)$ para amostras de solo inteiro das áreas analisadas, sendo: AN SEM - fazenda Areona sem adição de biossólido; AN LODO - fazenda Areona com adição de biossólido; ER SEM - fazenda Entre Rios sem adição de biossólido; ER LODO - fazenda Entre Rios com adição de biossólido. 104

Fig. 39 - Gráficos valores de fluxo de $\mathrm{CO}_{2}$ obtidos para amostras de solo das áreas analisadas, sendo: AN SEM - fazenda Areona sem adição de biossólido; AN LODO - fazenda Areona com adição de biossólido; ER SEM - fazenda Entre Rios sem adição de biossólido; ER LODO - fazenda Entre Rios com adição de biossólido. 106

Fig. 40 - Espectros de infravermelho para amostras de AH extraídos de solo proveniente da fazenda Entre Rios, no perfil analisado, sendo: ER LODO - fazenda Entre Rios com adição de biossólido; ER SEM - fazenda Entre Rios sem adição de biossólido. 108

Fig. 41 - Espectros de infravermelho para amostras de AH extraídos de solo proveniente da fazenda Areona, no perfil analisado, sendo: AN LODO - fazenda Areona com adição de biossólido; AN SEM - fazenda Areona sem adição de biossólido.

Fig. 42 - Espectros de absorção de UV Vis, para amostras de AH extraídos de solo proveniente da fazenda Entre Rios, no perfil analisado, sendo: ER LODO - fazenda Entre Rios com adição de biossólido; ER SEM - fazenda Entre Rios sem adição de biossólido.

Fig. 43 - Espectros de absorção de UV Vis, para amostras de AH extraídos de solo proveniente da fazenda Areona, no perfil analisado, sendo: AN LODO - fazenda Areona com adição de biossólido; AN SEM - fazenda Areona sem adição de biossólido.

Fig. 44 - Espectros de emissão de fluorescência obtidos pela metodologia de Milori et al., 2002, para amostras de AH extraídos de solo proveniente da fazenda Entre Rios, no perfil analisado, sendo: ER LODO - fazenda Entre Rios com adição de biossólido; ER SEM - fazenda Entre Rios sem adição de biossólido.

Fig. 45 - Espectros de emissão de fluorescência obtidos pela metodologia de Milori et al., 2002, para amostras de AH extraídos de solo proveniente da fazenda Areona, no perfil analisado, sendo: AN LODO - fazenda Areona com adição de biossólido; AN SEM - fazenda Areona sem adição de biossólido..

Fig. 46 - Espectros de emissão de fluorescência obtidos pela metodologia de Zsolnay et al., 1999, para amostras de AH extraídos de solo proveniente da fazenda Entre Rios, no perfil analisado, sendo: ER LODO - fazenda Entre Rios com adição de biossólido; ER SEM - fazenda Entre Rios sem adição de biossólido.

Fig. 47 - Espectros de emissão de fluorescência obtidos pela metodologia de Zsolnay et al., 1999, para amostras de AH extraídos de solo proveniente da fazenda Areona, no perfil analisado, sendo: AN LODO - fazenda Areona com adição de biossólido; AN SEM - fazenda Areona sem adição de biossólido.

Fig. 48 - Espectros de varredura sincronizada de fluorescência obtidos pela metodologia de Kalbitz et al., 1999, para amostras de AH extraídos de solo proveniente da fazenda Entre Rios, no perfil analisado, sendo: ER LODO - fazenda Entre Rios com adição de biossólido; ER SEM - fazenda Entre Rios sem adição de biossólido...... 
Fig. 49 - Espectros de varredura sincronizada de fluorescência obtidos pela metodologia de Kalbitz et al., 1999, para amostras de AH extraídos de solo proveniente da fazenda Areona, no perfil analisado, sendo: AN LODO - fazenda Areona com adição de biossólido; AN SEM - fazenda Areona sem adição de biossólido. 


\section{LISTA DE TABELAS}

Tabela 1 - Áreas globais de cultivo agrícola por plantio direto

Tabela 2 - Composição de esterco aviário aplicado em campo experimental norte-americano .

Tabela 3 - Especificação de processos de condicionamento de solo para fazendas analisadas. .

Tabela 4 - Caracterização de biossólido aplicado nas áreas em análise.

Tabela 5 - Valores de teor de $\mathrm{C}$ para amostras de solo para os diferentes sistemas analisados, onde PC - plantio convencional com manejo mínimo, ORG2 - agricultura orgânica de 2 anos, ORG3 agricultura orgânica de 3 anos, ORG6 - agricultura orgânica de 6 anos e PD - plantio direto sem manejo.

Tabela 6 - Valores de densidade de solo para amostras de solo intacto para os diferentes sistemas analisados, onde PC - plantio convencional com manejo mínimo, ORG2 - agricultura orgânica de 2 anos, ORG3 - agricultura orgânica de 3 anos, ORG6 - agricultura orgânica de 6 anos e PD - plantio direto sem manejo.

Tabela 7 - Valores de teores de $\mathrm{C}$ e $\mathrm{N}$ para amostras de matéria organica particulada livre (MOPI) para os diferentes sistemas analisados, onde PC - plantio convencional com manejo mínimo, ORG2 agricultura orgânica de 2 anos, ORG3 - agricultura orgânica de 3 anos, ORG6 - agricultura orgânica de 6 anos e PD - plantio direto sem manejo.

Tabela 8 - Valores de teores de $\mathrm{C}$ e $\mathrm{N}$ para amostras de matéria organica particulada oclusa (MOPo) para os diferentes sistemas analisados, onde PC - plantio convencional com manejo mínimo, ORG2 agricultura orgânica de 2 anos, ORG3 - agricultura orgânica de 3 anos, ORG6 - agricultura orgânica de 6 anos e PD - plantio direto sem manejo.

Tabela 9 - Identificação dos picos e bandas destacados nos espectros de infravermelho obtidos para as amostras analisadas

Tabela 10 - Índices de condensação (IC) e hidrofobicidade (IH) para amostras de MOPl e MOPo em sistemas PD - plantio direto sem manejo

Tabela 11 - Índices de condensação (IC) e hidrofobicidade (IH) para amostras de MOPl e MOPo em sistemas PC - plantio convencional com manejo mínimo

Tabela 12- Índices de condensação (IC) e hidrofobicidade (IH) para amostras de MOPl e MOPo em sistemas ORG2 - agricultura orgânica de 2 anos.

Tabela 13 - Índices de condensação (IC) e hidrofobicidade (IH) para amostras de MOPl e MOPo em sistemas ORG3 - agricultura orgânica de 3 anos

Tabela 14 - Índices de condensação (IC) e hidrofobicidade (IH) para amostras de MOPl e MOPo em sistemas ORG6 - agricultura orgânica de 6 anos

Tabela 15 - Picos identificados para ambas frações de MOS. 
Tabela 16 - Picos de maior relevância identificados para amostras de matéria organica particulada leve-oclusa e leve-livre (MOPo e $\mathrm{MOPl}$, respectivamente), considerando os manejos e perfil analisados

Tabela 17 - Análise estatística de picos de maior relevância identificados para amostras de matéria organica particulada leve-oclusa (MOPo), considerando os manejos e perfil analisados.

Tabela 18 - Análise estatística de picos de maior relevância identificados para amostras de matéria organica particulada leve-livre (MOPl), considerando os manejos e perfil analisados. Sinais - e + (para método de Kruskal-Wallis), e manejos destacados (para método de Mann-Whitney), indicam diferença estatisticamente significativa ou não na referida profundidade, $\operatorname{com} \mathrm{pd}=$ plantio direto, $\mathrm{pc}=$ plantio convencional e org 2,3 e 6 = agricultura orgânica com rotação de cultura a cada 2,3 e 6 anos respectivamente

Tabela 19 - Valores de teor de $\mathrm{C}$ obtidos para amostras de solo inteiro das áreas analisadas, sendo: AN SEM - fazenda Areona sem adição de biossólido; AN LODO - fazenda Areona com adição de biossólido; ER SEM - fazenda Entre Rios sem adição de biossólido; ER LODO - fazenda Entre Rios com adição de biossólido.

Tabela 20 - Valores de grau de humificação obtidos por Fluorescência Induzida por Laser $\left(\mathrm{H}_{\mathrm{FIL}}\right)$ para amostras de solo inteiro das áreas analisadas, sendo: AN SEM - fazenda Areona sem adição de biossólido; AN LODO - fazenda Areona com adição de biossólido; ER SEM - fazenda Entre Rios sem adição de biossólido; ER LODO - fazenda Entre Rios com adição de biossólido. Valores expressos em notação $\left(x 10^{3}\right)$.

104

Tabela 21 - Valores de fluxo de $\mathrm{CO}_{2}$ obtido para amostras de solo das áreas analisadas, sendo: $\mathrm{AN}$ SEM - fazenda Areona sem adição de biossólido; AN LODO - fazenda Areona com adição de biossólido; ER SEM - fazenda Entre Rios sem adição de biossólido; ER LODO - fazenda Entre Rios com adição de biossólido.

106

Tabela 22 - Identificação dos picos e bandas destacados no espectro de infravermelho obtidos para as amostras analisadas

Tabela 23 - Indices de condensação (IC) e hidrofobicidade (IH) para amostras de ácidos humicos extraídos de solo coletado em ambas as fazendas, sendo: ER LODO - fazenda Entre Rios com adição de biossólido; ER SEM - fazenda Entre Rios sem adição de biossólido; AN LODO - fazenda Areona com adição de biossólido; AN SEM - fazenda Areona sem adição de biossólido.

110

Tabela 24 - Valores de razão $\mathrm{E}_{4} / \mathrm{E}_{6}$ para amostras de ácidos humicos extraídos de solo coletado em ambas as fazendas, sendo: ER LODO - fazenda Entre Rios com adição de biossólido; ER SEM fazenda Entre Rios sem adição de biossólido; AN LODO - fazenda Areona com adição de biossólido; AN SEM - fazenda Areona sem adição de biossólido.

Tabela 25 - Valores de grau de humificacao para amostras de ácidos humicos extraídos de solo coletado em ambas as fazendas, sendo: ER LODO - fazenda Entre Rios com adição de biossólido; ER SEM - fazenda Entre Rios sem adição de biossólido; AN LODO - fazenda Areona com adição de biossólido; AN SEM - fazenda Areona sem adição de biossólido 


\section{LISTA DE SIGLAS E ABREVIATURAS}

$\mathrm{AH}$

$\mathrm{AF}$

AN

ANOVA

ARS

BARC

CONAMA

ER

FAO

FEBRAPDP

FIL

FLL

FLO

FSP

FTIR

GEE

GWP

IPCC

MOP1

MOPo

MOS

IV

LE

ONU

PC

PD

$\mathrm{PY}-\mathrm{GC} / \mathrm{MS}$
Ácidos Húmicos

Ácidos Fúlvicos

Fazenda Areona

Análise de Variância

Serviço de Pesquisa Agrícola

Centro de Pesquisa Agrícola de Beltsville

Conselho Nacional do Meio Ambiente

Fazenda Entre Rios

Organização das Nações Unidas para Alimentação e Agricultura

Federação Brasileira de Plantio Direto na Palha

Fluorescência Induzida por Laser

Fração Leve-Livre

Fração Leve-Oclusa

Farming Systems Project

Infravermelho com Transformada de Fourier

Gases do Efeito Estufa

Potencial de Aquecimento Global

Painel Intergovernamental de Mudanças Climáticas

Matéria Orgânica Particulada Leve-Livre

Matéria Orgânica Particulada Leve-Oclusa

Matéria Orgânica do Solo

Infravermelho

Lodo de Esgoto

Organização das Nações Unidas

Plantio Convencional

Plantio Direto

Pirólise acoplada à Cromatografia a Gás/Espectrometria de Massas 
QELCR

RCBD

RPE

$\mathrm{SH}$

UNCED

UNFCCC

USDA
Termos de Limitação ou Redução de Emissão Quantificada

Distribuição de Bloco ao Acaso

Ressonância Paramagnética Eletrônica

Substâncias Húmicas

Conferência das Nações Unidas de Meio Ambiente e Desenvolvimento

Convenção das Nações Unidas sobre Mudanças Climáticas

Departamento de Agricultura dos Estados Unidos 


\section{RESUMO}

O objetivo do presente estudo foi avaliar a dinâmica e reatividade da matéria orgânica do solo (MOS) e substâncias húmicas (SH) em duas situações distintas, no que concerne ao manejo de solo, práticas agroflorestais e condições climáticas, avaliando o potencial de sequestro de $\mathrm{C}$ e mitigação de efeitos do aumento do efeito estufa. $\mathrm{O}$ estudo foi conduzido em dois campos experimentais, sendo o primeiro, instalado em Beltsville - Maryland, Estados Unidos, sob coordenação do Departamento de Agricultura norte-americano (USDA/ARS), composto por sistemas agrícolas convencionais com manejo mínimo (PC), plantio direto sem manejo (PD) e orgânicos com plantio direto (2, 3 e 6 anos, com adição de esterco aviário). O segundo campo experimental, instalado em Itatinga - São Paulo, Brasil, compreende área de reflorestamento de floresta de eucalipto, em duas fazendas (Entre Rios - ER - e Areona - AN) com perfis de solo diferentes (Latossolo e Neossolo quartzarênico, respectivamente) com e sem adição de biossólido. Para o primeiro campo foram coletadas amostras de solo até $30 \mathrm{~cm}$ em 5 incrementos, sendo realizado, em seguida, o fracionamento físico da MOS, em matéria orgânica particulada livre (MOPl) e oclusa (MOPo) para análises de espectroscopia na região do infravermelho (MIR) e pirólise acoplada a GC/MS (PY-GC/MS). Para o segundo campo experimental foram coletadas amostras de solo até $20 \mathrm{~cm}$, seguindo de extração de SH para análises espectroscópicas. No campo experimental americano, observou-se maior teor de $\mathrm{C}$ nos sistemas de plantio direto, sobretudo nos sistemas orgânicos, em comparação ao sistema convencional (cerca de $24 \%$ de aumento). Os dados obtidos através da espectroscopia de MIR mostraram maiores graus de condensação e hidrofobicidade, influindo em maior humificação e resistência à atividade microbiana para as amostras nos sistemas orgânicos. Os resultados de PY-GC/MS foram analisados por testes não paramétricos de Kruskal-Wallis e Mann-Whitney, sendo observada a maior incidência de estruturas moleculares de caráter fenólico aromático em amostras de MOPo para os sistemas orgânicos considerados, e a maior ocorrência de núcleos condensados, oriundos de lignina e outras fontes, ligados a cadeias alifáticas em amostras de MOPl para os mesmos sistemas, em relação aos demais analisados em estudo. Os resultados obtidos para o campo experimental americano ilustrou maior impacto do manejo orgânico do solo, frente aos demais considerados, no que concerne ao potencial acumulo de carbono e incidência de estruturas mais condensadas e de maior recalcitrância. Os dados do segundo campo experimental, em áreas de reflorestamento de eucalipto no estado de São Paulo, demonstraram comportamentos distintos com maior teor de $\mathrm{C}$ e menor grau de humificação (cerca de 25 e $30 \%$, respectivamente) para áreas submetidas à adição de biossólido para a fazenda Areona (AN), sendo observado perfil inverso para a fazenda Entre Rios (ER) (decréscimo de cerca de $20 \%$ para $\mathrm{C}$ e aumento de, aproximadamente, $100 \%$ no grau de humificação). Através dos dados obtidos através de espectroscopia de infravermelho, pôde-se observar maiores índices de condensação (grau de humificação), em ambas as fazendas, nas áreas sob adição de biossólido, ao passo que somente na fazenda ER foram observados maiores índices de hidrofobicidade (resistência à degradação microbiana) nestas mesmas áreas. Assim como nos resultados obtidos as amostras de solo intacto, foi observado maior grau de humificação para amostras de AH na fazenda ER, em áreas condicionadas com biossólido, ao passo que menor grau de humificação para as mesmas áreas na fazenda AN. Assim sendo, conforme mencionado, uma das áreas de reflorestamento tratada com biossólido mostrou aumento no teor de carbono no solo (em solo arenoso) e a outra mostrou decréscimo (solo com teor mediano de argila). As análises qualitativas, como determinação do grau de humificação da matéria orgânica em amostras de solos e substâncias húmicas, foram coerentes com o aumento ou decréscimo dos teores de carbono nos dois solos, dando consistência as observações das duas situações de campo analisadas. Dessa maneira, verificou-se o maior impacto da adição da aplicação de biossólido em Latossolos em relação à área de Neossolo quartzarênico. O entendimento e avaliação da resposta da matéria orgânica e seus constituintes húmicos frente a diferentes situações é de extrema importância para obtenção de sustentabilidade ambiental, no que concerne à mitigação de efeitos inerentes às mudanças climáticas globais.

Palavras-chave: matéria organica do solo, matéria organica particulada, substâncias húmicas, biossólido, sistemas de manejo, análises espectroscópicas, pirólise acoplada à cromatografia a gás/espectrometria de massas (GC/MS). 


\begin{abstract}
The aim of the following study was to evaluate the dynamics and reactivity of soil organic matter (SOM) and humic substances (HS) in two different situations, regarding soil tillage, forestry practices and climate conditions, considering $\mathrm{C}$ sequestration potential and greenhouse effects mitigation. The study was conducted in two different field experiments, being the first one a long-term field trial project installed in Beltsville, Maryland - United States, coordinated by the United States Department of Agriculture (USDA), comprising different soil tillage systems as it follows: chiesel till (CT), no till (NT) and 2, 3 and 6-year organic agriculture (with poultry manure addition). The second experimental field was installed in Itatinga, São Paulo - Brazil, comprising an eucalyptus forestry system being two farms (Entre Rios - ER, and Areona - AN), presenting different soil prolife (Oxisol and Quartzarenic Neosoil) and sewage sludge (SS) amended areas. For the first experimental field soil samples were collected to $30 \mathrm{~cm}$ depth in 5 increments, followed by SOM physical fractionation in occluded and free particulate organic matter (oPOM and fPOM, respectively) for mid infrared (MIR) spectroscopy and pyrolysis coupled with gas chromatography/mass spectrometry (PY-GC/MS) analysis. For the second experimental field, soil samples were collected to $20 \mathrm{~cm}$ depth, followed by HS extraction and spectroscopic analysis. The results for the first experimental field showed a $\mathrm{C}$ content increase (about $24 \%$ ) for the organic systems, comparing to the others considered. Data obtained by MIR spectroscopy showed higher condensation and hydrophobicity degrees, resulting in higher humification and microbial decomposition resistance, for the organic systems samples. The results obtained by PYGC/MS were analyzed by Kruskal-Wallis and Mann-Whitney non parametric tests and it was observed a higher incidence of phenolic and aromatic molecular structures in oPOM samples, and a higher occurrence of condensed structures, derived from lignin and other sources, bonded to aliphatic chains, in fPOM samples for the organic systems analyzed, comparing to the others systems considered. This way, the results obtained for the American experimental field showed a higher impact of organic tillage systems, regarding the soil carbon accumulation potential and the incidence of more condensed and recalcitrant structures. The results regarding the second experimental field showed an interesting behavior with $\mathrm{C}$ content increase and humification degree decrease in the SS amended areas (about 25 and 30\%, respectively) for the Areona (AN) farm, nevertheless, being observed an inverse behavior for the Entre Rios (ER) farm samples (about 20\% C content decrease and nearly $100 \%$ humification degree increase). From the infrared spectroscopy data it could be observed higher condensation degree (inferring higher humification degree) in the SS amended areas for both farms considered, however only for the ER samples it was noted a higher hydrophobicity degree (higher microbial decomposition resistance). The same way noted for the soil samples, it was observed higher humification degree for humic acids samples in the SS amended areas for the ER farm, while for the AN samples it was noted smaller humification degree for its respective SS amended area. This way, as mentioned before, one of the SS amended forestry areas showed an increase in the soil C content (in the quartzarenic neosoil) while the other one presented soil $\mathrm{C}$ content decrease (oxisoil, with about $20 \%$ clay content). The qualitative analysis, such as organic matter humification degree determination for soil and HS samples were coherent to the C content increase or decrease observed for both soil profiles, being consistent to the results obtained on the field experiment scenario. This way, the results for the Brazilian experimental field showed a higher impact of the sewage sludge application in the Oxisol area, comparing to the Quartzarenic Neosoil one. The understanding and evaluation about organic matter and humic constituents response regarding different field situations is extremely important to achieve environmental sustainability and climate change effects mitigation.
\end{abstract}

Key-words: soil organic matter, particulate organic matter, humic substances, sewage sludge, soil tillage, spectroscopic analysis, pyrolysis coupled to gas chromatography/mass spectrometry (GC/MS) 


\section{INTRODUÇÃO}

O solo, em especial a matéria orgânica do solo (MOS), constitui um importante componente dos ecossistemas terrestres, apresentando papel fundamental em sistemas agrícolas de produção. Além de representar o principal meio para o desenvolvimento de cultivares, o solo atua como um dos principais agentes para sustentabilidade da produção agrícola e regulação, em parte, do fluxo de gás carbônico $\left(\mathrm{CO}_{2}\right)$ atmosférico (Lal (2008)).

Estima-se que o conteúdo de carbono orgânico compreendido na parcela até $30 \mathrm{~cm}$ (mais sujeita a modificações devido ao manejo do solo) seja de 684 a 724 Pg, representando cerca de duas vezes o montante de carbono presente na atmosfera na forma de $\mathrm{CO}_{2}$ (Powlson (2011)).

A agricultura pode ser uma aliada importante para a mitigação da concentração de $\mathrm{CO}_{2}$ atmosférico. Pela fotossíntese pode-se converter o $\mathrm{CO}_{2}$ da atmosfera em massa vegetal e, além disso, por meio de um manejo adequado desta massa pode-se reter parte do carbono no solo caracterizando o mecanismo de sequestro de carbono da atmosfera pelo solo (Lal (2008)).

O setor agrícola, em função de suas características e sensibilidade ao clima, é extremamente vulnerável às prováveis mudanças climáticas, distinguindo-se dos demais setores no que se refere ao tratamento do tema. Neste contexto, o Brasil é um dos países que mais se dedica à discussão sobre mudanças climáticas no âmbito internacional (MAPA (2013)). O Programa ABC - Agricultura de Baixo Carbono, instituído pelo Governo Federal, através do Ministério da Agricultura, Pecuária e Abastecimento (MAPA), tem como objetivo a redução das emissões de carbono através do incentivo a processos tecnológicos que neutralizam ou minimizam o impacto dos gases de efeito estufa no campo, com metas e resultados previstos até 2020.

Práticas conservacionistas de agricultura, tais como plantio direto e convencional, têm introduzido mudanças importantes na dinâmica do carbono no solo e tem, em algumas situações, favorecido seu sequestro em frações da matéria orgânica do solo (MOS). Contudo, tais práticas necessitam ser estudadas com maiores detalhes a fim de elucidar os mecanismos relacionados diretamente com o $\mathrm{C}$ do solo e vislumbrar a possibilidade de sistemas agrícolas como agentes no processo de sequestro de carbono, assim reduzindo emissões de gases do efeito estufa (Suddick et al., (2010)).

Sistemas orgânicos de produção também podem, em algumas situações, aumentar os níveis de MOS, pelo uso de resíduos animais e plantas de cobertura, além de reduzirem emissões de gases pela degradação de fertilizantes sintéticos. Alguns aspectos da agricultura 
orgânica podem ser implementados juntamente com outros sistemas de agricultura sustentável, tais como sistemas com ausência de manejo ou manejo mínimo, aumentando o potencial de mitigação de mudanças climáticas (Schahzenski e Hill (2009)).

Além das atividades agrícolas, sistemas florestais tem o potencial de sequestrar quantidades significativas de $\mathrm{C}$ e, assim contribuir para a mitigação de mudanças climáticas. Nos últimos anos, tem-se dado muita atenção ao sequestro em espécies de árvores neste tipo de sistema, contudo o papel do solo é de grande importância em vários destes sistemas (Verchot et al., (2010)). Ainda, conforme Vries e Posch (2010) com seu considerável potencial para sequestro de $\mathrm{C}$, as florestas constituem um dos principais elementos no ciclo global de C.

Contudo, apesar da existência de estudos abordando os efeitos diferentes sistemas de manejo, em parâmetros químicos, físicos e biológicos do solo, ainda existe certa carência de informação no que tange à avaliação da dinâmica e reatividade de MOS e suas frações, considerando campos experimentais submetidos a diferentes condições climáticas e práticas de uso do solo, no que concerne ao potencial de sequestro e acúmulo de carbono. 


\section{OBJETIVOS}

O objetivo do presente estudo é avaliar e caracterizar a dinâmica e reatividade da matéria orgânica do solo (MOS) frente a diferentes práticas de uso do solo, no que concerne ao acúmulo e sequestro de carbono, em campos experimentais com condições climáticas diferenciadas.

Para tanto serão utilizados procedimentos de fracionamento físico (densimétrico) e químico da MOS, para a obtenção de frações leve-livre e leve-oclusa e de substâncias húmicas, respectivamente, seguidos da aplicação de métodos analíticos e análises espectroscópicas.

A expectativa é a obtenção de informações, em escala molecular, a respeito das frações de MOS e seus constituintes húmicos frente às diferentes práticas de uso do solo, vislumbrando a avaliação do potencial de acúmulo e sequestro de carbono no solo, inerentes a tais atividades, e consequente, mitigação efeitos intrínsecos às mudanças climáticas. 


\section{REVISÃO DE LITERATURA}

A problemática envolvendo sequestro de carbono e mitigação de gases do efeito estufa é contemporânea e desperta interesse tanto nacional quanto internacional (Mahecha et al., (2010)), uma vez que a quantificação e entendimento da intensidade de mecanismos de interação entre atividades agrícolas e/ou florestais (além de demais ecossistemas terrestres) e clima são os maiores desafios no que diz respeito à compreensão do ciclo global de carbono. No presente capítulo é feita revisão bibliográfica explanando os principais tópicos abordados em pesquisa.

\subsection{Emissão de Gases do Efeito Estufa (GEE)}

De acordo com VijayaVengataRaman et al., (2012), desde o advento da Revolução Industrial, há cerca de 150 anos, algumas atividades antrópicas tem adicionado um montante significativo de gases do efeito estufa (GEE) à atmosfera terrestre. Ainda, segundo os mesmos, na medida em que tais atividades aumentam a concentração atmosférica de GEE, aumenta a tendência de elevação da temperatura global nas próximas décadas e séculos.

A concentração atmosférica de $\mathrm{CO}_{2}$ e demais GEE tem aumentado consideravelmente nas ultimas décadas, sendo ainda esperado um maior aumento nos próximos anos (Albretch e Kandji (2003)). A figura 1 a seguir ilustra o comportamento e evolução do $\mathrm{CO}_{2}$ atmosférico nos últimos anos.

Fig. 1 - Níveis de concentração de $\mathrm{CO}_{2}$ atmosférico através dos anos (adaptado de VijayaVengataRaman, et al., 2012).

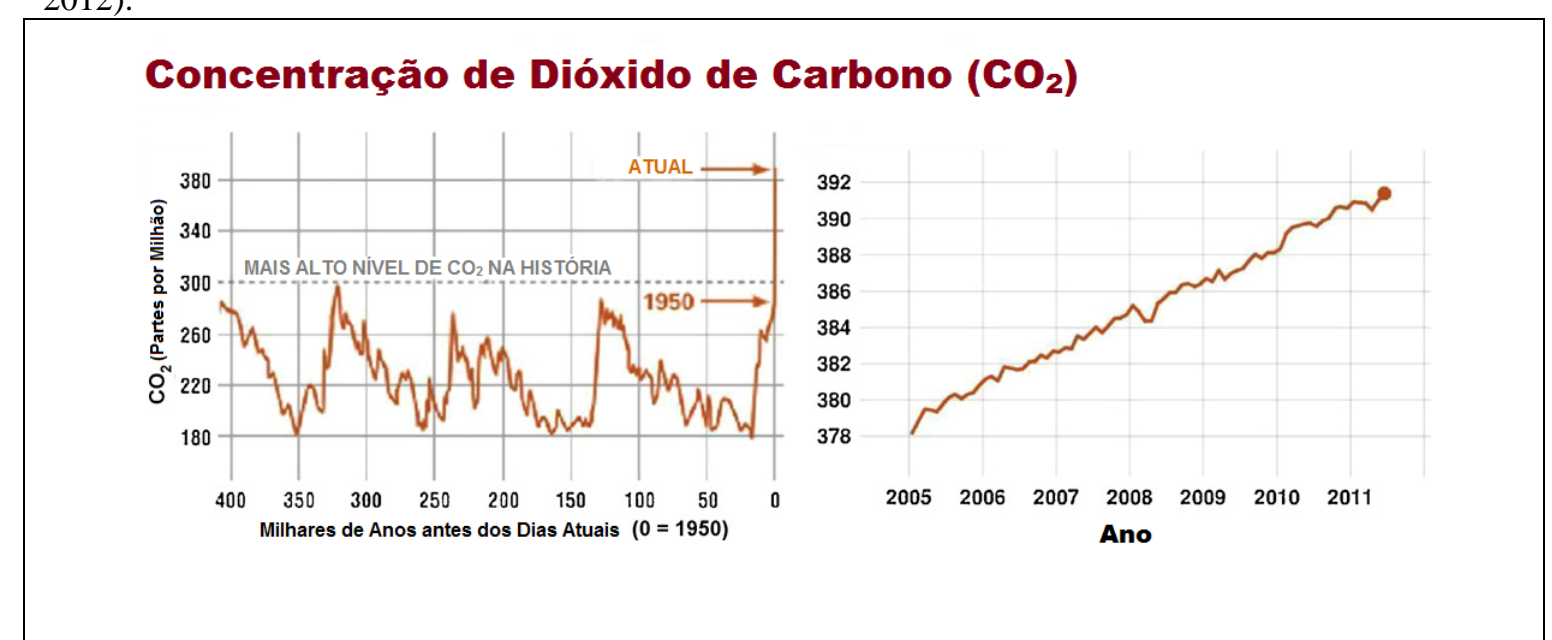

Fonte: VIJAYAVENGATARAMAN, S.; INIYAN, S.; GOIC, R. A review of climate change, mitigation and adaptation. Renewable and Sustainable Energy Reviews, v. 16, p. 878 - 897, 2012.

O efeito estufa é um processo que ocorre naturalmente na atmosfera terrestre, constituindo um mecanismo de captação e aprisionamento, realizado pela camada de $\mathrm{CO}_{2}$ e outros GEE existentes na atmosfera terrestre, calor proveniente da radiação solar (antes de seu 
retorno à atmosfera), a fim da manutenção da temperatura. Contudo, nos últimos anos tem havido aumento na concentração de tais gases, fazendo com exista maior retenção de calor e, consequente, aumento na temperatura global, como ilustra a figura 2 a seguir.

Fig. 2 - Ilustração de mecanismo de efeito estufa (adaptado de Schahzenski e Hill, 2009). Radiação solar atravessa a camada natural de gases atmosféricos. Alguns raios solares incidentes no planeta são absorvidos e transformados em calor (1), levando ao aquecimento da superfície. A superfície, por sua vez, reemite a radiação para a atmosfera (2), sendo esta parcialmente absorvida pelos GEE (3), que por sua vez a "devolve" à superfície terrestre (4). O montante não absorvido pelos GEE é retornado ao espaço (5). Atividades humanas que levam à emissão adicional de GEE para a atmosfera (6) aumentam a quantidade de radiação que é absorvida, antes de ser reemitida para o espaço, assim aumentando o efeito estufa e levando, consequentemente, ao aquecimento global.

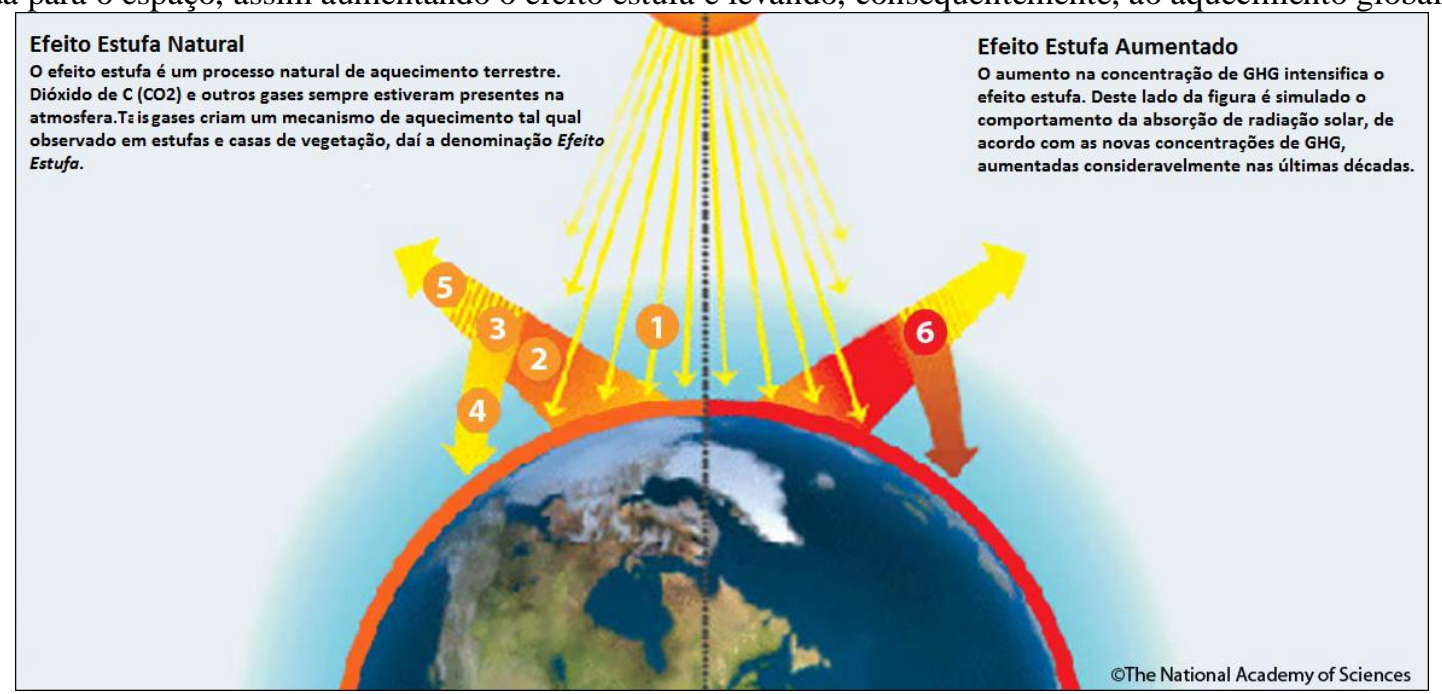

Fonte: SCHAHCZENSKI, J.; HILL, H. Agriculture, climate change and carbon sequestration. Butte: ATTRA, 2009. 16 p. (Boletim de Pesquisa).

Segundo levantamento realizado em 2007 pelo Painel Intergovernamental de Mudanças Climáticas (IPCC), durante a década de 90 as emissões de $\mathrm{CO}_{2}$ devido às atividades de uso do solo contabilizaram um total variando entre 0,5 - 2,7 Pg C por ano, dentro de um total de emissões de 7,9 Pg C ao ano, correspondendo a um montante entre 6 e $39 \%$ do total de emissões de $\mathrm{CO}_{2}$.

Conforme Houghton (2003) historicamente estima-se que emissões derivadas de mudanças de atividades do uso do solo têm contribuído em cerca de 156 Pg C, ao montante de emissões correspondente as atividades antrópicas, no período de 1850-2000. Ainda, de acordo com mesmo, a emissão de cerca de 2,24 Pg C ao ano pode ser atribuída ao desmatamento de florestas ocorrido durante a década de 90 , sendo o maior contribuinte de emissões no setor de atividades de uso do solo.

Com o intuito de comparar quantitativamente o potencial de aquecimento inerente aos diferentes tipos de GEE, o índice de potencial de aquecimento global (GWP) tem sido utilizado em diversos estudos e pesquisas. Tal índice baseia-se na proporção da radiação 
emitida por dois gases em determinado tempo ou, arbitrariamente, de acordo com sua permanência na atmosfera (VijayaVengataRaman et al., (2012)).

Segundo Forster et al., 2007, os três GEE mais proeminentes, oriundos de atividades antropicas, são metano $\left(\mathrm{CH}_{4}\right)$ e oxido nitroso $\left(\mathrm{N}_{2} \mathrm{O}\right)$, além de $\mathrm{CO}_{2}$. Cada um desses gases apresentam diferentes impactos atmosféricos, no que concerne as mudanças climáticas, levando-se em consideração seus respectivos GWP. De acordo com os mesmos, a titulo de comparação, os valores de GWP são expressos em termos de equivalentes de $\mathrm{CO}_{2}\left(\mathrm{CO}_{2}\right.$-eq), sendo que 1 tonelada de $\mathrm{CO}_{2}$-eq refere-se ao equivalente GWP na mesma quantidade de $\mathrm{CO}_{2}$ durante 100 anos ( 1 tonelada de $\mathrm{N}_{2} \mathrm{O} \approx 298$ toneladas de $\mathrm{CO}_{2}$-eq and 1 tonelada de $\mathrm{CH}_{4} \approx 25$ toneladas $\mathrm{CO}_{2}$-eq).

De acordo com Booth (2012) a necessidade de limitar as emissões de GEE nos próximos anos deve-se ao fato de que um montante significativo de $\mathrm{CO}_{2}$ permanece na atmosfera por um grande período de tempo, dessa forma, mesmo que as emissões atinjam o sue mínimo, ainda haverá certa resposta da temperatura global frente ao montante de $\mathrm{CO}_{2}$ remanescente.

Conforme Ceschia et al., (2010) a atividade agrícola contribui para a emissão de GEE através de distúrbios, provocados por suas práticas, nos reservatórios de carbono no solo, no fluxo de GEE proveniente da comunidade microbiana, e também através das atividades de campo realizadas com o uso de maquinários pesados em algumas praticas de manejo (liberação de GEE através da queima de combustíveis fósseis).

Segundo estudo realizado por Sainju et al., (2008) a emissão de $\mathrm{CO}_{2}$ é frequentemente menor em sistemas agrícolas sob o regime de plantio direto em comparação a sistemas agrícolas de plantio convencional; contudo algumas pesquisas apontam maiores emissões também em sistemas de plantio direto (Oorts et al., (2007)). Conforme Dendooven et al., (2012) as emissões de $\mathrm{N}_{2} \mathrm{O}$ são resultados de vários mecanismos interagindo entre si, sendo, dessa maneira, difícil avaliar a influência de sistemas de plantio direto e convencional no processo de emissão. Segundo os mesmos, tem-se assumido que menores temperaturas, melhor estrutura de solo e menor compactação em sistemas de plantio direto acarretam em menores fluxos de $\mathrm{N}_{2} \mathrm{O}$ em detrimento aos sistemas de plantio convencional. Entretanto, maior conteúdo de MOS, umidade e nitrogênio mineral favorecem a emissão em ambos os casos. Sistemas agrícolas geralmente não constituem fonte ou sumidouro de metano $\left(\mathrm{CH}_{4}\right)$ (Chan e Parkin (2001)). Segundo Johnson et al., (2007) tais sistemas somente se enquadram no perfil de fonte de $\mathrm{CH}_{4} \operatorname{logo}$ após a aplicação de dejetos animais ou outro tipo de material orgânico. 
Estima-se que o potencial global de mitigação inerente às atividades agrícolas, até o ano de 2030, considerando todos GEE, esteja na faixa entre 4500 a 6000 milhões de toneladas de $\mathrm{CO}_{2}$-eq ao ano (Caldeira et al., (2004) e Smith et al., (2007)).

De acordo com Branca et al., (2013) a atividade agrícola representa um dos maiores setores em termos de economia, geração de emprego e comércio para os países constituintes do chamado bloco BRIC (Brasil, Rússia, Índia e China). Contudo, segundo Cerri et al., (2009) o Brasil constitui, também, um dos maiores emissores mundiais de GEE, o que tem mobilizado as políticas locais no que tange a elaboração de planos de ação, visando reduções significativas para o setor.

A proposta de intensificação de prática de agricultura sustentável no Brasil apresenta grande potencial de geração de efeitos benéficos no que tange à mitigação de mudanças climáticas inerentes à emissão de GEE, além de potencial de aumento de sequestro de carbono no solo (Branca et al., (2013)).

Em suma, conforme Aertsens et al., (2013) as práticas agrícolas fornecem varias possibilidades de "opções de mitigação de mudanças climáticas". Segundo os mesmos, os sistemas adotados devem ser avaliados levando-se em consideração condições climáticas, características de solo, registros de manejo previamente empregados, além das condições socioeconômicas da área em questão.

\subsection{Mudanças Climáticas}

O termo mudanças climáticas refere-se à variação estatisticamente significativa na média climática, persistindo por um período prolongado (geralmente décadas ou mais). Tais mudanças podem ocorrer devido a processos naturais internos ou alterações contínuas devido à ação antrópica na composição atmosférica ou uso do solo (VijayaVengataRaman et al., (2012)).

Segundo Li et al., (2013) a concentração atmosférica elevada de $\mathrm{CO}_{2}$ tem sido considerada com o maior agente contribuinte no processo de aquecimento global, e, consequentes mudanças climáticas.

Conforme levantamento realizado pelo IPCC, as mudanças climáticas são balizadas pelo aumento da concentração de gases do efeito estufa (GEE), principalmente $\mathrm{CO}_{2}$, o que leva a um aumento na temperatura terrestre (Booth (2012)). Ainda, o mesmo levantamento lista algumas das evidências de alterações climáticas que tem ocorrido com o passar dos anos, tais como: 
(a) Aumento do nível dos oceanos: o nível global dos oceanos aumentou cerca de 17 cm no século passado. Contudo, a taxa de aumento observada na última década foi aproximadamente o dobro do observado no último século;

(b) Aumento da temperatura global: segundo o estudo, a maior parte deste aquecimento global tem ocorrido desde 1970, com os dez anos mais quentes já registrados ocorrendo no período dos últimos 12 anos;

(c) Aquecimento dos oceanos: os oceanos tem absorvido grande parte do calor crescente inerente às mudanças climáticas, principalmente na camada superficial (até $700 \mathrm{~m}$ de profundidade);

(d) Diminuição das calotas polares: as calotas polares da Groenlândia e Antártica tem perdido massa. Dados da NASA mostram que a primeira perdeu cerca de $150 \mathrm{~km}^{3}$ de gelo por ano no período de 2002 a 2006, enquanto a segunda perdeu aproximadamente $152 \mathrm{~km}^{3}$ de gelo entre 2002 e 2005;

(e) Redução do mar Ártico: tanto a extensão quanto a espessura do mar Ártico tem apresentado declínios severos nos últimos anos;

As figuras 3 e 4 a seguir ilustram algumas das evidências pontuadas por levantamento do IPCC.

Fig. 3 - Variação de temperatura global (adaptado de VijayaVengataRaman, et al., 2012).

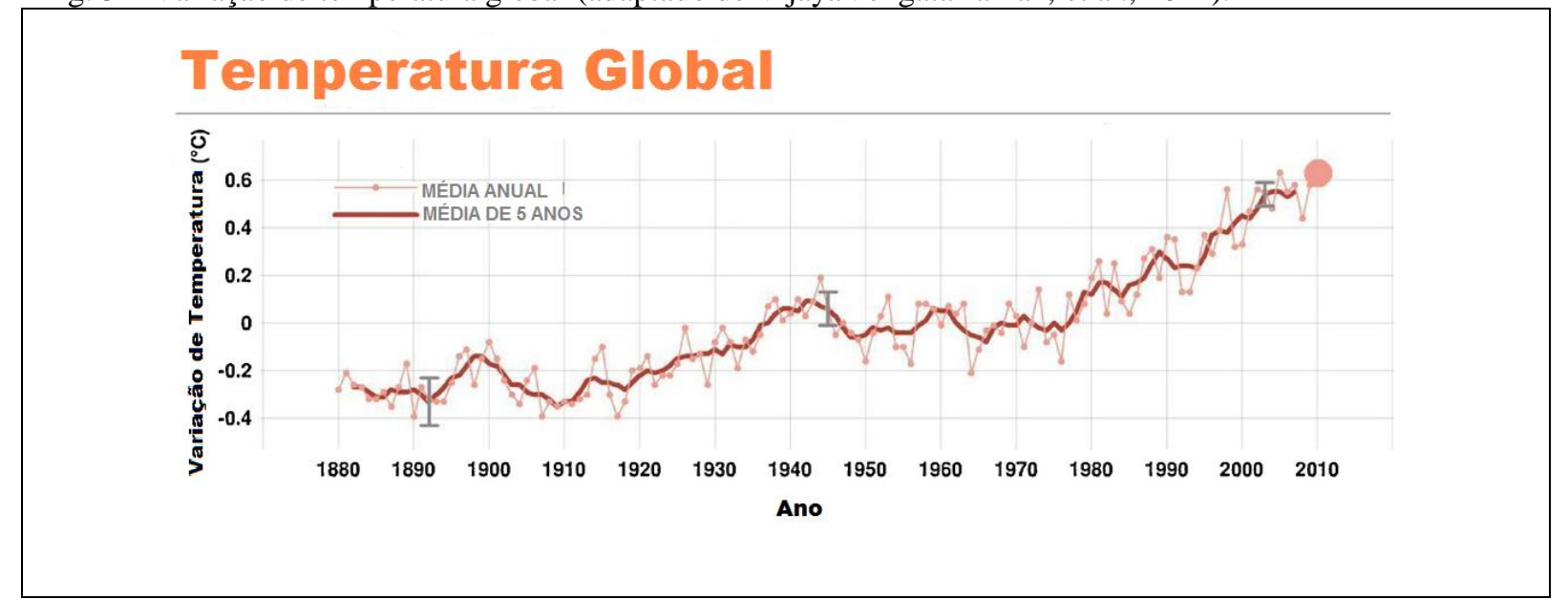

Fonte: VIJAYAVENGATARAMAN, S.; INIYAN, S.; GOIC, R. A review of climate change, mitigation and adaptation. Renewable and Sustainable Energy Reviews, v. 16, p. 878 - 897, 2012. 
Fig. 4 - Variação de nível do mar (adaptado de VijayaVengataRaman, et al., 2012).

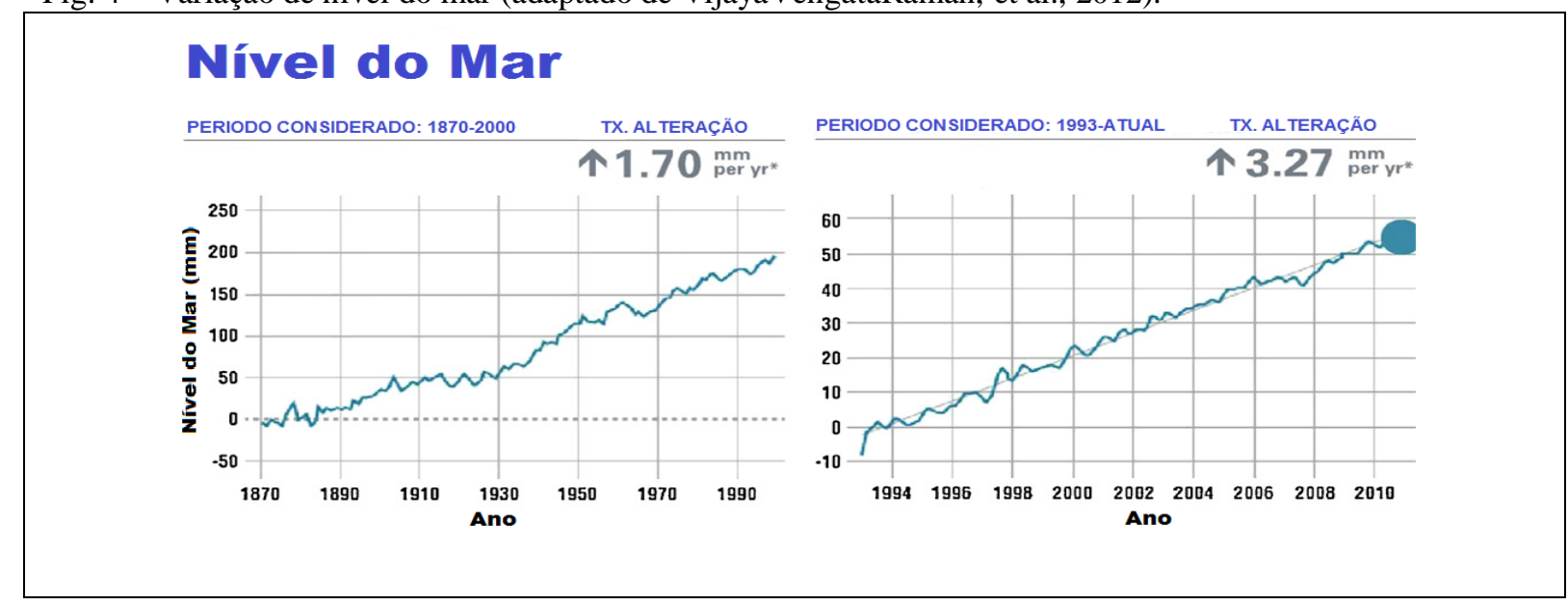

Fonte: VIJAYAVENGATARAMAN, S.; INIYAN, S.; GOIC, R. A review of climate change, mitigation and adaptation. Renewable and Sustainable Energy Reviews, v. 16, p. 878 - 897, 2012.

Segundo outro estudo realizado pelo IPCC, estima-se que, por volta do ano de 2100, a concentração atmosférica de $\mathrm{CO}_{2}$ seja, aproximadamente, 570 ppm, ocasionando um aumento na temperatura média global de cerca de $1,9{ }^{\circ} \mathrm{C}$ (Li et al., (2013)).

Segundo Alig et al., (2002) mudanças climáticas globais induzidas pelo lançamento de GEE, principalmente $\mathrm{CO}_{2}$, constituem um dos maiores desafios ambientais que o mundo enfrenta hoje. A quantidade de possíveis efeitos deletérios de tais mudanças em sistemas agrícolas e florestais tem aumentado, e atualmente muito se tem debatido acerca de como reduzir ou contrabalancear o montante, oriundo de atividades industriais e práticas de uso do solo, lançado na atmosfera.

Conforme Huang et al., (2011) projeções envolvendo mudanças climáticas são variáveis e existem diferentes pontos de vista no que concerne à extensão dos efeitos de tais mudanças junto à agricultura mundial. Ainda, de acordo com os mesmos, apesar dessa disparidade, o consenso geral é de que áreas de produção agrícola com culturas menos resilientes sentirão os efeitos inerentes às mudanças climáticas com maior intensidade, sendo que são esperadas maiores variações de temperaturas em locais de menor latitude (áreas tropicais e semi tropicais).

Os efeitos das mudanças climáticas no ciclo de carbono em solos aráveis e seus respectivas culturas são de peculiar importância. Por exemplo, o potencial de sequestro de carbono por alguns tipos de cultivo devem ser massivamente estudados e considerados para futuras condições climáticas. Estima-se que o conteúdo global de carbono no solo seja 1500 $\mathrm{Pg}$, sendo o dobro do conteúdo atmosférico e o triplo do teor encontrado nas culturas (Poll et al., (2013)). Contudo, os fluxos (por exemplo, respiração do solo) entre estes reservatórios de carbono podem ser alterados pelas mudanças climáticas, acarretando em mecanismos, 
positivos ou negativos, de troca de $\mathrm{CO}_{2}$ atmosférico, levando a um aumento ou decréscimo dos reservatórios de carbono no solo (Shaver et al., (2000)).

\subsection{Cenário Político e Mudanças Climáticas}

A problemática que abrange o tópico de mudanças climáticas globais tem sido alvo de discussões periódicas, levando a aprimoramentos e resoluções diversas. Conforme Smith (2004a), o sequestro de carbono no solo é, talvez, um dos tópicos que mais promovem discussões acaloradas nas esferas científicas.

Segundo Jabbour et al., (2012) desde a conferência das Nações Unidas em Estocolmo, 1972, a importância em uma colaboração multilateral, no que diz respeito a assuntos ambientais, tem recebido ampla atenção e reconhecimento, resultando em um crescente número de instituições ambientais, metas e tratados.

Vinte anos após a conferência de Estocolmo, líderes mundiais se encontraram no Rio de Janeiro na conferência da ONU de Meio Ambiente e Desenvolvimento (UNCED), também conhecida por "Cúpula da Terra". Tal encontro foi resultante do crescente conhecimento acerca do meio ambiente em si e a extensão do grau de conservação de parâmetros ambientais críticos (Jabbour et al., (2012)).

Os resultados da Cúpula da Terra de 1992 foram a Declaração do Rio e a Agenda 21, importantes ferramentas na busca do desenvolvimento sustentável. O primeiro lista 27 princípios, aos quais as nações participantes comprometem-se a seguir, ao passo que o segundo articula um plano de ação para o desenvolvimento sustentável no século 21 . Tal plano engloba assuntos socioeconômicos e ambientais, e atribui funções para as diversas partes interessadas, em todos os níveis sociais, incluindo organizações não governamentais internacionais, comunidade, governos locais e organizações sociais civis (Andonova e Hoffmann (2012)).

Os debates acerca do aumento na concentração atmosférica de GEE e seu papel no aquecimento global culminaram criação do Protocolo de Kyoto na terceira edição da Conferência das Partes, realizada pela Convenção das Nações Unidas sobre Mudanças Climáticas (UNFCCC) em 1997, sancionando, entre demais tópicos, o comprometimento de alguns países para redução da concentração atmosférica de GEE. De acordo com o mesmo, a redução de GEE, em termos de $\mathrm{C}$, pode ser alcançada através de dois mecanismos principais, sendo (1) redução da emissão antrópica de $\mathrm{CO}_{2}$ e (2) criação e/ou aumento de sumidouros de C na biosfera (Albretch e Kandji (2003)).

Conforme Smith (2004a), sumidouros terrestres de C atmosférico tem sido analisados mais minuciosamente desde sua inclusão, pela UNFCCC, no Protocolo de Kyoto, na quarta 
Conferência das Partes (COP4). De acordo com o mesmo, a natureza exata de fontes e sumidouros e quais modalidades e métodos de classificação foram discutidos nas Conferências subsequentes, culminando na publicação do Acordo de Marrakesh, na sétima edição em 2001.

Segundo Dessai e Schipper (2003) o Acordo de Marrakesh estabelece um regime de gerenciamento climático efetivo e funcional. Ainda, de acordo com Smith (2004b) tal acordo permite que fontes e sumidouros de C sejam inclusos nos Termos de Limitação ou Redução de Emissão Quantificada (QELCRs).

Em Dezembro de 2009, na décima quinta edição da conferência (COP15), realizada na Dinamarca, foi elaborado o Acordo de Copenhagen, onde ficou estabelecido que os países participantes deveriam adotar medidas urgentes com o intuito de limitar o aumento da temperatura média terrestre em menos de $2{ }^{\circ} \mathrm{C}$. No evento seguinte (COP16), realizado em Cancun, México, em Dezembro de 2010, 90 países, representando 80\% das emissões globais, fizeram campanha para redução de poluição de C. Na sequência, em Dezembro de 2011, em Durban, África do Sul, na COP17, as partes da UNFCCC acordaram em negociar para 2015 um novo termo legal para redução de emissões, que entraria em vigor a partir de 2020 (Booth (2012)).

Alguns países já adotaram medidas a fim de mitigar efeitos de mudanças climáticas, como por exemplo, a Alemanha, que se comprometeu a diminuir seu percentual de emissão de $\mathrm{CO}_{2}$ em $40 \%$ até 2020, e o Reino Unido, da mesma maneira, que se compromete a reduzir seu equivalente percentual de emissão de $\mathrm{CO}_{2}$ em $26 \%$ até 2020, e em $80 \%$ até 2050, levando-se em consideração para ambos os países, o ano base de 1990 (Wende et al., (2012)).

Em Junho de 2012, líderes de estado, mercado e sociedade reuniram-se novamente no Rio de Janeiro para a "Segunda Cúpula da Terra", mais conhecida por "Rio+20". O objetivo deste encontro foi a renovação de compromissos políticos, avaliação dos progressos feitos desde a primeira reunião da cúpula em 1992, e refletir a respeito dos desafios que ainda continuam a obstruir os objetivos de sustentabilidade em escalas locais e globais (Jabbour et al., (2012)).

De acordo com Ishwaran (2012) a Rio+20 marcou o início de uma era de aumento de consciência ambiental, que abrange todos os setores da sociedade em todas as partes do mundo. Segundo o mesmo, existe agora não somente um alto nível de consciência a respeitos dos desafios ambientais, econômicos e sociais aos quais a humanidade enfrenta; também há agora certa prontidão para experimentar e testar soluções. 


\subsection{Práticas de Uso do Solo}

Práticas de manejo e cultivo de solo podem alterar a quantidade de matéria orgânica do solo (MOS) estabilizada, mas ao mesmo tempo podem incrementar os processos de proteção de carbono do solo exercida por esta. A fim de melhor entendimento da dinâmica relacionada com esta problemática, faz-se necessário um estudo mais apropriado acerca do reflexo de tais práticas junto a MOS (John et al., (2005)).

Quando o solo é submetido a um tipo de operação que resulta em alteração de seu perfil, o fluxo de emissão de $\mathrm{CO}_{2}$ sofre aumento. Este aumento começa imediatamente após o término da atividade e perdura por certo periodo de tempo (Carbonell-Bojollo et al., (2011)).

Ainda, de acordo com Gonzalez-Chavez et al., (2010) práticas de uso do solo podem afetar a composição, diversidade e função das comunidades microbianas, refletindo significativamente nos processos do solo. Conforme os mesmos, com um melhor entendimento de como tais atividades interferem no comportamento das comunidades microbianas, é possível inferir-se em novos procedimentos de sequestro de $\mathrm{C}$ e aumento de fertilidade em sistemas agrícolas.

Além dos sistemas agrícolas, os sistemas florestais também desempenham papel crucial na questão do ciclo de C e mitigação de gases do efeito estufa. Segundo Nave et al., (2010) o melhor entendimento de fatores que afetam o sequestro de C em florestas é de fundamental importância para o acompanhamento das mudanças em seus ecossistemas, recursos hídricos e mitigação de gases do efeito estufa.

\subsection{Manejos Agrícolas}

O manejo adequado de solo em sistemas agrícolas é ferramenta de suma importância, sendo considerada uma forma de moldar alguns parâmetros químicos, físicos e biológicos, criando condições favoráveis para manutenção de estrutura, germinação e cultivo (Organização das Nações Unidas para Alimentação e Agricultura - FAO, 2002). Segundo Carbonell-Bojollo et al., (2011) o manejo de solo em sistemas agrícolas provoca alterações no conteúdo de carbono orgânico do solo através de variações no tipo de uso, praticas de cultivo e atividades relacionadas.

Conforme Chirinda et al., (2010) práticas de manejo de solo utilizadas em sistemas agrícolas tem influência direta nas propriedades do solo, eficiência de nutrientes e produção de culturas. Segundo Pimentel et al., (2005) práticas de manejo convencional, baseadas na aplicação de fertilizantes inorgânicos e defensivos agrícolas químicos, tem, nos últimos anos, aumentado a produção agrícola, apresentando, contudo, alto risco ambiental. 
Em contrapartida, sistemas orgânicos de manejo solo, dependentes de fontes orgânicas de nutrientes (dejetos animais, resíduos de culturas, plantas de cobertura) tem potencial de manter a produtividade agrícola, também a elevado risco ambiental (Watson et al., (2002)).

De acordo com Fasinmirin e Reichert (2011) algumas práticas de manejo agrícola expõem o solo a diversas formas de degradação e decomposição estrutural. Conforme os mesmos, o uso de equipamentos pesados, frequentemente leva à compactação do solo, distúrbios nas características de infiltração, redução de fertilidade, aumento de densidade e resistência à penetração, além de prejudicar o crescimento das culturas.

Ainda, de acordo com Montgomery (2007) além do impacto relacionado às características do solo, algumas práticas podem interferir diretamente no equilíbrio e manutenção da atividade microbiana, e, consequentemente, nos respectivos processos biológicos decorrentes.

Dessa forma, segundo Lal et al., (1999) as práticas de manejo do solo devem ser realizadas com parcimônia e escolhidas de maneira a conservar sua estrutura, o equilíbrio biológico, ao mesmo tempo em que otimiza o cultivo. Na sequência são apresentadas características dos sistemas agrícolas mais empregados e analisados no presente estudo.

\subsubsection{Plantio Direto (PD)}

Segundo Lal (1982) entende-se por plantio direto (PD) à prática de plantio diretamente no solo ou sobre resíduos de culturas, sem que estes tenham sido previamente manejados em relação ao primeiro cultivo. Conforme o mesmo, o máximo de resíduos de culturas é retido na superfície e as pragas são controladas por pesticidas ou plantas de cobertura, ou ainda uma combinação de ambos os procedimentos.

O desenvolvimento da prática tem sido considerado uma grande revolução que tem impactado sistemas agrícolas ao redor do mundo (Triplett e Dick (2008)). Segundo DeLaune e Sij (2012) o sistema de PD tem sido adotado intensivamente devido à sua capacidade de aumento de conservação de solo e retenção de água, manutenção de estrutura do solo e menor necessidade de implementos.

De acordo com levantamento realizado em 2009 pela Federação Brasileira de Plantio Direto na Palha (FEBRAPDP), o sistema de PD é praticado em, aproximadamente, metade de sua extensão agrícola, chegando a 25.502.000 hectares no período de 2007/2008. A tabela a seguir ilustra a extensão da prática em diversos países. 
Tabela 1 - Áreas globais de cultivo agrícola por plantio direto

\begin{tabular}{|l|r|}
\hline \multicolumn{1}{|c|}{ Pais } & $\begin{array}{r}\text { Área sob Plantio Direto (ha) } \\
\text { 2007/ 2008 }\end{array}$ \\
\hline EE.UU. & 26.500 .000 \\
\hline Argentina & 25.785 .000 \\
\hline Brasil & 25.502 .000 \\
\hline Austrália & 17.000 .000 \\
\hline Canadá & 13.481 .000 \\
\hline Paraguai & 2.400 .000 \\
\hline China & 1.330 .000 \\
\hline Casaquistão & 1.300 .000 \\
\hline Bolivia & 706.000 \\
\hline Uruguai & 655.000 \\
\hline Espanha & 650.000 \\
\hline África do Sul & 368.000 \\
\hline Venezuela & 300.000 \\
\hline França & 200.000 \\
\hline Finlândia & 200.000 \\
\hline Chile & 180.000 \\
\hline Nova Zelândia & 162.000 \\
\hline Colômbia & 102.000 \\
\hline Ucrânia & 100.000 \\
\hline Outros (Estimativa) & 1.000 .000 \\
\hline Total & $\mathbf{1 1 6 . 9 2 1 . 0 0 0}$ \\
\hline
\end{tabular}

Fonte: www.febrapdp.org

Diversos estudos da literatura listam os benefícios da prática de PD, em comparação aos sistemas convencionais, sendo estes: redução de erosão do solo, aumento no conteúdo de carbono orgânico, maior atividade microbiana, evaporação reduzida, dentre outros (Lal et al., (2003)). Ainda, em complemento, de acordo com Reicosky (2008) a prática leva à diminuição do processo de oxidação da $\mathrm{MOS}$ em $\mathrm{CO}_{2}$, provocado por alguns sistemas de manejo.

De acordo com Lal, et al., (2003) a prática de PD tem se tornado o método de maior custo-benefício e mais eficaz no combate à erosão no solo em território nacional, e também em território norte-americano, quando comparado às demais práticas conservacionistas.

Cabe ressaltar que, segundo definição proposta pela FAO, 2002, práticas conservacionistas compreendem sistemas manejo baseados nos seguintes princípios básicos: (i) redução crítica ou inexistência de quaisquer distúrbios no solo, à exceção quando da época de colheita, (ii) preservação de cobertura permanente ou semi permanente (resíduos de culturas) e (iii) rotação de culturas economicamente viáveis.

Contudo, de acordo com Fasinmirin e Reichert (2011) existe uma série de fatores que devem ser levados em consideração para a correta condução desse tipo de sistema concatenado à rotação de culturas, tais como: tipo e quantidade de herbicida a ser utilizada, a frequência de sua aplicação, a escolha de quais serão as culturas a serem empregadas, 
gerenciamento do período de rotação de culturas, a permanência dos respectivos resíduos e escolha de possíveis plantas de cobertura.

Resíduos de culturas remanescentes resultam em uma camada que protege o solo do impacto de chuva e vento, além de estabilizar umidade e temperatura na superfície, criando, dessa maneira, um ambiente adequado para uma série de organismos, que vão desde insetos até fungos e bactérias. Estes organismos consomem o resíduo depositado, transformando-o em partículas menores, misturando-o com o solo, o que leva à formação do húmus, mantendo estável a estrutura do solo (Fasinmirin e Reichert (2011)).

De acordo com Six et al., (1998) o sistema de PD aumenta o teor de carbono na camada arável devido à redução da taxa de decomposição, levando a um aumento na proteção física de carbono, em macroagregados do solo. Contudo, conforme Salvo et al., (2010) a taxa de acúmulo de carbono orgânico no solo em áreas sob regime de PD tem mostrado alta variação, uma vez que sua dinâmica depende, não somente do sistema de manejo em si, mas também da mineralogia, condições climáticas, quantidade de resíduos dispostos e adições de N.

Segundo Six et al., (2000) microagregados formados dentro de macroagregados ou não, tornam-se mais estáveis com o tempo quando submetidos ao regime de PD. Em complemento, de acordo com os mesmos, o teor de carbono contido em microagregados do solo é menos suscetível à decomposição quando liberado dos macroagregados.

Em estudo realizado por West e Post (2002) analisando 67 experimentos de longoprazo, foi observado um aumento significativo no conteúdo de carbono orgânico do solo, quando da mudança de sistema de manejo de plantio convencional (PC) para PD. Os autores verificaram que em, aproximadamente, $85 \%$ dos casos, o aumento ocorreu na camada superficial de $0-7 \mathrm{~cm}$.

Resultados similares foram obtidos por Gal et al., (2007) analisando o comportamento dos sistemas de $\mathrm{PD}$ e $\mathrm{PC}$, no que diz respeito à dinâmica de $\mathrm{N}$ e carbono orgânico. Foram observados maiores valores para as amostras da camada superficial referentes ao PD, sendo que, considerando o perfil de $1 \mathrm{~m}$, os valores não apresentaram diferença significativa entre os sistemas analisados.

\subsubsection{Plantio Convencional (PC)}

Os sistemas agrícolas de plantio convencional (PC) caracterizam-se pela utilização de técnicas de aração (por meio mecânico ou animal), inversão e gradagem, no processo de cultivo, através de uso de maquinário específico para a atividade. 
A prática permite a germinação das sementes em áreas livres de qualquer interferente, maior incorporação de fertilizantes e reestruturação do solo. Contudo, as atividades de manejo de solo, características deste tipo de sistema, removem parte da cobertura vegetal existente, deixando o solo exposto às chuvas, vento, sendo mais suscetível à ocorrência de erosão (Shetto (1999)).

Os efeitos de um sistema de manejo nas propriedades do solo e ocorrência de erosão na área variam de acordo com as características intrínsecas do próprio solo em questão. Por exemplo, em áreas onde o solo apresenta estrutura favorável com grande proporção de agregados estáveis, apresentando também permeabilidade significativa, a perturbação do solo pelo uso de maquinário mecânico deve aumentar o risco de erosão. Entretanto, em áreas onde o solo apresenta um horizonte compactado, com grande incidência de estruturas instáveis, a atividade mecânica tende a minimizar o risco de erosão, ao menos, temporariamente (Fasinmirin e Reichert (2011)).

Outra característica deste tipo de regime agrícola é a incorporação, através do revolvimento, de alguns dos resíduos das culturas recém-semeadas. A incorporação destes materiais leva à diminuição de seu processo de decomposição, influenciando a população microbiana do solo por um período mais longo. Os resíduos não incorporados totalmente, remanescentes na superfície, apresentam menor tempo de decomposição, modificando, contudo, as características de temperatura e umidade do solo (Mari e Changying (2006)).

Dentre as práticas derivadas dos sistemas de PC, a prática de PC com manejo mínimo é frequentemente citada em diversos estudos da literatura. Entretanto, a terminologia "manejo mínimo" tem causado certa controvérsia, dado que cultivo mínimo necessário em dada cultura varia do simples uso manual do arado até uma gama completa de operações de manejo, dependendo das propriedades do solo e culturas.

De acordo com Fasinmirin e Reichert (2011) define-se o sistema de manejo mínimo como sendo a mínima manipulação de solo necessária para a produção das culturas, de acordo com condições climáticas pré-existentes da área em questão. Ainda, conforme os mesmos, as vantagens deste tipo de sistema são o rápido aquecimento do resíduo do cultivo remanescente no solo, possibilidade da adição de nutrientes em determinadas áreas, e sustentabilidade em solos com deficiência de drenagem.

Contudo, dentre as possíveis desvantagens do sistema pode-se citar os custos agregados às operações de pré-plantio, endurecimento de camada superficial ou erosão nas faixas sem a permanência dos resíduos de culturas, e o sistema não é adequado em regiões que apresentem solos estruturalmente danificados. 


\subsubsection{Agricultura Orgânica}

Segundo Kuepper e Gegner (2004) ao longo dos anos tem se tornado comum definir a prática de agricultura orgânica como sendo aquela que não utiliza pesticidas sintéticos e fertilizantes convencionais. Contudo, de acordo com os mesmos, tal afirmação deve ser considerada como característica do sistema antes de definição. Uma definição mais adequada para a prática foi estabelecida e apresentada, em 1995, pelo Departamento de Agricultura dos Estados Unidos (USDA), através de seu Painel Nacional de Padrões Orgânicos (NOSB), como sendo "um sistema de produção e manejo que promove e aumenta biodiversidade, ciclos biológicos e atividade biológica do solo, baseado no mínimo uso de insumos sintéticos e em atividades que restauram, mantém e aumentam o equilíbrio ecológico".

De acordo com os mesmos, não por acaso existe certo complemento entre os conceitos de agricultura orgânica e sustentável, haja vista que, segundo pesquisas, as principais características do regime agrícola orgânico são a redução da erosão do solo, menor consumo de combustíveis fósseis (maquinário de manejo), menor lixiviação de nitratos, maior sequestro de carbono e mínimo uso de pesticidas.

Conforme Ponti et al., (2012) durante os últimos 15 anos o conceito de agricultura orgânica tem se espalhado em muitas partes ao redor do mundo, contudo, apesar deste crescimento, e aumento em pesquisas, política, mídia e comoção pública, somente uma parte reduzida de área agrícola tem adotado este tipo de sistema.

Segundo Niggli et al., (2009) a prática de agricultura orgânica atende às necessidades de remediação do processo de erosão do solo, uma vez que aumenta sua fertilidade, e mitigação de efeitos inerentes às mudanças climáticas. Ainda, de acordo com os mesmos, as técnicas de manejo relacionadas a esse tipo de regime agrícola (tais como rotações de cultura balanceadas, condicionamento orgânico do solo, manejo reduzido) oferecem uma melhor estrutura para o solo.

O sistema de agricultura orgânica auxilia agricultores a adaptarem-se às mudanças climáticas, estabelecendo condições que aumentam a resistência do ecossistema do solo às alterações decorrentes. Tal aumento da capacidade do ecossistema permite uma melhor resposta do solo à variação climática (FAO, 2008).

De acordo com Schialabba e Müller-Lindenlauf (2010) considerando a hipótese de que todos os sistemas agrícolas fossem orgânicos, haveria uma diminuição de emissão de GEE cerca de $20 \%$, principalmente de $\mathrm{N}_{2} \mathrm{O}$, e redução de cerca de $10 \%$ de demanda de energia, levando-se em consideração os processos de síntese e aplicação de fertilizantes minerais. Ainda, conforme os mesmos, tais diminuições são ainda complementadas por um potencial de 
sequestro de carbono na faixa de 40 a $72 \%$, considerando as emissões anuais de GEE no setor agrícola.

Conforme Azadi et al., (2011) devido ao maior conteúdo de MOS gerado (acarretando, por consequência, em maior retenção de água no solo), as práticas de agricultura orgânica são menos dependentes de irrigação quando comparadas aos sistemas convencionais. Tal menor dependência representa, além da economia de água, redução de gastos relacionados com energia utilizada nos processos de irrigação.

Segundo pesquisa realizada por Lotter et al., (2003) sistemas agrícolas sob regimes orgânicos de produção apresentaram maior captura de água (na ordem de, aproximadamente, $100 \%$ ) e produção agrícola dos culturas (na ordem de 90\%) em comparação aos sistemas de manejo convencionais.

Ainda, a elevada eficiência em retenção de água, e consequente resistência a períodos de estiagem, além da economia de energia, apresentada pelos sistemas orgânicos de agricultura, são características benéficas e atraentes para agricultores de países em desenvolvimento (Azadi e Ho (2010)).

\subsection{Sistemas de Florestas}

Os sistemas florestais representam uma importante ferramenta na mitigação de efeitos inerentes às mudanças climáticas globais, através de seu potencial de regulação diversos parâmetros, tais como fluxo de GEE, quantidade de água no solo (retenção de água pelas raízes), além da influência direta na qualidade do solo (capacidade de tamponamento e filtração). Com seu potencial considerável para o sequestro de carbono, as florestas constituem um dos principais elementos do ciclo global de carbono (Vries e Posch (2010)).

De acordo com VijayaVengataRaman et al., (2012) uma estratégia para mitigar o aumento da concentração atmosférica de $\mathrm{CO}_{2}$ é a expansão territorial dos sumidouros terrestres de carbono, particularmente os sistemas florestais, utilizando as árvores como depuradores ambientais. Conforme os mesmos, o Protocolo de Kyoto também preconiza disposições acerca do uso de sistemas florestais em projetos e atividades para o sequestro de carbono, no que tange aos planos de mitigação de GEE.

Segundo Burley et al., (2007) no setor de atividades do uso solo (agrícolas ou florestais), o gerenciamento de carbono no solo é diretamente relacionado com o acúmulo e manutenção pela biomassa. Conforme os mesmos, qualquer prática de manejo que altere a biomassa de determinada área tem impacto direto na capacidade do solo em armazenar carbono atmosférico. Ainda, em complemento, os autores ratificam a existência de diversas práticas de uso do solo no setor florestal que podem utilizadas na redução da concentração de 
GEE atmosféricos, seja pelo aumento da taxa de acúmulo de carbono ou, ainda, pela redução (ou prevenção) de perda do montante previamente acumulado.

O sequestro de carbono na biomassa florestal tem sido considerado um sumidouro de carbono de grande significância. Uma vez que as mudanças climáticas globais podem modificar o crescimento, e, ainda, a distribuição geográfica de florestas, os efeitos biológicos de tais mudanças, no que concerne aos sistemas florestais, também devem ser considerados em qualquer análise, considerando os impactos para este setor (Alig et al., (2002)).

Contudo, a ameaça global mais visível e alarmante para o setor é o desmatamento florestal. Entre os efeitos negativos inerentes a esse tipo de prática, como a perda da biodiversidade, a interferência nos fluxos de emissão de GEE pode ser considerada a mais impactante. De acordo com levantamento realizado pela FAO estima-se que cerca de $30 \%$ da concentração de GEE emitida para atmosfera advém da atividade.

Conforme Kurz e Apps (2006) o processo de desmatamento florestal apresenta um impacto duplo junto ao ciclo global de carbono, através da perda da capacidade da realização de fotossíntese e pela perda do conteúdo de carbono previamente acumulado nos sistemas, e, mais importante, contido na MOS.

Segundo Dijkstra et al., (2009) a maior parte do conteúdo de carbono acumulado em sistemas florestais encontra-se no solo. De acordo com os mesmos, enquanto o sequestro de carbono nas árvores é devido a um processo cíclico e transitório (fotossíntese), o teor de carbono acumulado no solo tende a permanecer por um período mais longo, uma vez que o carbono sub superficial apresenta menor tempo de decomposição em detrimento ao superficial, sendo, dessa maneira, mais estável. Assim, em longo prazo, o solo torna-se o principal sumidouro (ou fonte) de $\mathrm{CO}_{2}$ atmosférico para estes sistemas.

De acordo com Booth (2012) devido à sua grande utilização e valorização em termos de economia mundial, as principais espécies cultivadas em sistemas de florestas, em escala global, são eucaliptos. Conforme o mesmo, as espécies de eucaliptos são cultivadas em mais de 90 países, abrangendo mais de 20 milhões de hectares, tendo como maiores centros produtores Brasil (4,2 milhões de hectares), Índia (3,9 milhões de hectares) e China (2,6 milhões de hectares).

Segundo Alig et al., (2002) a resposta dos solos sob sistemas florestais, no que concerne ao aumento da concentração atmosférica de $\mathrm{CO}_{2}$, tem influência significativa no ciclo global de carbono. Contudo, uma vez que um dos maiores desafios para este tipo de sistema é o entendimento concatenado acerca da dinâmica do carbono e o ciclo de 
crescimento das espécies em questão, o impacto inerente às mudanças climáticas junto aos solos em florestais ainda é complexo e requer estudos mais aprofundados.

\subsection{Uso de Condicionadores Orgânicos}

A aplicação de condicionadores orgânicos no solo (tais como resíduos de culturas, dejetos animais, entre outros) é considerada como potencial ferramenta para a prática agricultura sustentável, como evidenciado pelo aumento do interesse neste tipo de estratégia (Lu et al., (2000)). O uso de tais condicionadores tem se mostrado de grande utilidade no aumento do conteúdo de MOS e fertilidade do solo, além da prevenção da ocorrência de erosão nas áreas (Snapp et al., (2005)).

De acordo com Thangarajan et al., (2013) considerando as demandas globais e o aumento de custo de fertilizantes minerais, o uso de condicionadores orgânicos (incluindo esterco, compostos, resíduos de culturas e biossólido) tem crescido rapidamente e a prática de sua aplicação em áreas agrícolas em diversos países continua a crescer.

Os processos físicos, químicos e biológicos inerentes à aplicação de condicionadores orgânicos ao solo são ilustrados na figura 5 a seguir.

Fig. 5 - Representação esquemática dos efeitos da aplicação de condicionadores orgânicos na emissão de gases do efeito estufa $\left(\mathrm{CO}_{2}, \mathrm{CH}_{4}\right.$ e $\left.\mathrm{N}_{2} \mathrm{O}\right)$ (Adaptado de Thangarajan, et al., 2013).

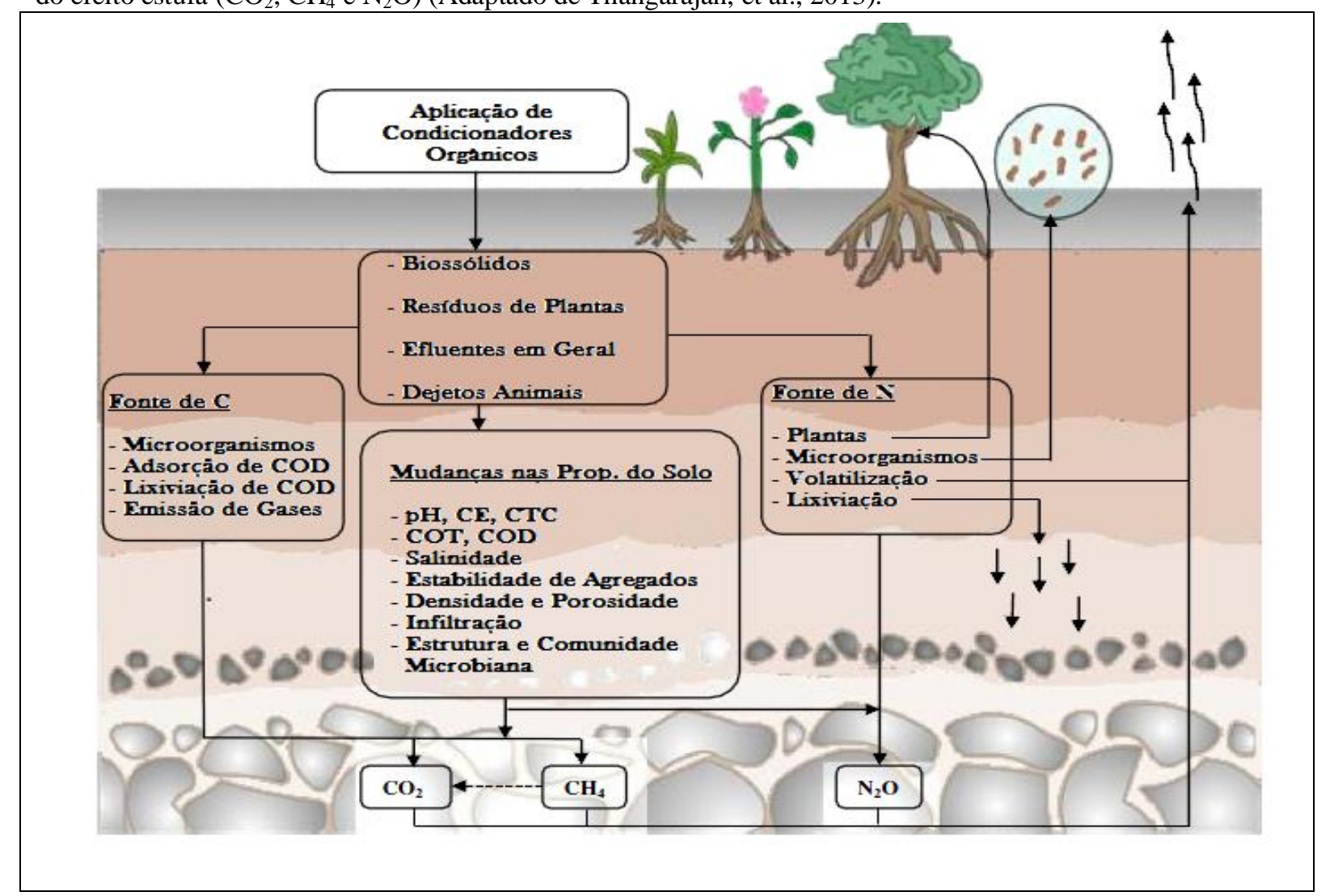

Fonte: THANGARAJAN, R.; BOLAN, N. S.; TIAN, G.; NAIDU, R.; KUNHIKRISHNAN, A. Role of organic amendment application on greenhouse gas emission from soil. Science of the Total Environment, p. 1- 25, 2013. 
Segundo Barral et al., (2009) o esperado aumento da temperatura superficial do solo devido ao aquecimento global ocasionará uma elevação da taxa de mineralização de MOS, e, portanto, a quantidade de condicionadores orgânicos adicionados ao solo, a fim de manter o conteúdo de matéria orgânica em níveis adequados, será maior.

O acúmulo de carbono orgânico no solo em sistemas agrícolas ocorre através do equilíbrio entre as adições de carbono provenientes das culturas e de condicionadores orgânicos e as perdas, predominantemente, através da decomposição de matéria orgânica e emissão de $\mathrm{CO}_{2}$ para a atmosfera (Huggins et al., (1998)). Ainda, segundo Adani e Tambone (2005) durante os primeiros anos de aplicação de condicionadores orgânicos, frequentemente há um aumento na biomassa microbiana e, por consequência, em sua atividade no solo.

Contudo, a adição de novos substratos ao solo, como condicionadores orgânicos, pode levar à ocorrência do fenômeno de priming effect, definido como alteração na taxa de mineralização da MOS nativa pela adição de substratos externos (Zimmerman et al., (2011) e Fontaine et al., (2007)). Na maioria dos casos, é mais comumente observado o "priming positivo", ou seja, mineralização acelerada de compostos menos recalcitrantes da MOS pela adição de uma fonte contendo carbono mais lábil. Contudo, os resultados observados, em muitos casos, não correspondem à terminologia de "positivo".

Segundo Fontaine et al., (2007) adições de compostos celulósicos resultaram em acréscimo de $100 \%$ na mineralização da MOS mais antiga (2500 anos) em camadas mais profundas. Ainda, o efeito observado, nestes casos, pode ser analisado como sendo consequência direta do aumento da produção de enzimas extracelulares, devido à adição do substrato, que co-metabolizam a MOS, ou ainda, resultado de mecanismos indiretos, tais como, estímulo da atividade microbiana no solo pela maior disponibilidade de material orgânico fresco, mudanças na aeração, umidade e estrutura do solo (Kuzyakov et al., (2000)).

Em contrapartida, entende-se por "priming negativo" qualquer retardo no processo de mineralização da MOS pela adição de um novo substrato, em decorrência de possível competição entre os organismos decompositores, levando à inibição de atividade microbiana no solo, causada pela alteração nas condições do solo (Kuzyakov et al., (2000)).

Entre as práticas de uso de solo visando o sequestro de carbono (adoção de sistemas agrícolas sem manejo de solo, rotação de culturas), o uso de condicionadores orgânicos, tais como dejetos de animais, tem sido alvo de diversas pesquisas (Thelen et al., (2010) e Fronning et al., (2008)).

Apesar das perdas através dos processos de oxidação, é estimado que, aproximadamente, metade da quantia de carbono, intrínseca ao esterco animal adicionado, é 
retida no solo (Rochette et al., (2008)). Em seu estudo, Sainju et al., (2008) observaram que a adição de esterco aviário promove aumento conteúdo de carbono acumulado, quando comparado com fertilizantes inorgânicos e resíduos de culturas.

Alguns estudos prévios demonstraram as diversas respostas do solo, no que tange à emissão de $\mathrm{CO}_{2}$, mediante a aplicação de condicionadores orgânicos (Mapanda et al., (2011)). A quantidade de $\mathrm{CO}_{2}$ emitida é dependente de vários fatores, particularmente, do tipo e quantia de condicionador utilizado, além do conteúdo de carbono do solo da área em questão (Six et al., (2002)).

Contudo, segundo Li et al., (2013) o entendimento do fluxo de emissão de $\mathrm{CO}_{2}$ do solo, inerente à adição de condicionadores orgânicos de quaisquer espécies, ainda não é totalmente elucidado pela literatura, em se tratando de um processo que apresenta certo grau de complexidade.

Drinkwater et al., (1998) comparando sistemas agrícolas sob regime convencional e sob adição de condicionadores orgânicos (esterco), observou que, mesmo em situações onde a quantia de carbono adicionada ao solo foi a mesma em ambos os sistemas, o sistema sob adição de esterco apresentou um aumento significativo no conteúdo de carbono acumulado no solo.

Quando comparado com resíduos de culturas depositados ao solo, é observada uma maior quantia de carbono derivado de esterco retido no solo. Tal comportamento, provavelmente, deve-se ao fato de o esterco apresentar certo grau de decomposição, acarretando na incidência de compostos orgânicos mais quimicamente recalcitrantes (Paustian et al., (1992)).

Além da variedade de dejetos animais que podem ser utilizados como alternativa para condicionamento de solo, o lodo de esgoto (LE) tem sido amplamente aplicado ao solo neste sentido.

O LE é um subproduto sólido do processo de tratamento de esgoto e tem potencial de aumentar a produtividade do solo, uma vez que contem altos níveis de matéria orgânica e nutrientes. $\mathrm{O}$ uso de LE como condicionador é considerado benéfico, tendo em vista que os conteúdos orgânicos e minerais contidos no lodo podem ser úteis para a fertilidade do solo e parâmetros biológicos, bem como para o desenvolvimento das culturas (Arraigada et al., (2009)).

Entretanto, dependendo de sua origem, o LE pode também conter traços de metais, que se acumulam na superfície do solo, onde são altamente resistentes (Parat et al., (2005)). 
Além disso, diversas pesquisas observaram reflexo da adição de LE na biomassa e atividade microbiana do solo (McGrath et al., (2000)).

Em estudo conduzido por Adani e Tambone (2005) foi observado que a população bacteriana do solo era maior em áreas sob adição de LE, em comparação às áreas de controle sem adição, com declínio ao longo do tempo. A explicação proposta para este comportamento baseava-se em duas hipóteses, sendo (i) mudanças na cadeia alimentar microbiana, levando à sucessão de espécies, com consumo dos organismos mais simples, e (ii) variação na concentrações de traços de metais, como $\mathrm{Cd}, \mathrm{Cu}, \mathrm{Pb}$ e $\mathrm{Zn}$, presentes no $\mathrm{LE}$, acarretando na alteração de características biológicas do solo.

Assim sendo, o uso de condicionadores orgânicos em solos, de qualquer natureza, em substituição aos fertilizantes sintéticos, deve ser feito em parcimônia, a fim de se obter otimização no processo de adição, minimizando possíveis efeitos deletérios junto ao solo, inerentes à prática indiscriminada.

\subsection{Sequestro de Carbono no Solo}

O solo constitui um importante componente dos ecossistemas terrestres, apresentando papel fundamental em sistemas agrícolas de produção. Além de representar o principal meio para o desenvolvimento de culturas, o solo atua como um dos principais agentes para sustentabilidade da produção agrícola e regulação, em parte, do fluxo de $\mathrm{CO}_{2}$ atmosférico (Lal (2008)).

A agricultura pode ser uma aliada importante para a mitigação da concentração de $\mathrm{CO}_{2}$ da atmosfera. Pela fotossíntese pode-se converter o $\mathrm{CO}_{2}$ da atmosfera em massa vegetal e, além disso, por meio de um manejo adequado desta massa pode-se reter parte do carbono no solo caracterizando um "sequestro de carbono" da atmosfera pelo solo (Lal (2004)).

Conforme Powlson et al., (2012) a transferência de C, na forma de $\mathrm{CO}_{2}$ atmosférico, para o solo (direta ou indiretamente - vegetação, por exemplo) é denominado por sequestro de $C$, representando potencial para mitigação de mudanças climáticas e podendo ser alcançado por alterações nas práticas de uso de solo, tais como reflorestamento e manejo diferenciado em sistemas agrícolas.

Contudo, de acordo com Stockmann et al., (2013) o termo "sequestro de carbono no solo" implica em um "aprisionamento" de carbono, proveniente de $\mathrm{CO}_{2}$ atmosférico, pelo acúmulo em frações de carbono no solo mais estáveis ou pelo aumento dos reservatórios, com diferentes tempos de residência.

Segundo Aertsens et al., (2013) o carbono perdido para atmosfera pode ser recuperado pela alteração dos fluxos de $\mathrm{CO}_{2}$ através determinadas atividades de uso do solo, promovendo 
dessa forma uma diminuição da concentração de $\mathrm{CO}_{2}$ atmosférico. De acordo com os mesmos, quaisquer práticas que aumentem o teor de carbono retido no solo através do processo de fotossíntese e/ou reduzam a quantia de $\mathrm{CO}_{2}$ emitida exercerão impacto positivo nas reservas de carbono do solo, estimulando o mecanismo de sequestro, dando origem a novos reservatórios de carbono. A figura 6 a seguir ilustra alguns dos mecanismos que levam à otimização do potencial de sequestro de carbono nos solos.

Fig. 6 - Representação esquemática de fatores que influenciam diretamente no potencial de sequestro de carbono no solo (adaptado de Nair et al., 2009)

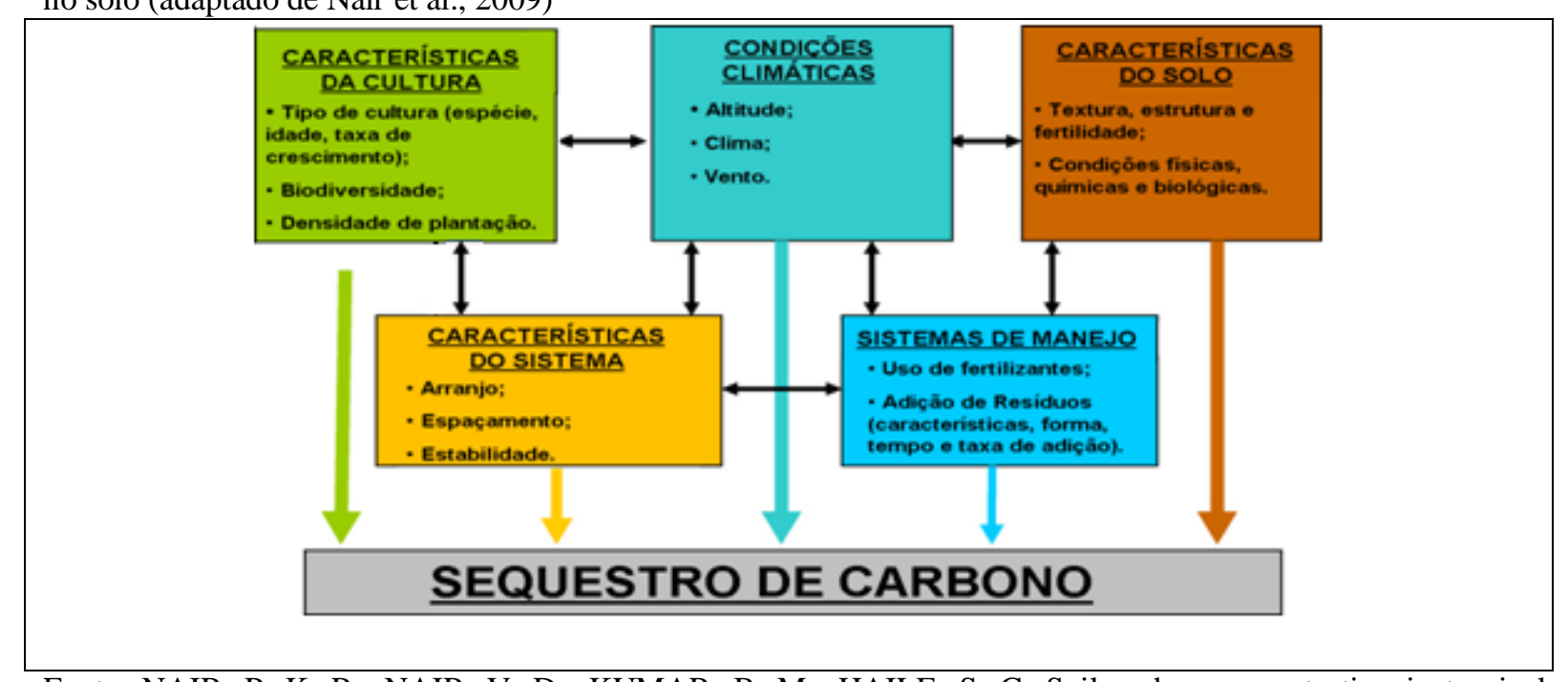

Fonte: NAIR, P. K. R.; NAIR, V. D.; KUMAR, B. M.; HAILE, S. G. Soil carbon sequestration in tropical agroforestry systems: a feasibility appraisal. Environmental Science and Policy, v. 12, n. 8, p. 1099-1111, 2009.

De acordo com VijayaVengataRaman et al., (2012) o mecanismo de sequestro de carbono no solo constitui uma importante ferramenta para a manutenção da concentração ideal de $\mathrm{CO}_{2}$ atmosférico, acarretando na mitigação de efeitos inerentes às mudanças climáticas.

O solo, dependendo do tipo de manejo empregado, tem função tanto de fonte emissora quanto sumidouro de $\mathrm{CO}_{2}$ atmosférico (Singh et al., (2009)). De acordo com Kukal et al., (2009) atividades agrícolas exercem profunda influência no conteúdo de carbono orgânico do solo, tanto em longo quanto em curto prazo.

A manipulação do tamanho e extensão dos reservatórios de carbono no solo é considerada a principal ferramenta no processo de sequestro. Atualmente os reservatórios são menores, levando-se em consideração seus respectivos tamanhos antes da interferência das atividades antrópicas. Historicamente, os solos perderam, globalmente, um montante entre 40 e 90 Pg de C devido ao cultivo e perturbação do solo (Houghton et al., (1999) e Lal (1999)). 
Conforme Smith (2004c) o sequestro de carbono no solo tem o potencial de anular cerca de um terço do montante atual de $\mathrm{CO}_{2}$ atmosférico, contudo a extensão da duração deste efeito tende a ser limitada, com impactos significantes durando entre 20 e 50 anos. Segundo o mesmo, juntamente com esta duração limitada, os aumentos na densidade demográfica e, consequente, demanda de energia per capita levam a crer que o sequestro de carbono no solo pode vir a apresentar uma função de coadjuvante no que tange às metas globais das emissões de carbono atmosférico estimadas até 2100, o que ressalta a necessidade da concatenação de práticas de manejo adequadas para a otimização do processo. Ainda, de acordo com a Royal Society (2001) o sequestro de C solo apresenta certas limitações em termos de mitigação de mudanças climáticas. A capacidade de reservatório de $\mathrm{C}$ do solo é finita, tendendo a um máximo após um período de décadas, ou mesmo séculos, uma vez que o conteúdo de $\mathrm{C}$ do solo apresenta um equilíbrio dinâmico característico do tipo de solo e clima, ainda relacionado diretamente com o tipo de manejo a ser empregado. Ainda, o processo é reversível, dessa forma, qualquer prática de manejo empregada com o intuito de aumentar o conteúdo de C orgânico do solo deve ser continuada de maneira constante.

Em complemento, segundo Smith (2005) enquanto existem diversas vantagens no conteúdo de carbono em reservatórios no solo, há também alguns tópicos a serem levados em consideração, o que torna, também, o processo de sequestro um mecanismo de risco para mitigação de efeitos inerentes às mudanças climáticas. $\mathrm{O}$ primeiro ponto a ser considerado é a possibilidade da saturação do reservatório (o carbono é removido da atmosfera até o ponto onde o solo atinge determinado nível de equilíbrio) e o segundo é a não permanência, ou seja, os sumidouros podem se tornar fonte de carbono atmosférico mediante práticas equivocadas de uso do solo. Segundo o mesmo, o conteúdo de carbono no solo obtido através de determinada prática de manejo é rapidamente perdido caso a atividade empregada não seja mantida, uma vez que a taxa de perda de carbono é maior do que a taxa de ganho.

O tempo de saturação (novo ponto de equilíbrio) de um reservatório de carbono no solo é altamente variável. Para solos em regiões de clima temperado, o período para que o sistema atinja um novo equilíbrio é de aproximadamente 100 anos (Smith et al., (2012)), ao passo que em solos tropicais tal período é menor.

Assim, segundo Smith (2004c) o sequestro de carbono no solo representa uma ferramenta de grande utilidade no que tange à satisfação de metas de curto a médio prazo no que concerne a emissão de GEE, conferindo efeitos benéficos para o solo, sendo uma opção viável para a redução da concentração atmosférica de $\mathrm{CO}_{2}$, além de permitir um maior tempo de estudo e pesquisa, em todos os setores da economia mundial, de novas soluções para os 
problemas de emissão e concentração elevada de alguns dos agentes causadores de mudanças climáticas.

Em complemento, de acordo com Powlson et al., (2012) diversas discussões sobre o papel do solo dentro do ciclo global de $\mathrm{C}$, no que diz respeito à possibilidade da mitigação de mudanças climáticas pelo sequestro de $\mathrm{C}$, têm estado em pauta e requerem maior atenção para melhor entendimento.

\subsection{Matéria Orgânica do Solo (MOS)}

De acordo com Jenkinson (1988) entende-se por matéria organica do solo (MOS) ao conjunto heterogêneo de substâncias (húmicas e não húmicas) derivadas da decomposição microbiana de resíduos de plantas e animais. Segundo o mesmo, durante o processo de decomposição, tais resíduos são inicialmente quebrados em partículas menores com características similares ao material original. A consequente ciclagem de tais partículas, e, ainda, de seus respectivos materiais de origem, pela ação da atividade microbiana do solo, origina um composto altamente estável, de cor escura, referido como húmus.

Segundo Trumbore (1997) a fração não húmica da MOS é, por convenção, dividida em três parcelas, sendo: (i) parcela ativa com taxa de decomposição de anos (exudatos de raiz, resíduos de plantas rapidamente decompostos), (ii) parcela intermediária com taxa de decomposição de décadas e, (iii) parcela passiva com período de decomposição de séculos ou milênios, constituída por matéria orgânica estabilizada por mecanismos físicos ou químicos.

Assim sendo, em complemento, conforme Stockmann et al., (2013) a MOS consiste em mistura complexa de substâncias parcialmente decompostas (moléculas orgânicas, tais como polissacarídeos, lignina, bio polímeros alifáticos, taninos, lipídeos, proteínas e amino açucares) derivadas tanto de resíduos de plantas e animais, quanto de biomassa microbiana.

Mecanismos de proteção física referem-se à oclusão de MOS em agregados do solo, formando barreira física, o que limita o acesso de decompositores e enzimas aos substratos orgânicos e à difusão de $\mathrm{O}_{2}$; tal modalidade de proteção é dependente do nível de agregação, sendo maior em microagregados em comparação a macroagregados (Pulleman e Marinissen (2004)). Os mecanismos de estabilização química referem-se à associação da matéria orgânica com partículas minerais, o que reduz a capacidade de degradação de decompositores e enzimas (Six et al., (2002)).

De acordo com a teoria da dinâmica de agregados proposta por Golchin et al., (1994) material fresco de plantas recém adicionado ao solo contem micro-organismos, apresentando partículas primárias ligadas pela ação de agentes microbianos, dando origem macroagregados estáveis. Com o tempo, o material fresco contido nos macroagregados formados é 
seletivamente decomposto, restando os materiais quimicamente mais recalcitrantes, os quais são envoltos por metabólitos microbianos e partículas minerais, formando os microagregados estáveis.

Por se tratar de um conjunto heterogêneo, a MOS pode ser fisicamente fracionada, levando-se em consideração as características das partículas que a compõem. Segundo Christensen (2001) o uso de fracionamento físico em estudos da dinâmica da MOS tem aumentado nas últimas duas décadas. Este intenso desenvolvimento da técnica é alicerçado no crescente entendimento de que tal dinâmica é relacionada com processos biológicos (além da relação intrínseca com a estrutura do solo) e que a disponibilidade de substratos para os organismos decompositores depende não somente de sua natureza química, mas também (e talvez, mais predominantemente) de sua associação com os componentes minerais do solo.

Ainda, de acordo com o mesmo, tal associação é manifestada pela formação de complexos organo-minerais. Dessa forma, os mecanismos responsáveis pela retenção e permanência da MOS incluem a recalcitrância química intrínseca do composto orgânico, estabilização da matéria orgânica disponível através de reações químicas com as superfícies minerais e proteção de substratos através da criação de barreiras físicas entre os mesmos e organismos decompositores.

Uma das modalidades de fracionamento físico considerada é o fracionamento densimétrico, fazendo uso de solução de densidade elevada, levando-se em consideração as diferentes densidades dos constituintes da MOS, originando as frações de matéria orgânica particulada (MOP) pesada, leve-livre e leve-oclusa (Christensen (2001), Marriot e Wander (2006) e Conceição et al., (2008)). Ainda, alternativamente, o fracionamento por tamanho de partículas, usando peneiramento, tem sido utilizado.

A fração leve-livre (FLL), ou inter agregados, possui composição comparável àquela de materiais vegetais, sendo o fator que determina sua estabilidade no solo, a recalcitrância de suas moléculas (Sollins (1996)). A fração leve-oclusa (FLO), ou intra-agregados, é constituída por um montante de compostos orgânicos mais restritos, com um grau de decomposição mais avançado em comparação à FLL, e sua recalcitrância é decorrente, além do fator intrínseco molecular, da oclusão, e consequente maior proteção física, no interior de agregados do solo (Golchin et al., (1994)). A fração pesada constitui a parcela orgânica em maior estado de decomposição, apresentando maior associação com minerais do solo (Conceição et al., (2008)). A figura 7 a seguir traça um comparativo entre as diferentes frações da MOS após o fracionamento densimétrico. 
Fig. 7 - Frações fisicamente separadas da MOS (Adaptado de Plaza, et al., 2013).

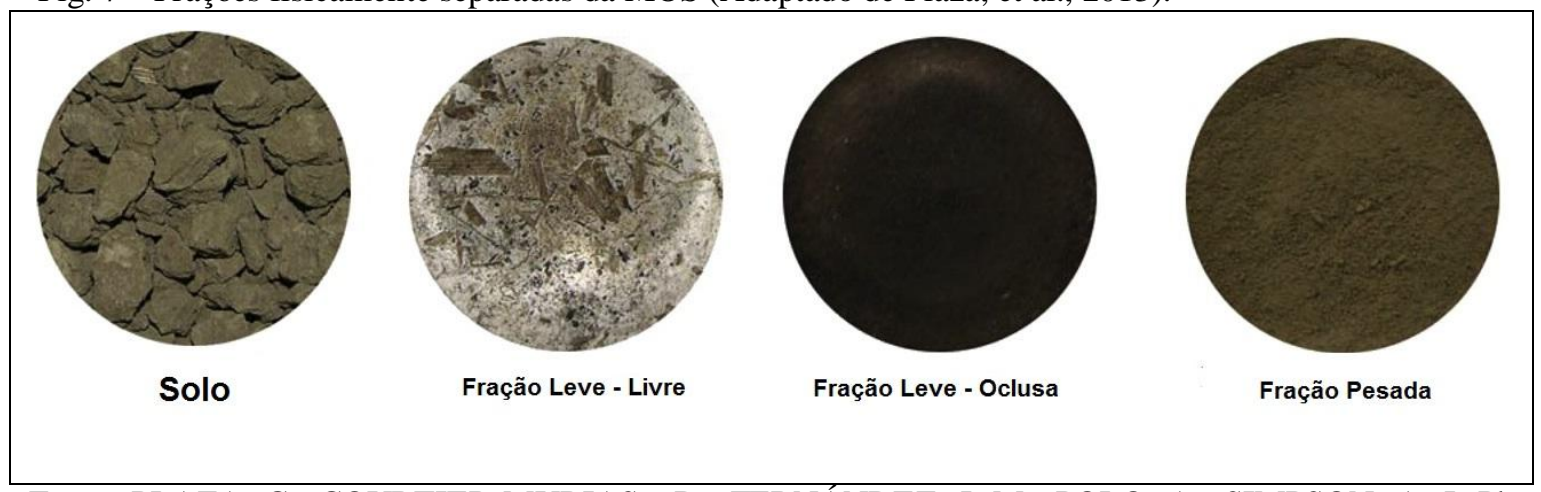

Fonte: PLAZA, C.; COURTIER-MURIAS, D.; FERNÁNDEZ, J. M.; POLO, A.; SIMPSON, A. J. Physical, chemical, and biochemical mechanisms of soil organic matter stabilization under conservation tillage systems: a central role for microbes and microbial by-products in C sequestration. Soil Biology \& Biochemistry, v. 57, p. 124-134, 2013.

Segundo Leifeld e Kögel-Knabner (2005) considera-se que a FLL apresente material de plantas parcialmente decomposto, caracterizando, dessa forma, um estado de transição no processo de humificação. Contudo, de acordo com Marriott e Wander (2006) a qualidade da FLO pode ser caracterizada como melhor indicador da qualidade de MOS, em detrimento às frações que possuem maior incidência de resíduos frescos.

Conforme Golchin et al., (1994) a fração leve-livre da MOP, localizada entre os agregados do solo, pode ser separada de partículas organo-minerais através de flotação em soluções com densidade elevada (cerca $1,6 \mathrm{~g} / \mathrm{cm}^{3}$ ). Após a remoção da FLL, a FLO pode ser separada do solo por fracionamento densimétrico, depois de seus agregados serem previamente rompidos por energia ultrassônica ou agitação intensa. De acordo com o mesmo, o tratamento ultrassônico de 5 minutos permite que os materiais orgânicos oclusos, que apresentem diferentes estágios de decomposição, sejam separados, uma vez que estes apresentam diferentes níveis de associação com as partículas minerais, apresentando, dessa maneira, diferentes valores de densidade.

As diferenças estruturais observadas entre FLL e FLO atuam como indicativos das mudanças da MOS, decorrentes processos de sua decomposição no solo (e consequente formação de agregados), incorporação à biomassa microbiana e adsorção em minerais (Golchin, et al., (1994)).

A identificação de frações sensíveis o suficiente para serem utilizadas como indicadores de mudanças do conteúdo de MOS, quanti e qualitativamente, é considerada de crucial importância para o desenvolvimento de práticas de manejo para agricultores, visando à otimização de uso de água e nutrientes em sistemas agrícolas e produção de culturas, aumentando a qualidade do solo. Diversos estudos têm utilizado as frações de MOP como parâmetro de acompanhamento de MOS, sendo tais frações capazes de apontar mudanças 
inerentes a qualquer que seja o sistema de manejo de solo empregado, independentemente do processo de fracionamento físico que tenha sido utilizado (Marriott e Wander (2006)).

Segundo Aertsens et al., (2013) o processo de decomposição da MOS é controlado por mecanismos biológicos relativamente complexos. Organismos do solo a decompõem para obtenção de energia e nutrientes, concomitantemente à liberação de dióxido de carbono, ocasionada pela respiração. Conforme os mesmos, as taxa de decomposição são diretamente afetadas por: (i) práticas de solo (manejo, espécie de cultivar, adição ou não de material orgânico, entre outros); (ii) parâmetros ambientais (temperatura, frequência de chuvas, condições aeróbicas e anaeróbicas); e (iii) características do solo (textura, biologia, entre outros).

De acordo com Six et al., (2004) existe uma relação intrínseca entre a dinâmica de agregados do solo, a decomposição da MOS e a emissão de GEE. Segundo os mesmos, o fluxo de GEE é moderado pela fração lábil do carbono orgânico do solo, incluindo a parcela ligada à fração leve-livre e leve-oclusa (intra-agregado).

A distribuição diferencial de carbono em frações de agregados e o nível de oclusão no interior de microagregados podem ser cruciais no que diz respeito à quantia de GEE liberado, levando-se em conta os efeitos causados pelas práticas de uso do solo, tais como sistemas de manejo (Sainju et al., (2006)).

Assim sendo, levando-se em consideração o observado por Elliot et al., (1986) onde se constatou que o montante de MOS ligado à microagregados dentro de macroagregados é perdido durante o cultivo, o tempo de decomposição de macroagregados também tem papel crucial na condição do solo como fonte ou sumidouro de GEE.

\subsection{Substâncias Húmicas (SH)}

Conforme Aiken et al., (1985) entende-se por substâncias húmicas (SH) ao conjunto heterogêneo, biogênico, e de ocorrência natural no solo, de substâncias orgânicas, caracterizado pela coloração enegrecida, alto peso molecular e refratabilidade. Ainda, segundo Qualls (2004) as SH apresentam características de coloides carregados negativamente, sendo recalcitrante à biodegradação, o que possibilita sua permanência no solo por longos períodos.

As SH são os principais constituintes dos reservatórios de carbono do solo, água e sedimentos e são cruciais para o ciclo global de carbono (Ikeya et al., (2011)). Devido a grande influência que exercem em diversos processos ambientais, informações acerca de composição e grupos funcionais das SH são de grande importância para melhor entendimento da reatividade com contaminantes orgânicos e inorgânicos (Giovanela et al., (2010)). 
As $\mathrm{SH}$ representam cerca de $80 \%$ da MOS, dessa forma, um entendimento mais completo acerca de suas propriedades funcionais e estruturais é crucial para o estudo da dinâmica e reatividade da matéria orgânica como um todo (Fernandes et al., (2010)). Em complemento, segundo Adani e Tambone (2005) além de serem os principais constituintes da MOS, as SH também apresentam conteúdo significativo em alguns condicionadores orgânicos, tais como biossólidos.

Segundo Santos et al., (2010) alguns resultados de estudos químicos e espectroscópicos mostraram que, em geral, as SH de condicionadores orgânicos diferem SH naturais pela menor quantidade de agrupamentos aromáticos e carboxílicos.

De acordo com Almendros (2008) o processo de formação de SH nos solos é extremamente complexo, sendo baseado em reações bióticas e abióticas, incluindo, intensa transformação estrutural de bio macromoléculas microbianas e de plantas, condensação de compostos simples oriundos da biodegradação de MOS ou sintetizados por plantas e microorganismos. Ainda, segundo o mesmo, por este motivo, uma série de fatores ambientais, principalmente condições climáticas e interações organominerais, interferem no processo de formação, originando SH com algumas particularidades estruturais.

As SH têm sido assunto de controvérsias científicas por mais de 200 anos (Muscolo et al., (2012)). Segundo Schnitzer e Monreal (2011) ao longo dos anos várias definições de SH foram propostas.

Um dos primeiros conceitos propostos para as $\mathrm{SH}$ foi o modelo macromolecular polimérico (Schnitzer e Schulten (1993) e Swift (1999)). De com este modelo, as SH seriam macromoléculas de peso molecular variando entre 20000 e 50000 Da, apresentando uma estrutura mais alongada em meios básicos ou em soluções de baixa força iônica, compactando-se em meio ácidos ou em soluções com alta força iônica.

Contudo, conforme Piccolo (2001) as SH são definidas pelo conjunto heterogêneo de associações supramoleculares de moléculas relativamente pequenas ( $\mathrm{PM}<1.000 \mathrm{Da})$, derivadas da degradação e decomposição de material biológico. Neste modelo supramolecular, as estruturas das SH são mantidas por forças dispersivas mais fracas (pontes de hidrogênio e forças de Van der Waals) no lugar de ligações covalentes. Ainda, segundo o mesmo, conforme o princípio de energia interna mínima, a introdução de pequenos compostos anfifílicos, como ácido acético, resulta em uma organização diferente das interações mencionadas, não havendo interação com ligações covalentes.

Conforme Wershaw (2004), o modelo supramolecular é considerado a melhor representação dos extratos de MOS em comparação à estrutura macromolecular de polímeros 
húmicos. Em complemento, segundo Nebbioso e Piccolo (2012) o modelo supramolecular implica que as moléculas húmicas podem ser separadas, utilizando-se métodos apropriados, e caracterizadas de maneira compreensiva. As figuras 8 e 9 ilustram os modelos de $\mathrm{SH}$ propostos, preconizando as diferenças conceituais.

Fig. 8 - Modelo macromolecular de ácidos húmicos proposto por Schulten e Schnitzer (1993).

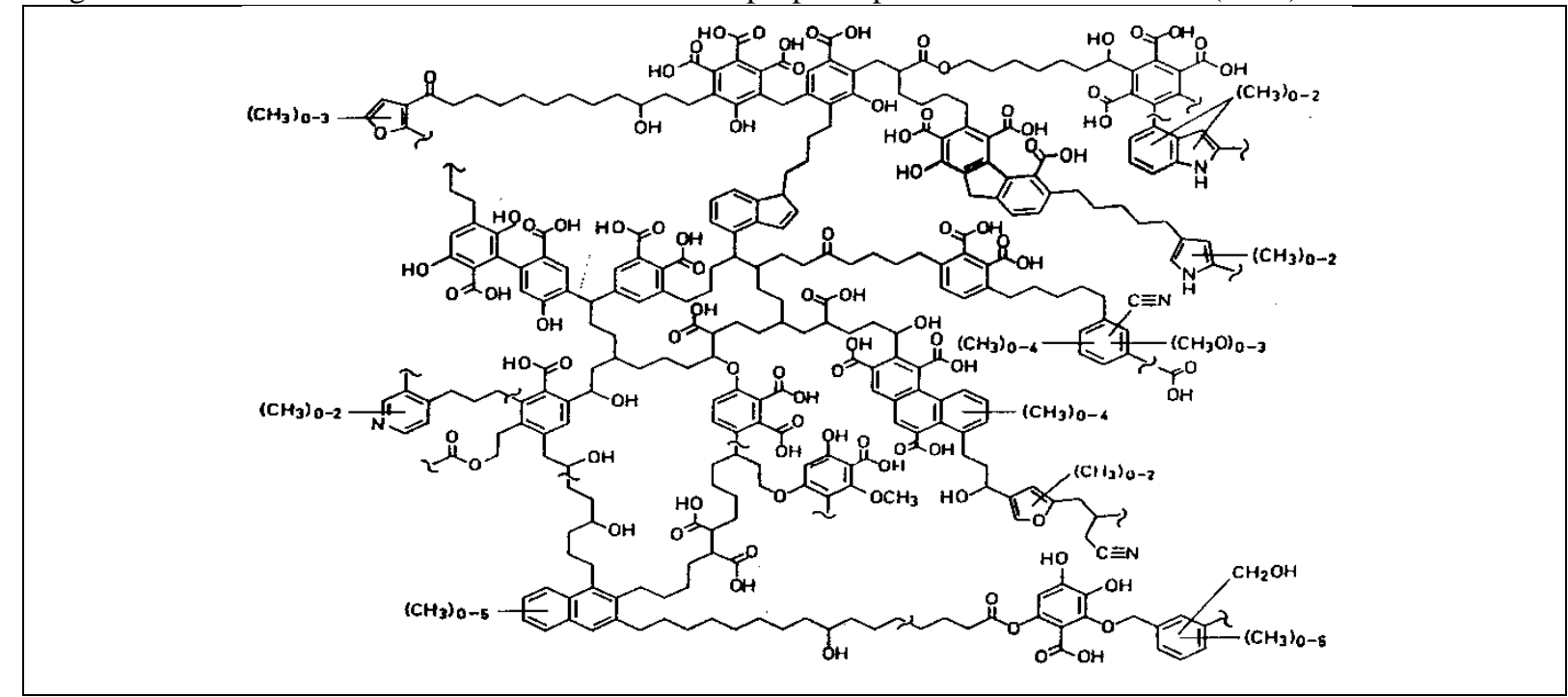

Fonte: SCHULTEN, H. R.; SCHNITZER, M. A state of art structural concept for humic substances. Naturwissenschaften, v. 80, p. 29-30, 1993.

Fig. 9 - Comparativo entre os modelos de estruturas de substâncias húmicas propostas por Simpson. et al., (2002). Em (A) observa-se a proposta de que as SH sejam uma única macromolécula. Em (B) observa-se a proposta de que as SH sejam um agregado de molécula com menor massa molecular (> 2.000 Da). Em vermelho representam-se cátions metálicos, em marrom, fragmentos de lignina, em azul, polipeptídeos, em preto, polissacarídeos e em verde, cadeias alifáticas.

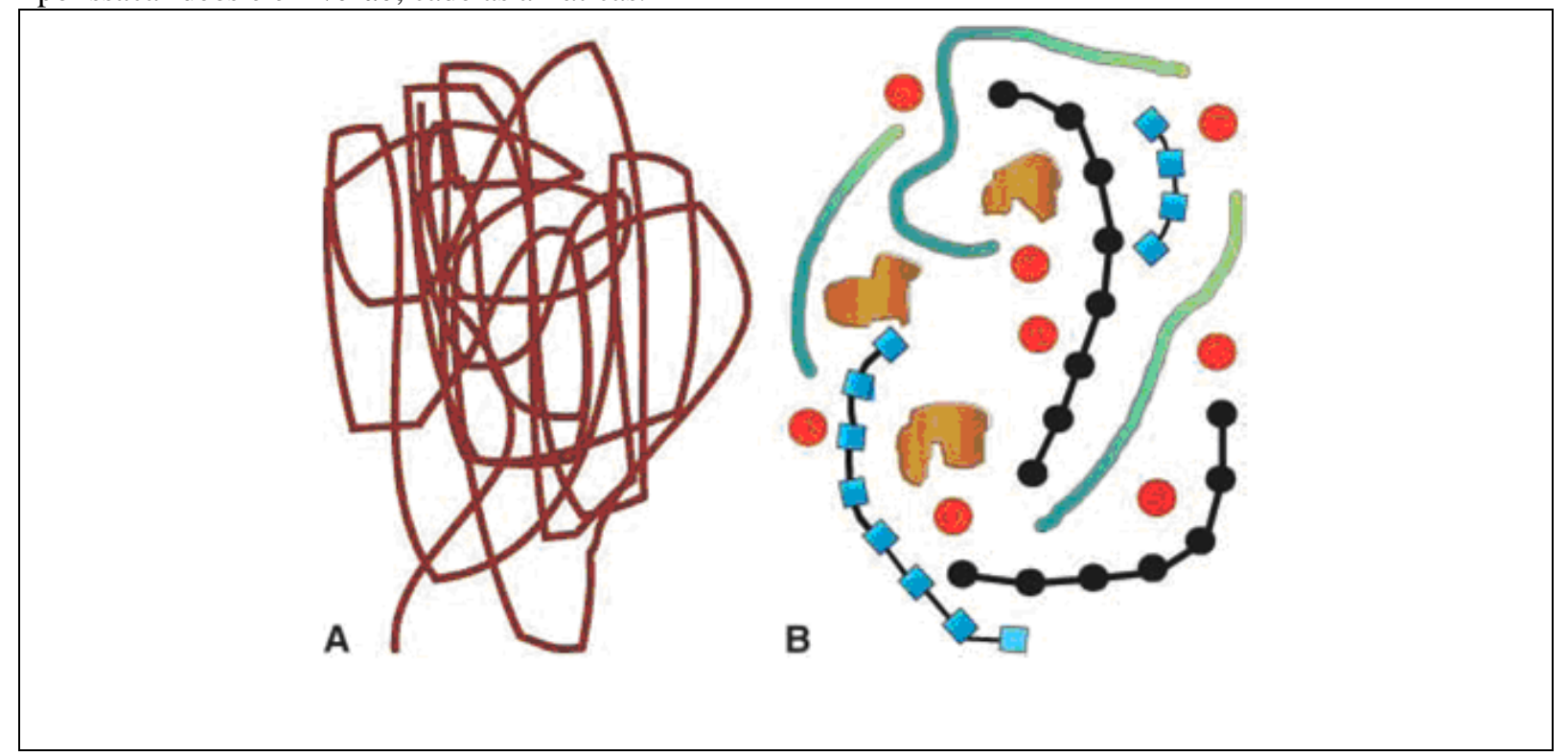

Fonte: SIMPSON, A. J.; KINGERY, W. L.; SWAW, D. R.; SPRAUL, M.; HUMPFER, E.; DVORTSAK, P. Molecular structures and associations of humic substances in the terrestrial environment. Naturwissenschaften, v. 89 , p. 84-88, 2002. 
De acordo com Helal et al., (2011) o conhecimento das estruturas básicas das SH é necessário para um entendimento mais completo a respeito de suas respectivas funções no ambiente. Contudo, devido à multiplicidade das moléculas que as compõem, juntamente com os diversos tipos de interações que as mantém ligadas, ainda é um desafio a elaboração de uma fórmula estrutural precisa. Neste sentido, diversas são as técnicas espectroscópicas utilizadas para tanto, tais como: ressonância magnética nuclear, cromatografia a gás (ou líquida) acoplada à espectrometria de massas, análise elementar, dentre outros.

As SH são classificadas, de acordo com a solubilidade em diferentes meios, em três componentes, sendo: ácidos húmicos $(\mathrm{AH})$, ácidos fúlvicos $(\mathrm{AF})$ e humina. Os $\mathrm{AH}$ constituem a fração insolúvel em água em meios ácidos e solúvel em meios alcalinos. Esta fração é frequentemente citada como sendo a de maior massa molecular aparente, com valores variando entre 1.500 e $5.000 \mathrm{Da}$ em meios aquosos, e 50.000 a 500.000 Da em solos. Os AF representam a fração solúvel em qualquer meio (seja ácido ou alcalino), com massa molecular aparente variando entre 600 e $1.000 \mathrm{Da}$, em cursos d'água, e 1.000 a 5.000 em solos. A terceira fração, humina, é caracterizada por ser insolúvel em água em qualquer valor de $\mathrm{pH}$ (McDonald et al., (2004)).

Segundo Baalousha et al., (2006) o nível de agregação das SH depende não somente da estrutura molecular em si, mas também das condições dos meios, tais como força iônica, pH e presença ou não de íons metálicos. Dessa forma, o comportamento das SH com relação a diferentes valores de $\mathrm{pH}$ é de suma importância.

Cada componente (ácidos húmicos, fúlvicos, humina) deve ser considerado como sendo um conjunto de moléculas de diferentes tamanhos que, dentre as quais, poucas apresentam a mesma configuração estrutural ou arranjo de grupos funcionais reativos (Helal et al., (2011)).

De acordo com Canellas et al., (2003) os AH representam a parcela intermediária entre a estabilização dos compostos pela interação com o material mineral (humina) e a ocorrência de ácidos orgânicos oxidados livres na solução do solo (AF). Dessa forma, atuam como demarcadores naturais do processo de humificação e refletem tanto as condições de gênese quanto de manejo do solo.

Ainda, de acordo com Piccolo (2001) levando-se em consideração o modelo supramolecular de $\mathrm{SH}$, os $\mathrm{AH}$ seriam formados a partir das associações de compostos predominantemente hidrofóbicos, estabilizados em meio neutro por forces hidrofóbicas dispersivas, ao passo que os AF seriam formados através da associação de pequena moléculas 
hidrofílicas, com número suficiente de grupos funcionais ácidos para manter os agregados dispersos em qualquer valor de $\mathrm{pH}$.

\subsection{Técnicas Analíticas e Espectroscópicas}

O emprego de métodos espectroscópicos e analíticos tem fornecido informações de grande valia no estudo do comportamento e estruturas de matéria orgânica e seus constituintes húmicos, sobretudo quando submetidos à ação de agentes externos. Como exemplo da aplicação de tais métodos pode-se citar a identificação de grupos funcionais, compreensão de mecanismos reacionais de $\mathrm{SH}$ e MOS com agentes externos, tais como, metais pesados e pesticidas, entre outros.

De acordo com Polak et al., (2009) diversas técnicas espectroscópicas (tais como ressonância paramagnética eletrônica (RPE), infravermelho, entre outros) e métodos analíticos tem sido empregados para estudo das propriedades de SH extraídas de solos, compostos, sedimentos e água, avaliando também seus respectivos processos de humificação.

Corroborando, alem das já citadas técnicas, informações acerca das estruturas de SH podem ainda ser obtidas através de processos de oxidação, hidrólise e pirólise, sendo estes de caráter destrutivo (Mao et al., (2011)).

Ainda, segundo, Kögel-Knabner (2000) a maior parte do conteúdo de MOS está presente em estruturas macromoleculares, necessitando submeterem-se a métodos destrutivos para investigadas em nível molecular. De acordo com o mesmo, em geral, o processo investigativo da MOS envolve degradação térmica (pirólise) ou química (fracionamento) da macromolécula em moléculas menores, viabilizando a análise por métodos cromatográficos.

\subsubsection{Pirólise Acoplada a Cromatografia a Gás/Espectrometria de Massas (PY-GC/MS)}

A técnica de pirólise acoplada à cromatografia a gás/espectrometria de massas (PYGC/MS) compreende a volatilização em temperatura controlada de amostras, seguida de separação por cromatografia a gás e identificação por espectrometria de massas. O espectro resultante possibilita a semi quantificação e comparação relativa entre as substâncias pirolizadas (Vancampenhout et al., (2010)).

Segundo De la Rosa et al., (2012) PY-GC/MS é um método analítico relativamente rápido e de grande reprodutibilidade, que tem sido amplamente utilizado na caracterização estrutural de MOS.

A prática da pirólise analítica requer o aquecimento da amostra em temperatura significativamente maior que a temperatura ambiente. A faixa de temperatura comumente utilizada varia entre 500 e $800^{\circ} \mathrm{C}$, sendo, contudo, passível de adequação a menores valores, de acordo com a amostra em análise. Segundo o autor, o pirolizador (que possui uma fonte de 
aquecimento intrínseca) possui interface com demais equipamentos analíticos, responsáveis pela identificação dos compostos pirolizados. Ainda, de acordo com o mesmo, as técnicas mais comuns utilizadas para este propósito são cromatografia a gás (GC), cromatografia a gás/ espectrometria de massas (GC/MS), espectrometria de massas (MS), dentre outras, sendo o acoplamento com GC/MS o mais amplamente empregado (Moldoveanu, (2005)).

O uso frequente de GC como técnica de separação analítica, acoplada à pirólise, devese à complexidade química intrínseca dos analitos pirolizados, além da incidência de fragmentos de baixa massa molecular gerados após o processo pirolítico. Ainda, o uso de MS como ferramenta de detecção possibilita apresenta alta sensibilidade, além da alta capacidade de identificação de fragmentos moleculares. Esta alta sensibilidade é crucial, uma vez que o montante de amostras utilizado nas análises é pequeno, da ordem de miligramas.

Segundo Moldoveanu (2001) o aquecimento do aparelho de pirólise pode ocorrer em diversas modalidades, tais como filamentos aquecidos por resistência, aquecimento induzido, tipo forno, ou ainda aquecimento por radiação. Conforme os mesmos, o pirolizador consiste em uma pequena câmara, a qual é aquecida, a fim de evitar a condensação dos compostos pirolizados em suas paredes. A temperatura da câmara, geralmente varia entre 200 e $250^{\circ} \mathrm{C}$, e não há contato direto com a amostra, sendo que, para a inserção da amostra a ser analisada, um probe é utilizado. A extremidade deste probe é constituída pelo porta- amostras e o componente aquecedor, sendo geralmente um filamento de platina, o qual pode alcançar os patamares de temperatura desejados previamente programados, quando da passagem de corrente elétrica.

O porta-amostras geralmente é um tubo de quartzo ou "barco" de porcelana, onde a quantia adequada da amostra a ser analisada é depositada. Um fluxo de gás inerte percorre o interior da câmara do pirolizador, levando os compostos pirolizados para a instrumentação analítica. O fluxo de gás inerte pode ser utilizado com gás carreador caso o equipamento esteja acoplado a um cromatógrafo a gás (Moldoveanu et al., (1998)). A figura 10 ilustra sucintamente a estrutura de um pirolizador. 
Fig. 10 - Representação esquemática de pirolizador (Adaptado de Moldoveanu, 2005).

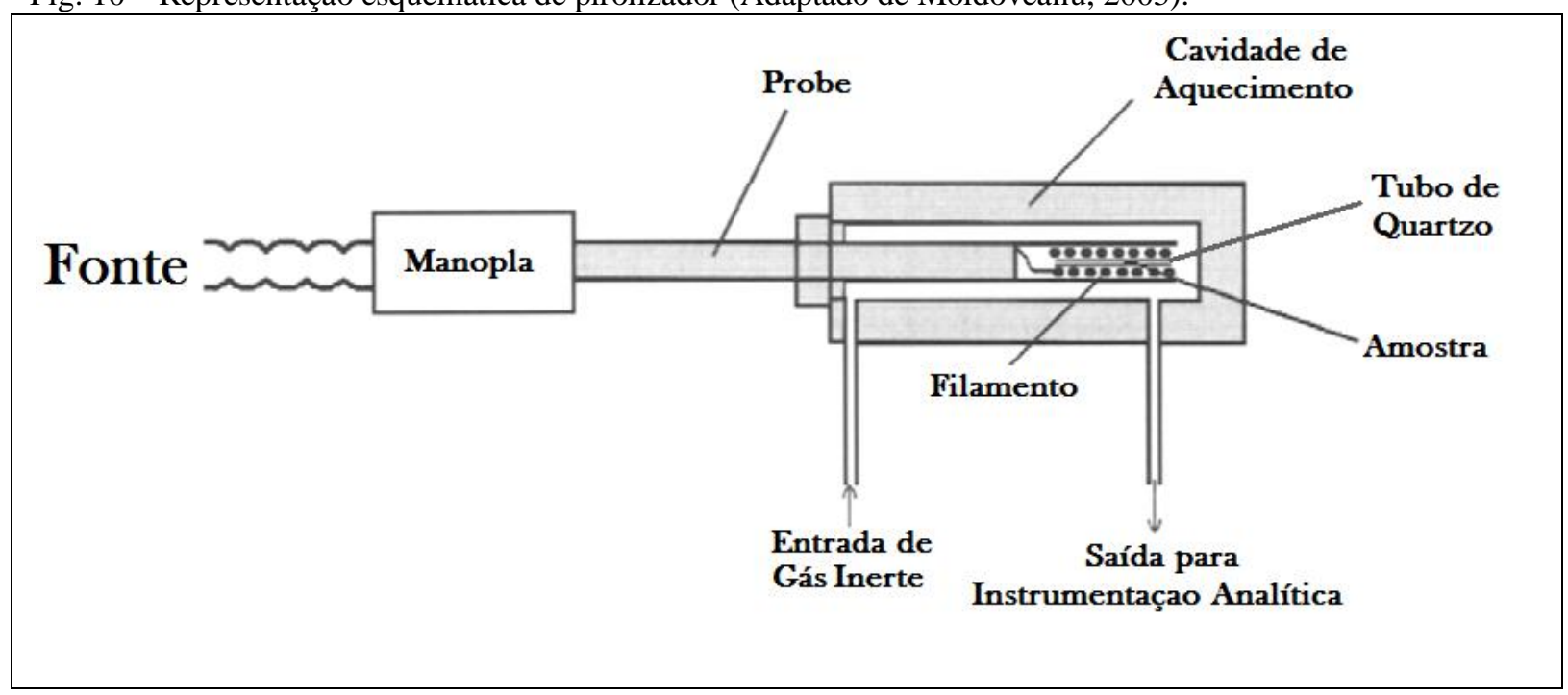

Fonte: MOLDOVEANU, S. C. Review of analytical pyrolysis instrumentation. Analytical Pyrolysis of Sintetic Organic Polymers, v. 25, p. 109-143, 2005.

De acordo com a literatura, duas técnicas de aquecimento rápido em pirólise são mais utilizadas, sendo estas (1) ponto de Curie (Moldoveanu, (2001)) e (2) “tiro duplo" (GonzálezPérez et al., (2007)). Ambos os métodos baseiam-se na ocorrência de pirólise em temperatura específica, que depende da temperatura crítica (ponto de Curie) do porta amostras (300 a $800^{\circ} \mathrm{C}$ ). A metodologia de tiro duplo usa dois patamares de temperatura para distinguir compostos termicamente lábeis dos mais estáveis e complexados.

A temperatura de equilíbrio $\left(\mathrm{T}_{\mathrm{eq}}\right)$ do processo de pirólise também é considerada como temperatura final do processo, uma vez que, que é impossível o aquecimento instantâneo da amostra à $T_{\text {eq }}$, embora o período para a obtenção do equilíbrio é relativamente curto. Em se tratando de um processo analítico que apresenta certa complexidade, não existe norma exata para a escolha de qual $\mathrm{T}_{\text {eq }}$ deve ser utilizada para determinada amostra. $\mathrm{O}$ valor depende diretamente da característica do material a ser analisado e do escopo da análise (Moldoveanu, (2005)).

Conforme Leinweber et al., (2013) para a detecção por espectrometria de massas, os compostos são ionizados por impacto de elétrons a $70 \mathrm{eV}$, gerando o íon molecular e fragmentos ionizados com diferentes massas, para cada composto volatilizado. A obtenção contínua de espectros de massas dá origem a cromatogramas, onde cada respectivo espectro obtido pode ser comparado a um banco de dados para identificação dos picos observados.

Segundo Dignac et al., (2006) as interações entre os produtos de pirólise com a fase estacionária da coluna cromatográfica direcionam sua separação. De acordo com os mesmos, devido à complexidade dos compostos pirolizados, a escolha do tipo de coluna cromatográfica 
a ser utilizada na análise de amostras de matéria orgânica não é simples. Colunas não polares são frequentemente utilizadas uma vez que apresentam maior capacidade de separação de compostos com diferentes polaridades. Ainda, este tipo de coluna apresenta menor sangria e suportam maiores temperaturas (mais de $350^{\circ} \mathrm{C}$ ).

Colunas polares são menos robustas e mais sensíveis à temperatura (máximo de $250^{\circ} \mathrm{C}$ ), contudo permitem melhor separação de analitos polares, e podem ser mais propícias para análise de matéria orgânica em processo de humificação (Dignac et al., (2005)).

Ainda, segundo Moldoveanu (2001) há certo número de detalhes técnicos relacionados com a técnica de PY-GC/MS, sendo alguns relacionados com o processo de separação no cromatógrafo a gás e outros com a identificação espectral. Conforme o mesmo, a separação cromatográfica deve ser realizada de maneira a diferenciar todos os compostos pirolizados, levando-se em consideração ainda os compostos mais pesados. Tais condições são de certa forma, contraditórias entre si, uma vez que uma coluna com maior número de pratos teóricos, e possivelmente mais polar, apresenta grande utilidade no processo de separação, ao passo que, colunas mais curtas e de maior resiliência ao aquecimento em altas temperaturas são necessárias para maior eluição dos produtos da coluna. Dessa forma, a escolha da fase estacionária da coluna cromatográfica (tipicamente capilar) torna-se crítica para boas separações.

Outras características da coluna cromatográfica, tais como comprimento, diâmetro interno, espessura da fase estacionária, entre outros, também devem ser escolhidas de maneira correta para a otimização do processo de separação (Moldoveanu (2001)).

O processo de pirólise de amostras de MOS gera uma ampla gama de produtos que podem ser diretamente relacionados com seus respectivos compostos de origem, tais como metoxi-fenóis de lignina, furanos de polissacarídeos e moléculas contendo $\mathrm{N}$ provenientes de proteínas (Leinweber e Schulten (1995)).

Embora seja assumido que os compostos obtidos apresentem as mesmas características da estrutura original, frequentemente a validade do método é questionada devido à possibilidade de ocorrência de "artefatos", compostos formados por reações secundárias e fragmentação durante o processo de pirólise (Zang e Hatcher (2002)).

As formações de "artefatos" observadas mais comuns são furanos de carboidratos, alquil aromáticos de ácidos graxos cíclicos, nitrilas e aromáticos heterocíclicos contendo $\mathrm{N}$ de aminoácidos e peptídeos e nitrilas originadas da reação de ácidos carboxílicos e $\mathrm{NH}_{4}{ }^{+}$ligado a minerais. Contudo, a possibilidade de formação de tais moléculas não interfere na ocorrência dos compostos originalmente identificados na estrutura da MOS (Assis et al., (2012)) 


\subsubsection{Respiração do Solo}

O processo de respiração do solo é considerado um dos principais mecanismos de controle da perda de C de ecossistemas terrestres (Peng et al., (2009)).

De acordo com Raich et al., (2002) e Schimel et al., (2001) considerando escala global, estima-se que o processo de respiração do solo produza cerca de 80,4 Pg de C ao ano, com possibilidade de variação entre 79,3 e 81,8 Pg de C/ano, o que contabiliza de 60 a 90\% do total de respiração de ecossistemas terrestres globais. Ainda, conforme Marland et al., (2000) tais montantes de emissão correspondem a cerca de 11 vezes a quantia de $\mathrm{CO}_{2}$ emitida pela queima de combustíveis fósseis.

Segundo Ferrea et al., (2012) diversos fatores bióticos e abióticos podem influencia a respiração do solo, sendo: umidade e temperatura do solo (Chen et al., (2011)), quantidade e qualidade de MOS (Lal (2008)), biomassa microbiana, além de propriedades químicas e físicas do solo (Subke et al., (2011)).

Assim, conforme Laganiere et al., (2012) o mecanismo de respiração do solo é composto pela soma da respiração autotrófica (produzida por raízes e exudatos) e respiração heterotrófica (gerada pela decomposição microbiana da MOS). A figura 11 a seguir ilustra sucintamente o processo de respiração do solo, destacando os dois mecanismos citados.

Fig. 11 - Representação esquemática do processo de respiração (Adaptado de material de aula do Prof. Dr. Carlos E. P. Cerri).

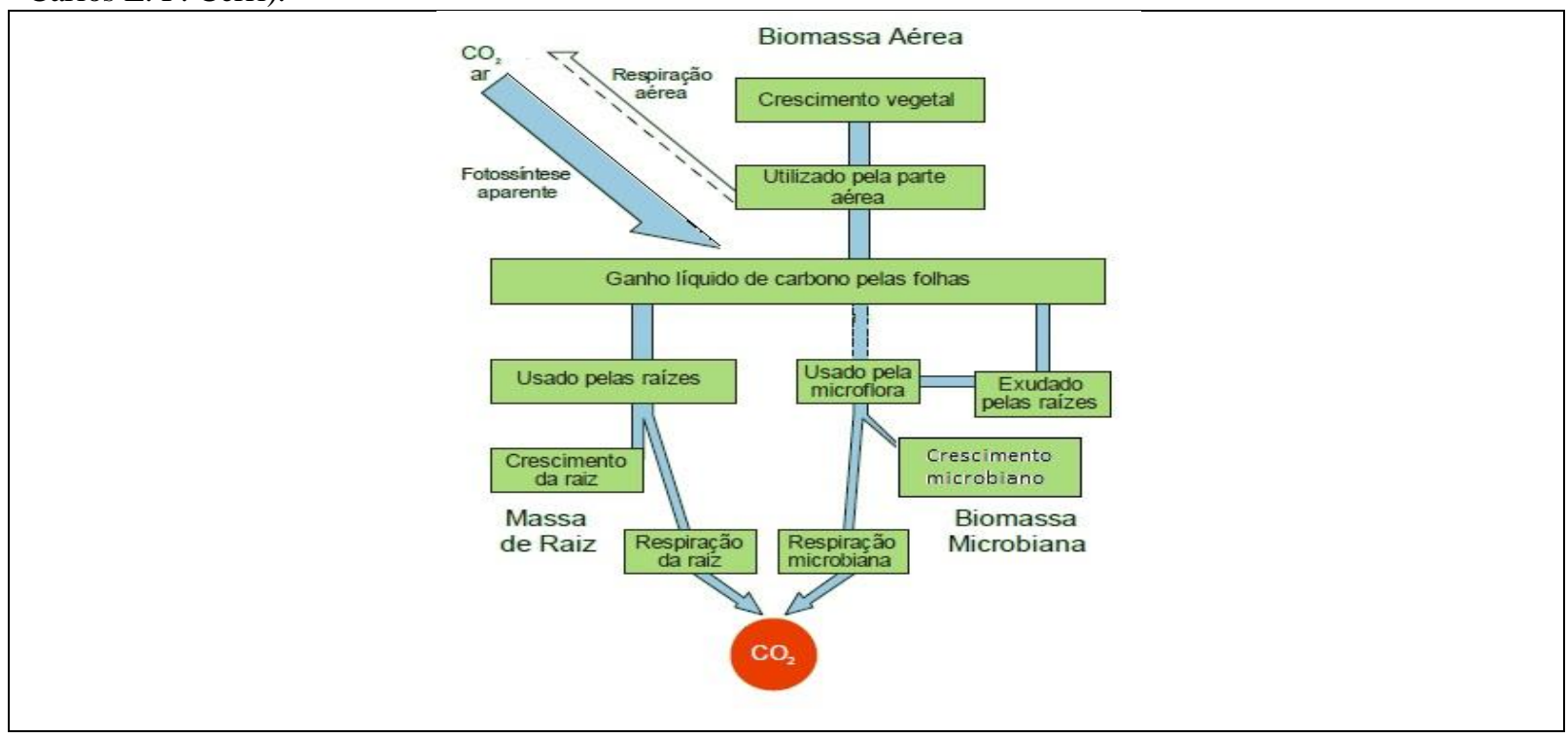

De acordo com Schaefer et al., (2009) a permanência de resíduos de plantas (serrapilheira) na cobertura do solo tem afetado diretamente o mecanismo de respiração do 
solo, uma vez que constitui fonte de matéria orgânica para crescimento de comunidade microbiana, aumentando dessa maneira, a respiração microbiana.

Conforme Zhou et al., (2013) a estimativa da montante emitido pela superfície do solo é de suma importância na avaliação do papel do mecanismo de respiração no contexto do aquecimento global, uma vez que a respiração do solo é um dos agentes determinantes no balanço de $\mathrm{C}$ nos ecossistemas terrestres.

Segundo Falk et al., (2005) a respiração do solo é frequentemente medida por sistemas de câmaras ou Eddy-covariância. De acordo com os mesmos, através dos sistemas de câmaras (idealmente, não devendo apresentar nenhum tipo de vazamento) são coletadas amostras do fluxo total emitido pelo solo, criando uma atmosfera superficial sobre a área delimitada pela câmara. O processo de Eddy-covariância realiza amostragem em áreas mais amplas.

Conforme Wilson e Meyers (2001) medidas de Eddy-covariância são passíveis de perda de alguns dados relativos aos fluxos do solo devido às limitações de medidas em alta frequência e interferência de turbulência em medidas (em se tratando de técnica que quantifica a concentração de GEE, ao mesmo tempo em monitora a direção, tridimensionalmente, do vento).

\subsubsection{Espectroscopia de Absorção na Região do Infravermelho}

A espectroscopia de infravermelho (IV) é considerada uma técnica clássica, não destrutiva, amplamente utilizada na caracterização de frações da MOS. O espectro eletromagnético, destacando a região espectral do infravermelho é ilustrado na figura 12.

Fig. 12 - Representação de espectro eletromagnético (Adaptado de Rossell, et al., (2006)).

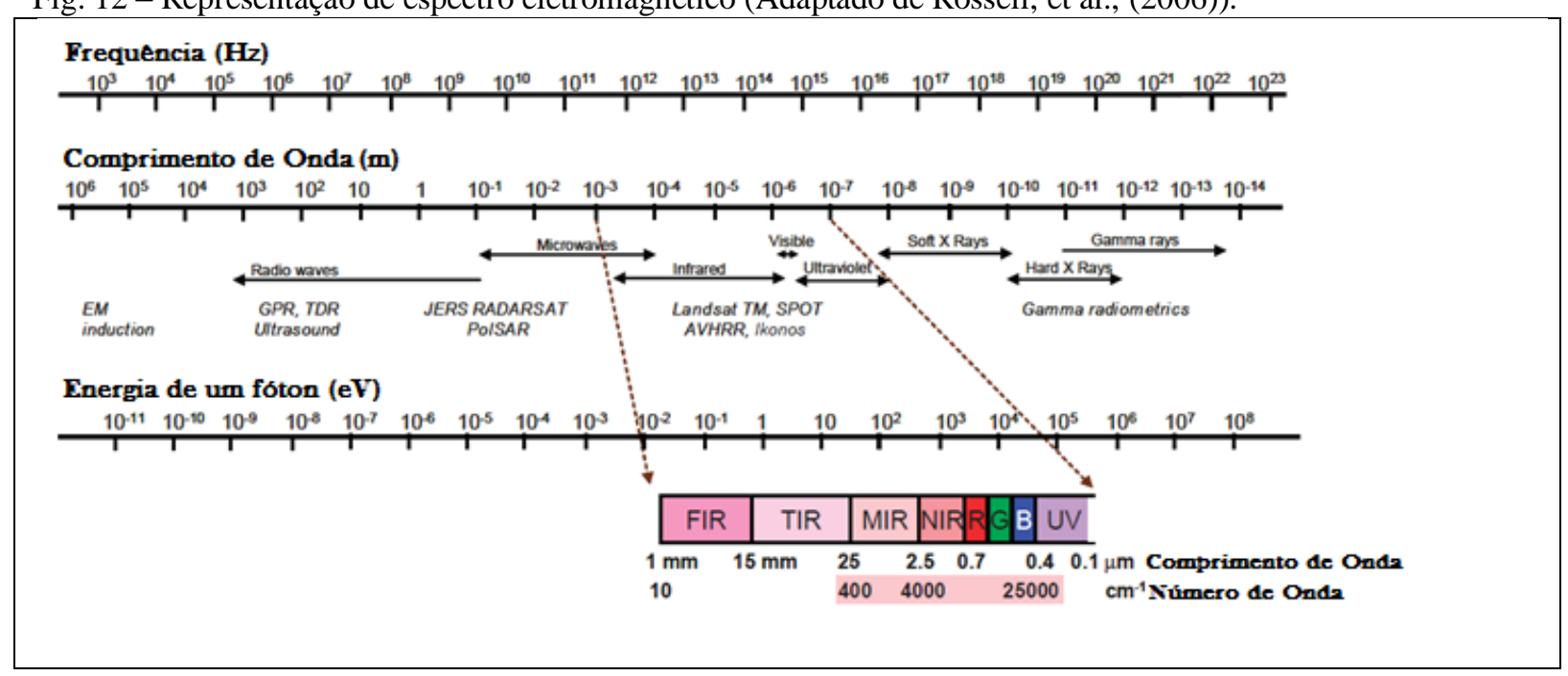

Fonte: ROSSEL, R. A. V.; WALVOORT, D. J. J.; McBRATNEY, A. B.; JANIK, L. J.; SKJEMSTAD, J. O. Visible, near infrared or combined diffuse reflectance spectroscopy for simultaneous assessment of various soil properties. Geoderma, v. 131, p. 59-75, 2006. 
A região espectral do infravermelho é dividida em três regiões distintas, de acordo com seu comprimento de onda, em próximo (400 a $2500 \mathrm{~nm}$ ), médio (2500 a $25000 \mathrm{~nm}$ ) e distante, sendo as duas primeiras as mais utilizadas em análises espectroscópicas de amostras de solo.

Segundo Bellon-Maurel e McBratney (2011) a principal diferença entre as duas principais regiões é o fato de que a absorção na região do médio corresponde a bandas fundamentais de vibrações moleculares, ao passo que na região do próximo a absorção corresponde a superposições e combinações de tais bandas.

Conforme Rossell et al., (2006) as técnicas espectroscópicas de infravermelho são altamente sensíveis às fases orgânicas e inorgânicas do solo, agregando alta aplicabilidade à técnica para análises de amostras de áreas de ciências agrícolas e ambientais. Ainda, de acordo com os mesmos, as frequências moleculares mais intensas, relacionadas com componentes do solo, ocorrem na região do médio (entre 2500 e $25000 \mathrm{~nm}$ ).

O desenvolvimento de novas ferramentas complementares à análise de espectros de IV, tal como a transformada de Fourier, tem sido de grande valia no estudo de materiais heterogêneos e de grande complexidade (como é caso das SH), uma vez que possibilita a obtenção de informações adicionais a cerca de possíveis superposições intrínsecas das bandas identificadas (Chen et al., (2002)).

De acordo com Fernandes et al., (2010) a técnica de espectroscopia de infravermelho com transformada de Fourier (FTIR) tem sido utilizada em estudos relacionados com ácidos húmicos e tem fornecido informações de grande valia no que tange à natureza, reatividade e arranjo estrutural de grupos funcionais diversos.

Segundo Miller (2001) para a obtenção de um espectro de IR para amostras de solo, a radiação contendo todas as frequências relevantes em determinada faixa são direcionadas para a amostra. Dependendo dos constituintes da amostra de solo, a radiação aplicada causa vibração (estiramento ou deformação) em determinadas ligações moleculares, levando à absorção de luz com uma quantia específica de energia, correspondente à diferença entre os níveis (anterior e posterior à aplicação de radiação). Uma vez que o quantum de energia é diretamente proporcional à frequência (e inversamente proporcional ao comprimento de onda), o espectro de absorção resultante produz uma banda característica que pode ser utilizada com propósitos analíticos.

Ainda, conforme o mesmo, o comprimento de onda no qual ocorre o processo de absorção (ou seja, a magnitude de energia) depende também da matriz química da amostra e 
fatores ambientais, ou seja, grupos funcionais vizinhos e temperatura, permitindo a detecção de uma gama de moléculas que possam conter os mesmos tipos de ligação.

\subsubsection{Espectroscopia de Absorção na Região do Ultravioleta e Visível (UV - Vis)}

A espectroscopia de absorção na região do UV-Vis é utilizada para a identificação de transições eletrônicas entre orbitais do tipo $n-, \pi-\mathrm{e} \sigma-$ de estado energético fundamental para estado excitado. A região espectral do ultravioleta (UV) compreende a faixa de comprimento de onda $(\lambda)$ de 200 a $400 \mathrm{~nm}$, ao passo que a região do visível abrange a faixa de 400 a $800 \mathrm{~nm}$.

A excitação de elétrons de ligação é geralmente responsável pela absorção de radiação ultravioleta ou visível, correlacionando, dessa maneira, comprimentos de onda dos picos e tipos de ligação das espécies em estudo. A absorção de radiação por uma molécula orgânica é proporcionada por, basicamente, dois tipos de elétrons: os que participam diretamente na formação da ligação atômica (estando, dessa forma, associados a mais de um átomo) e os chamados não ligantes ou externos. Diversos compostos orgânicos, além de apresentarem elétrons em orbitais dos tipos $\sigma$ e $\pi$, possuem elétrons em orbitais não ligantes, representados por n (Skoog et al., (2002)).

Uma transição na qual um elétron ligante em um orbital do tipo $\sigma$ é excitado para um orbital antiligante também do tipo $\sigma$ é denominada $\sigma \longrightarrow \sigma^{*}$. Da mesma forma, $\pi \longrightarrow \pi^{*}$ representa a transição de um elétron de um par isolado para um orbital antiligante do tipo $\pi^{*}$. Assim, os quatro tipos possíveis de transição eletrônica são os que se seguem: $\sigma \longrightarrow \sigma^{*}$; $\mathrm{n} \longrightarrow \sigma^{*} ; \mathrm{n} \longrightarrow \pi^{*} \mathrm{e} \pi \longrightarrow \pi^{*}$. A figura 13 a seguir ilustra as diferenças de níveis de energia para as transições eletrônicas possíveis.

Fig. 13 - Representação esquemática de transições eletrônicas possíveis entre orbitais (Adaptado de Skoog, et al., (2002)).

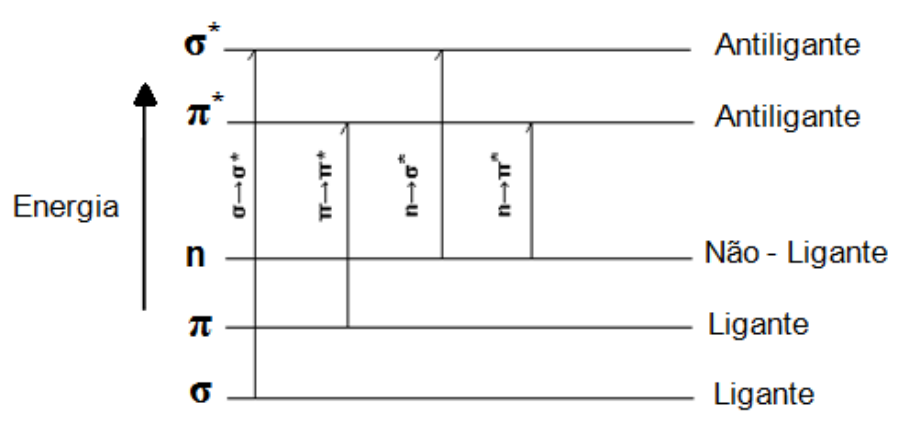

Fonte: SKOOG, D. A.; HOLLER, F. J.; NIEMAN, T. A. Princípios de análise instrumental. Porto Alegre: Bookman, 2002. 836 p. 
As transições do tipo $\sigma \longrightarrow \sigma^{*}$ correspondem à excitação, através da absorção de radiação, de um elétron ocupante de um orbital $\sigma$ para seu respectivo antiligante, $\sigma^{*}$. Dos quatro tipos de transições possíveis, esta é a que demanda uma maior quantia de energia. Um exemplo clássico de molécula cujos elétrons realizam este tipo de transição é o metano, $\mathrm{CH}_{4}$, que apresenta em sua estrutura somente ligações simples. Transições do tipo $n \longrightarrow \sigma^{*}$ são características de compostos saturados com pares de elétrons não compartilhados. Neste caso, a energia requerida é menor e dependente do tipo de ligação e estrutura da molécula em questão. No entanto, as transições do tipo $n \rightarrow \pi$ e $\pi \longrightarrow \pi^{*}$ são comuns em compostos orgânicos na espectroscopia de absorção, tendo em vista a faixa espectral (200 a $700 \mathrm{~nm}$ ) a que seus respectivos valores de energia correspondem. Em ambos os casos há necessidade de ocorrência de grupos funcionais insaturados como fonte de orbitais $\pi$. Os dois tipos de transição sofrem efeito de solvente sobre o comprimento de onda dos picos, apresentando comportamentos opostos quando do aumento de polaridade do solvente. Para o primeiro caso observa-se o deslocamento do pico para comprimentos de onda menores (fenômeno conhecido como deslocamento hipsocrômico, ou para a região do azul), enquanto para o segundo observa-se um comportamento oposto (deslocamento batocrômico, ou para o vermelho) (Skoog et al., (2002)).

Moléculas polares apresentam diferenças gritantes quando interagem com solventes polares. Interações entre soluto e solvente levam a um alargamento na banda de absorção e consequente redução de resolução espectral (Thermo Spectronic (2011)).

Fuentes et al., (2006) afirmam que valores obtidos pelo uso da espectroscopia de absorção de radiação UV-Vis, assim como a espectroscopia de fluorescência, tem fornecido dados úteis para o acompanhamento da evolução do grau de humificação de SH extraídas de materiais orgânicos de diversas origens.

Ainda, de acordo com os mesmos, em se tratando de espectroscopia de absorção de radiação UV-Vis, índices clássicos de avaliação de amostras, tais como a razão entre as intensidades de absorbância em 465 e $665 \mathrm{~nm}$ (razão $\mathrm{E}_{4} / \mathrm{E}_{6}$ ), os valores de absorbância em $600 \mathrm{~nm}$ e em $280 \mathrm{~nm}$ por unidade de carbono orgânico $\left(\mathcal{E}_{600 \mathrm{~nm}}\right.$ e $\left.\varepsilon_{280 \mathrm{~nm}}\right)$, tem se demonstrado de grande valia na obtenção de informações no que concerne às características estruturais das SH.

Contudo, dentre os diversos índices obtidos, a razão $\mathrm{E}_{4} / \mathrm{E}_{6}$ tem se mostrado de uso mais frequente (Polak et al., (2009), Giovanela et al., (2010) e Helal et al., (2011)). Ainda, de acordo com Helal et al., 2011, a razão de absorbância em SH é considerada um parâmetro tradicional para a avaliação do grau de humificação e tamanho molecular. Os valores de razão 
$\mathrm{E}_{4} / \mathrm{E}_{6}$ geralmente decrescem com o aumento do peso molecular e conteúdo de anéis aromáticos condensados. Segundo Polak et al., (2009) valores baixos de razão $\mathrm{E}_{4} / \mathrm{E}_{6}$ podem ser atribuídos à absorção por grupos funcionais $\mathrm{C}=\mathrm{C}$ aromáticos.

A energia característica de uma transição e, consequente comprimento de onda da absorção, é propriedade de determinados grupos de átomos, não necessariamente relacionando-se com arranjos eletrônicos (Thermo Spectronic (2011)).

Tais grupos são denominados cromóforos (significando portadores de cor), apresentando espectros de absorção característicos na região do visível e ultravioleta. Quando ocorre a conjugação de um cromóforo com outro (do mesmo tipo ou diferente), um cromóforo múltiplo é formado, acarretando em uma nova banda de absorção de maior intensidade e comprimento de onda do que as bandas de seus respectivos cromóforos constituintes (Thermo Spectronic (2011)).

Segundo Baes e Bloom (1990) os cromóforos responsáveis pela absorção na região do UV são principalmente arenos fenólicos, ácidos benzóicos, derivados de anilina e ainda hidrocarbonetos aromáticos policíclicos com dois ou mais anéis. Ainda, conforme os mesmos, a absorbância na região do visível apresenta certo grau de complexidade, uma vez que para esta região o fenômeno de absorção é decorrência da incidência de conjugações mais extensas em cadeias alifáticas ou poli aromáticas, estruturas do tipo quinonas, sistemas ceto-enóis, além da presença de complexos metálicos.

De acordo com Fuentes et al., (2006) os cromóforos presentes em moléculas de SH são geralmente constituídos de anéis aromáticos diferentemente substituídos por vários tipos de grupos funcionais, tais como fenóis, ácidos carboxílicos e cadeias alifáticas. A figura abaixo ilustra alguns cromóforos presentes nas $\mathrm{SH}$.

Os espectros eletrônicos obtidos para moléculas orgânicas contendo cromóforos são, em sua maioria, complexos devido à combinação de linhas superpostas originada pela superposição de transições vibracionais e eletrônicas, assim o que se observa é uma banda larga que geralmente parece ser contínua (Skoog et al., (2002)).

Em complemento, de acordo com Chen et al., (2002) geralmente as SH apresentam forte absorbância na faixa do UV-Vis (entre 200 e $800 \mathrm{~nm}$ ), particularmente na região do UV, devido à presença de cromóforos aromáticos e outros compostos orgânicos.

\subsubsection{Espectroscopia de Fluorescência de Luz UV - Vis}

Fotoluminescência é a propriedade que algumas substâncias possuem de emitir luz sob o efeito de uma excitação causada por radiação ultravioleta ou na região do visível (Skoog et al., (2002)). 
Segundo Lakowicz (1999) o fenômeno de luminescência é formalmente dividido em duas categorias: fluorescência e fosforescência. Para melhor entendimento dos processos, algumas terminologias específicas são empregadas. Entende-se por singlete ao estado eletrônico molecular no qual todos os spins eletrônicos estão emparelhados, e triplete o estado eletrônico onde spins encontram-se com orientações paralelas, ou seja, desemparelhados. No fenômeno de fluorescência, que ocorre em singletes excitados, o elétron que ocupa o orbital excitado é emparelhado com o elétron do orbital em estado fundamental. Assim sendo, o retorno do elétron excitado ao estado fundamental ocorre rapidamente pela emissão de um fóton. O processo de fosforescência é caracterizado pela emissão de luz de um triplete excitado, no qual tanto o elétron do estado excitado quanto o elétron ocupante do orbital no estado fundamental possuem a mesma orientação de spin, ficando paralelos e desemparelhados.

O fenômeno de fluorescência tem comportamentos diferentes em relação a átomos e moléculas, sendo classificado em ressonante e não ressonante. A fluorescência ressonante refere-se ao processo no qual a radiação emitida é idêntica, em frequência, à radiação empregada na excitação, sendo mais comumente produzida em átomos em estado gasoso, os quais não possuem estados de energia vibracional superpostos aos níveis de energia eletrônicos. Entretanto, o fenômeno de fluorescência não ressonante é produzido pela irradiação de moléculas em solução ou em estado gasoso. A absorção de radiação pelas moléculas faz com que estas deixem o estado eletrônico fundamental e assumam qualquer um dos muitos níveis vibracionais associados a estados eletrônicos excitados. Devido à diferença de duração entre estados excitados vibracionais e eletrônicos $\left(10^{-15}\right.$ e $10^{-8} \mathrm{~s}$, respectivamente), o processo de relaxação vibracional ocorre antes da relaxação eletrônica, acarretando em um menor valor de energia emitida em relação à absorvida. Assim sendo, a radiação emitida apresenta menor frequência (maior comprimento de onda) do que a radiação que causa a fluorescência, configurando o processo denominado Deslocamento de Stokes (Skoog et al., (2002)).

Os processos de absorção e emissão de luz que ocorrem durante o fenômeno de fluorescência são evidenciados pelo diagrama de Jablonski (Lakowicz (1999)), também conhecido por diagrama de níveis de energia, ilustrado pela figura 14. 
Fig. 14 - Diagrama de Jablonski (Adaptado de Sotomayor, et al., (2008)).

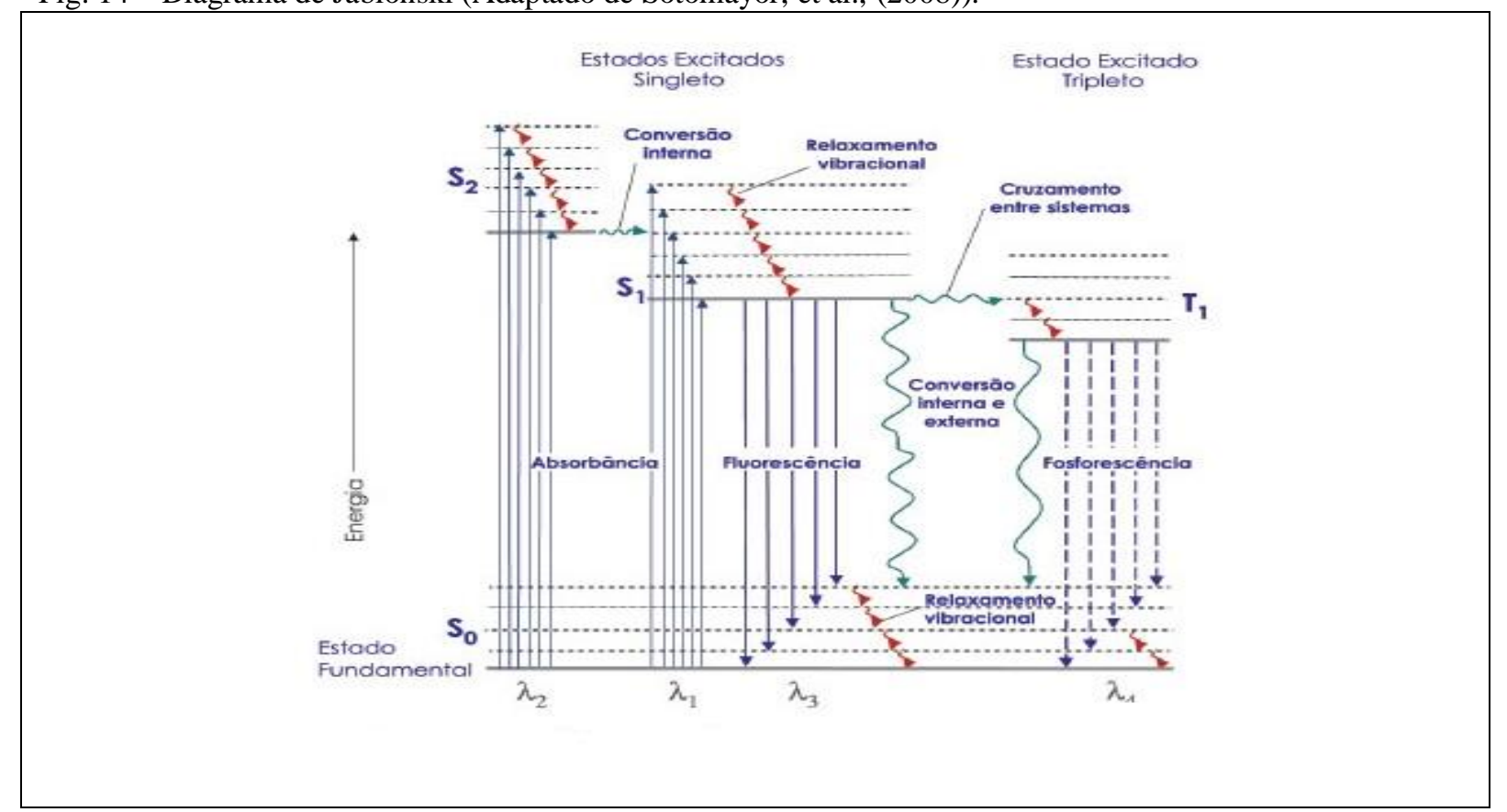

Fonte: SOTOMAYOR, M. D. P. T.; DIAS, I. L. T.; LANZA, M. R. V.; MOREIRA, A. B.; KUBOTA, L. T. Aplicação e avanços na espectroscopia de luminescência em análises farmacêuticas. Química Nova, v. 31, n. 7 , p. $1755-1774,2008$.

Assim como a espectroscopia de RPE, a espectroscopia de fluorescência constitui um método não destrutivo, possibilitando o reaproveitamento da amostra em análise. Contudo, conforme Milori et al., (2002) a técnica de RPE, embora seja de fundamental importância para o estudo da estrutura e humificação de matéria orgânica, nem sempre é acessível devido a sua alta complexidade e valor agregado. Dessa forma, neste contexto, a técnica de fluorescência apresenta vantagens sobre as demais, sendo mais acessível, simples e sensível.

Vários estudos tem mostrado a aplicação das técnicas de fluorescência para a análise de diferenças entre as $\mathrm{SH}$ extraídas, além de ponderar diferentes aspectos intrínsecos às determinadas classes de SH (ácidos húmicos - AH - e ácidos fúlvicos - AF) (Fuentes et al., (2006)).

Em seu estudo, Bertoncini et al., (2005) observaram que AH e AF apresentaram diferenças específicas nos perfis de seus espectros de fluorescência nas três categorias geralmente empregadas: emissão, excitação e sincronizado. Nos espectros no modo de emissão, as amostras de $\mathrm{AH}$ apresentaram maiores valores de comprimento de onda, contudo menores valores de intensidade de fluorescência, quando comparadas com os valores obtidos para amostras de AF. Tal comportamento corroborou com o observado quando da análise em modo sincronizado, onde as mesmas amostras de $\mathrm{AH}$ denotaram maiores valores de intensidade em comprimentos de onda mais longos. 
Segundo Senesi et al., (1991) o perfil observado pode ser indicativo da maior ocorrência de anéis aromáticos policondensados em AH, ou ainda, de sistemas conjugados em estruturas alifáticas insaturadas. Ainda, conforme os mesmos, os menores valores de intensidade de fluorescência obtidos para as mesmas amostras de $\mathrm{AH}$ podem ser indicativo de presença de substituintes com maior afinidade eletrônica nos anéis aromáticos, tais como grupos carbonila ou carboxila, além de possível interferência de fluoróforos em interações intra e intermoleculares.

Segundo Chen et al., (2002) a alta sensibilidade, seletividade e a natureza não destrutiva da técnica tem permitido a identificação de diferentes fluoróforos aromáticos com grupos funcionais doadores de elétrons, assim como, o estudo das propriedades da dinâmica de $\mathrm{SH}$ em diferentes ambientes.

Conforme Miano e Senesi, (1992) a posição e largura de um pico de fluorescência são relacionados com características estruturais tais como tamanho molecular ou policondensação, e conteúdo de grupos funcionais aromáticos, fenólicos, carboxílicos e hidroxílicos.

A literatura fornece pelo menos três metodologias diferentes para a análise de $\mathrm{SH}$, sendo Kalbitz et al., (1999), Milori et al., (2002) e Zsolnay et al., (1999).

A metodologia de Kalbitz et al., (1999) utiliza o modo de varredura sincronizada (emissão e excitação simultâneos), efetuando varredura na faixa de 300 a $600 \mathrm{~nm}$, com um $\Delta \lambda$ $=55 \mathrm{~nm}$ e com filtro sempre aberto. Índice de humificação neste caso é obtido pela razão entre os valores de maior e menor intensidade de fluorescência observados (em 468 e 375 nm, respectivamente). Os autores propuseram que o deslocamento de intensidade do máximo de fluorescência de comprimentos de onda mais curtos para mais longos é atribuído à presença de sistemas aromáticos condensados.

Segundo Miano e Senesi, (1992) a utilização da técnica no modo sincronizado levou a um aumento na resolução do pico observado e maior seletividade dos componentes estruturais das SH, quando em comparação aos métodos de emissão e excitação.

A metodologia elaborada por Milori et al., (2002) propõe a obtenção dos dados através de espectro de emissão com excitação em 465 nm, realizando varredura de 480 a $700 \mathrm{~nm}$, também com filtro sempre aberto. Para este método o grau de humificação é obtido pela integração da área sob o espectro obtido. Em seu trabalho com amostras de AH dissolvido, os autores observaram que comprimentos de onda na região do azul eram mais eficientes para promover a excitação de estruturas, cujas concentrações aumentaram durante o processo de humificação. 
A metodologia de Zsolnay et al., (1999) também utiliza espectro de emissão, porém com excitação em $240 \mathrm{~nm}$, com varredura de 300 a $700 \mathrm{~nm}$ e filtro em $290 \mathrm{~nm}$. Neste caso o índice de humificação é obtido dividindo-se a área do espectro obtido em quatro sub áreas e efetuando-se o quociente de $A_{4}(561-640 \mathrm{~nm})$ por $A_{1}(327-405 \mathrm{~nm})$, dando origem a um índice de humificação conhecido por $\mathrm{A}_{4} / \mathrm{A}_{1}$. Os autores observaram que, ao excitar a amostra no comprimento de onda mencionado, o sinal de fluorescência é deslocado para comprimento de ondas maiores, evidenciando progressão no processo de humificação.

Contudo, apesar das vantagens (tais como, alta seletividade e sensibilidade) que a técnica apresenta em relação às demais, a espectroscopia de fluorescência também é passível de sofrem interferência em seu sinal. Plaza et al., (2005) conduzindo estudo a respeito da complexação de metais com AH, observaram que alguns íons metálicos, particularmente os paramagnéticos, apresentam a capacidade de suprimir o sinal de fluorescência de alguns ligantes das SH, constituindo o processo denominado "quenching de fluorescência". Segundo os mesmos, tal processo pode ocorrer em duas formas: quenching estático e dinâmico, sendo que o primeiro tipo é relacionado ao local da molécula onde ocorre a complexação, e o segundo, à concentração do íon ligante.

\subsubsection{Espectroscopia de Fluorescência Induzida por Laser (FIL)}

A espectroscopia de fluorescência induzida por laser (FIL) tem se mostrado uma técnica de análise espectroscópica, tendo ampla aplicação no estudo do grau de humificação de amostras de solo, sem a necessidade de uso de processos de extração (Milori et al., (2006)), evitando possíveis perdas e alteração de características da amostra.

Segundo González-Pérez et al., (2007) a técnica permite o estudo do teor de MOS mesmo em amostras de solo que contenham grandes quantidades de íons paramagnéticos (interferentes em outras técnicas espectroscópicas como, por exemplo, a ressonância paramagnética eletrônica).

A instrumentação e técnica empregadas na análise por FIL são semelhantes às empregadas em análises por fluorescência convencional, onde são analisadas amostras em solução. A maior diferença entre a instrumentação das técnicas encontra-se nas fontes de radiação utilizadas, uma vez que em FIL a excitação da amostra é realizada através de laser de argônio (González-Pérez et al., (2007)).

Recentemente diversas pesquisas tem se dedicado ao desenvolvimento de instrumentação portátil para a análise em campo de amostras de solo, seguindo os mesmos princípios da instrumentação de bancada. 
A instrumentação de bancada consiste em sistema composto por um laser de argônio sintonizado na linha de $458 \mathrm{~nm}$ com uma potência de $300 \mathrm{~mW}$, um prisma para separação da emissão do laser da fluorescência do gás, espelho para a condução da excitação até as amostras de solos, uma lente para coletar a fluorescência, um modulador óptico, um filtro para suprimir a excitação no sistema de detecção, um monocromador (1200 g.mm ${ }^{-1}$ e "blaze" em $500 \mathrm{~nm}$ ), uma fotomultiplicadora com pico de resposta espectral em $530 \mathrm{~nm}$, um amplificador lock-in, um microcomputador dotado de uma placa de aquisição e software de controle e aquisição de dados (Milori et al., (2006)).

A instrumentação do aparelho portátil consiste em um laser de diodo emitindo em 405 $\mathrm{nm}$, com potencia máxima de $50 \mathrm{~mW}$, acoplado a um cabo óptico composto por seis fibras ópticas que excitam a amostra e uma fibra óptica central que coleta o sinal de fluorescência do solo. A fluorescência e a reflectância da amostra são conduzidas até um miniespectrômetro de alta sensibilidade. Antes de atingir o miniespectrômetro, o sinal é filtrado para atenuar o sinal de reflectância. A emissão da amostra é então decomposta através de uma grade de difração fixa e detectada por um conjunto de fotodiodos previamente calibrados. Desta forma, obtémse o espectro de emissão que é enviado para um computador, o qual é responsável por fazer o controle, a aquisição e o tratamento dos dados (Milori et al., (2012)). A figura 15 a seguir ilustra ambas instrumentações da espectroscopia de FIL.

Fig. 15 - Comparativo entre instrumentações de FIL de bancada (a) e portátil (b). Em (a): (1) laser de Argônio, (2) prisma, $(3,4,5)$ espelhos planos, (6) lente convergente, (7) modulador (optical chopper), (8) filtro, (9) monocromador, (10) fotomultiplicadora, (11) amplificador lock-in e (12) aquisição de dados (Milori et al., (2012)).

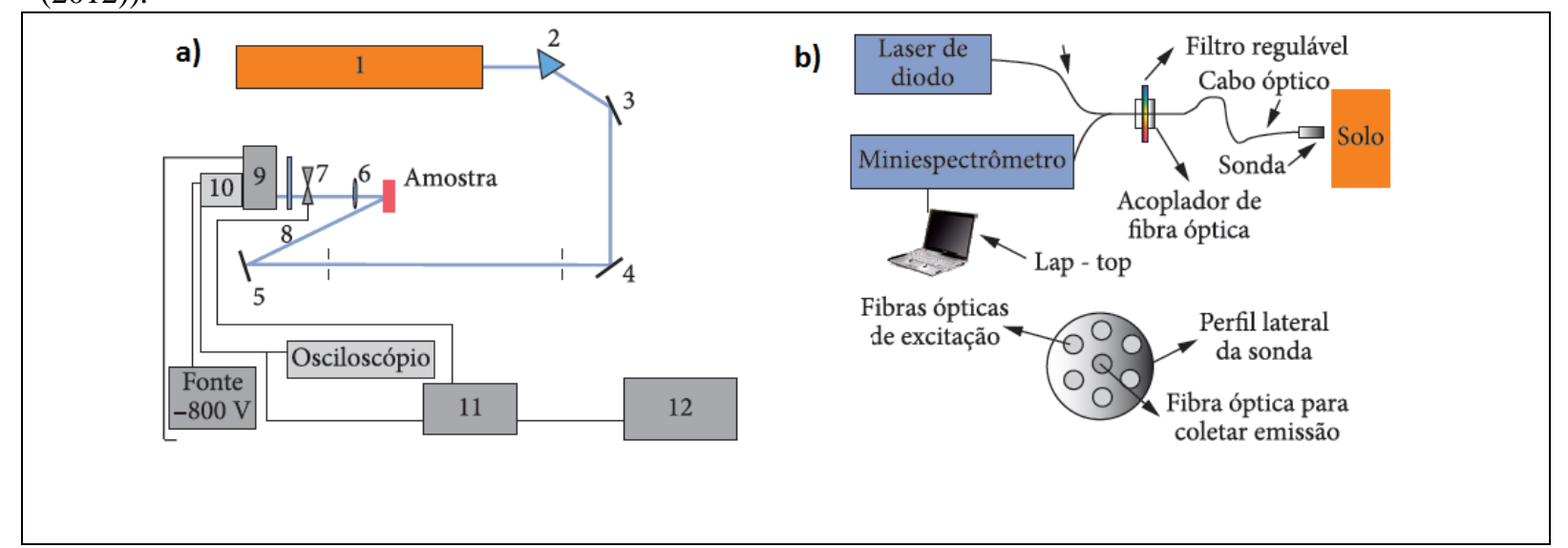

Fonte: MILORI, D. M. B. P.; MARTIN-NETO, L.; BOAS, P. R. V.; FERREIRA, E. C.; SEGNINI, A.; FERREIRA, E. J.; SANTOS, C. H.; ROMANO, R. A.; SILVA, W. T. L.; SIMÕES, M. L; POSADAS, A. Avaliação de um equipamento portátil para determinação do grau de humificação da matéria orgânica de solos. São Carlos: Embrapa, 2012. 5 p. (Boletim de Pesquisa).

O cálculo do grau de humificação da amostra em questão é proporcional à área sob a curva dos espectros obtidos, normalizada pelo teor de carbono da amostra, para ambas 
modalidades de instrumentação. Os resultados de grau de humificação obtidos para a instrumentação portátil e de bancada tem apresentado grande correlação $(r=0,997)$ (Milori et al., (2012)).

\section{MATERIAIS E MÉTODOS}

\section{1 Área Experimental 1}

O campo experimental instalado em Beltsville, Maryland, Estados Unidos $\left(39^{\circ} 2^{\prime} 15^{\prime \prime} \mathrm{N}\right.$ 76 55'4"O), consiste em área, com sistemas diferenciados de manejos de solo e rotação de culturas, localizado no Centro de Pesquisa Agrícola de Beltsville (BARC), pertencente ao Departamento de Agricultura do Estados Unidos / Serviço de Pesquisa Agrícola (USDA / ARS, compreendendo o Beltsville FSP (Farming Systems Project).

De acordo com Cavigelli et al., (2009) o campo possui área de 16 ha e, antes de sua instalação definitiva em 1996, não havia recebido nenhuma prática de manejo em um período de 11 anos. Ainda, segundo os mesmos, a média de precipitação anual é de $1110 \mathrm{~mm}$, distribuídos uniformemente durante o ano, e a média anual de temperatura é de $12,8^{\circ} \mathrm{C}$.

O FSP tem como temática principal o estudo e a avaliação de sistemas diferenciados de manejo de solo (agricultura orgânica versus agricultura convencional) e rotação de culturas, enfatizando sustentabilidade agrícola e benefícios ambientais.

Segundo Cavigelli et al., (2009) a escolha das culturas empregadas foi feita com a consultoria de fazendeiros de grãos da região, incluindo fazendeiros orgânicos; agentes de extensão, especialistas e pesquisadores da Universidade de Maryland e Universidade Estadual de Delaware; gestores de fazendas de várias organizações governamentais e não governamentais; e um representante da Agência Nacional de Transferência de Tecnologia para Áreas Rurais.

Ainda, de acordo com os mesmos, as práticas de manejos de solo são revisadas anualmente por um grupo de especialistas da Universidade de Maryland, gestores de fazendas do próprio BARC e, informalmente, por um grupo de fazendeiros orgânicos de Maryland.

As rotações de cultura e sistemas de manejo ocorrem da seguinte forma: plantio direto sem manejo (PD) de milho/soja/trigo/soja, plantio convencional com manejo mínimo (manejo mínimo do solo, PC) de milho/soja/trigo/soja, agricultura orgânica de 2 anos com rotação de soja/milho, agricultura orgânica de 3 anos com rotação de milho/soja/trigo e agricultura orgânica de 6 anos com rotação de milho/soja/trigo/alfafa (Spargo et al., (2011)). Cabe ressaltar que todos os sistemas orgânicos são submetidos a plantio direto.

Além da duração do período de rotação de culturas, os sistemas orgânicos diferem entre si pela quantidade (4500 - $6700 \mathrm{~kg} / \mathrm{ha} / \mathrm{aplicação)} \mathrm{e} \mathrm{frequência} \mathrm{de} \mathrm{esterco} \mathrm{aviário}$ 
adicionado. O sistema de agricultura orgânica de 2 anos recebe esterco aviário todo ano, ao passo que os sistemas de 3 e 6 anos recebem em 2 de cada 3 anos e em 2 de cada 6 anos, respectivamente. Os sistemas PC e PD recebem fertilização mineral pela aplicação de N, P, K. A composição do esterco aviário aplicado é ilustrada na tabela 2 a seguir e o delineamento experimental do FSP é ilustrado pela figura 16.

Tabela 2 - Composição de esterco aviário aplicado em campo experimental norte-americano

\begin{tabular}{|c|c|c|c|}
\hline Composição & Quantidade & Composição & Quantidade \\
\hline Sólidos & $73,28 \%$ & $\mathrm{~K}$ & $3,10 \%$ \\
\hline C Orgânico & $27,73 \%$ & $\mathrm{Ca}$ & $2,30 \%$ \\
\hline Matéria Orgânica & $48,67 \%$ & $\mathrm{Mg}$ & $0,60 \%$ \\
\hline Cinzas & $28,53 \%$ & $\mathrm{~S}$ & $0,85 \%$ \\
\hline $\mathrm{N}$ & $2,94 \%$ & $\mathrm{Na}$ & $0,80 \%$ \\
\hline $\mathrm{NH}_{4}-\mathrm{N}$ & $0,80 \%$ & $\mathrm{Mn}$ & $411,32 \mathrm{ppm}$ \\
\hline $\mathrm{N} \mathrm{Orgânico}$ & $2,15 \%$ & $\mathrm{Zn}$ & $459,07 \mathrm{ppm}$ \\
\hline $\mathrm{P}$ & $1,28 \%$ & $\mathrm{Cu}$ & $315,30 \mathrm{ppm}$ \\
\hline
\end{tabular}

Fig. 16 - Delineamento experimental do FSP. As diferentes cores representam as localizações dos sistemas analisados e as numerações ilustram identificação logística de campo. As letras apresentadas representam as culturas em cada parcela, sendo: A1,A2,A3 - alfafa de $1^{\circ}, 2^{\circ}$ e $3^{\circ}$ ano, respectivamente; C - milho, SB - soja; W/SB - trigo/soja; W/F - trigo/baga; r,v - plantas de cobertura. Em destaque, as parcelas de onde foram coletadas as amostras de solo.

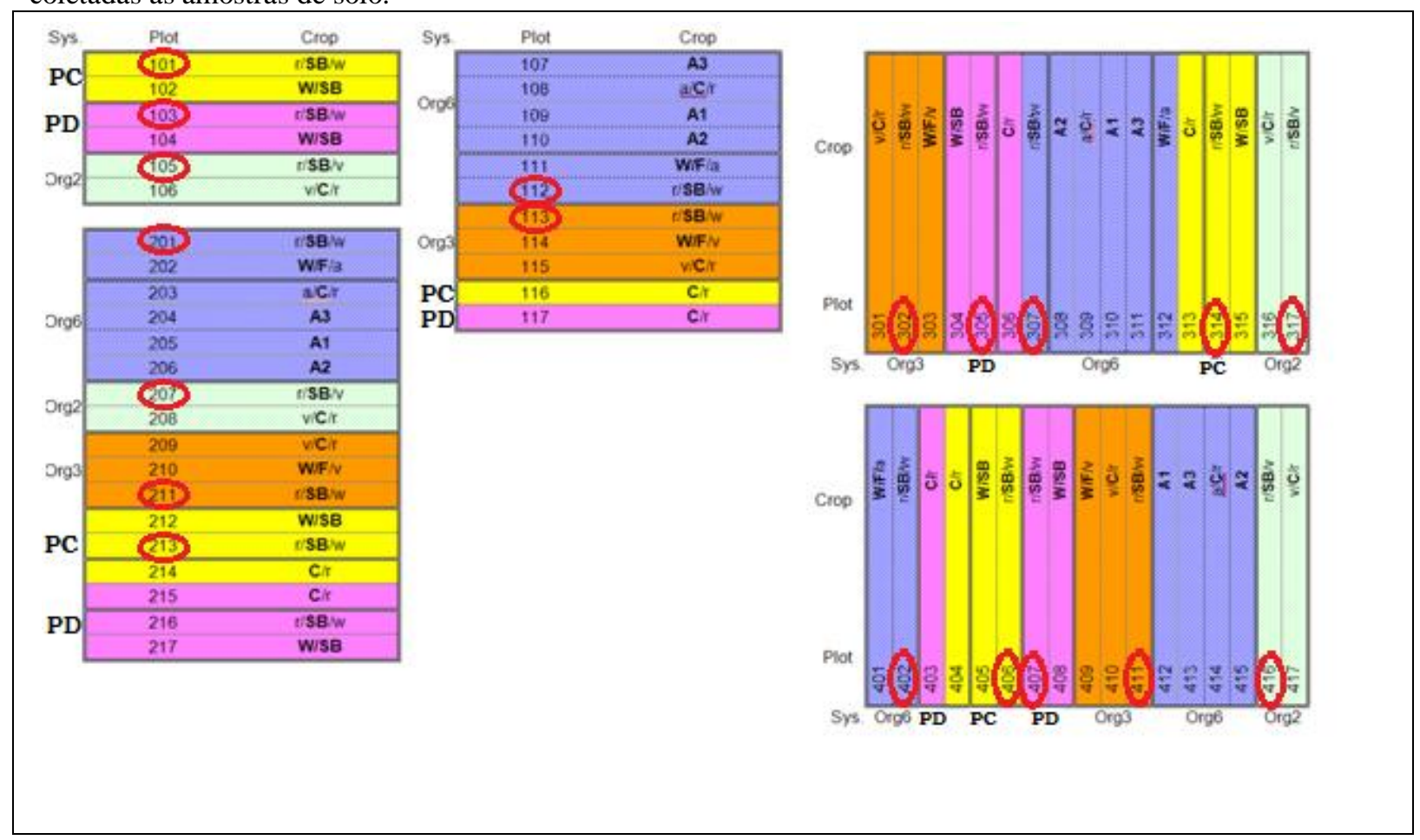

De acordo com Cavigelli et al., (2008) embora considerado de caráter homogêneo, o solo do FSP apresenta as seguintes classificações: Matapeake (latossolo vermelho distrófico mésico), Keyport (latossolo hidromórfico mésico), Mattapex (latossolo hidromórfico mésico) e Christiana (caulinítico, Argissolo mésico). 
O delineamento experimental do FSP segue a orientação de Distribuição de Bloco ao Acaso (RCBD). De acordo com estudo conduzido por Van Es et al., (2007) foi verificado que cerca de $97 \%$ de experimentos de campo utilizam o método RCBD em seu delineamento experimental. Segundo os mesmos, esta modalidade tem apresentado grande êxito em experimentos de longo prazo onde há homogeneidade entre os blocos. As variáveis de campo são identificadas como base para implementação dos blocos, e estes são distribuídos com determinados tamanhos, formas e orientações de forma a adequar os manejos em questão, minimizando a variabilidade espacial.

As amostras de solo foram coletadas em 4 replicatas por manejo analisado até a profundidade de $30 \mathrm{~cm}$, de acordo com a seguinte distribuição: 0-5; 5-10; 10-20; 20-25 e 25$30 \mathrm{~cm}$. Foi analisada amostra composta pelas quantias coletadas, representativa das respectivas parcelas referentes ao manejo a que foram submetidas.

\subsubsection{Fracionamento Físico - Área Experimental 1}

De acordo com Christensen (2001) o fracionamento físico do solo de acordo com seus componentes tem recebido maior atenção em estudos relacionados com o conteúdo de carbono orgânico do solo, uma vez que permite a separação deste em sítios com diferentes características de composição. Ainda, segundo Golchin et al., (1995) e Six et al., (2000) os sítios de MOS em frações fisicamente separadas (tais como matéria orgânica particulada, suas frações leve (livre e oclusa) e pesada) podem ser utilizados com indicadores da dinâmica da MOS de acordo com o uso do solo em função do tempo.

O fracionamento físico da MOS particulada foi realizado de acordo com procedimento proposto por Marriott e Wander (2006). A metodologia para obtenção de matéria orgânica particulada gera três frações: pesada, leve-livre e leve-oclusa (sendo analisadas, no presente estudo, as duas últimas, visto maior relação destas, também, com fertilidade do solo). Dessa forma, foi pesada, em frasco adequado, uma quantia de cerca de $40 \mathrm{~g}$ de amostra de solo e adicionados $75 \mathrm{~mL}$ de solução de politungstato de sódio (PTS), com densidade de $1,7 \mathrm{~g} / \mathrm{cm}^{3}$, seguido de agitação por um período de uma hora a $100 \mathrm{rpm}$. Ao término da agitação, o sistema foi transferido para um béquer, ficando em repouso por um intervalo de 16 horas para separação em fases pesada e leve, esta última contendo as frações livre e oclusa, respectivamente. Ao fim deste intervalo, a fração livre da MOS foi aspirada por filtração a vácuo passando um filtro de poliéster de $53 \mu \mathrm{m}$. A fração leve presa ao filtro foi lavada duas vezes com água deionizada, seca a $60^{\circ} \mathrm{C}$ por 24 horas e armazenada em dessecador para posterior análise. 
À fração remanescente no béquer, que contem a fração oclusa da MOS, foram adicionados $50 \mathrm{~mL}$ de solução $10 \%$ de hexameta-fosfato de sódio, seguindo de agitação por duas horas. Ao término do período de agitação, o conjunto foi peneirado em malha de $53 \mu \mathrm{m}$, sendo o material retido em malha transferido, com auxílio de água deionizada, para filtração a vácuo. Na sequência o material coletado em filtro foi seco a $60^{\circ} \mathrm{C}$ por 48 horas e reservado em dessecador para posteriores análises.

\section{2 Área Experimental 2}

O campo experimental de Itatinga, São Paulo ( $\left.23^{\circ} 06^{\prime} 06^{\prime \prime} \mathrm{S}, 48^{\circ} 366^{\prime} 57^{\prime \prime} \mathrm{O}\right)$ e composto por duas fazendas (Entre Rios e Areona) com plantio clonal de Eucaliptus grandis, com diferentes perfis de solo e inicio de atividades florestais.

O município de Itatinga localiza-se na região sudoeste do estado, a $221 \mathrm{~km}$ de distância da capital paulista, pertencendo à mesorregião de Bauru e fazendo divisa ao norte com Botucatu, ao sul com Angatuba e Paranapanema, a leste Pardinho e Bofete e, a oeste, Avaré. O clima do município e classificado como tropical Aw e sua altitude e de $845 \mathrm{~m}$ em relação ao nível do mar.

O plantio da espécie foi realizado em três repetições por talhão e as amostras foram coletadas nas camadas superficiais, ou seja, 0-10 e 10-20cm, sendo coletadas em Dezembro de 2010 e Março de 2011 com trado holandês, nas profundidades supramencionadas, de acordo com repetições de talhão em ambas as fazendas. Ambas fazendas compreendem área de reflorestamento pertencentes a Cia. Suzano Papel e Celulose S/A, sendo que o início de atividade na fazenda Entre Rios se deu em 2004, ao passo que na fazenda Areona em 2008.

A primeira fazenda (Entre Rios) possui Latossolo Vermelho-Amarelo Distrófico típico, horizonte A moderado, textura média leve, com teor de argila variando entre 16 e 20 $\%$; a segunda (Areona) possui Neossolo Quartzarênico Órtico típico, horizonte A moderado, fase cerrado, relevo plano e teor de argila variando entre 5 e $12 \%$.

Ambas as fazendas tiveram suas areas separadas de acordo com a adição ou não de biossólido. O biossólido é originado da estação de tratamento de esgoto (ETE) Jundiaí, São Paulo (2311'09" S, 4653'02" O) , operada pela Companhia de Saneamento de Jundiaí, onde o tratamento do lodo de esgoto é feito por lagoas aeradas, seguidas por lagoas de decantação.

As amostras coletadas foram identificadas de acordo com a sua procedência e adição ou não de biossólido, como se segue: ER 228 - fazenda Entre Rios sem adição de biossólido; ER 60 - fazenda Entre Rios com adição de biossólido; AN 36 - fazenda Areona sem adição de biossólido e AN 254 - fazenda Areona com adição de biossólido. O montante coletado foi seco a temperatura ambiente, com posterior limpeza manual (retirada de raízes e plantas), 
peneiramento em malha de $5 \mathrm{~mm}$ e maceração para início das análises com amostras de solo e seguinte extração de substâncias húmicas.

Os diferentes processos de condicionamento de solo para ambas fazendas é ilustrado pela tabela 3 a seguir.

Tabela 3 - Especificação de processos de condicionamento de solo para fazendas analisadas.

\begin{tabular}{|c|c|c|c|}
\hline AREA & ETAPA & CONDICIONAMENTO & DOSAGEM (kg/ha) \\
\hline \multirow{2}{*}{ ER 60} & PRE-PLANTIO & NPK 06-30-10 + 0,3\% B & 265 \\
& & BIOSSOLIDO & 2030 \\
\hline ER 228 & PRE-PLANTIO & CINZAS & 3500 \\
\hline \multirow{2}{*}{ AN 254 } & PRE-PLANTIO & BIOSSOLIDO & 3000 \\
& CRE-PLANTIO & CINZAS & 2900 \\
\hline AN 36 & CINZAS & 5000 \\
\hline
\end{tabular}

De acordo com Firme et al., (2010) o biossólido utilizado foi caracterizado conforme resolução CONAMA n 375 de 2006, apresentando 78\% de umidade $(\mathrm{m} / \mathrm{m}), \mathrm{pH}$ de 5,8, e as seguintes características ilustradas pela tabela 4 a seguir.

Tabela 4 - Caracterização de biossólido aplicado nas áreas em análise.

\begin{tabular}{|c|c|}
\hline Composição & ${\text { Quantia }\left(\mathbf{g . k g} \mathbf{~}^{-1}\right)}^{\prime}$ \\
\hline C orgânico & 322 \\
\hline N total & 30 \\
\hline N amoniacal & 2,2 \\
\hline N nitrato/nitrito & 0,02 \\
\hline $\mathrm{P}$ & 11 \\
\hline $\mathrm{K}$ & 2,8 \\
\hline $\mathrm{Ca}$ & 19 \\
\hline $\mathrm{Mg}$ & 2,8 \\
\hline $\mathrm{S}$ & 17 \\
\hline $\mathrm{Na}$ & 2,1 \\
\hline
\end{tabular}

Fonte: FIRME, L. P.; BACA, C. M.; ABREU, C. H.; NETO, S. P. M.; MURAOKA, T.; GAVA, J. L. Lodo de esgoto como fonte de nitrogênio e fósforo em floresta de eucalipto. In: WORKSHOP - REDE AGRORECICLA, 2010, São Carlos. Anais... São Carlos: Embrapa, 2010. CD-ROM.

\subsubsection{Fracionamento Químico - Área Experimental 2}

Segundo Giovanela et al., (2010) devido a grande influência que exercem em diversos processos ambientais, informações acerca de composição e grupos funcionais das SH são de grande importância para melhor entendimento da reatividade com contaminantes orgânicos e inorgânicos. No presente estudo a extração e purificação das SH foi efetuada de acordo com procedimento proposto pela Sociedade Internacional de Substâncias Húmicas (IHSS), como se segue. 
Inicialmente, efetuou-se extração através de adição de solução $0,1 \mathrm{~mol} \mathrm{~L}^{-1}$ de $\mathrm{HCl}$, atendendo a proporção de $1 \mathrm{~g}$ de amostra para $10 \mathrm{~mL}$ de solução ácida. Assim sendo, foi pesada uma quantia de $200 \mathrm{~g}$ de solo para um volume utilizado de $2 \mathrm{~L}$ de solução, seguindo de agitação por uma hora. Na sequência, o sistema foi deixado em repouso por um intervalo de quatro horas, com a finalidade de separar o sobrenadante por sedimentação. O sobrenadante obtido nesta primeira fase da extração e a parcela 1 de ácidos fúlvicos, que foi retirada por sifonação. Em seguida foi realizada nova extração pela adição de solução $0,1 \mathrm{~mol} \mathrm{~L}^{-1}$ de $\mathrm{NaOH}$ ao precipitado, seguindo a mesma proporção anterior (1g amostra:10mL solução), submetendo-se o sistema a agitação por quatro horas. Ao final da agitação, o conjunto foi mantido em repouso por um periodo de 16 horas, separando, novamente, o sobrenadante do resíduo. Ao término do tempo de repouso, coletou-se o sobrenadante e o precipitado (fração humina) foi lavado com água destilada ate $\mathrm{pH}$ próximo de 7,0 e seco em estufa a $45^{\circ} \mathrm{C}$.

O sobrenadante coletado foi transferido para frascos apropriados e centrifugado para eliminação de argila. Na sequência este foi acidificado com solução $6,0 \mathrm{~mol} \mathrm{~L}^{-1}$ de $\mathrm{HCl}$, até atingir um $\mathrm{pH}$ de aproximadamente 2,0, ficando em repouso por 12 horas em seguida. $\mathrm{O}$ precipitado obtido contém a fração de ácidos húmicos, ao passo que o sobrenadante representa a segunda parcela de ácidos fúlvicos, que, da mesma forma que a primeira parcela, foi retirada via sifonação.

Ao fim da fase de extração, iniciou-se a etapa de purificação dos ácidos húmicos extraídos pela dissolução em solução $0,1 \mathrm{~mol} \mathrm{~L}^{-1}$ de $\mathrm{KOH}$ e adição de $\mathrm{KCl}$, ate que se completasse uma concentração de íons $\mathrm{K}^{+}$equivalente a $3,0 \mathrm{~mol} \mathrm{~L}^{-1}$. Esta solução foi então centrifugada para eliminação de sólidos suspensos. Na sequência, o ácido húmico foi reprecipitado, submetido a diálise por um período de seis dias em membranas Spectra/Por 6000-8000 D, livres de suas substâncias conservantes, ativadas de acordo com metodologia de McPhie (1971). Por fim, o ácido húmico submetido à diálise foi liofilizado e armazenado em dessecador para análises posteriores.

\subsection{Análise Elementar}

Os teores de $\mathrm{C}$ e $\mathrm{N}$ das frações de matéria orgânica particulada (MOP) (livre e oclusa, $M O P l$ e $M O P o$, respectivamente) foram determinados por combustão a seco utilizando 600 mg de amostra em equipamento Vario Max CN (Elementar Americas, Inc.). Foram realizadas leituras de amostras de branco e padrão LECO a cada intervalo de 10 determinações das amostras de MOP em análise. Os dados foram analisados por one-way ANOVA por aumento de profundidade (nível de significância $\mathrm{p}<0.10$ ). 


\subsection{Espectroscopia de Fluorescência Induzida por Laser (FIL)}

A técnica baseia-se na hipótese de que os sinais de fluorescência são emitidos por sistemas conjugados rígidos, presentes em moléculas individuais ou estruturas, independente do estado físico da amostra em questão, ou seja, quer seja solução, quer seja sólido (Milori et al., (2006)).

Os espectros de emissão de FIL foram obtidos para pastilhas de amostras de solo (coletadas nas fazendas Entre Rios e Areona) previamente peneiradas, prensadas em forma de aço, sob pressão de 8,0 ton, nas dimensões de 1,0 cm de diâmetro, 2,0 mm de espessura e cerca de 0,5 g de massa, em instrumentação pertencente à Embrapa Instrumentação.

\subsection{Respiração do Solo}

$\mathrm{O}$ processo de respiração do solo e emissão de $\mathrm{CO}_{2}$ é crucial para o ciclo de $\mathrm{C}$ em ecossistemas terrestres, e pequenas mudanças podem alterar drasticamente os mecanismos de sequestro de C solo (Wang e Wang (2011)).

De acordo com Chirinda et al., (2010) nos solos, o $\mathrm{CO}_{2}$ é predominantemente produzido pelo processo de decomposição de matéria orgânica realizado pela comunidade microbiana do solo, que é também diretamente relacionado com a mineralização de $\mathrm{N}$ no solo. Dessa forma, além de ser um GEE, o $\mathrm{CO}_{2}$ emitido atua também como um indicador da disponibilidade de $\mathrm{C}$ para a atividade microbiana.

Os fluxos de $\mathrm{CO}_{2}$ foram coletados em área delimitada por câmara estática de PVC com diâmetro de $10 \mathrm{~cm}$, inseridos a uma profundidade de aproximadamente $2 \mathrm{~cm}$, distribuídos em ambas fazendas analisadas para a segunda área experimental. As medidas de emissão de $\mathrm{CO}_{2}$ foram realizadas utilizando-se de espectroscopia de absorção ótica no infravermelho (LICOR, NE - USA), de acordo com adequação do procedimento proposto por Chavez et al., (2009) e Brito et al., (2010).

\subsection{Espectroscopia de Absorção na Região do Infravermelho}

De acordo com Helal et al., (2011), a espectroscopia de infravermelho é uma ferramenta que pode ser aplicada na identificação de compostos complexos, podendo ser utilizada na analise qualitativa de bandas e grupos funcionais de ácidos húmicos, bem como frações da matéria orgânica do solo (MOS).

Ainda, segundo Fernandes et al., (2010), a técnica provê informações consideráveis sobre natureza, reatividade e, sobretudo, arranjos estruturais de grupos funcionais oxigenados nas substâncias húmicas e MOS.

Os espectros na região do infravermelho médio foram obtidos em espectrômetro Digilab FTS7000 com Transformada de Fourier, utilizando detector DTGS (Deuterated 
Triglycine Sulfate) e KBr como padrão, através de 64 varreduras acumuladas com resolução de $4 \mathrm{~cm}^{-1}$, sendo 4000 a $400 \mathrm{~cm}^{-1}$ a região de leitura.

\subsection{Pirólise Acoplada a Cromatografia a Gás/Espectrometria de Massas (PY - GC/MS)}

A técnica de pirólise acoplada a GC/MS compreende a volatilização em temperatura controlada das frações extraídas de MOS, seguida de separação por cromatografia a gás e identificação por espectrometria de massas. O espectro resultante possibilita a semi quantificação e comparação relativa entre as substâncias pirolizadas (Vancampenhout et al., (2010)).

De acordo com Dignac et al., (2006) a pirólise de compostos orgânicos gera uma grande variedade de produtos com diferentes propriedades químicas de acordo com sua origem biológica (compostos alifáticos, metoxi-fenóis derivados de lignina, cetonas cíclicas e furanos de polissacarídeos, moléculas contendo $\mathrm{N}$ de proteínas, ácidos orgânicos e outros). Somente os compostos voláteis pirolizados com afinidade química à coluna cromatográfica podem ser analisados via cromatografia a gás. Assim, segundo os mesmos, as interações entre os produtos da pirólise e a fase estacionária da coluna cromatográfica que direcionam sua separação. Dessa forma, a escolha da coluna cromatográfica de acordo com a polaridade dos analitos torna-se um fator crucial para uma análise de sucesso.

As análises de pirólise - GC/MS foram realizadas em equipamento Pyroprobe modelo 5200 (CDS Analytical, Inc.), em $600{ }^{\circ} \mathrm{C}$ por $20 \mathrm{~s}$, acoplado a cromatógrafo a gás/espectrômetro de massas Perkin-Elmer Clarus 500, usando He como fase móvel e coluna cromatográfica modelo DB-35MS com $20 \mathrm{~m}$ de comprimento, $0.180 \mathrm{~mm}$ diâmetro e $35 \%$ fenol como fase estacionária.

\subsection{Espectroscopia de Absorção na Região do Ultravioleta e Visível (UV - Vis)}

Conforme mencionado anteriormente, a espectroscopia de absorção na região do UV Vis e utilizada para a identificação de transições eletrônicas em orbitais do tipo n - , $\pi$ - , $\sigma-$ de seu estado energético fundamental para seu estado excitado. A região espectral do ultravioleta (UV) compreende a faixa de comprimento de onda que vai de 200 a $400 \mathrm{~nm}$, ao passo que a região visível, varre a faixa 400 a $800 \mathrm{~nm}$.

Fuentes et al., (2006) afirmam que valores obtidos pelo uso deste tipo de espectroscopia, juntamente com demais técnicas, tem fornecido dados uteis para o acompanhamento da evolução do grau de humificação de SH extraídas de materiais orgânicos de diversas origens. 
Para o presente trabalho a técnica de absorção eletrônica foi utilizada obtenção de espectros e medidas da razão $\mathrm{E}_{4} / \mathrm{E}_{6}$ (quociente da intensidade de absorbância em $465 \mathrm{~nm}$ por $665 \mathrm{~nm}$ ), servindo de parâmetro para a medida do grau de condensação e aromaticidade.

Os espectros foram obtidos em duplicata por amostra a partir de soluções dos ácidos húmicos em análise, partindo-se da diluição de solução 220 ppm, preparada com 2,0 mg de amostra e $10 \mathrm{~mL}$ de $\mathrm{NaHCO}_{3} 0,05$ mol. $\mathrm{L}^{-1}$, com valor de $\mathrm{pH}$ ajustado para 8,0 (Stevenson (1994)).

\subsection{Espectroscopia de Fluorescência de Luz UV-Vis}

Conforme mencionado anteriormente, os diferenciais dessa metodologia são a alta sensibilidade e seletividade, tendo em vista que os grupos funcionais que podem ser observados indicam que a intensidade da fluorescência tem um comportamento inversamente proporcional ao tamanho molecular e ao incremento de grupos funcionais $\mathrm{C}=\mathrm{O}, \mathrm{COOH}$ e $\mathrm{C}$ aromáticos, constatando de tal forma a idade das $\mathrm{SH}$, apontando uma maior quantidade de grupos $\mathrm{COOH}$ para ácidos húmicos mais antigos.

Os espectros de fluorescência de amostras de ácidos húmicos, extraídos de solo submetido ou não à adição de biossólido, foram obtidos em modos de emissão e excitação de acordo com as metodologias de Kalbitz et al., (1999), Milori et al., (2002) e Zsolnay et al., (1999). Os espectros foram obtidos em duplicata por amostra, a partir de soluções dos ácidos humicos em análise, com as mesmas características das soluções utilizadas durante análise por absorção na região do UV-Vis.

\section{RESULTADOS E DISCUSSÃO}

\section{1 Área Experimental 1}

\subsubsection{Teor de C para Amostras de Solo}

A figura 17 e tabela 5 a seguir ilustram o comportamento do teor de $\mathrm{C}$ para as amostras dos diferentes sistemas analisados, considerando todo o perfil estudado em campo experimental. 
Fig. 17 - Gráfico de valores de teor de C para amostras de solo para os diferentes sistemas analisados, onde PC - plantio convencional com manejo mínimo, ORG2 - agricultura orgânica de 2 anos, ORG3 agricultura orgânica de 3 anos, ORG6 - agricultura orgânica de 6 anos e PD - plantio direto sem manejo.

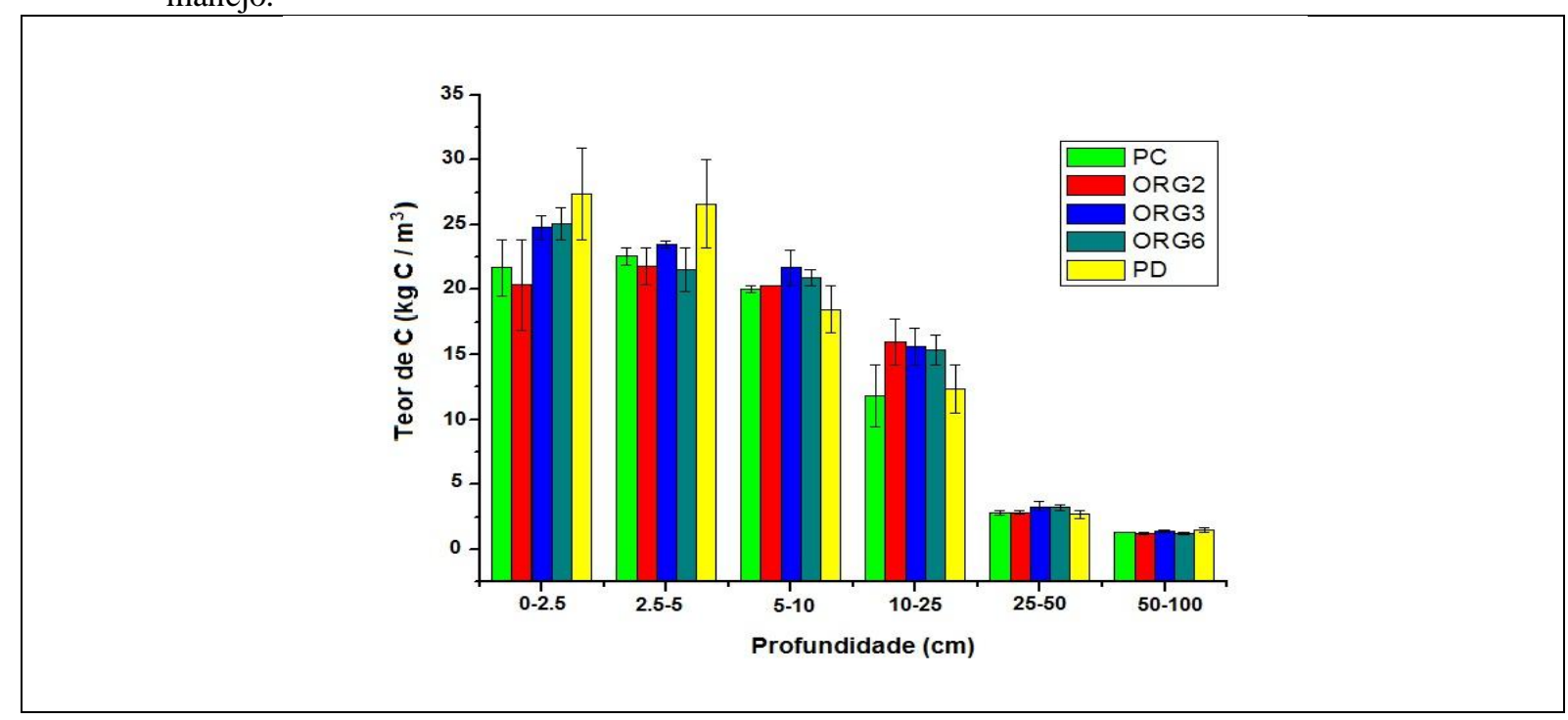

Tabela 5 - Valores de teor de C para amostras de solo para os diferentes sistemas analisados, onde PC - plantio convencional com manejo mínimo, ORG2 - agricultura orgânica de 2 anos, ORG3 - agricultura orgânica de 3 anos, ORG6 - agricultura orgânica de 6 anos e PD - plantio direto sem manejo.

\begin{tabular}{|c|c|c|c|c|c|}
\hline Profundidade (cm) & PC & ORG2 & ORG3 & ORG6 & PD \\
\hline $0-2,5$ & $21,67 \pm 2,18$ & $20,36 \pm 3,49$ & $24,77 \pm 0,93$ & $25,07 \pm 1,22$ & $27,37 \pm 3,52$ \\
\hline $2,5-5$ & $22,56 \pm 0,63$ & $21,81 \pm 1,38$ & $23,48 \pm 0,29$ & $21,51 \pm 1,68$ & $26,59 \pm 3,40$ \\
\hline $5-10$ & $20,00 \pm 0,26$ & $20,27 \pm 0,01$ & $21,67 \pm 1,41$ & $20,89 \pm 0,63$ & $18,47 \pm 1,79$ \\
\hline $10-25$ & $11,81 \pm 2,41$ & $15,96 \pm 1,74$ & $15,61 \pm 1,39$ & $15,36 \pm 1,14$ & $12,36 \pm 1,86$ \\
\hline $25-50$ & $2,80 \pm 0,17$ & $2,83 \pm 0,13$ & $3,30 \pm 0,34$ & $3,21 \pm 0,25$ & $2,67 \pm 0,29$ \\
\hline $50-100$ & $1,31 \pm 0,02$ & $1,23 \pm 0,11$ & $1,39 \pm 0,05$ & $1,25 \pm 0,09$ & $1,51 \pm 0,17$ \\
\hline
\end{tabular}

Cabe ressaltar que o teor de carbono para amostras de solo nesta área experimental foi obtido pelo grupo de pesquisa norte-americano, em análise prévia, justificando o perfil de $1 \mathrm{~m}$ de profundidade apresentado.

Segundo Powlson et al., (2011) diversas práticas agrícolas com potencial de sequestro de $\mathrm{C}$ necessitam mudanças no sistema de cultivo ou ainda pesquisa intensa. Sendo assim, para um aumento no conteúdo de $\mathrm{C}$ orgânico no solo, e consequente mitigação dos efeitos de mudanças climáticas, existe a necessidade de transferência de $\mathrm{C}$ atmosférico para o solo, que pode ser realizada principalmente por dois mecanismos, sendo: fotossíntese e processo de decomposição de matéria orgânica do solo, levando à sua estabilização.

Ainda, segundo os mesmos, um erro recorrente é a afirmação de qualquer aumento no conteúdo de $\mathrm{C}$ orgânico do solo através de uma mudança em um sistema de manejo é relacionada com a mitigação de efeitos de mudanças climáticas. Esse é o caso de mudanças 
relacionadas com a adição de material extra ao solo, como esterco animal, onde ocorre somente a transferência de C orgânico do material para o solo.

Em complemento, de acordo com Paterson et al., (2009) a adição de novos substratos (como é o caso dos resíduos adicionados ao solo) altera a atividade microbiana e pode acelerar o processo de decomposição da MOS, alterando assim o processo de sequestro de C no solo.

Na parcela de 0-5 cm, o conteúdo de C mostrou-se cerca de $20 \%$ maior no sistema PD (plantio direto) em comparação aos outros sistemas. Contudo, na parcela de 10-25 cm, os três sistemas orgânicos apresentaram, aproximadamente, $30 \%$ a mais de teor de $\mathrm{C}$ em detrimento aos demais. Este comportamento reflete possível maior incorporação, em profundidade, no solo de materiais orgânicos (resíduos de culturas, plantas de cobertura, excrementos animais) nos sistemas de agricultura orgânica (seja 2, 3 ou 6 anos) quando comparados aos sistemas convencionais com manejo mínimo (PC) e de plantio direto sem manejo (PD). Cabe ressaltar que as amostras de solo provenientes do sistema PD apresentaram, em média, teor de C $20 \%$ maior em comparação ao sistema PC, considerando o perfil analisado.

Uma vez que a quantidade e qualidade dos incrementos de $\mathrm{C}$ adicionados diferem entre os sistemas orgânicos, a hipótese é de que a qualidade do C do próprio solo também apresente características diferentes entre tais sistemas.

Medidas de $\mathrm{C}$ no solo frequentemente exibem altos níveis de variabilidade temporal e especial, o que dificulta a avaliação dos efeitos de manejo no processo de sequestro de C, dentro de determinado sítio (Nave et al., (2010)).

Segundo Sainju et al., (2006) o aumento do conteúdo de matéria orgânica em camadas superficiais, principalmente na faixa de $0-5 \mathrm{~cm}$, em sistemas de plantio direto, em detrimento a sistemas de plantio convencional, é amplamente reportado diversos estudos. Conforme Lichter et al., (2008) a técnica de plantio direto sem manejo favorece agregados do solo estáveis, protegendo fisicamente a matéria orgânica do solo, reduzindo, dessa forma a taxa de mineralização.

Práticas de manejo de solo podem levar à redução do conteúdo de $\mathrm{C}$ em camadas superficiais, contudo também podem ocasionar o aumento de tal conteúdo em profundidade, à medida que o material orgânico superficial é incorporado pelas práticas inerentes aos sistemas agrícolas de plantio convencional (VandenBygaart e Angers (2006)).

De acordo com Luo et al., (2010) o declínio no teor C em sistemas agrícolas se deve, principalmente, ao cultivo. De acordo com os mesmos, o cultivo altera a quantidade e a qualidade dos aportes de $\mathrm{C}$ ao solo, além das propriedades físicas do solo que afetam o 
processo de decomposição de C. Práticas de manejo voltadas para a prevenção da perda de C devem levar em consideração o balanço entre a perda natural de $\mathrm{C}$ do solo com a adição de novos materiais, sendo a taxa de perda de $\mathrm{C}$ extremamente relacionada com as condições climáticas do ambiente.

Ainda, em sequência, os mesmos afirmam que a entrada de C no solo é predominantemente controlada pela produção de biomassa dos culturas, que por sua vez também é dependente da variável climática, além das condições do solo, adição de fertilizantes e do próprio sistema de manejo.

Em estudo recente comparando os efeitos, em longo prazo, de práticas convencionais e orgânicas de uso do solo, no que tange à estabilização da MOS, Kong e Six, (2010) verificaram aumento no conteúdo de $\mathrm{C}$ em amostras referentes aos sistemas orgânicos (submetidos à aplicação anual de esterco e emprego de plantas de cobertura) em comparação às áreas de plantio convencional. Segundo os mesmos a taxa de sequestro de $\mathrm{C}$ nas áreas sob regime de agricultura orgânica foi 14 vezes maior, em detrimento aos demais sistemas considerados, sendo que tal taxa não apresentou proporcionalidade à quantia de material orgânico adicionado. Os dados obtidos reportaram estabilização preferencial de C em sistemas orgânicos em camadas subsuperficiais.

Segundo Triberti et al., (2008) existem combinações complexas entre os diversos tipos de sistemas de manejo e práticas de uso do solo (tipo de fertilizantes utilizados, tipo de cultura empregado, aporte de material orgânico) que afetam a dinâmica do $\mathrm{C}$ do solo, no que concerne à sua quantidade e qualidade. Conforme os mesmos, a redução nos distúrbios do solo, causados por alguns sistemas de manejo, e a maior incorporação de material orgânico favorecem o aumento dos estoques de C orgânico no solo.

\subsubsection{Densidade de Solo}

A figura 18 e tabela 6 a seguir ilustram os valores de densidade do solo para as amostras dos diferentes sistemas analisados, considerando todo o perfil estudado em campo experimental. 
Fig. 18 - Gráfico de valores de densidade de solo para amostras de solo intacto para os diferentes sistemas analisados, onde PC - plantio convencional com manejo mínimo, ORG2 - agricultura orgânica de 2 anos, ORG3 - agricultura orgânica de 3 anos, ORG6 - agricultura orgânica de 6 anos e PD - plantio direto sem manejo

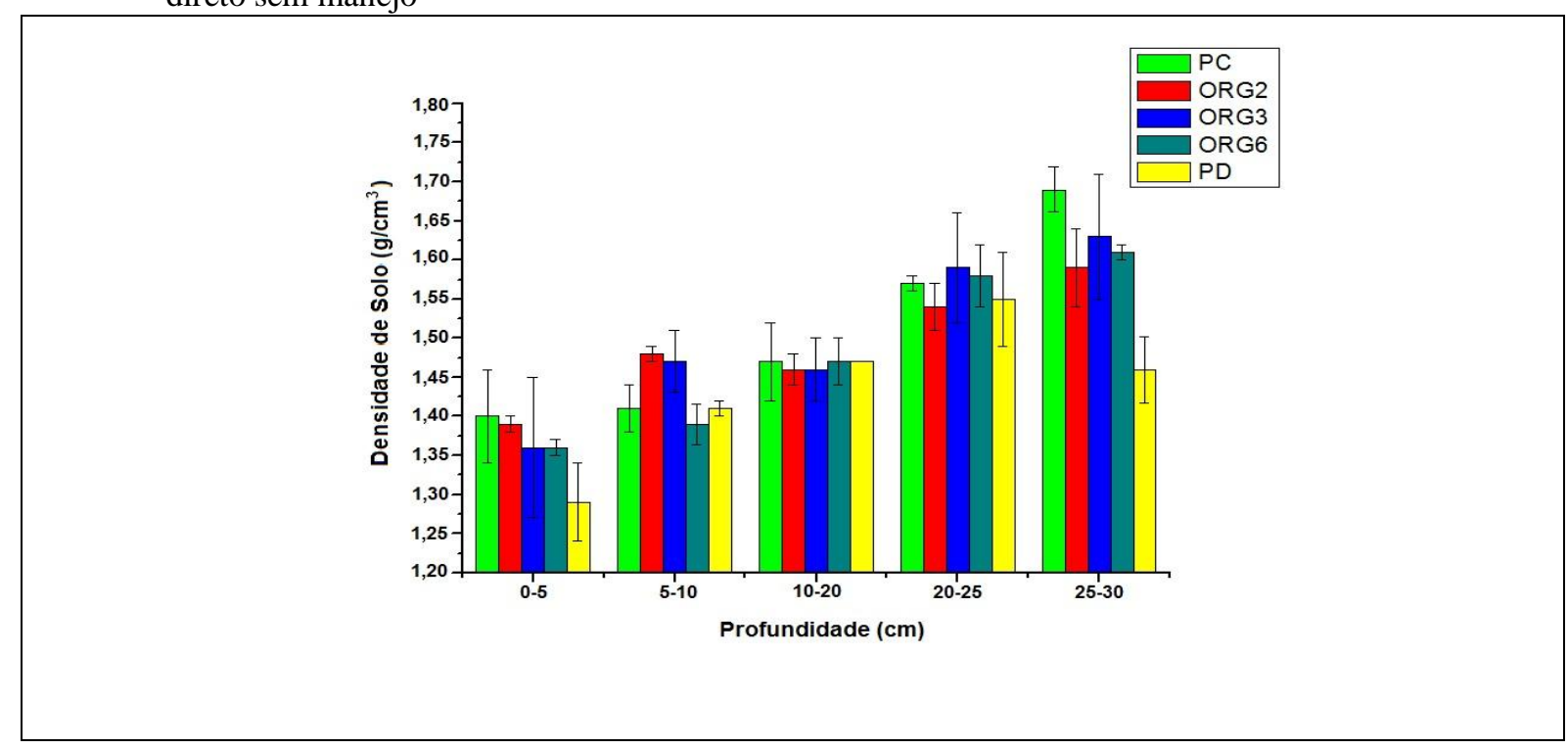

Tabela 6 - Valores de densidade de solo para amostras de solo intacto para os diferentes sistemas analisados, onde PC - plantio convencional com manejo mínimo, ORG2 - agricultura orgânica de 2 anos, ORG3 agricultura orgânica de 3 anos, ORG6 - agricultura orgânica de 6 anos e PD - plantio direto sem manejo

\begin{tabular}{|c|c|c|c|c|c|}
\hline Profundidade (cm) & PC & ORG2 & ORG3 & ORG6 & PD \\
\hline $0-5$ & $1,42 \pm 0,06$ & $1,39 \pm 0,01$ & $1,36 \pm 0,09$ & $1,36 \pm 0,01$ & $1,29 \pm 0,05$ \\
\hline $5-10$ & $1,41 \pm 0,03$ & $1,48 \pm 0,01$ & $1,47 \pm 0,04$ & $1,39 \pm 0,03$ & $1,41 \pm 0,01$ \\
\hline $10-20$ & $1,47 \pm 0,05$ & $1,46 \pm 0,02$ & $1,46 \pm 0,04$ & $1,47 \pm 0,03$ & $1,47 \pm 0,01$ \\
\hline $20-25$ & $1,57 \pm 0,01$ & $1,54 \pm 0,03$ & $1,59 \pm 0,07$ & $1,58 \pm 0,04$ & $1,55 \pm 0,06$ \\
\hline $25-30$ & $1,69 \pm 0,03$ & $1,59 \pm 0,05$ & $1,63 \pm 0,08$ & $1,61 \pm 0,01$ & $1,46 \pm 0,04$ \\
\hline
\end{tabular}

Densidade do solo é considerada como parâmetro para medida de qualidade de solo devido à relação que tem com demais fatores, tais como, porosidade, umidade de solo, condutividade hidráulica, compactação, entre outros (Dam et al., (2005)).

Ainda, de acordo com os mesmos, os diferentes tipos de manejo e adição de resíduos agrícolas tem o potencial de alterar significativamente características do solo e da própria cultura em questão, especialmente se tais práticas são adotadas por um longo período de tempo.

Em seu trabalho analisando os impactos de diferentes manejos de solo e adição de resíduos agrícolas em experimento de longo prazo, Dam et al., (2005), observaram que a densidade do solo foi afetada pelas práticas de manejo aplicadas, entretanto não houve qualquer influência dos resíduos adicionados durante os 11 anos de experimento. Porém, 
Blevins et al., (1994) verificaram que não houveram diferenças nos resultados de densidade do solo obtidos para amostras de áreas submetidas a manejo convencional e sem manejo.

Contudo, no presente estudo não foram observadas diferenças significativas nos valores de densidade de solo, considerando todo o perfil analisado, entre as parcelas dos sistemas analisados. Tal comportamento pode ser indicativo de homogeneidade de solo ao longo do campo experimental ou ainda ilustra possível menor influência inerente à adição de material orgânico (esterco aviário) ao solo, no tange à densidade de solo.

Segundo Abu-Hamdeh (2003) a determinação da densidade do solo é um importante indicador do grau de compactação do solo. O aumento da compactação do solo compromete as relações solo-ar e solo-água, afetando a atividade microbiológica, a absorção de nutrientes e a retenção de água.

Alguns estudos mostraram que a mistura de materiais orgânicos com as frações minerais mais densas do solo leva a diminuição da densidade do solo em si. Segundo Tejada et al., 2008, o aumento no conteúdo de matéria orgânica resulta em um aumento da porosidade e, consequente, diminuição de densidade.

Em pesquisa conduzida por Celik et al., (2010) foi verificado que o acúmulo de matéria orgânica na camada 0 a $15 \mathrm{~cm}$ levou à diminuição nos valores de densidade em comparação à camada subsequente $(15 \mathrm{a} 30 \mathrm{~cm})$ e às respectivas áreas de controle.

Além da prática de adição de materiais orgânicos, no que concerne a seu impacto junto à densidade do solo, algumas práticas de manejo de solo tem se mostrado eficientes na diminuição da densidade em camadas superficiais.

Contudo, de acordo com Franzluebbers et al., (1995) o efeito de práticas de manejo do solo junto à sua densidade é temporário, uma vez que o solo recobra sua densidade original após certo tempo da realização da atividade de manejo. Ainda, no que tange aos reflexos de diferentes sistemas de manejo, diversos estudos foram conduzidos no intuito de comparar e avaliar os efeitos de sistemas de plantio direto e convencional, tendo apresentado comportamentos diferentes.

Algumas pesquisas reportaram aumento de densidade de solo, na camada superficial 0-5 cm, em sistemas de plantio direto comparados com sistemas convencionais (Unger e Jones (1998) e Wander e Bollero (1999)), ao passo que em outras não foi observada diferença de comportamento entre os sistemas analisados (Ferreras et al., (2000) e Logsdon e Cambardella (2000)), e, ainda, uma terceira vertente reportou decréscimo na densidade em sistemas de plantio direto, principalmente quando foi observado aumento de conteúdo de matéria orgânica na camada superficial (Crovetto et al., (1998)). 
Segundo Lampurlanés e Cantero-Martinez (2003) a levando-se em consideração o aumento da densidade logo após a prática de manejo, verifica-se, com o tempo, uma diminuição da diferença de impacto inerente às diferentes atividades de manejo frente à densidade do solo.

Assim, de acordo com Grant e Lafond (1993) o manejo não afeta consistentemente a resistência à penetração e a densidade do solo da mesma forma como a textura do solo, agregação, conteúdo de matéria orgânica e condições de umidade podem influenciar a sensibilidade do solo à compactação. Ainda, segundo os mesmos, a sequência de culturas, ou rotação, podem também influenciar na característica do solo e sua densidade.

\subsubsection{Análise Elementar}

As figuras a seguir (19 e 20) e tabelas (7 e 8) ilustram o comportamento dos teores de $\mathrm{C}$ e $\mathrm{N}$ das frações livre e oclusa, respectivamente, para as amostras dos diferentes sistemas analisados em todo o perfil estudado.

\subsubsection{Matéria Orgânica Particulada Livre (MOPI)}

\subsection{Teor de $\mathrm{C}$ e $\mathrm{N}$}

Fig. 19 - Gráfico de valores de teores de $\mathrm{C}$ e $\mathrm{N}$ para amostras de matéria organica livre particulada (MOPI) para os diferentes sistemas analisados, onde PC - plantio convencional com manejo mínimo, ORG2 - agricultura orgânica de 2 anos, ORG3 - agricultura orgânica de 3 anos, ORG6 - agricultura orgânica de 6 anos e PD plantio direto sem manejo

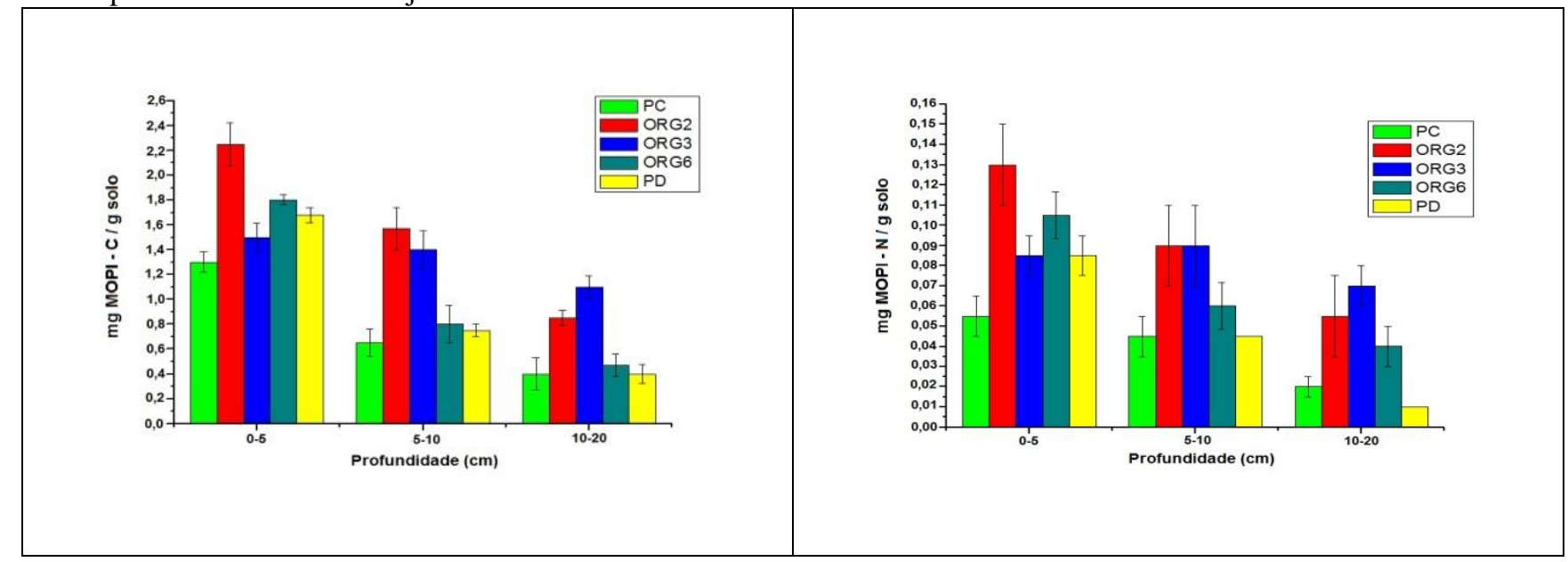

Tabela 7 - Valores de teores de C e N para amostras de matéria organica livre particulada (MOPI) para os diferentes sistemas analisados, onde PC - plantio convencional com manejo mínimo, ORG2 - agricultura orgânica de 2 anos, ORG3 - agricultura orgânica de 3 anos, ORG6 - agricultura orgânica de 6 anos e PD plantio direto sem manejo

\begin{tabular}{|c|c|c|c|c|c|}
\hline Profundidade (cm) & PC & ORG2 & ORG3 & ORG6 & PD \\
\hline $0-5$ & $1,37 \pm 0,08$ & $2,25 \pm 0,17$ & $1,59 \pm 0,11$ & $1,85 \pm 0,04$ & $1,68 \pm 0,06$ \\
\hline $5-10$ & $0,65 \pm 0,11$ & $1,57 \pm 0,17$ & $1,45 \pm 0,15$ & $0,83 \pm 0,15$ & $0,75 \pm 0,05$ \\
\hline $10-20$ & $0,42 \pm 0,13$ & $0,85 \pm 0,06$ & $1,13 \pm 0,09$ & $0,47 \pm 0,09$ & $0,46 \pm 0,08$ \\
\hline
\end{tabular}


De acordo com Puget e Drinkwater (2001) em estudos a respeito da dinâmica da MOS tem-se dado maior atenção à fração de matéria orgânica particulada (MOP). Segundo os mesmos, tal fração, composta principalmente por resíduos de plantas em diferentes estágios de decomposição, sendo muito sensível às entradas e saídas de $\mathrm{C}$ ao longo do tempo.

O uso do fracionamento físico nos estudos de tempo de decomposição de MOS tem recebido maior ênfase nas últimas décadas. Esse maior enfoque advém do fato de que, cada vez mais, tem se percebido que tal processo de decomposição é devido a processos biológicos, intrinsecamente relacionados com a estrutura do solo, e que a disponibilidade de substratos para os organismos decompositores depende não somente de sua natureza química do substrato, como também com a natureza de sua associação com os minerais do solo (Christensen (2001)).

Ainda, segundo Christensen (2001) a matéria orgânica particulada ocorre em duas classes: livre e oclusa. Conforme o mesmo, a fração livre abrange partículas orgânicas soltas no solo e ainda partículas de MOP ligadas ao exterior de complexos organominerais secundários. Tal fração também é conhecida por matéria orgânica interagregados; ao passo que a fração oclusa abrange partículas de MOP presas e fisicamente protegidas no interior destes complexos secundários (sendo assim também conhecida por intra-agregados).

Devido à sua natureza lábil, a decomposição da MOP é fortemente influenciada pela sua localização em meio à estrutura do solo (Gregorich (1997)). Assim, a fração oclusa é menos decomponível em comparação à fração livre (Christensen (2001)).

Pela análise dos resultados obtidos, pôde-se notar maiores valores (cerca de 80\%) de conteúdo de MOPl - C para os sistemas orgânicos (sobretudo nos sistemas com rotação de cultura de 2 e 3 anos), o que pode representar uma maior disponibilidade de material exógeno, e consequente adesão à parte exterior dos agregados organominerais do solo, proporcionada pela adição do material orgânico nos respectivos sistemas orgânicos, em comparação aos demais analisados.

Segundo Zotarelli et al., (2007) os reservatórios desprotegidos da MOS, tais como a MOPl, são altamente influenciados pela quantidade e qualidade de aporte resíduos de culturas e material orgânico, como também pelas práticas de manejo do solo, tais como plantio direto, convencional e agricultura orgânica.

No que diz respeito ao teor de $\mathrm{N}$, à profundidade de $0-5 \mathrm{~cm}$ os valores foram maiores para os sistemas de agricultura orgânica de 2 e 6 anos (ORG2 e ORG6, com aumento de 30 e $23 \%$, respectivamente) e menores para o sistema de plantio convencional com manejo mínimo 
(PC). Entretanto, na parcela seguinte $(5-10 \mathrm{~cm})$ os maiores valores são observados para os sistemas ORG2 e ORG3, em detrimento aos demais analisados.

Tal comportamento pode refletir maiores incrementos de $\mathrm{N}$ orgânico nos sistemas orgânicos em comparação aos sistemas de manejo mínimo e sem manejo, além de ratificar a maior aplicação de esterco aviário nos tratamentos de agricultura orgânica de 2 e 3 anos, em comparação ao de 6 anos.

Segundo Willson et al., (2001) tanto MOP-C e -N, quando combinados com informações a respeito de resíduos de culturas recentemente adicionados, podem ser considerados bons índices para estimativa do potencial de mineralização de $\mathrm{N}$ em sistemas utilizando manejos convencionais ou orgânicos (com adição de esterco ou resíduos de culturas).

\subsubsection{Matéria Orgânica Particulada Oclusa (MOPo)}

\subsection{Teor de $\mathrm{C}$ e $\mathrm{N}$}

Fig. 20 - Gráfico de valores de teores de $\mathrm{C}$ e $\mathrm{N}$ para amostras de matéria organica particulada oclusa (MOPo) para os diferentes sistemas analisados, onde PC - plantio convencional com manejo mínimo, ORG2 - agricultura orgânica de 2 anos, ORG3 - agricultura orgânica de 3 anos, ORG6 - agricultura orgânica de 6 anos e PD plantio direto sem manejo

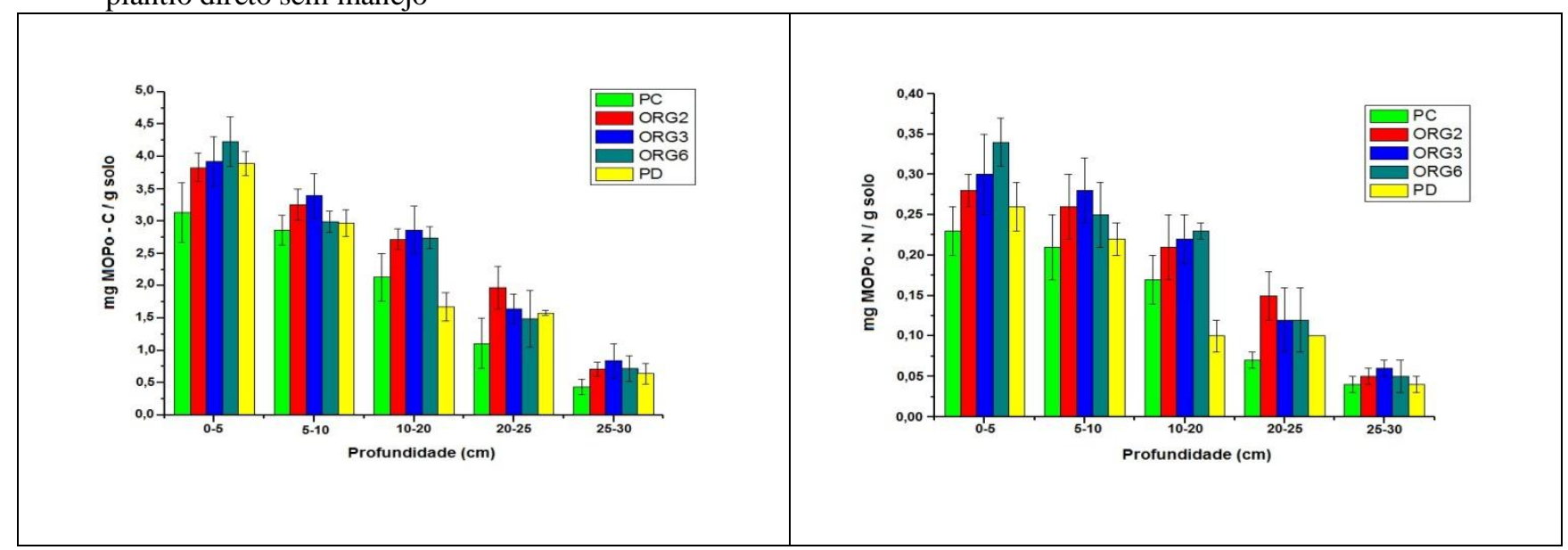

Tabela 8 - Valores de teores de $\mathrm{C}$ e $\mathrm{N}$ para amostras de matéria organica particulada oclusa (MOPo) para os diferentes sistemas analisados, onde PC - plantio convencional com manejo mínimo, ORG2 - agricultura orgânica de 2 anos, ORG3 - agricultura orgânica de 3 anos, ORG6 - agricultura orgânica de 6 anos e PD plantio direto sem manejo

\begin{tabular}{|c|c|c|c|c|c|}
\hline Profundidade (cm) & PC & ORG2 & ORG3 & ORG6 & PD \\
\hline $0-5$ & $3,13 \pm 0,46$ & $3,83 \pm 0,22$ & $3,92 \pm 0,38$ & $4,23 \pm 0,38$ & $3,89 \pm 0,18$ \\
\hline $5-10$ & $2,86 \pm 0,23$ & $3,25 \pm 0,24$ & $3,39 \pm 0,35$ & $2,99 \pm 0,16$ & $2,97 \pm 0,21$ \\
\hline $10-20$ & $2,13 \pm 0,37$ & $2,72 \pm 0,16$ & $2,86 \pm 0,37$ & $2,74 \pm 0,17$ & $1,68 \pm 0,22$ \\
\hline $20-25$ & $1,11 \pm 0,39$ & $1,97 \pm 0,33$ & $1,64 \pm 0,23$ & $1,49 \pm 0,44$ & $1,58 \pm 0,04$ \\
\hline $25-30$ & $0,44 \pm 0,12$ & $0,71 \pm 0,11$ & $0,84 \pm 0,27$ & $0,72 \pm 0,20$ & $0,64 \pm 0,16$ \\
\hline
\end{tabular}


Os padrões de teor de C e N para amostras de MOPo se apresentaram muito similares, com diferenças notadas, particularmente, na camada $10-20 \mathrm{~cm}$. Nesta profundidade os teores foram menores para o sistema PD, comparando-se com os demais analisados, o que ilustra o impacto da incorporação de resíduos nos sistemas de produção orgânica em um experimento de longa duração, durante 16 anos.

Porém, em seu estudo analisando a influência de diferentes sistemas de manejo junto a diferentes frações da MOP, Wander e Yang (2000) verificaram que as concentrações de C na fração oclusa foram consistentemente maiores nas parcelas superficiais dos sistemas PD em comparação aos demais sistemas.

Percebe-se um maior conteúdo de MOPo-C e -N para os sistemas orgânicos, quando em comparação com os demais convencionais (com manejo mínimo e sem manejo). Outrossim, nota-se também que não há diferença significativa entre tais valores, dentre os três sistemas orgânicos. Tal comportamento pode ser indicativo de uma maior oclusão de MOP em intra-agregados do solo, propiciada pela adição do material orgânico (no caso, o esterco aviário).

Em seu estudo analisando o comportamento de MOS total e lábil em sistemas orgânicos e convencionais, Marriott e Wander (2006) também verificaram que os teores de MOP-C e -N foram maiores nos sistemas orgânicos em detrimentos aos demais analisados, e que ainda o acréscimo de materiais orgânicos aumentou em cerca de 30 a $40 \%$ tais frações de MOP.

Em complemento, os mesmos ainda verificaram que não houve diferença entre os dois tipos de sistemas orgânicos analisados. Ainda, de acordo com Nissen e Wander (2003) o conteúdo de MOP-C no solo apresenta boa correlação com a quantidade de $\mathrm{N}$ absorvida do solo pelas culturas, e também com a quantidade de fertilizantes nitrogenados retida no solo.

Segundo Six et al., (2000) mesmo em situações de campo onde o aporte de C é o mesmo em dada sequência de rotação de culturas em sistemas de plantio direto e convencional, observa-se uma maior estabilização de $\mathrm{C}$ no primeiro sistema, em parte devido à maior agregação, a qual promove a proteção física do $\mathrm{C}$ do solo.

O menor distúrbio do solo, característico de prática de plantio direto, leva à interação com argila, diminuindo a decomposição de $\mathrm{C}$, promovendo a formação de agregados do solo. Em suma, sob regime de plantio direto, a quantidade de macroagregados estáveis é geralmente maior, a sua taxa de decomposição é, aproximadamente, a metade da observada em áreas sob plantio convencional, resultando em maiores tempos de permanência e acumulação de C no solo nas camadas superficiais. 
No que concerne ao reflexo da adição de material orgânico (esterco animal) junto às frações da MOP, Hai et al., (2010) verificaram aumentos de 29 e 55\% nos teores de C orgânico e N, respectivamente, para a fração oclusa, e 26 e 33\% nos mesmos teores, respectivamente, para a fração livre, em comparação às áreas de controle.

Assim sendo, pela análise das diferentes situações de campo consideradas, pôde-se perceber o impacto inerente às práticas de agricultura orgânica com plantio direto, em detrimento às demais, verificando maiores teores de $\mathrm{C}$ e $\mathrm{N}$ em suas frações livre e oclusa de MOP, o que possivelmente representa maior disponibilidade de material orgânico fresco exógeno, constituindo a fração livre, e, ao mesmo tempo, uma maior oclusão e proteção intraagregado de material orgânico, provavelmente ocasionada pela atividade microbiana do solo.

\subsubsection{Razão $\mathbf{C} / \mathbf{N}$}

De acordo com Lou, et al., (2012) a razão C/N constitui um importante indicador de fertilidade do solo por estabelecer relação entre o conteúdo de carbono orgânico do solo e nitrogênio total.

A figura 21 a seguir ilustra o comportamento dos valores obtidos para $\mathrm{C} / \mathrm{N}$ de amostras de MOPl (esquerda) e MOPo (direita) para os sistemas analisados.

Fig. 21 - Gráfico de valores de razão C/N para amostras de matéria orgânica particulada livre (MOPl), à direita, e oclusa (MOPo), à esquerda, para os diferentes sistemas analisados, onde $\mathrm{PC}$ - plantio convencional com manejo mínimo, ORG2 - agricultura orgânica de 2 anos, ORG3 - agricultura orgânica de 3 anos, ORG6 agricultura orgânica de 6 anos e PD - plantio direto sem manejo
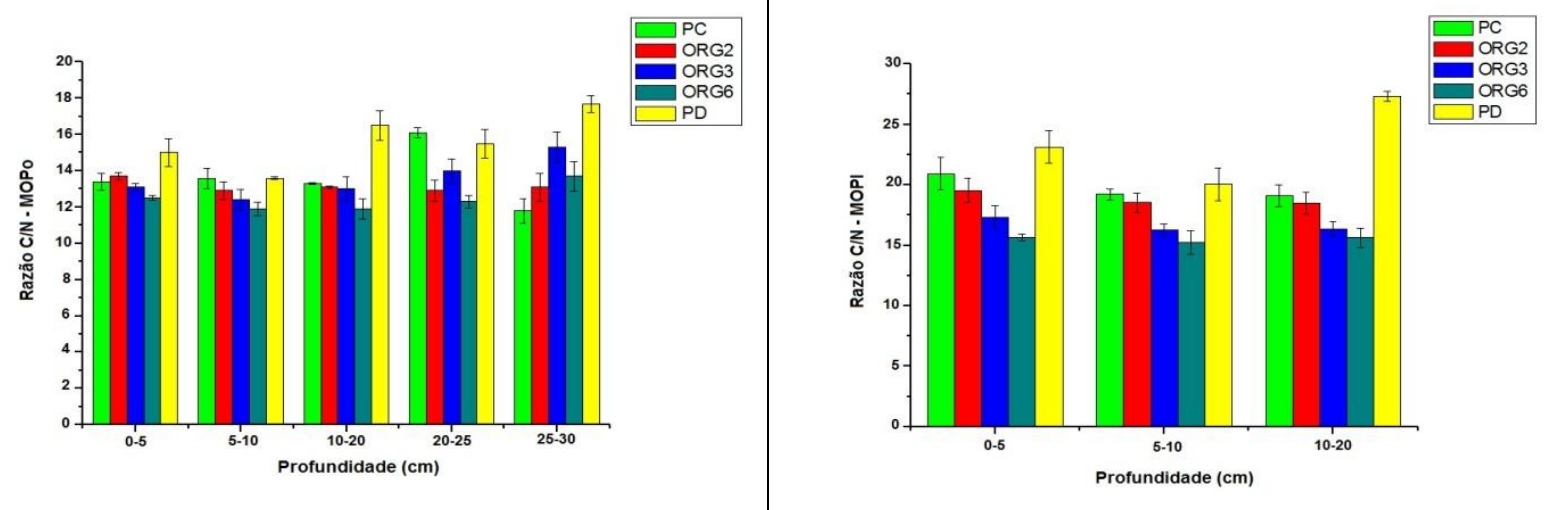

A razão $\mathrm{C} / \mathrm{N}$ para as amostras de $\mathrm{MOPl}$ referentes ao sistema ORG6 foi menor em todo perfil analisado, possivelmente refletindo maior aporte de $\mathrm{N}$ para este sistema em detrimento aos demais. O padrão dos valores obtidos para o sistema PD foi nitidamente distinto em relação aos demais, representando possível aumento na recalcitrância de MOPl de acordo com a profundidade e ainda menor incorporação de $\mathrm{N}$. 
De acordo com Blanco-Canqui e Lal (2008) sistemas de manejo do tipo plantio direto apresentam melhor resposta no que diz respeito à conservação de solo e água, porém seu potencial de sequestro de carbono em situações diversas, bem como seu impacto junto ao teor de carbono orgânico do solo, ainda necessitam ser estudados em maiores detalhes. Sendo assim, segundo os mesmos, o comportamento de sistema de manejo em situações variáveis em campo pode diferir em comparação às condições originais de pesquisa.

No que concerne aos valores da razão $\mathrm{C} / \mathrm{N}$ para $\mathrm{MOPo}$, não observadas mudanças significativas constantes entre os valores e os sistemas analisados. Corroborando, Wander e Marriott (2006) em seu estudo, analisando diferentes sistemas de manejo, também verificaram tal comportamento de ausência de variação significativa entre os valores de razão C/N para as frações de MOP.

Segundo Yan et al., (2012) o uso agrícola do solo geralmente ocasiona redução nos valores da razão $\mathrm{C} / \mathrm{N}$. Conforme os mesmos, a intensificação de atividades de manejo de solo em sistemas agrícolas provoca aumento na taxa de decomposição de materiais orgânicos adicionados e de MOS, acarretando na diminuição da razão C/N. Grande parte do C é emitida pelo processo de respiração, ao passo que parte do $\mathrm{N}$ mineralizado é perdida por lixiviação ou por emissões gasosas, ou ainda, em caso de permanência no solo, é reincorporado aos reservatórios de MOS.

Embora os valores obtidos para tal razão geralmente não apresentem grande variação entre si, a razão $\mathrm{C} / \mathrm{N}$ é influenciada por diversos fatores tais como: condições climáticas (Miller et al., (2004)), condições de solo (Diekow et al., (2005)), espécies de culturas (Puget e Lal (2005)), além das já mencionadas práticas de manejo de solo (Dalal et al., (2011) e Liang et al., (2011)).

Contudo, por se tratar de um índice intrinsecamente ligado à dinâmica de $\mathrm{N}$ no solo, a razão $\mathrm{C} / \mathrm{N}$ deve ser utilizada juntamente com demais dados, para a obtenção de informações mais concretas, haja visto que pode refletir tanto reflexos de manejo do solo quanto incorporação de N.

\subsubsection{Espectroscopia de Absorção na Região do Infravermelho}

As figuras 22 a 26 a seguir ilustram os espectros de infravermelho obtidos para as amostras de MOPI (esquerda) e MOPo (direita) para os sistemas analisados 
Fig. 22 - Espectros de infravermelho para amostras de matéria orgânica particulada livre (MOPI), à esquerda, e oclusa (MOPo), à direita, para o sistema PD - plantio direto sem manejo, sendo (a) 0-5, (b) 5-10, (c) 10-20, (d) 20-25 e (e) $25-30 \mathrm{~cm}$. Nos espectros estão representados os picos mais relevantes.

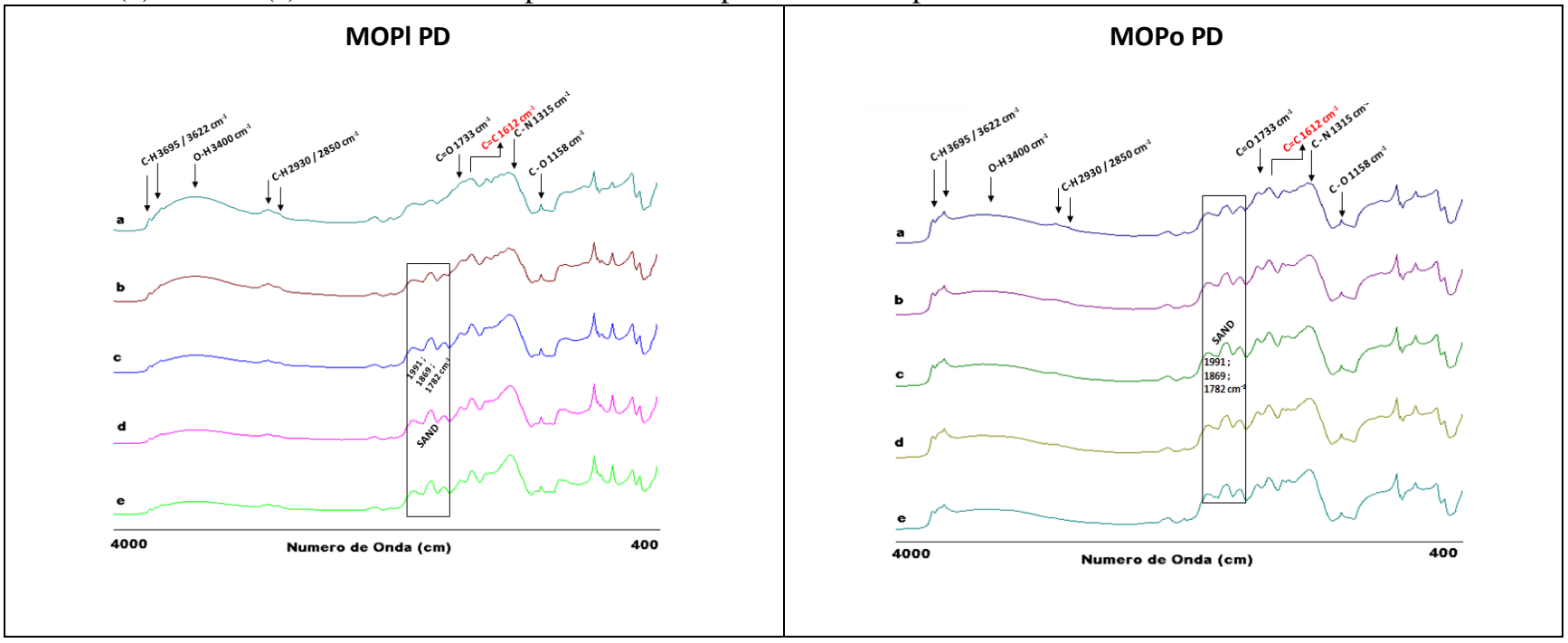

Fig. 23 - Espectros de infravermelho para amostras de matéria orgânica particulada livre (MOPI), à esquerda, e oclusa (MOPo), à direita, para o sistema PC - plantio convencional com manejo mínimo, sendo (a) 0-5,

(b) 5-10, (c) 10-20, (d) 20-25 e (e) 25-30 cm. Nos espectros estão representados os picos mais relevantes.

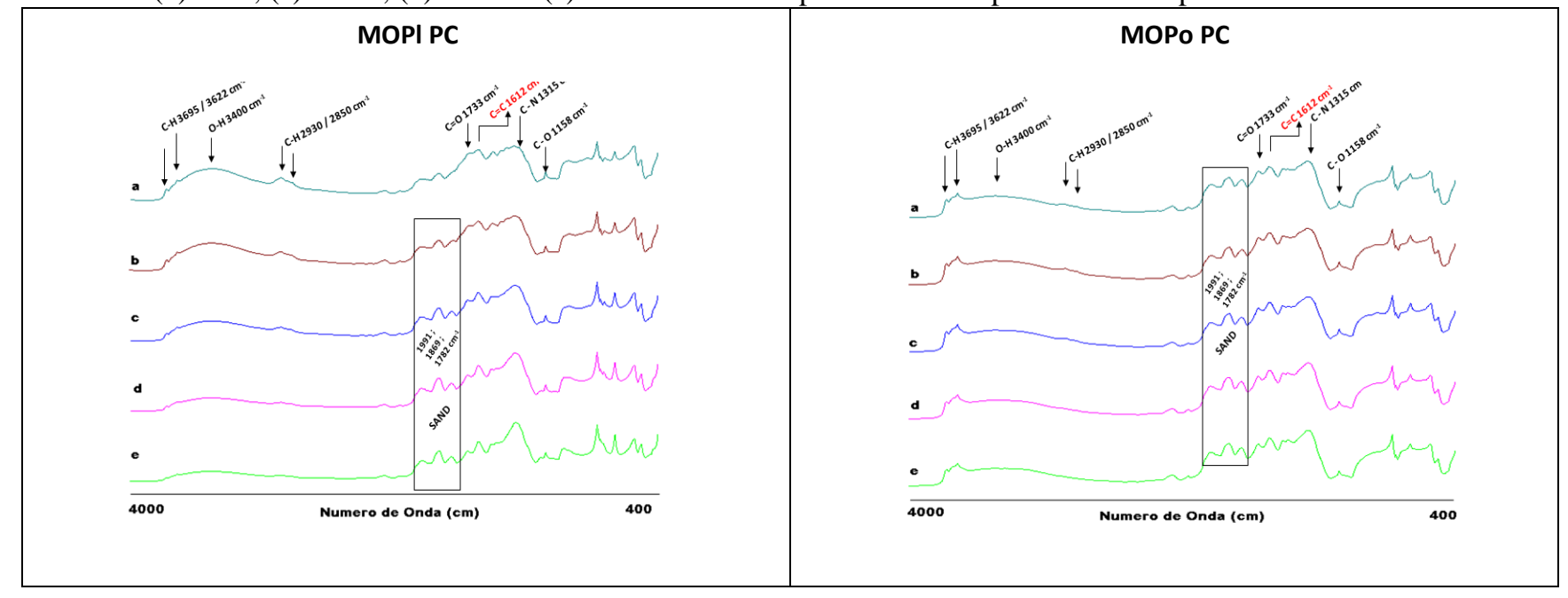


Fig. 24- Espectros de infravermelho para amostras de matéria orgânica particulada livre (MOPl), à esquerda, e oclusa (MOPo), à direita, para o sistema ORG2 - Agricultura Orgânica de 2 anos, sendo (a) 0-5, (b) 5-10, (c) 10-20, (d) 20-25 e (e) 25-30 cm. Nos espectros estão representados os picos mais relevantes.

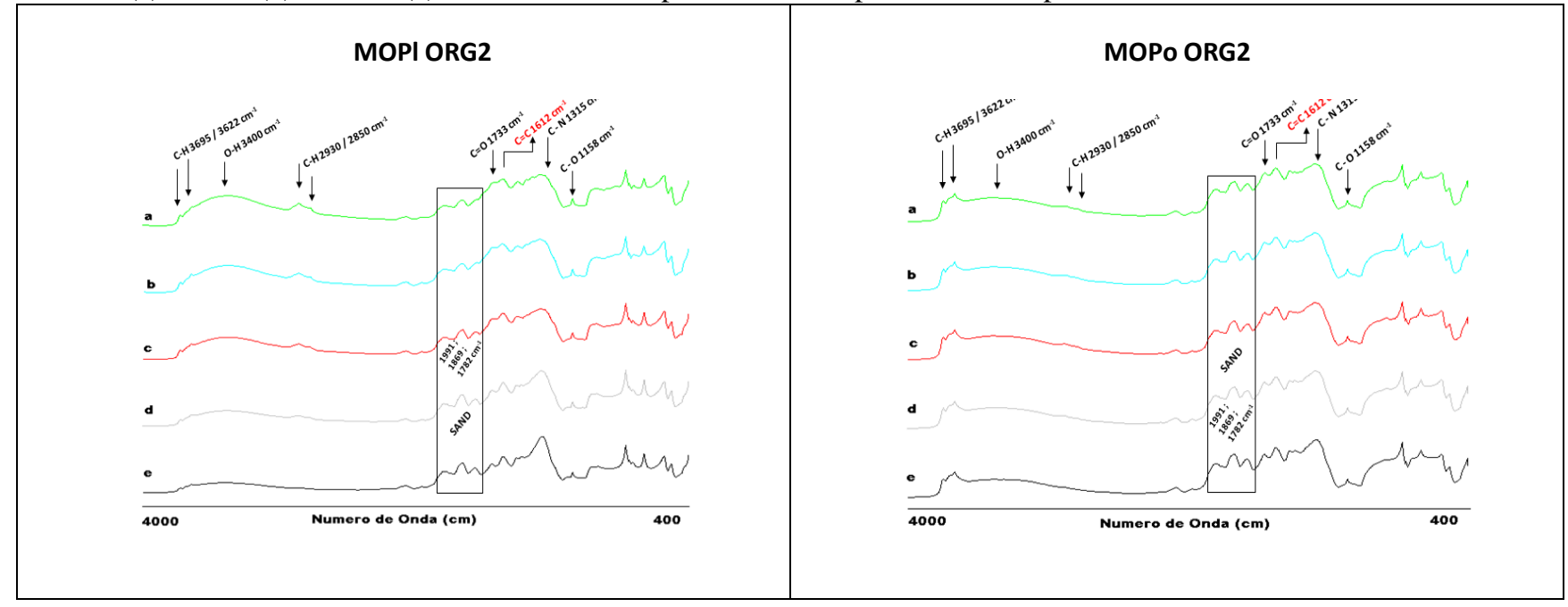

Fig. 25 - Espectros de infravermelho para amostras de matéria orgânica particulada livre (MOPl), à esquerda, e oclusa (MOPo), à direita, para o sistema ORG3 - Agricultura Orgânica de 3 anos, sendo (a) 0-5, (b) 5-10, (c) 10-20, (d) 20-25 e (e) 25-30 cm. Nos espectros estão representados os picos mais relevantes.

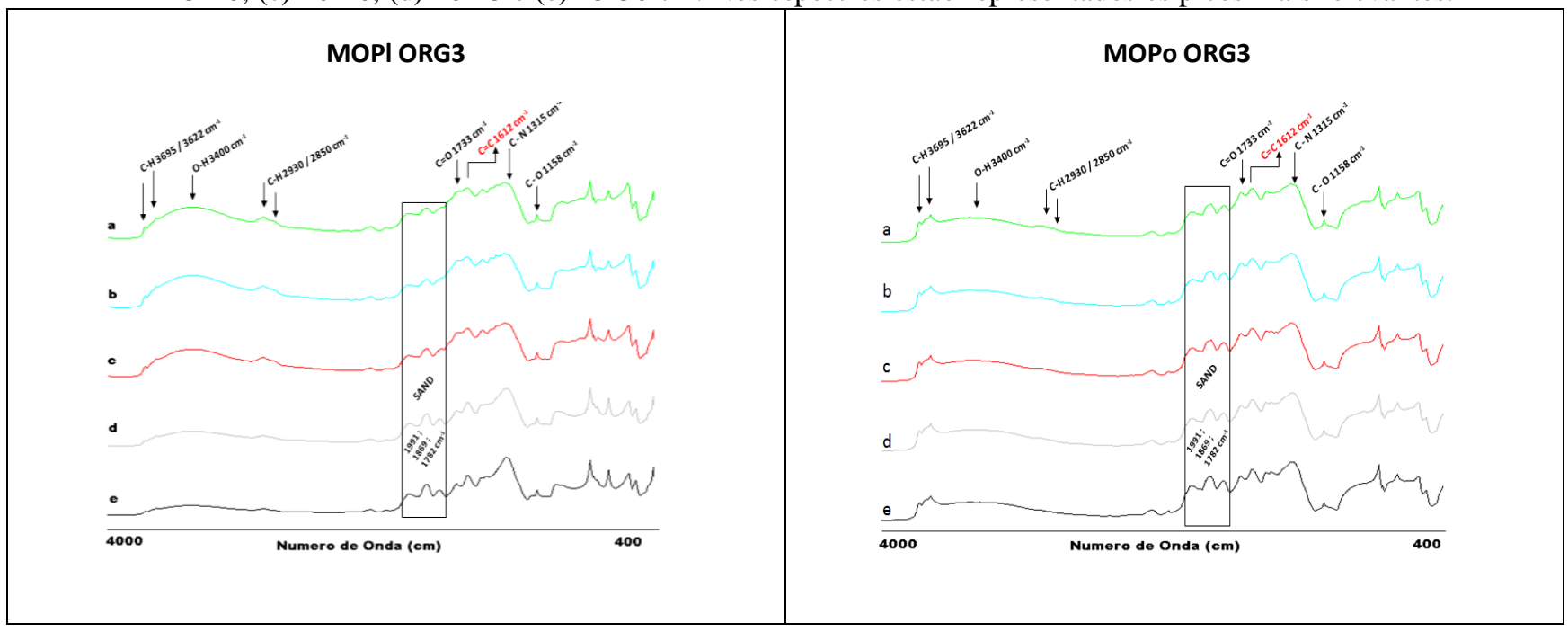


Fig. 26 - Espectros de infravermelho para amostras de matéria orgânica particulada livre (MOPl), à esquerda, e oclusa (MOPo), à direita, para o sistema ORG6 - Agricultura Orgânica de 6 anos, sendo (a) 0-5, (b) 5-10, (c) 10-20, (d) 20-25 e (e) 25-30 cm. Nos espectros estão representados os picos mais relevantes.

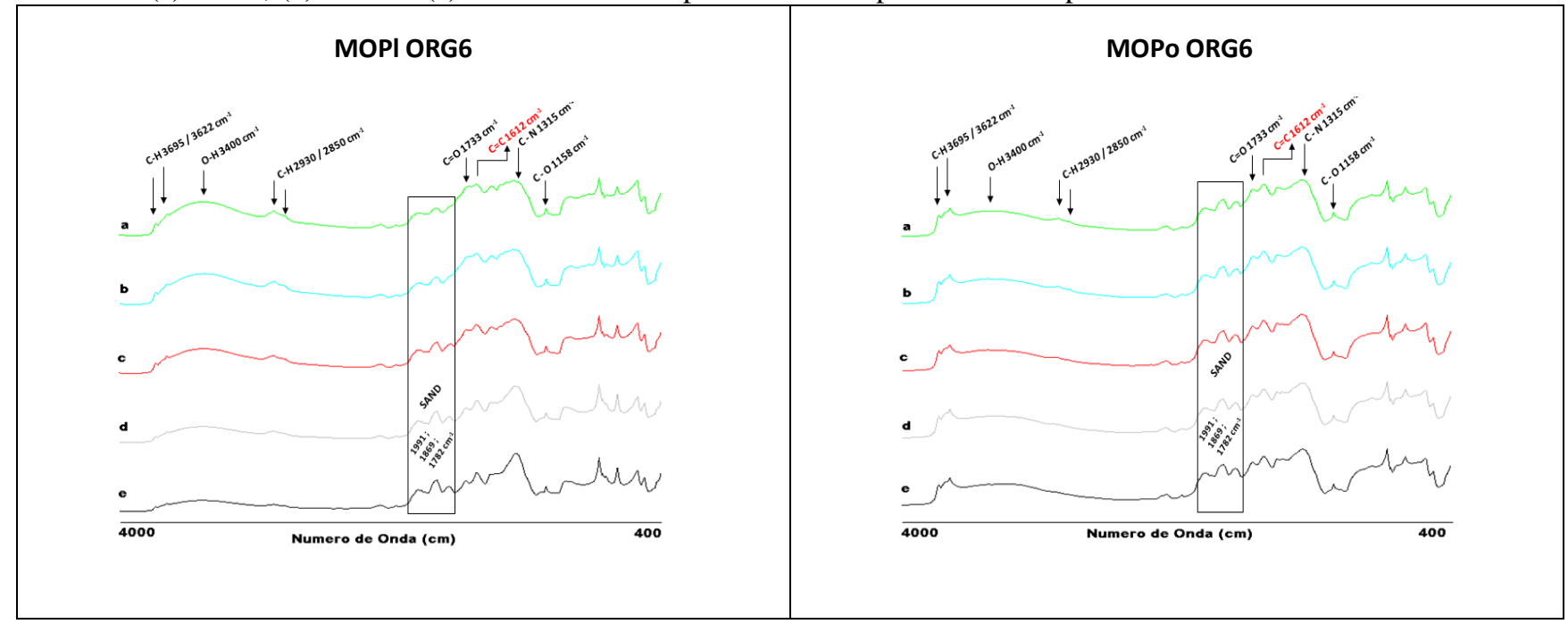

Em seu estudo analisando as diferentes frações da MOS submetidas a tipos de manejo de variado, Freixo et al., (2002) observaram que na região espectral entre 3.700 e $3.000 \mathrm{~cm}^{-1}$, correspondente as vibrações de estiramento de grupamentos $\mathrm{O}-\mathrm{H}$ e $\mathrm{N}-\mathrm{H}$, os espectros da fração leve-livre apresentaram bandas de absorção mais nítidas, quando comparadas a fração leve intra-agregado.

Tal comportamento também pode ser observado nos espectros obtidos para as amostras em análise, onde observa-se uma breve diferença de intensidade na banda de absorção em $3.400 \mathrm{~cm}^{-1}$ entre as amostras de MOPl e MOPo para todos os sistemas analisados.

Ainda, Freixo, et al., 2002, notaram que os grupamentos alifáticos $\left(-\mathrm{CH}_{3}\right.$ e $\left.-\mathrm{CH}_{2}\right)$ apresentaram variações pronunciadas de acordo com o tipo de preparo do solo, sendo as bandas de absorção referentes às amostras correspondentes às frações leve-livre e intraagregado do solo sob sistema de plantio direto mais definidas, em comparação às respectivas frações quando submetidas a plantio convencional.

Tal perfil também pôde ser notado nas amostras de MOPl das áreas dos sistemas orgânicos, em detrimento aos demais avaliados no presente estudo. Contudo, as mesmas bandas não tiveram a mesma definição nas respectivas amostras de MOPo.

Em determinadas regiões do espectro (especificamente entre 1612 e $1315 \mathrm{~cm}^{-1}$ ) de amostras de MOPl, identifica-se tênue superposição de bandas, ratificando maior número de grupos funcionais nesta parcela em detrimento à MOPo.

Segundo Vergnoux et al., (2011) na região entre 1.800 e $1.500 \mathrm{~cm}^{-1}$ são esperadas vibrações de estiramento de grupamentos do tipo $\mathrm{C}=\mathrm{O}$ de carbonilas em ligações do tipo $\mathrm{C}=\mathrm{C}$ 
de aromáticos. Em seu estudo analisando substâncias húmicas extraídas de solo, os mesmos verificaram a existência de duas bandas intensas, sendo a primeira aproximadamente em $1.700 \mathrm{~cm}^{-1}$ e a segunda em $1.620-1.640 \mathrm{~cm}^{-1}$.

De acordo com Richard et al., (2007) esta primeira banda pode ser atribuída à vibração de estiramento de grupos $\mathrm{C}=\mathrm{O}$ de ácidos carboxílicos.

No entanto, conforme Vergnoux et al., (2011) a atribuição de grupos funcionais para a segunda banda observada e mais complexa, uma vez que, nesta mesma região, existe probabilidade de incidência de bandas relativas a ligações $\mathrm{C}=\mathrm{C}$ de aromáticos, grupamentos de carbonilas conjugadas (quinona), grupos de sais carboxílicos ( $\mathrm{COO}-$ ) e grupamentos $\mathrm{C}=\mathrm{O}$ de amidas do tipo I.

Tal superposição de bandas também é ressaltado por Calderon et al., (2011) e brevemente observado nas amostras de MOPl, em comparação a MOPo, analisadas no presente estudo, conforme ilustrado pelos espectros apresentados.

A seguir, tabela identificando e atribuindo possíveis ligações e grupamentos observados para as principais bandas observadas para amostras de MOP extraídas do solo dos diferentes tipos de sistemas estudados.

Tabela 9 - Identificação dos picos e bandas destacados nos espectros de infravermelho obtidos para as amostras analisadas

\begin{tabular}{|c|c|c|}
\hline Número de Onda $\left(\mathbf{c m}^{-1}\right)$ & Atribuição & Referência \\
\hline $3695 / 3622$ & Estiramento C - H característico de argila & Smidt et al., (2009) \\
\hline 3400 & Estiramento O - H típico de resíduos de \\
culturas & Calderon et al., (2011) \\
\hline $2930 / 2850$ & Estiramento C - H de grupos metileno & Tandy et al., (2010) \\
\hline $1991 / 1869 / 1782$ & Possível sílica / areia & Calderon et al., (2011) \\
\hline 1733 & Agrupamento C = O de acido carboxílico & Stenberg et al., (2010) \\
\hline 1612 & Overlapping de picos com predominância de \\
& C = C aromático & Calderon et al., (2011) \\
\hline 1315 & Agrupamento C - N de aminas & Tandy et al., (2010) \\
\hline 1158 & Agrupamento C - O de polissacarídeos & (2010) \\
\hline
\end{tabular}

Ainda, segundo Vergnoux et al., (2011) bandas observadas na região entre 1.200 e $1.150 \mathrm{~cm}^{-1}$ são atribuídas a vibrações de estiramento de fenóis, enquanto as observadas entre 1.130 e $1.000 \mathrm{~cm}^{-1}$ são características de estiramento de C-O de éteres e alcoóis, além de carboidratos. 
Corroborando, Freixo et al., (2002) a região entre 1.300 e $1.000 \mathrm{~cm}^{-1}$ seria a mais peculiar para compostos orgânicos, podendo ser utilizada para comparações do processo de humificação da MOS.

A literatura (Freixo et al., (2002)) propõe a elaboração de dois índices, baseados na razão de intensidade de determinadas bandas, para melhor extração de resultados a respeito das alterações da MOS, decorrentes do seu processo de humificação inerente aos sistemas de manejo aplicados. Em seu trabalho, os autores consideraram a razão entre os valores de intensidade de absorbância em 2.929 e $1.050 \mathrm{~cm}^{-1}$ como índice de hidrofobicidade (IH), por relacionar grupos polares e apolares, e a razão entre 1.660 e $2.929 \mathrm{~cm}^{-1}$ como índice de condensação (IC), já que relaciona a proporção de grupos conjugados e alifáticos.

Para o presente trabalho, foram consideradas as intensidades de banda em $2.930 \mathrm{e}$ $1.158 \mathrm{~cm}^{-1}$ para IH e 1.612 e $2.930 \mathrm{~cm}^{-1}$ para IC. A seguir, tabelas ilustrando os valores obtidos para as amostras das frações de MOP obtidas, para os sistemas analisados.

Tabela 10 - Índices de condensação (IC) e hidrofobicidade (IH) para amostras de MOPl e MOPo em sistemas PD plantio direto sem manejo

\begin{tabular}{|c|c|c|c|c|c|c|c|c|c|c|}
\hline Fração & \multicolumn{5}{|c|}{ MOPI } & \multicolumn{5}{|c|}{ MOPo } \\
\hline Profundidade $(\mathrm{cm})$ & $0-5$ & $5-10$ & $10-20$ & $20-25$ & $25-30$ & $0-5$ & $5-10$ & 10-20 & $20-25$ & $25-30$ \\
\hline IC $(1.612 / 2.930)$ & 2,31 & 2,00 & 8,33 & 2,30 & 6,33 & 1,07 & 2,29 & 1,91 & 1,70 & 3,14 \\
\hline IH $(2.930 / 1.158)$ & 1,85 & 2,00 & 1,00 & 0,81 & 0,60 & 1,64 & 2,12 & 1,14 & 1,43 & 0,86 \\
\hline
\end{tabular}

Tabela 11 - Índices de condensação (IC) e hidrofobicidade (IH) para amostras de MOPl e MOPo em sistemas PC plantio convencional com manejo mínimo

\begin{tabular}{|c|c|c|c|c|c|c|c|c|c|c|}
\hline Fração & \multicolumn{5}{|c|}{ MOPI } & \multicolumn{5}{|c|}{ MOPo } \\
\hline Profundidade $(\mathbf{c m})$ & $0-5$ & $5-10$ & $10-20$ & $20-25$ & $25-30$ & $0-5$ & $5-10$ & $10-20$ & $20-25$ & $25-30$ \\
\hline IC (1.612/2.930) & 1,00 & 1,40 & 1,59 & 2,86 & 9,71 & 2,04 & 2,73 & 1,07 & 7,50 & 12,30 \\
\hline IH (2.930/1.158) & 2,16 & 1,88 & 1,61 & 1,08 & 0,33 & 1,09 & 1,38 & 2,14 & 0,67 & 0,53 \\
\hline
\end{tabular}

Tabela 12- Índices de condensação (IC) e hidrofobicidade (IH) para amostras de MOP1 e MOPo em sistemas ORG2 agricultura orgânica de 2 anos

\begin{tabular}{|c|c|c|c|c|c|c|c|c|c|c|}
\hline Fração & \multicolumn{5}{|c|}{ MOPI } & \multicolumn{5}{|c|}{ MOPo } \\
\hline Profundidade $(\mathrm{cm})$ & $0-5$ & $5-10$ & $10-20$ & $20-25$ & $25-30$ & $0-5$ & $5-10$ & $10-20$ & $20-25$ & $25-30$ \\
\hline IC $(1.612 / 2.930)$ & 1,57 & 2,26 & 2,67 & 4,44 & 11,57 & 3,63 & 3,15 & 1,67 & 5,86 & 10,18 \\
\hline IH $(2.930 / 1.158)$ & 2,30 & 1,90 & 1,50 & 0,82 & 0,40 & 1,60 & 1,60 & 1,03 & 1,00 & 0,55 \\
\hline
\end{tabular}

Tabela 13 - Índices de condensação (IC) e hidrofobicidade (IH) para amostras de MOPl e MOPo em sistemas ORG3 agricultura orgânica de 3 anos

\begin{tabular}{|c|c|c|c|c|c|c|c|c|c|c|}
\hline Fração & \multicolumn{5}{|c|}{ MOPI } & \multicolumn{5}{|c|}{ MOPo } \\
\hline Profundidade $(\mathrm{cm})$ & $0-5$ & $5-10$ & $10-20$ & $20-25$ & $25-30$ & $0-5$ & $5-10$ & $10-20$ & $20-25$ & $25-30$ \\
\hline IC (1.612/2.930) & 2,30 & 2,60 & 1,65 & 5,13 & 8,11 & 3,36 & 5,38 & 6,14 & 5,67 & 10,82 \\
\hline IH (2.930/1.158) & 2,22 & 2,00 & 1,24 & 0,80 & 0,47 & 1,57 & 1,14 & 1,00 & 0,86 & 0,58 \\
\hline
\end{tabular}


Tabela 14 - Índices de condensação (IC) e hidrofobicidade (IH) para amostras de MOPI e MOPo em sistemas ORG6 agricultura orgânica de 6 anos

\begin{tabular}{|c|c|c|c|c|c|c|c|c|c|c|}
\hline Fração & \multicolumn{9}{|c|}{ MOPI } & \multicolumn{5}{|c|}{ MOPo } \\
\hline Profundidade (cm) & $\mathbf{0 - 5}$ & $\mathbf{5 - 1 0}$ & $\mathbf{1 0 - 2 0}$ & $\mathbf{2 0 - 2 5}$ & $\mathbf{2 5 - 3 0}$ & $\mathbf{0 - 5}$ & $\mathbf{5 - 1 0}$ & $\mathbf{1 0 - 2 0}$ & $\mathbf{2 0 - 2 5}$ & $\mathbf{2 5 - 3 0}$ \\
\hline IC (1.612/2.930) & 2,13 & 2,47 & 3,19 & 3,60 & 7,70 & 3,54 & 4,30 & 7,14 & 6,17 & 8,33 \\
\hline IH (2.930/1.158) & 2,30 & 2,11 & 1,78 & 0,91 & 0,50 & 1,22 & 1,11 & 1,00 & 0,75 & 0,67 \\
\hline
\end{tabular}

Através das análises dos dados obtidos, pôde-se observar que os sistemas orgânicos apresentam maiores valores de índice de condensação (IC), principalmente para amostras referentes à fração oclusa, em comparação aos demais estudados, havendo um aumento no valor de acordo com o perfil de profundidade considerado. Assim sendo, percebe-se que as amostras relativas aos sistemas orgânicos possuem provável maior grau de humificação, não havendo diferenças significativas tais sistemas.

De acordo com Freixo et al., (2002) tal índice estabelece uma relação indireta com grau de condensação/humificação da amostra em análise. Ainda, segundo os mesmos, valores de índice de hidrofobicidade $(\mathrm{IH})$, são diretamente proporcionais à resistência da amostra à degradação microbiana.

Ao contrário do observado aos valores de IC, os valores de IH diminuem com aumento da profundidade, retratando assim uma possível vulnerabilidade à atividade microbiana em camadas mais profundas do solo. O comportamento sugere a possível incidência em profundidade de estruturas sujeitas à degradação microbiana, ainda que exista ocorrência de estruturas mais condensadas, de maior recalcitrância. Cabe ressaltar que o perfil de decréscimo de tal índice foi observado para amostras de todos os sistemas analisados, não havendo diferença significativa entre os valores obtidos. Contudo, em se tratando de amostras provenientes de campo experimental, é recomendável a utilização de outras técnicas espectroscópicas, complementando os resultados obtidos para este índice.

\subsubsection{Pirólise Acoplada a Cromatografia a Gás/Espectrometria de Massas (PY - GC/MS)}

Por se tratar de uma técnica de alta sensibilidade, foi possível a identificação de uma série de picos para os sistemas analisados. A tabela 15 lista os picos identificados para as amostras de ambas as frações de matéria orgânica em análise, enquanto as figuras 27 a 36 representam cromatogramas e tabelas reduzidas para os sistemas analisados, em determinada profundidade, listando os picos identificados. 
Tabela 15 - Picos identificados para ambas frações de MOS.

\begin{tabular}{|c|c|c|c|}
\hline PICOS & CLASSIFICAÇAO & PICOS & CLASSIFICAÇAO \\
\hline 1-hidroxi, 2-butanona & Cetona & 1,2,4-trimetilbenzeno & Aromático \\
\hline 1-penten-3-ona & Cetona & 1,3,5-trimetilbenzeno & Aromático \\
\hline 1,2-benzenodiol & Aromático & 1,4-dimetoxi, -2-metilbenzeno & $\begin{array}{l}\text { Aromático } \\
\text { Carboxílico }\end{array}$ \\
\hline 1,2-benzenodiol, 3-metoxi- & Aromático & 1,4-dimetoxi, -2-metilbenzeno & $\begin{array}{l}\text { Aromático } \\
\text { Carboxílico }\end{array}$ \\
\hline 1,2-benzenodiol, 4-metil- & Aromático & Benzeno & Aromático \\
\hline 1,2-ciclopentanediona, 3-metil- & Cetona & 4-etenil, 1,2-dimetoxibenzeno & $\begin{array}{l}\text { Aromático } \\
\text { Carboxílico }\end{array}$ \\
\hline 1,2,3-trimetoxibenzeno & Aromático & Hexametilbenzeno & Aromático \\
\hline 1,2,4-trimetoxibenzeno & Aromático & 2,3-dihidrobenzofurano & Furano Aromático \\
\hline 1,3-benzenodiol, 2-metil- & Aromático & 7-metilbenzofurano & Furano Aromático \\
\hline 1,3-benzenodiol, 4-etil- & Aromático & Ácido Benzóico & $\begin{array}{l}\text { Aromático } \\
\text { Carboxílico }\end{array}$ \\
\hline 1,3-ciclohexadieno & Alceno Cíclico & Ácido 4-formil-benzóico & $\begin{array}{l}\text { Aromático } \\
\text { Carboxílico }\end{array}$ \\
\hline 1,3-ciclopentadieno & Alceno Cíclico & Ácido 4-hidroxi-3-metoxi-benzóico & $\begin{array}{l}\text { Aromático } \\
\text { Carboxílico }\end{array}$ \\
\hline 1,3-ciclopentanediona, 2-metil- & Carboxílico Cíclico & $\begin{array}{l}\text { Ácido benzoico, 4-hidroxi, 3- } \\
\text { metoxi-metilester }\end{array}$ & $\begin{array}{l}\text { Aromático } \\
\text { Carboxílico }\end{array}$ \\
\hline 1,4-benzenodiol, 2-metoxi- & Aromático Cíclico & Dióxido de Carbono & \\
\hline 1,4-benzenodiol, 2-metil- & Aromático Cíclico & Ciclopentanol & $\begin{array}{l}\text { Lipídeo do } \\
\text { Solo/Cíclico } \\
\end{array}$ \\
\hline 1,6-anidro-.beta.-D-glucFuranose & Carboidrato & Desaspidinol & $\begin{array}{l}\text { Aromático } \\
\text { Carboxílico }\end{array}$ \\
\hline $\begin{array}{l}\text { 1,6-anidro-.beta.-D- } \\
\text { glucopirano(levoglucosan) }\end{array}$ & Carboidrato & Dimetileter & Alifático \\
\hline 1H-inden1-ona, 2,3-dihidro- & Aromático Cíclico & 1-(2furanil)-etanona & Furano \\
\hline 1Hindeno, 3-metil- & Aromático & 1-(3-hidroxi-4-metoxifenil)-etanona & $\begin{array}{l}\text { Aromático } \\
\text { Carboxílico }\end{array}$ \\
\hline 1-propeno, 2-metil- & Alifático & 1-(3-metoxifenil)-etanona & $\begin{array}{l}\text { Aromático } \\
\text { Carboxílico }\end{array}$ \\
\hline 2-butanona & Cetona & 1-(3,4-dimetoxifenil)-etanona & $\begin{array}{l}\text { Aromático } \\
\text { Carboxílico }\end{array}$ \\
\hline 2-butenal & Carboxílico & $\begin{array}{l}\text { 1-(4-hydroxy-3,5- } \\
\text { dimethoxyphenyl)-etanona }\end{array}$ & $\begin{array}{l}\text { Aromático } \\
\text { Carboxílico }\end{array}$ \\
\hline 2-butenal, 2-metil- & Carboxílico & Eugenol & Aromático \\
\hline $\begin{array}{l}\text { 2-ciclopenten1-ona, 2-hidroxi-, 3- } \\
\text { metil- }\end{array}$ & Carboxílico Cíclico & Furano & Furano \\
\hline 2-ciclopenten1-ona, 2-metil- & Carboxílico Cíclico & 2-etil-5-metilfurano & Furano \\
\hline 2-ciclopenten1-ona, 2,3-dimetil- & Carboxílico Cíclico & 2-metilfurano & Furano \\
\hline 2-ciclopenten1-ona, 3-metil- & Carboxílico Cíclico & 2-propilfurano & Furano \\
\hline 2-ciclopenteno, 1,4-diona & Carboxílico Cíclico & 2,4-dimetilfurano & Furano \\
\hline 2-metoxi-, 4-vinilfenol & Lignina/Fenol & 2,5-dihidrofurano & Furano \\
\hline 2-metoxi-, 5-metilfenol & Lignina/Fenol & 2,5-dimetilfurano & Furano \\
\hline 2-metoxi-, 6-metilfenol & Lignina/Fenol & 3-metilfurano & Furano \\
\hline 2-metoxiresorcinol & Aromático Carb. & Furfural & Furano \\
\hline $\begin{array}{l}\text { 2-propanona, 1-(4-hidroxi-3- } \\
\text { metoxifenil)- }\end{array}$ & $\begin{array}{l}\text { Aromático } \\
\text { Carboxílico }\end{array}$ & Hidroquinona & Aromático \\
\hline 2-propanona, 1-(acetiloxi)- & Carboxílico & Indeno & Aromático \\
\hline 2-propanona, 1-hidroxi- & Carboxílico & Ismaltol & Furano \\
\hline 2-propenal & Carboxílico & Álcool isopropílico & Alifático \\
\hline $\begin{array}{l}\text { Ácido 2- propenóico, 3-(4-hidroxi- } \\
\text { 3-metoxifenil)-metilester }\end{array}$ & Carboxílico & Ceteno & Carboxílico \\
\hline
\end{tabular}




\begin{tabular}{|c|c|c|c|}
\hline 2,3-butanediona & Carboxílico & Limoneno & Cíclico \\
\hline 2,3-dimetilanisol & Aromático & Maltol & $\begin{array}{l}\text { Aromático } \\
\text { Carboxílico }\end{array}$ \\
\hline 2,3-pentanodiona & Carboxílico & Mequinol & Aromático \\
\hline 2,5-dimetoxi, -4-etilbenzaldeído & Aldeído & Clorometano & Alifático \\
\hline 2,5-dimetilanisol & Aromático & o-xileno & Aromático \\
\hline 2',4'-dihidroxipropiofenona & $\begin{array}{l}\text { Aromático } \\
\text { Carboxílico }\end{array}$ & p-xileno & Aromático \\
\hline 2(3H)furanona, 5-etildihidro- & Furano & Fenol & Aromático \\
\hline 2(3H)furanona, 5-metil- & Furano & 2-etilfenol & Aromático \\
\hline 2(3H)furanona, dihidro-3-metileno- & Furano & 2-etil-4-metilfenol & Aromático \\
\hline $2(5 \mathrm{H})$ furanona & Furano & 2-etil-5-metilfenol & Aromático \\
\hline 2(5H)furanona, 5-metil- & Furano & 2-etil-6-metilfenol & Aromático \\
\hline $\begin{array}{l}\text { 2furanocarboxaldeído, 5- } \\
\text { (hidroximetil)- }\end{array}$ & Furano & 2-metoxifenol & $\begin{array}{l}\text { Aromático } \\
\text { Carboxílico }\end{array}$ \\
\hline 2furanocarboxaldeído, 5-metil- & Furano & 2-metoxi-3-(2-propenil)-fenol & $\begin{array}{l}\text { Aromático } \\
\text { Carboxílico }\end{array}$ \\
\hline Ácido 2-furanocarboxílico & Carboidrato & 2-metoxi-3-metilfenol & $\begin{array}{l}\text { Aromático } \\
\text { Carboxílico }\end{array}$ \\
\hline 2-furanometanol & Furano & 2-metoxi-4-1-propenil)-fenol & $\begin{array}{l}\text { Aromático } \\
\text { Carboxílico }\end{array}$ \\
\hline 3-Furaldeído & Furano & 2-metoxi-4-1-propenil)-(E)-fenol & $\begin{array}{l}\text { Aromático } \\
\text { Carboxílico }\end{array}$ \\
\hline $\begin{array}{l}\text { Ácido 3-hidroxi-4-metoxi- } \\
\text { mandélico }\end{array}$ & $\begin{array}{l}\text { Aromático } \\
\text { Carboxílico }\end{array}$ & 2-metoxi-4-1-propenil)-(Z)-fenol & $\begin{array}{l}\text { Aromático } \\
\text { Carboxílico }\end{array}$ \\
\hline 3-metoxi, -5-metilfenol & $\begin{array}{l}\text { Aromático } \\
\text { Carboxílico }\end{array}$ & 2-metoxi-4-metilfenol & $\begin{array}{l}\text { Aromático } \\
\text { Carboxílico }\end{array}$ \\
\hline 3,4-dimetoxitolueno & $\begin{array}{l}\text { Aromático } \\
\text { Carboxílico }\end{array}$ & 2-metoxi-(6-1-propenil)-fenol & $\begin{array}{l}\text { Aromático } \\
\text { Carboxílico }\end{array}$ \\
\hline 3,4-dimetoxi, -5-hidroxi benzaldeído & Aldeído & 2-metil-fenol & Aromático \\
\hline 3,4-dimetilanisol & Aromático & 2,3-dimetil-fenol & Aromático \\
\hline $\begin{array}{l}\text { 3,5-dimetoxi-4-hidroxi } \\
\text { cinamaldeído }\end{array}$ & $\begin{array}{l}\text { Aromático } \\
\text { Carboxílico }\end{array}$ & 2,4-dimetil-fenol & Aromático \\
\hline 3',5'-dimetoxiacetofenona & $\begin{array}{l}\text { Aromático } \\
\text { Carboxílico }\end{array}$ & 2,5-dimetil-fenol & Aromático \\
\hline 3-furanmetanol & Furano & 2,6-dimetoxi-fenol & $\begin{array}{l}\text { Aromático } \\
\text { Carboxílico }\end{array}$ \\
\hline 4-acetoxi-3-metoxi acetofenona & $\begin{array}{l}\text { Aromático } \\
\text { Carboxílico }\end{array}$ & 2,6-dimetoxi-4-(2-propenil)-fenol & $\begin{array}{l}\text { Aromático } \\
\text { Carboxílico }\end{array}$ \\
\hline 4-hidroxi-2-metoxi benzaldeído & $\begin{array}{l}\text { Aromático } \\
\text { Carboxílico }\end{array}$ & 2,6-dimetil-fenol & Aromático \\
\hline 4-metoxi-benzeno, 1,2-diol & Aromático & 3-etil-fenol & Aromático \\
\hline $\begin{array}{l}\text { 4H-piran-4-ona, 3,5-dihidroxi-2- } \\
\text { metil- }\end{array}$ & $\begin{array}{l}\text { Aromático } \\
\text { Carboxílico }\end{array}$ & 3-metil-fenol & Aromático \\
\hline 5-tert-butilpirogalol & Aromático & 3,4-dimetoxi-fenol & $\begin{array}{l}\text { Aromático } \\
\text { Carboxílico }\end{array}$ \\
\hline $\begin{array}{l}\text { 7-Hidroxi-6-metoxyi-2H1- } \\
\text { benzopiran-2-ona }\end{array}$ & $\begin{array}{l}\text { Aromático } \\
\text { Carboxílico }\end{array}$ & 3,4-dimetil-fenol & Aromático \\
\hline Acetaldeído & Carboxílico & 3,5-dimetil-fenol & Aromático \\
\hline Hidroxi-acetaldeído & Aldeído & 4-etil-fenol & Aromático \\
\hline Ácido Acético & Carboxílico & 4-etil-2-metoxi-fenol & $\begin{array}{l}\text { Aromático } \\
\text { Carboxílico }\end{array}$ \\
\hline Acetiacidmethyester & Carboxílico & 4-etil-2-metil-fenol & Aromático \\
\hline 4'-hidroxi-acetofenona & $\begin{array}{l}\text { Aromático } \\
\text { Carboxílico }\end{array}$ & 4-metoxi-3-metil-fenol & $\begin{array}{l}\text { Aromático } \\
\text { Carboxílico }\end{array}$ \\
\hline 2-metil-benzofurano & Furano & 4-metil-fenol & Aromático \\
\hline Benzaldeído & $\begin{array}{l}\text { Aromático } \\
\text { Carboxílico }\end{array}$ & Ácido propanoico 2-oxo-metilester & Carboxílico \\
\hline
\end{tabular}




\begin{tabular}{|c|c|c|c|}
\hline 3-hidroxi-benzaldeído & $\begin{array}{l}\text { Aromático } \\
\text { Carboxílico }\end{array}$ & Propeno & Alceno Alifático \\
\hline 4-hidroxi-3,5-dimetoxi-benzaldeído & $\begin{array}{l}\text { Aromático } \\
\text { Carboxílico }\end{array}$ & Resorcinol & Aromático \\
\hline 4-metil-benzaldeído & $\begin{array}{l}\text { Aromático } \\
\text { Carboxílico }\end{array}$ & Estireno & Aromático \\
\hline 1,2-dimetoxi-benzeno & $\begin{array}{l}\text { Aromático } \\
\text { Carboxílico }\end{array}$ & Tolueno & Aromático \\
\hline 1,2-dimetoxi-4-1-propenil), benzeno & $\begin{array}{l}\text { Aromático } \\
\text { Carboxílico }\end{array}$ & Triacontano & Alifático \\
\hline 1,2,3-trimetoxi-5-metil-benzeno & $\begin{array}{l}\text { Aromático } \\
\text { Carboxílico }\end{array}$ & Vanilina & $\begin{array}{l}\text { Aromático } \\
\text { Carboxílico }\end{array}$ \\
\hline $\begin{array}{l}\text { 1,2,4-trimetoxi-5-1-propenil)-(Z)- } \\
\text { benzeno }\end{array}$ & $\begin{array}{l}\text { Aromático } \\
\text { Carboxílico }\end{array}$ & Vinilfurano & Furano \\
\hline
\end{tabular}

Fig. 27 - Cromatograma para amostras de matéria orgânica particulada livre (MOPl), na profundidade 5-10 cm, para o sistema PD - plantio direto sem manejo. Ao lado estão identificados os picos e seus respectivos tempos de retenção (RT).

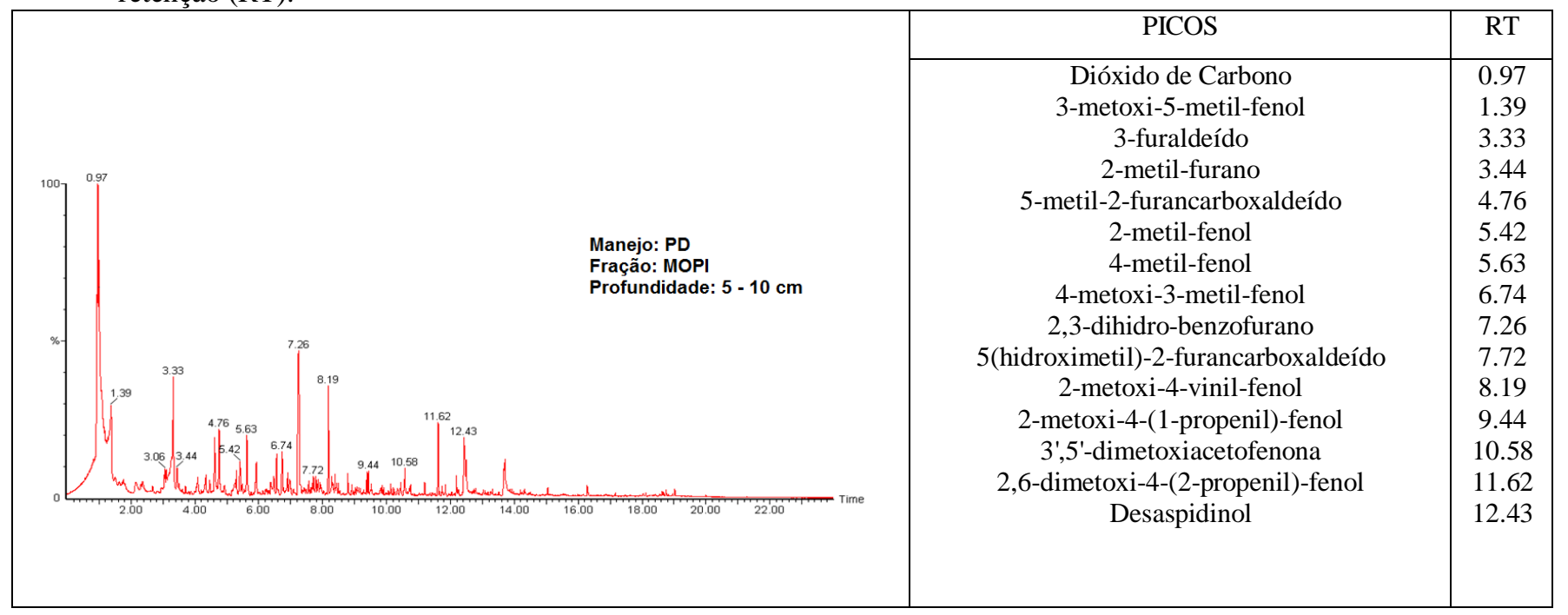

Fig. 28 - Cromatograma para amostras de matéria orgânica particulada livre (MOPl), na profundidade 5-10 cm, para o sistema PC - plantio convencional com manejo mínimo. Ao lado estão identificados os picos e seus respectivos tempos de retenção (RT).

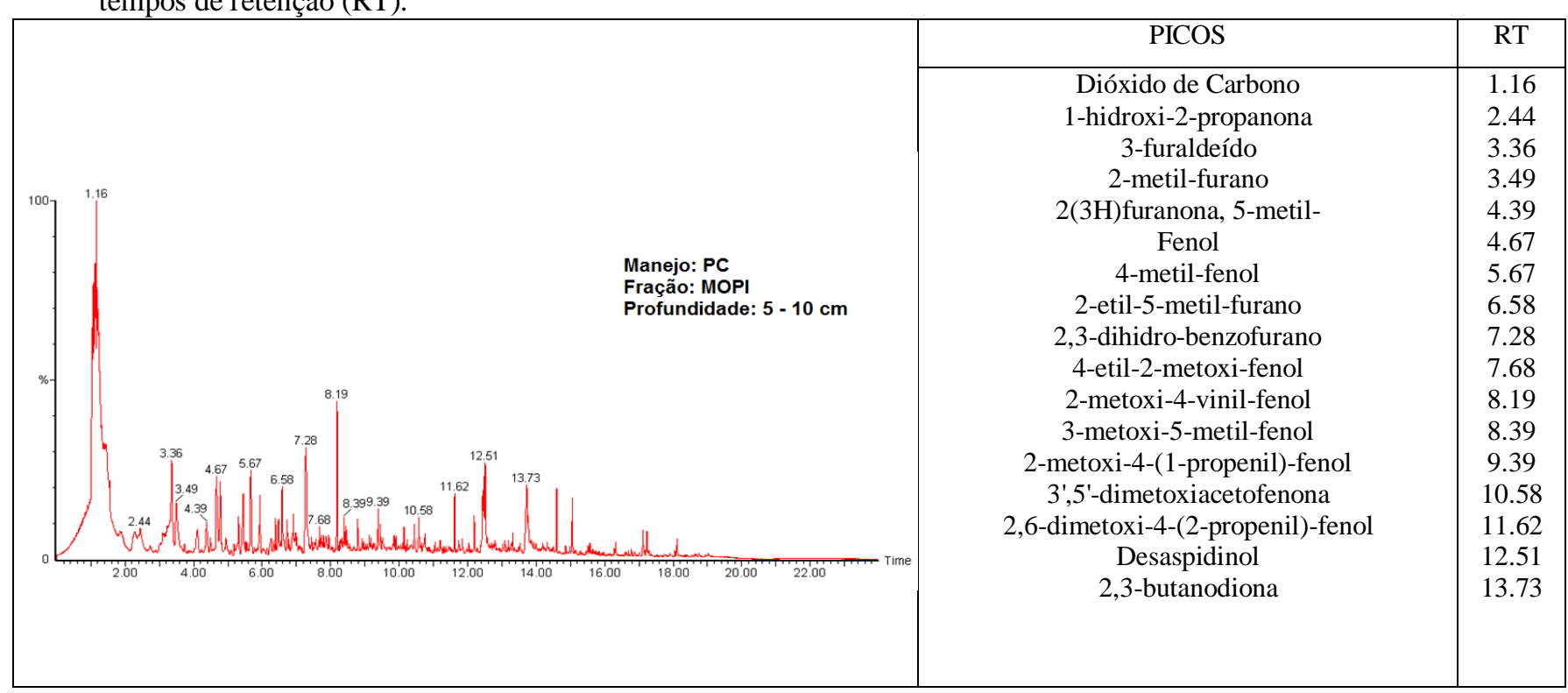


Fig. 29 - Cromatograma para amostras de matéria orgânica particulada livre (MOPl), na profundidade 5-10 cm, para o sistema ORG2 - agricultura orgânica de 2 anos. Ao lado estão identificados os picos e seus respectivos tempos de retenção (RT).

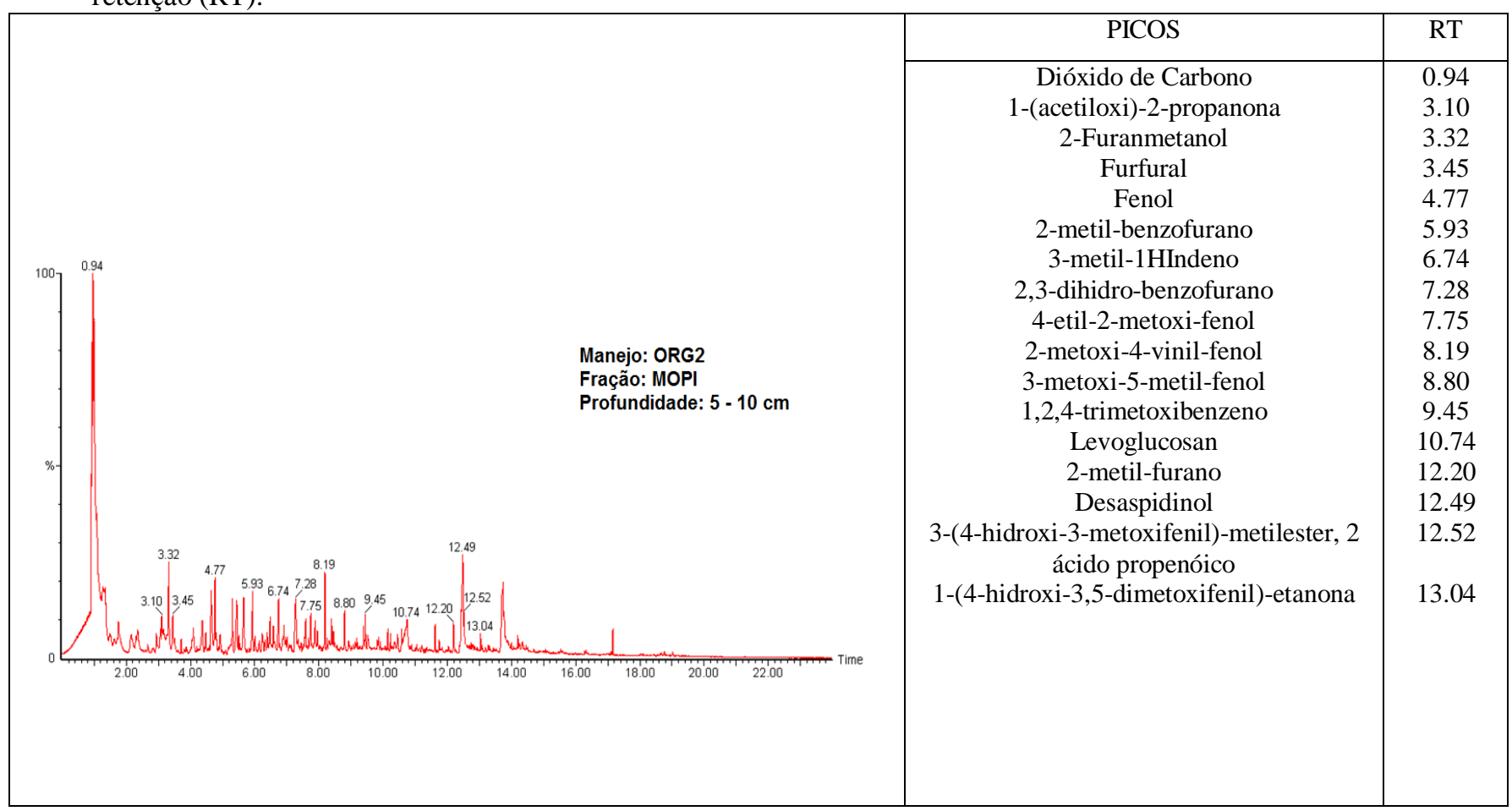

Fig. 30 - Cromatograma para amostras de matéria orgânica particulada livre (MOPl), na profundidade 5-10 $\mathrm{cm}$, para o sistema ORG3 - agricultura orgânica de 3 anos. Ao lado estão identificados os picos e seus respectivos tempos de retenção (RT).

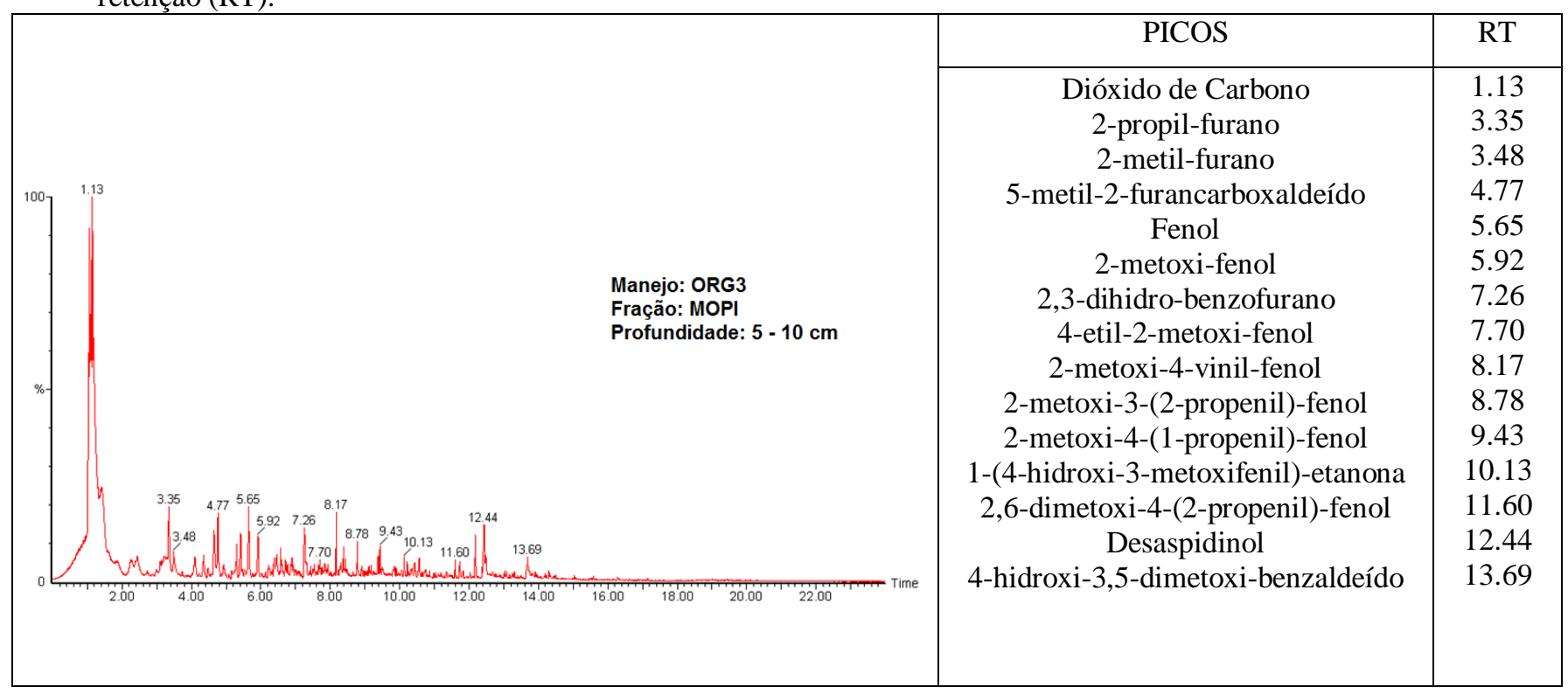


Fig. 31 - Cromatograma para amostras de matéria orgânica particulada livre (MOPl), na profundidade 5-10 cm, para o sistema ORG6 - agricultura orgânica de 6 anos. Ao lado estão identificados os picos e seus respectivos tempos de retenção (RT).

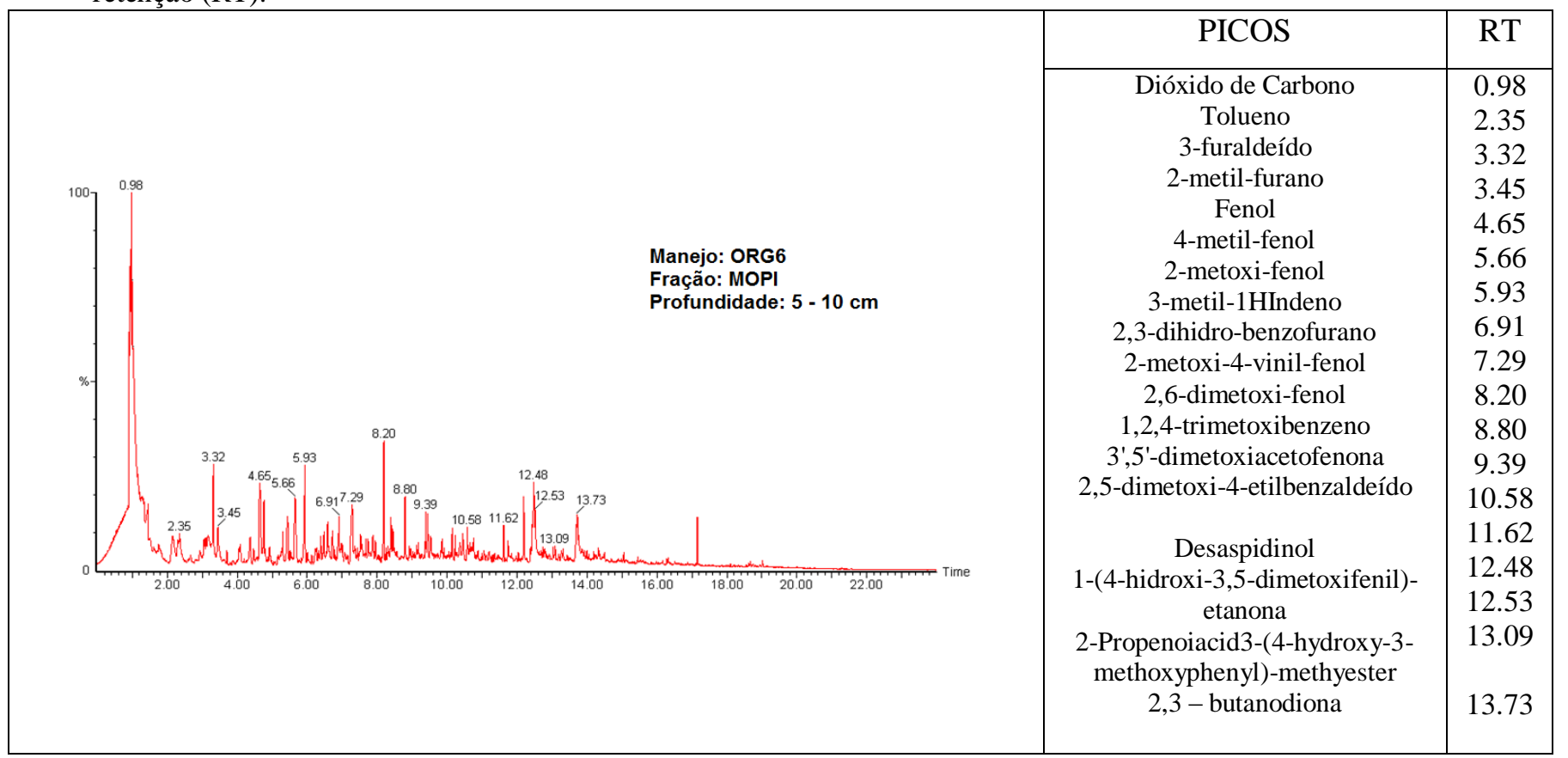

Fig. 32 - Cromatograma para amostras de matéria orgânica particulada oclusa (MOPo), na profundidade 5-10 cm, para o sistema PD - plantio direto sem manejo. Ao lado estão identificados os picos e seus respectivos tempos de retenção (RT).

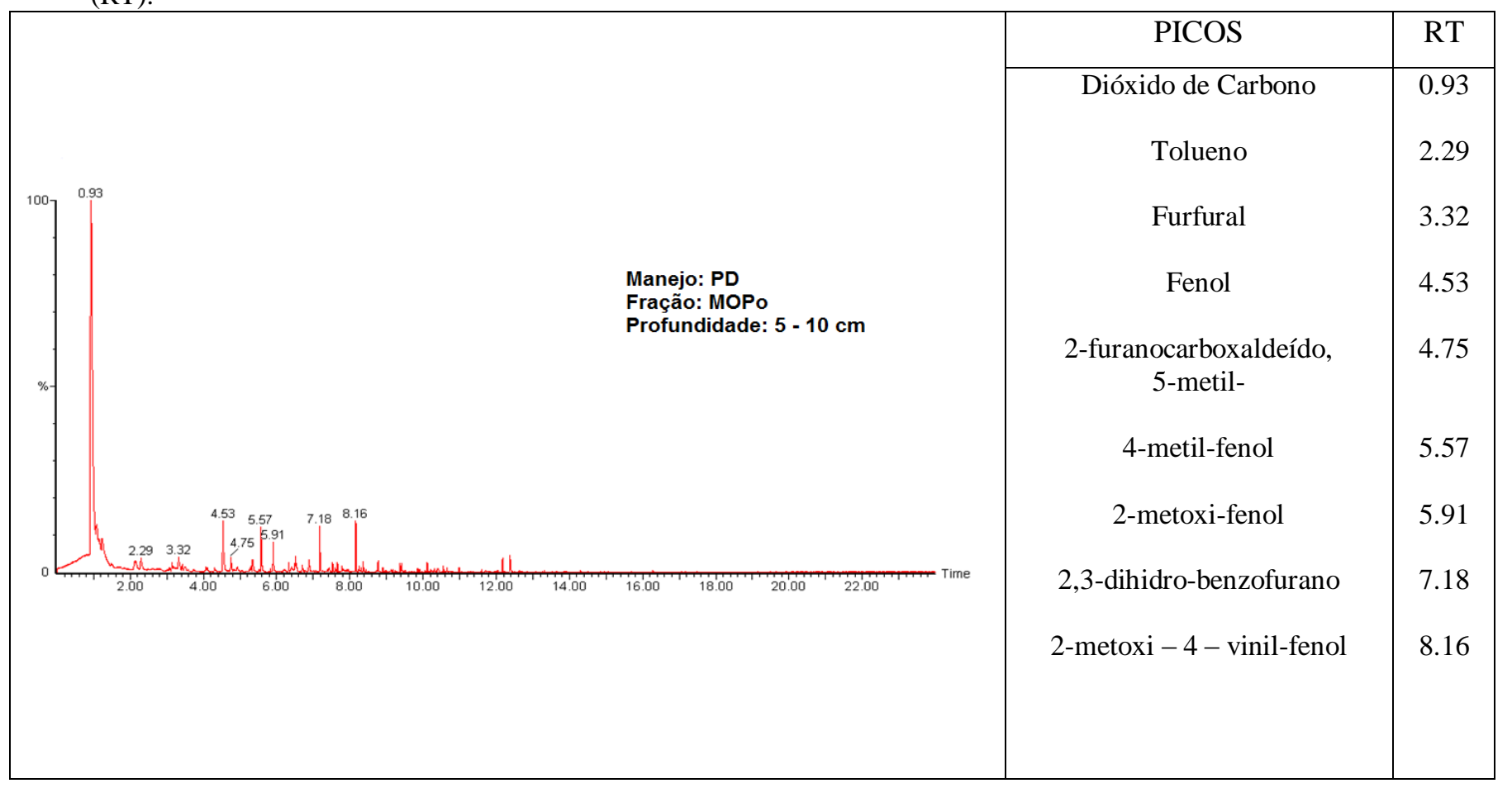


Fig. 33 - Cromatograma para amostras de matéria orgânica particulada oclusa (MOPo), na profundidade 5-10 cm, para o sistema PC - plantio convencional com manejo mínimo. Ao lado estão identificados os picos e seus respectivos tempos de retenção (RT).

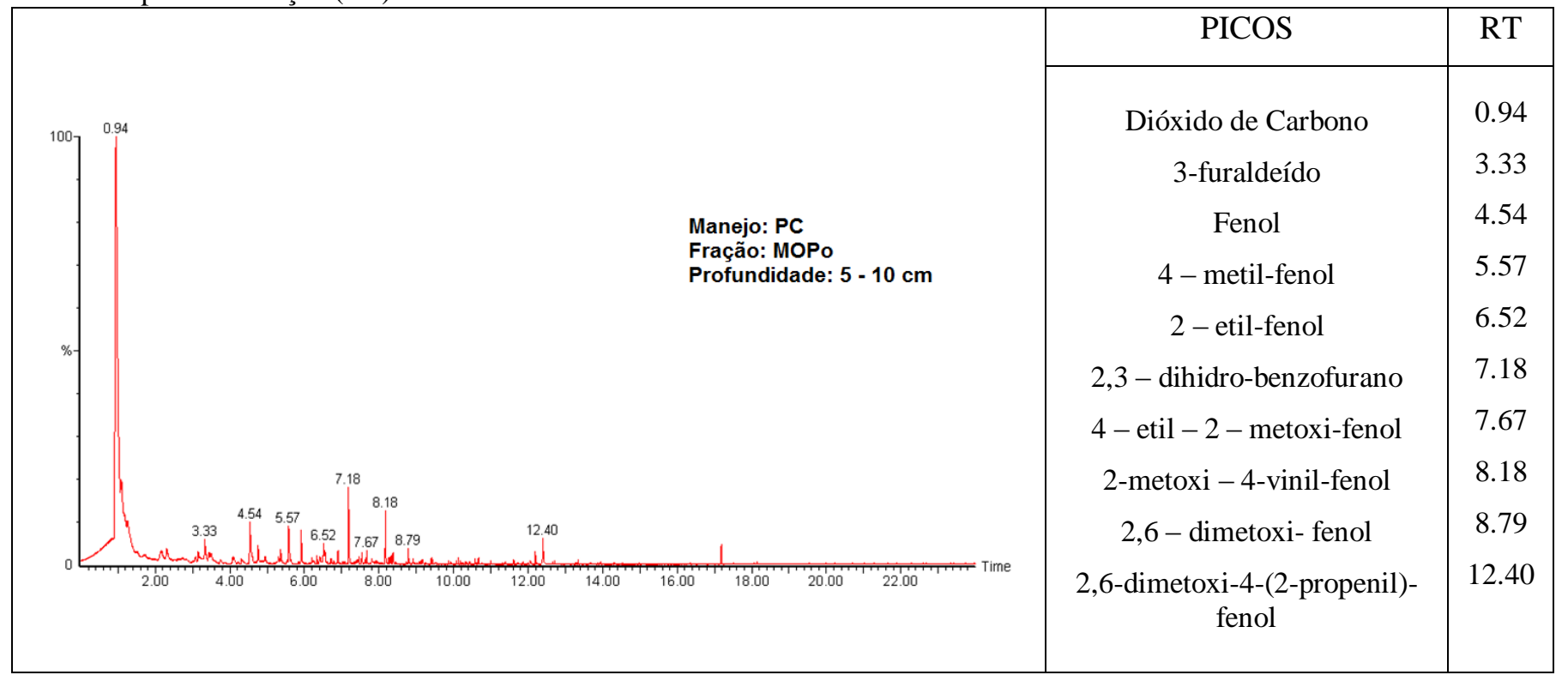

Fig. 34 - Cromatograma para amostras de matéria orgânica particulada oclusa (MOPo), na profundidade 5-10 cm, para o sistema ORG2 - agricultura orgânica de 2 anos. Ao lado estão identificados os picos e seus respectivos tempos de retenção (RT).

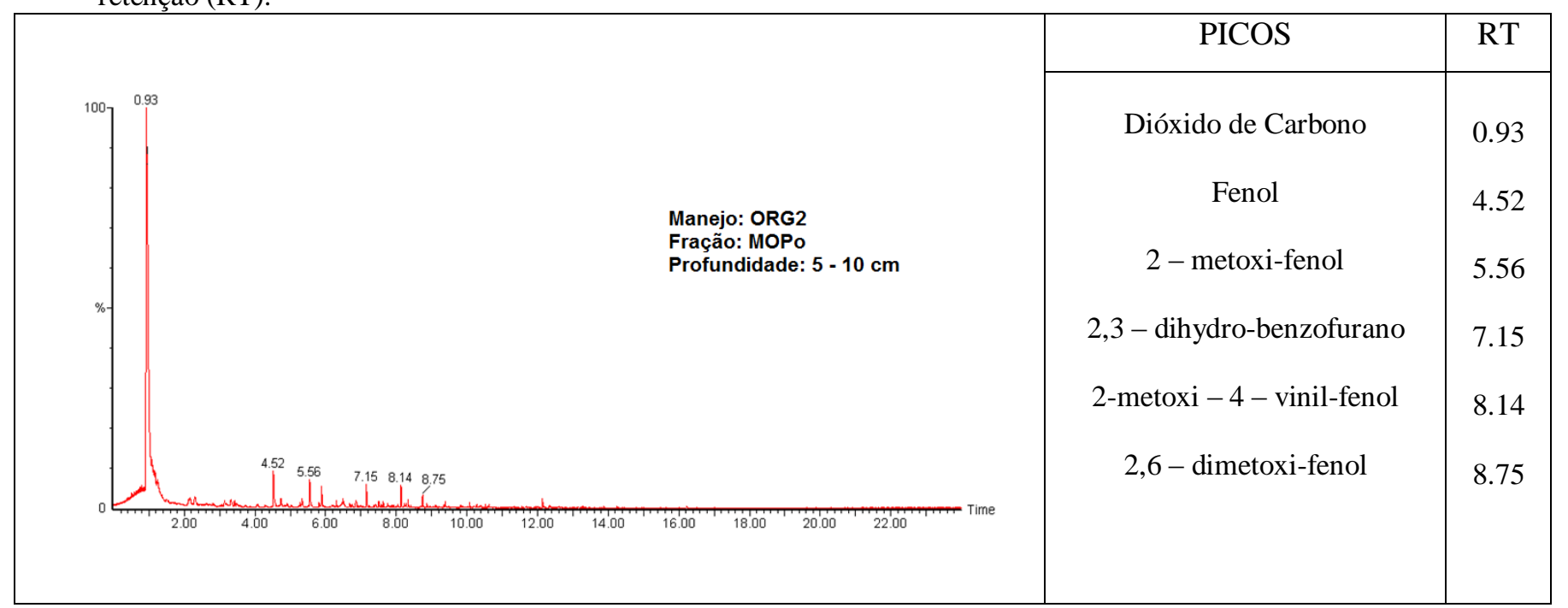


Fig. 35 - Cromatograma para amostras de matéria orgânica particulada oclusa (MOPo), na profundidade 5-10 cm, para o sistema ORG3 - agricultura orgânica de 3 anos. Ao lado estão identificados os picos e seus respectivos tempos de retenção (RT).

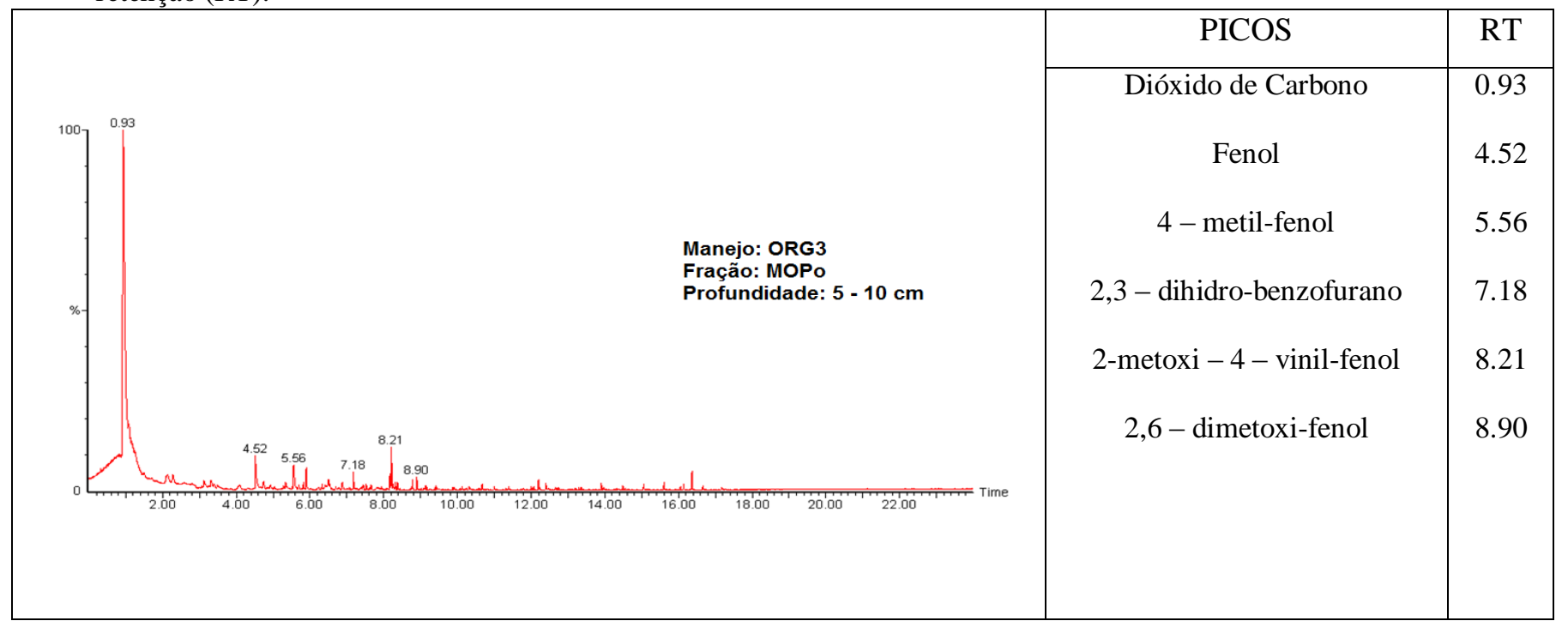

Fig. 36 - Cromatograma para amostras de matéria orgânica particulada oclusa (MOPo), na profundidade 5-10 cm, para o sistema ORG6 - agricultura orgânica de 6 anos. Ao lado estão identificados os picos e seus respectivos tempos de retenção (RT).

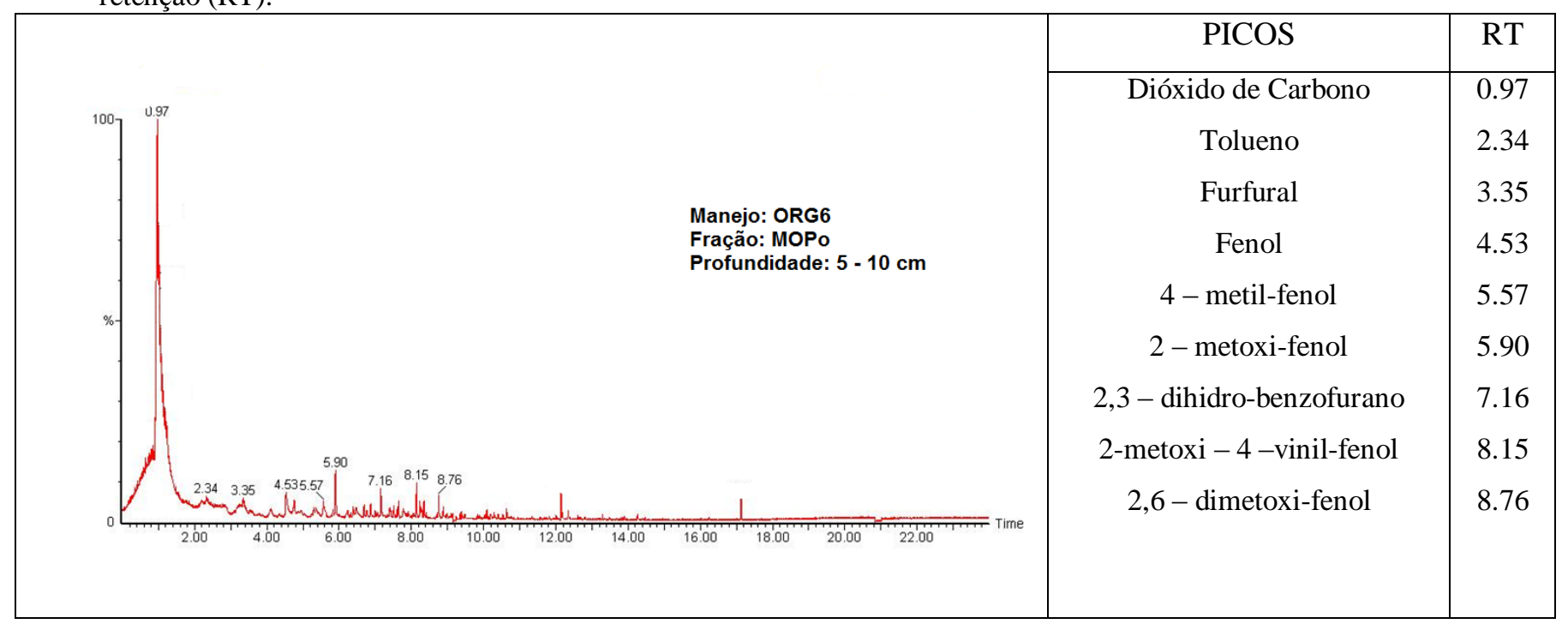

A técnica de pirólise em associação à cromatografia a gás e espectrometria de massas (PY -GC/MS) tem sido amplamente utilizada na caracterização molecular de estruturas macromoleculares complexas e apresenta vantagens sobre outras técnicas destrutivas, na análise estrutural da MOS recalcitrante, além de ter boa reprodutibilidade e requerer pequena quantidade de amostra (Assis et al., (2012)).

Ainda, em complemento, de acordo com Stewart (2012) a técnica possibilita a análise de fragmentos bioquímicos que podem estar relacionados com lignina, polissacarídeos, lipídeos, compostos contendo N, aromáticos e fenóis. 
A tabela abaixo lista os picos mais relevantes encontrados em ambas frações analisadas (leve-livre e leve-oclusa), assinalando a respectiva incidência de acordo com as frações em questão. Os picos foram selecionados após análise estatística utilizando técnicas de ganho de informação (Hall et al., (2009)).

Tabela 16 - Picos de maior relevância identificados para amostras de matéria organica particulada leve-oclusa e leve-livre (MOPo e MOPI, respectivamente), considerando os manejos e perfil analisados

\begin{tabular}{|c|c|c|}
\hline PICOS & Leve-Oclusa (MOPo) & Leve-Livre (MOPl) \\
\hline 1,2,4-trimetoxibenzeno & & $\mathrm{X}$ \\
\hline 1,3-benzenodiol, 4-etil- & & $\mathrm{X}$ \\
\hline 1HIndeno, 3-metil- & & $\mathrm{X}$ \\
\hline $2(5 \mathrm{H})$ furanona & & $\mathrm{x}$ \\
\hline 2',4'-dihidroxipropiofenona & & $\mathrm{x}$ \\
\hline 2-ciclopenten1-ona, 2-hidroxi-3-metil- & & $\mathrm{X}$ \\
\hline 2-ciclopenten1-ona, 2-metil- & & $\mathrm{x}$ \\
\hline 2-ciclopenten1-ona, 3-metil- & & $\mathrm{X}$ \\
\hline 2-furanocarboxaldeído, 5-metil- & $\mathrm{X}$ & \\
\hline 2-metoxi-4-vinil-fenol & $\mathrm{X}$ & \\
\hline 2-metoxi-5-metil-fenol & $\mathrm{x}$ & $\mathrm{x}$ \\
\hline 2-Propanona, 1-(4-hidroxi-3-metoxifenil)- & & $\mathrm{x}$ \\
\hline 2-propanona, 1-hidroxi- & & $\mathrm{X}$ \\
\hline $\begin{array}{l}\text { Ácido 2-Propenóico, 3-(4-hidroxi-3-metoxifenil)- } \\
\text { metilester }\end{array}$ & & $\mathrm{X}$ \\
\hline 3',5'-dimetoxiacetofenona & $\mathrm{X}$ & $\mathrm{X}$ \\
\hline Ácido 3-hidroxi-4-metoxi-mandélico & $\mathrm{x}$ & \\
\hline Acetofenona, 4'-hidroxi- & & $\mathrm{X}$ \\
\hline 2-metil-benzofurano & & $\mathrm{X}$ \\
\hline 1,3,5-trimetilbenzeno & $\mathrm{X}$ & \\
\hline 2,3-dihidro-benzofurano & $\mathrm{X}$ & \\
\hline 1-(3-hidroxi-4-metoxifenil)-etanona & $\mathrm{X}$ & \\
\hline Furano & & $\mathrm{X}$ \\
\hline Furfural & $\mathrm{X}$ & \\
\hline Maltol & & $\mathrm{X}$ \\
\hline Fenol & $\mathrm{X}$ & \\
\hline 2,6-dimetoxi-fenol & $\mathrm{X}$ & $\mathrm{X}$ \\
\hline 2,6-dimetoxi-4-(2-propenil)-fenol & & $\mathrm{X}$ \\
\hline 2-etil-fenol & $\mathrm{X}$ & $\mathrm{X}$ \\
\hline 2-etil-4-metil-fenol & & $\mathrm{x}$ \\
\hline 2-metoxi-fenol & $\mathrm{X}$ & $\mathrm{X}$ \\
\hline 4-etil-2-metoxi-fenol & & $\mathrm{x}$ \\
\hline 4-metoxi-3-metil-fenol & & $\mathrm{X}$ \\
\hline 4-metil-fenol & $\mathrm{x}$ & $\mathrm{X}$ \\
\hline Estireno & X & \\
\hline
\end{tabular}


De acordo com Pognani et al., (2011) e Dignac et al., (2006) hidrocarbonetos do tipo alceno encontrados nas análises podem representar picos de lipídeos provenientes de bactérias, ao passo que alcanos correlacionam-se com picos de lipídeos oriundos de matéria orgânica de resíduos adicionados ao meio. Segundo os mesmos, seus correspondentes cíclicos (ou seja, ciclo-alcenos e ciclo-alcanos, respectivamente) são originados da pirólise de moléculas de triglicerídeos.

Picos de furanos observados são oriundos da fração de polissacarídeos de microrganismos, enquanto ciclo-cetonas e piranos são também provenientes de polissacarídeos, contudo originados de material vegetal (celulose) degradado e não degradado, respectivamente (Dignac et al., (2005)).

Conforme Dignac et al., (2005) e González-Vila et al., (2009) as moléculas aromáticas identificadas podem ser divididas em sub-classes, levando-se em consideração suas diferentes propriedades químicas e origem, sendo: metoxi-fenóis e metil-cetonas (oriundas de lignina) e benzenos e fenóis (moléculas aromáticas de origem desconhecida). Contudo, de acordo com Assis et al., (2012) fenóis e alquil-fenóis podem ser provenientes da pirólise de lignina, taninos, proteínas e carboidratos.

Em complemento, segundo Pognani et al., (2011) compostos poliaromáticos, tais como naftaleno e indeno, são provavelmente originados de moléculas com características de substâncias húmicas (referidas como humic-like substances).

Pela análise dos resultados obtidos através da técnica de PY - GC/MS pôde-se observar maior numero de picos para a parcela MOPl em detrimento a MOPo para todos os sistemas analisados. Nota-se também a predominância de picos referentes a derivados de furano e polissacarídeos (tais como metil-furanos e furaldeídos), derivados aromáticos de lignina (fenóis, metoxi-fenóis) e alguns lipídeos do solo sob a forma de cetona. Todavia, o menor número de picos observados para a fração oclusa, em detrimento à livre, pode ser decorrência de presença de material mais homogêneo, devido à transformação pela atividade microbiana do solo.

Pôde-se também observar maior quantidade de picos para os sistemas orgânicos em comparação aos sistemas sem manejo e manejo convencional. Contudo, foi observada diferença mais pronunciada quantitativa à qualitativa, haja visto que a gama de picos observada para as amostras não apresentaram grande variabilidade em suas características químicas.

Ainda, segundo Nierop et al., (2001) a diferença na composição de MOS em sistemas de agricultura orgânica e convencional é devida, principalmente, ao aporte de material 
orgânico (característica do primeiro), e às atividades de manejo do solo, que propiciam o distúrbio homogêneo da MOS na extensão da camada arável.

Visando assegurar a relevância estatística das diferenças observadas entre os manejos de solo considerados, levando-se em consideração os picos mais eminentes identificados nas frações de MOP, foi realizada análise de variância (ANOVA) não paramétrica. A adoção deste tipo de modalidade para os tratamentos estatísticos é considerada como requisito apropriado para análise de variáveis semiquantitativas, neste caso, típicas de dados provenientes da técnica de PY-GC/MS (Vancampenhout et al., (2012)). Neste sentido, foram aplicados os testes de Kruskal-Wallis (Moore (2010)), seguido de Mann-Whitney (Hole (2011)), para comparações par a par dos manejos considerados.

Segundo Moore (2010) testes estatísticos não paramétricos (como é o caso dos testes de Kruskal-Wallis e Mann-Whitney) frequentemente apresentam melhores resultados, em algumas situações, comparando-se com respectivos testes paramétricos.

Ainda, de acordo com o mesmo, o modelo de análise de variância do teste de KruskalWallis compara dados do grupo selecionado, baseando-se em amostras aleatórias pertencentes aos grupos em questão. Ainda, segundo o mesmo, existe a possibilidade de hipótese nula para método (onde a distribuição da variável de resposta é a mesma para as amostras do grupo considerado) e hipótese alternativa (onde é assumido que a resposta é sistematicamente maior em alguns grupos em relação a outros).

O teste de Mann-Whitney é indicado para comparação de dois grupos para verificação de pertinência, ou não, à mesma população. O mecanismo do teste de Mann-Whitney é ranquear os dados para cada condição (neste caso, manejos de solo), seguido da verificação da discrepância entre estes. Se existir uma diferença sistemática entre as duas condições, a maioria dos valores mais altos ranqueados fará parte de um grupo e, consequentemente, os valores menores constituirão outro grupo, denotando a diferença entre as condições analisadas. Por outro lado, se ambas as condições analisadas são similares, tanto os maiores quanto os menores valores ranqueados estarão distribuídos entre as condições consideradas, não apresentando diferença entre si (Hole (2011)).

As tabelas 17 e 18 listam os resultados das analises estatísticas para os picos de maior relevância identificados para as frações leve-oclusa e leve-livre, respectivamente. 
Tabela 17 - Análise estatística de picos de maior relevância identificados para amostras de matéria organica particulada leve-oclusa (MOPo), considerando os manejos e perfil analisados. (continua)

\begin{tabular}{|c|c|c|c|c|c|c|}
\hline COMPOSTO & \multicolumn{2}{|c|}{2 furanocarboxaldeído, 5-metil- } & FORMULA & $\mathrm{C}_{6} \mathrm{H}_{6} \mathrm{O}_{2}$ & ESTRUTURA & \\
\hline PROFUNDIDADE & $0-5$ & 5 a 10 & 10 a 20 & $20-25$ & $25-30$ & \\
\hline Kruskal-Wallis & \multirow{2}{*}{\multicolumn{5}{|c|}{ Dados não apresentaram diferença estatisticamente significativa $(\alpha=0,05)$}} & \\
\hline Mann-Whitney & & & & & & \\
\hline COMPOSTO & \multicolumn{2}{|c|}{ 2-metoxi-4-vinil-fenol } & FORMULA & $\mathrm{C}_{9} \mathrm{H}_{10} \mathrm{O}_{2}$ & ESTRUTURA & \multirow{4}{*}{$\mathrm{H}_{2} \mathrm{C}=\mathrm{OCH}_{3}$} \\
\hline PROFUNDIDADE & $0-5$ & 5 a 10 & 10 a 20 & $20-25$ & $25-30$ & \\
\hline Kruskal-Wallis & \multirow{2}{*}{\multicolumn{5}{|c|}{ Dados não apresentaram diferença estatisticamente significativa $(\alpha=0,05)$}} & \\
\hline Mann-Whitney & & & & & & \\
\hline COMPOSTO & \multicolumn{2}{|c|}{ 2-metoxi-5-metil-fenol } & FORMULA & $\mathrm{C}_{8} \mathrm{H}_{10} \mathrm{O}_{2}$ & ESTRUTURA & \\
\hline PROFUNDIDADE & $0-5$ & 5 a 10 & 10 a 20 & $20-25$ & $25-30$ & \\
\hline Kruskal-Wallis & \multirow{2}{*}{\multicolumn{5}{|c|}{ Dados não apresentaram diferença estatisticamente significativa $(\alpha=0,05)$}} & \\
\hline Mann-Whitney & & & & & & \\
\hline COMPOSTO & \multicolumn{2}{|c|}{ Ácido 3-hidroxi-4-metoxi mandélico } & FORMULA & $\mathrm{C}_{9} \mathrm{H}_{10} \mathrm{O}_{5}$ & ESTRUTURA & \\
\hline PROFUNDIDADE & $0-5$ & 5 a 10 & 10 a 20 & $20-25$ & $25-30$ & \\
\hline Kruskal-Wallis & \multirow{2}{*}{\multicolumn{5}{|c|}{ Dados não apresentaram diferença estatisticamente significativa $(\alpha=0,05)$}} & \\
\hline Mann-Whitney & & & & & & \\
\hline COMPOSTO & \multicolumn{2}{|c|}{ 3',5'-dimetoxiacetofenona } & FORMULA & $\mathrm{C}_{10} \mathrm{H}_{12} \mathrm{O}_{3}$ & ESTRUTURA & \\
\hline PROFUNDIDADE & $0-5$ & 5 a 10 & 10 a 20 & $20-25$ & $25-30$ & \\
\hline Kruskal-Wallis & \multirow{2}{*}{\multicolumn{2}{|c|}{ Dados não apresentara }} & tictiono & iostiug $(a-1$ & & \\
\hline Mann-Whitney & & & atisticanterite & Mativa $\left(a-a^{2}\right.$ & & \\
\hline COMPOSTO & & FORMULA & $\mathrm{C}_{9} \mathrm{H}_{12}$ & ESTRUTURA & \\
\hline PROFUNDIDADE & $0-5$ & 5 a 10 & 10 a 20 & $20-25$ & $25-30$ & \\
\hline Kruskal-Wallis & \multirow{2}{*}{\multicolumn{2}{|c|}{ Dados não apresentaran }} & & & & \\
\hline Mann-Whitney & & & atisticamente si & Icativa $(\alpha=$ & & \\
\hline COMPOSTO & \multicolumn{2}{|c|}{ 2,3-dihidro-benzofurano } & FORMULA & $\mathrm{C}_{8} \mathrm{H}_{8} \mathrm{O}$ & ESTRUTURA & \\
\hline PROFUNDIDADE & $0-5$ & 5 a 10 & 10 a 20 & $20-25$ & $25-30$ & \\
\hline Kruskal-Wallis & \multirow{2}{*}{\multicolumn{5}{|c|}{ Dados não apresentaram diferença estatisticamente significativa $(\alpha=0,05)$}} & \\
\hline Mann-Whitney & & & & & & \\
\hline COMPOSTO & \multicolumn{2}{|c|}{ 1-(3-hidroxi-4-metoxifenil)-etanona } & FORMULA & $\mathrm{C}_{9} \mathrm{H}_{10} \mathrm{O}_{3}$ & ESTRUTURA & \\
\hline PROFUNDIDADE & $0-5$ & 5 a 10 & 10 a 20 & $20-25$ & $25-30$ & \\
\hline Kruskal-Wallis & \multirow{2}{*}{\multicolumn{5}{|c|}{ Dados não apresentaram diferença estatisticamente significativa $(\alpha=0,05)$}} & \\
\hline Mann-Whitney & & & & & & \\
\hline COMPOSTO & \multicolumn{2}{|c|}{ Furfural } & FORMULA & $\mathrm{C}_{5} \mathrm{H}_{4} \mathrm{O}_{2}$ & ESTRUTURA & \\
\hline PROFUNDIDADE & $0-5$ & 5 a 10 & 10 a 20 & $20-25$ & $25-30$ & \\
\hline
\end{tabular}




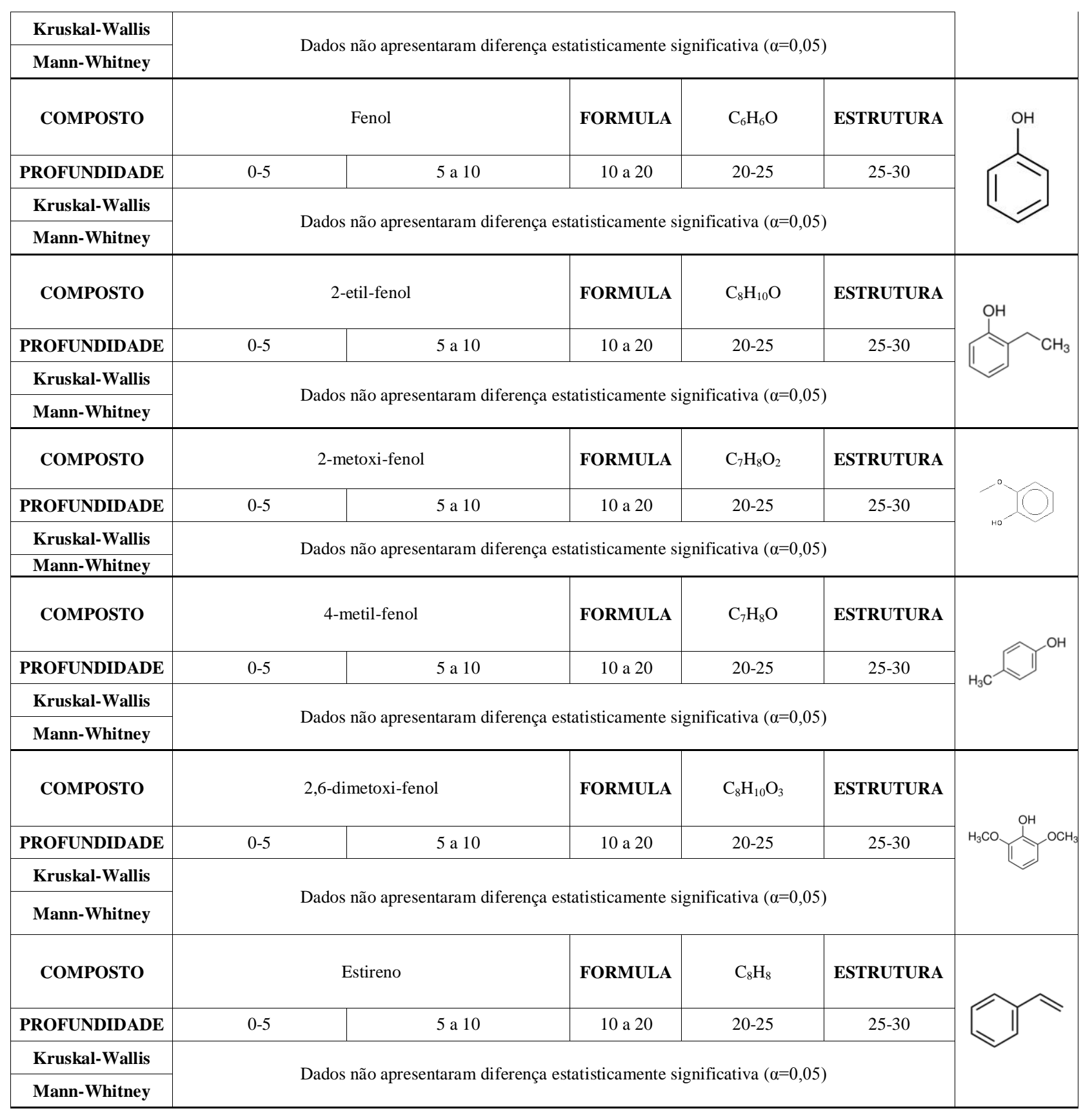

Tabela 18 - Análise estatística de picos de maior relevância identificados para amostras de matéria organica particulada leve-livre (MOPl), considerando os manejos e perfil analisados. Sinais - e + (para método de Kruskal-Wallis), e manejos destacados (para método de Mann-Whitney), indicam diferença estatisticamente significativa ou não na referida profundidade, $\operatorname{com} \mathrm{pd}=$ plantio direto, $\mathrm{pc}=$ plantio convencional e org 2,3 e $6=$ agricultura orgânica com rotação de cultura a cada 2,3 e 6 anos respectivamente. (continua).

\begin{tabular}{|c|c|c|c|c|c|}
\hline COMPOSTO & \multicolumn{2}{|c|}{ 1-Hindeno, 3-metil } & FORMULA & $\mathrm{C}_{10} \mathrm{H}_{10}$ & ESTRUTURA \\
\hline PROFUNDIDADE & $0-5$ & 5 a 10 & 10 a 20 & $20-25$ & $25-30$ \\
\hline Kruskal-Wallis & \multirow{2}{*}{\multicolumn{5}{|c|}{ Dados não apresentaram diferença estatisticamente significativa $(\mathrm{r}=95 \%)$}} \\
\hline Mann-Whitney & & & & & \\
\hline COMPOSTO & \multicolumn{2}{|c|}{ 2-ciclopenten1-ona, 2-hidroxi-3-metil- } & FORMULA & $\mathrm{C}_{6} \mathrm{H}_{8} \mathrm{O}_{2}$ & ESTRUTURA \\
\hline PROFUNDIDADE & $0-5$ & 5 a 10 & 10 a 20 & $20-25$ & $25-30$ \\
\hline Kruskal-Wallis & - & - & - & + & + \\
\hline
\end{tabular}




\begin{tabular}{|c|c|c|c|c|c|c|}
\hline Mann-Whitney & - & - & - & org3 $\mathrm{x}$ org6 & $\begin{array}{l}\text { pd } \mathrm{x} \text { org } 3 \\
\text { org } 3 \times \text { org } 6\end{array}$ & \\
\hline COMPOSTO & \multicolumn{2}{|c|}{ 2-ciclopenten1-ona, 2-metil- } & FORMULA & $\mathrm{C}_{6} \mathrm{H}_{8} \mathrm{O}$ & ESTRUTURA & \\
\hline PROFUNDIDADE & $0-5$ & 5 a 10 & 10 a 20 & $20-25$ & $25-30$ & \\
\hline Kruskal-Wallis & - & - & + & - & - & \\
\hline Mann-Whitney & - & - & $\begin{array}{l}\text { pc } \mathrm{x} \text { org } 3 \\
\text { org } 2 \times \text { org } 3\end{array}$ & - & - & \\
\hline COMPOSTO & \multicolumn{2}{|c|}{ 2-ciclopenten1-ona, 3-metil- } & FORMULA & $\mathrm{C}_{6} \mathrm{H}_{8} \mathrm{O}$ & ESTRUTURA & \\
\hline PROFUNDIDADE & $0-5$ & 5 a 10 & 10 a 20 & $20-25$ & $25-30$ & \\
\hline $\begin{array}{l}\text { Kruskal-Wallis } \\
\text { Mann-Whitney } \\
\end{array}$ & \multicolumn{5}{|c|}{ Dados não apresentaram diferença estatisticamente significativa $(\alpha=0,05)$} & \\
\hline COMPOSTO & \multicolumn{2}{|c|}{ 2-metoxi-5-metil-fenol } & FORMULA & $\mathrm{C}_{8} \mathrm{H}_{10} \mathrm{O}_{2}$ & ESTRUTURA & \\
\hline PROFUNDIDADE & $0-5$ & 5 a 10 & 10 a 20 & $20-25$ & $25-30$ & \\
\hline Kruskal-Wallis & - & - & - & - & + & \\
\hline Mann-Whitney & - & - & - & - & $\begin{array}{l}\text { pc } \times \text { org3; } \\
\text { pc } \times \text { org6 }\end{array}$ & \\
\hline COMPOSTO & \multicolumn{2}{|c|}{ 2-propanona, 1-(4-hidroxi-3-metoxi-fenil)- } & FORMULA & $\mathrm{C}_{10} \mathrm{H}_{12} \mathrm{O}_{3}$ & ESTRUTURA & \\
\hline PROFUNDIDADE & $0-5$ & 5 a 10 & 10 a 20 & $20-25$ & $25-30$ & \\
\hline Kruskal-Wallis & - & - & - & - & + & \\
\hline Mann-Whitney & - & - & - & - & $\begin{array}{l}\text { pd } \mathrm{x} \text { org } 2 \\
\text { org } 2 \times \text { org } 6\end{array}$ & \\
\hline COMPOSTO & \multicolumn{2}{|c|}{ 2-propanona, 1-hidroxi- } & FORMULA & $\mathrm{C}_{3} \mathrm{H}_{6} \mathrm{O}_{2}$ & ESTRUTURA & \multirow{4}{*}{$\mathrm{O}_{\mathrm{O}} \mathrm{OH}$} \\
\hline PROFUNDIDADE & $0-5$ & 5 a 10 & 10 a 20 & $20-25$ & $25-30$ & \\
\hline Kruskal-Wallis & - & - & - & + & - & \\
\hline Mann-Whitney & - & - & - & $\begin{array}{l}\text { pd x org6; } \\
\text { pc x org6; } \\
\text { org } 2 \text { x org6 }\end{array}$ & - & \\
\hline COMPOSTO & \multicolumn{2}{|c|}{$\begin{array}{l}\text { 2-Propenoic acid, 3-(4-hydroxy-3-methoxyphenyl)- } \\
\text { methyester }\end{array}$} & FORMULA & $\mathrm{C}_{11} \mathrm{H}_{12} \mathrm{O}_{4}$ & ESTRUTURA & \multirow{8}{*}{${ }^{\text {Hо }}$} \\
\hline PROFUNDIDADE & $0-5$ & 5 a 10 & 10 a 20 & $20-25$ & $25-30$ & \\
\hline Kruskal-Wallis & \multirow{2}{*}{\multicolumn{5}{|c|}{ Dados não apresentaram diferença estatisticamente significativa $(\alpha=0,05)$}} & \\
\hline Mann-Whitney & & & & & & \\
\hline COMPOSTO & \multicolumn{2}{|c|}{ 1,3-benzenodiol, 4-etil- } & FORMULA & $\mathrm{C}_{8} \mathrm{H}_{10} \mathrm{O}_{2}$ & ESTRUTURA & \\
\hline PROFUNDIDADE & $0-5$ & 5 a 10 & 10 a 20 & $20-25$ & $25-30$ & \\
\hline Kruskal-Wallis & + & - & - & - & - & \\
\hline Mann-Whitney & $\begin{array}{l}\text { pd x org6; } \\
\text { org } 2 \text { x org6; } \\
\text { org3 x org6 }\end{array}$ & - & - & - & - & \\
\hline COMPOSTO & \multicolumn{2}{|c|}{ 2',4'-dihidroxipropiofenona } & FORMULA & $\mathrm{C}_{9} \mathrm{H}_{10} \mathrm{O}_{3}$ & ESTRUTURA & \multirow{4}{*}{ OH } \\
\hline PROFUNDIDADE & $0-5$ & 5 a 10 & 10 a 20 & $20-25$ & $25-30$ & \\
\hline Kruskal-Wallis & - & + & - & - & - & \\
\hline Mann-Whitney & - & $\begin{array}{l}\mathrm{pd} x \operatorname{org} 2 \\
\mathrm{pd} \mathrm{x} \text { org6 }\end{array}$ & - & - & - & \\
\hline
\end{tabular}




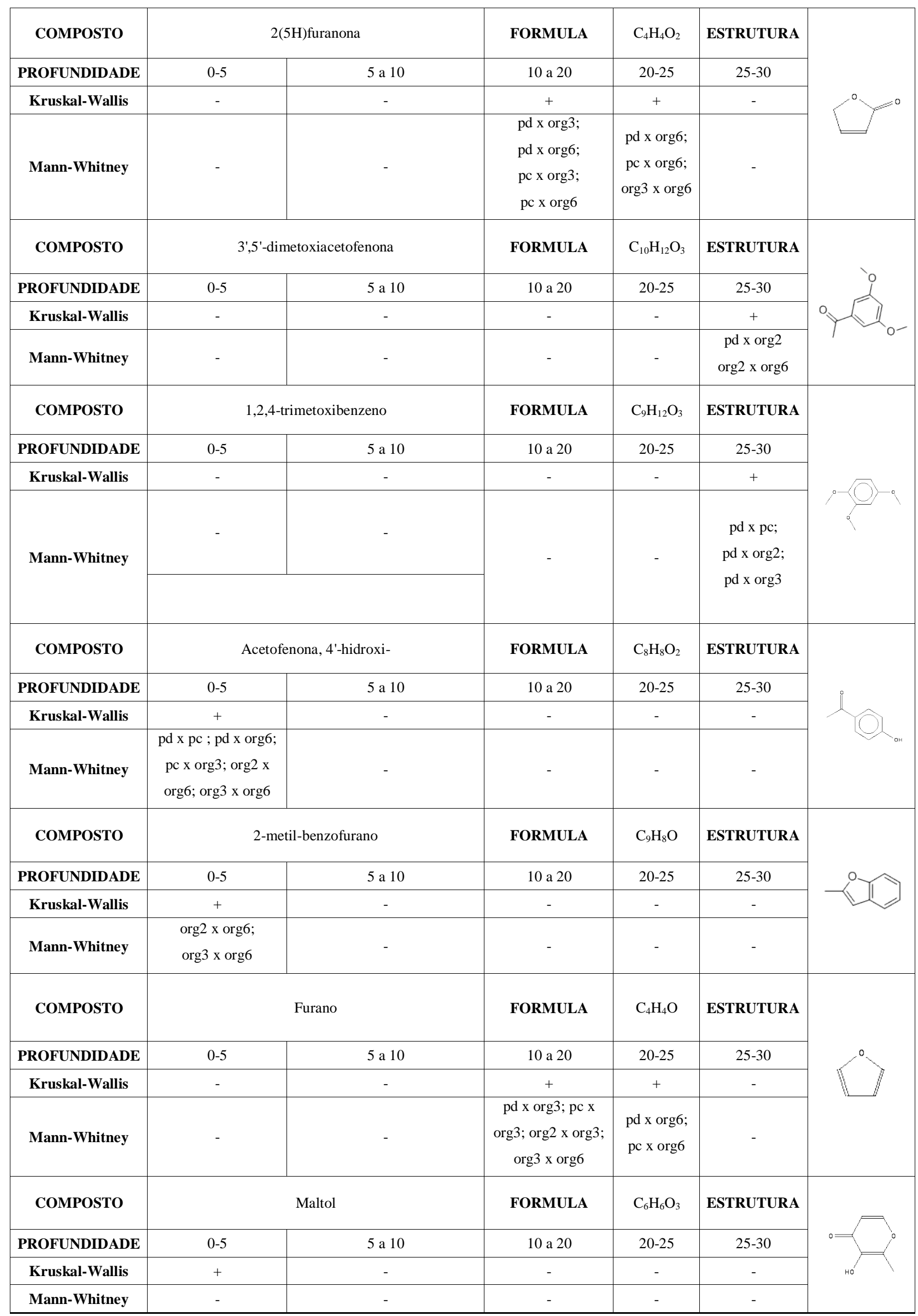




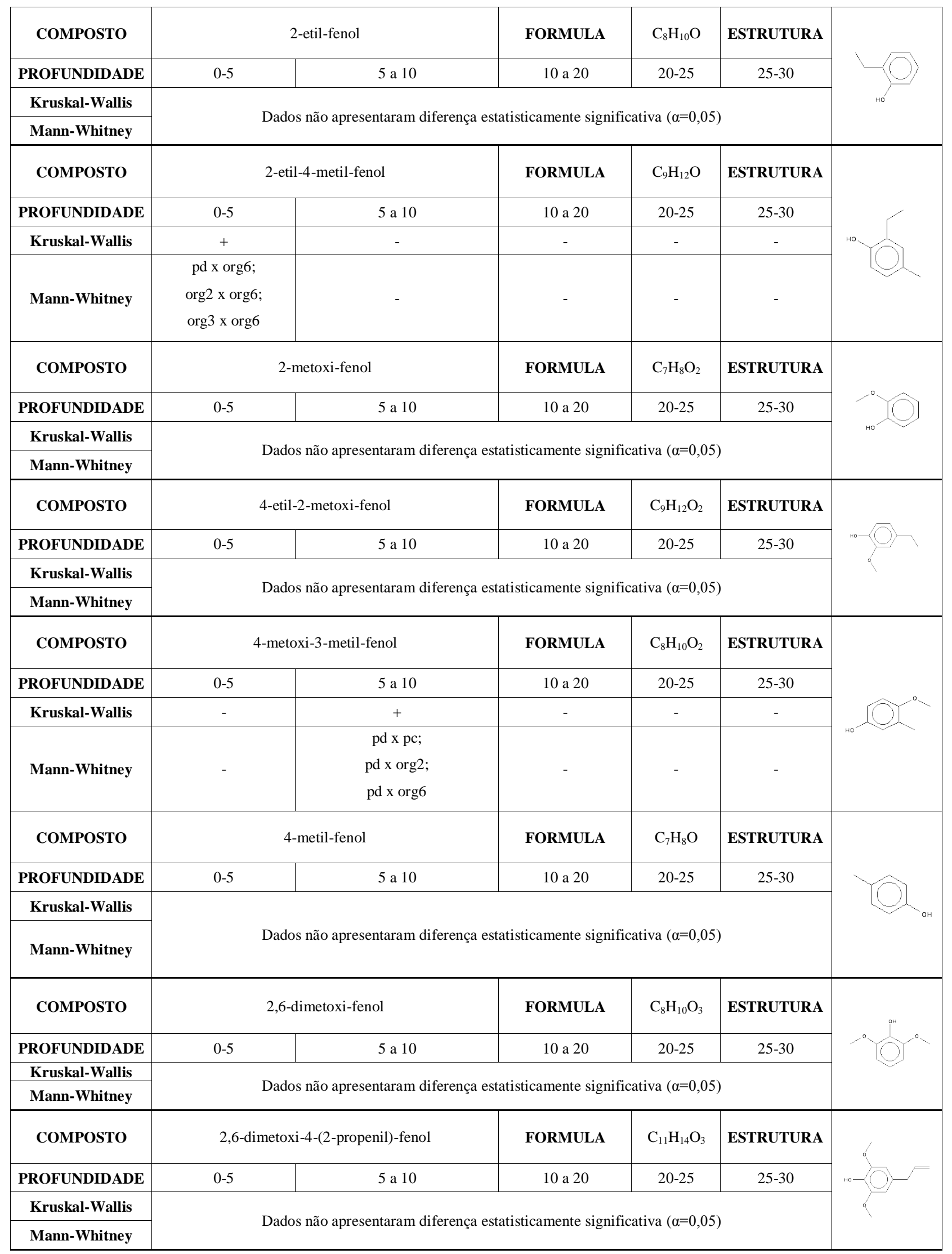

Os resultados obtidos através dos métodos de Kruskal-Wallis e Mann-Whitney para as amostras referentes à fração leve-oclusa (MOPo) mostraram que não houve diferença 
estatisticamente significativa entre os valores de intensidade observados. Ressaltando que o primeiro método leva em consideração todos os resultados de determinado pico (para todos os manejos analisados, considerando as respectivas replicatas), ao passo que o segundo considera as mesmas intensidades observadas para determinado pico, comparando manejo par a par. $\mathrm{O}$ comportamento observado ratifica o caráter homogêneo desta fração, ilustrando ainda a falta de correlação entre o tipo de manejo empregado e a maior incidência ou não de determinado composto para a fração em si. No que tange à fração leve-livre (MOPl), observam-se diferenças estatisticamente significativas (nível de significância $\alpha<0.05$ ), entre os manejos analisados, principalmente entre os sistemas orgânicos, denotando maior impacto deste tipo de prática junto à fração analisada.

Ainda, as diferenças estatísticas observadas em amostras referentes MOP1 apresentaram certa uniformidade de incidência em todo perfil considerado, principalmente em camadas subsuperficiais e em picos predominantemente com características similares a de lipídeos de solo e polissacarídeos.

Conforme Pognani et al., (2011) cabe ressaltar que resultados de PY-GC/MS são predominantemente aplicados para análise em caráter qualitativo, não refletindo a quantificação absoluta de $\mathrm{C}$ na amostra em questão.

De acordo com Kögel-Knabner (2000) a interpretação de dados resultantes da análise por PY-GC/MS requer um conhecimento mais detalhado acerca do comportamento de alguns compostos relacionados com as amostras em estudo, mediante o processo de pirólise. Segundo o mesmo, a pirólise de moléculas de celulose dá origem a compostos com grupos funcionais do tipo carbonila, ácidos, furanos, piranonas e fenóis. Moléculas de ácidos graxos podem ser descarboxiladas durante o processo de pirólise, especificamente quando de sua incidência em amostras de solos minerais, que por sua vez apresentam efeito catalítico em tal processo. Logo, principalmente compostos alcanos e alcenos podem ser identificados nos compostos pirolizados de amostras do solo, com baixa ocorrência de picos de ácidos graxos.

Assim, além da caracterização química do pico identificado, recomenda-se o conhecimento do prévio do respectivo possível material de origem analisado, para melhor elaboração de hipótese para o cenário observado.

Em sua pesquisa, Rumpel et al., (2009) verificaram que dados referentes às amostras de sistemas agrícolas apresentaram picos relacionados a derivados de polissacarídeos, lignina e alguns compostos de origem indefinida. Conforme os mesmos, os principais compostos derivados de polissacarídeos apresentaram estruturas do tipo furano, ciclopenteno e ciclopropano, enquanto que compostos derivados de lignina tiveram predominância de 
estruturas do tipo metoxi-fenóis. No que concerne aos compostos de origem indefinida, os autores atribuíram a essa modalidade picos identificados como ácido acético, metil fenóis, estireno e tolueno, uma vez que tais compostos podem ser provenientes da pirólise de proteínas, polissacarídeos, peptídeos de ligninas e taninos.

Ainda, segundo Muñoz et al., (2008) embora a técnica de PY-GC/MS não forneça informações a respeito do processo de decomposição da matéria orgânica, a distribuição dos diferentes compostos identificados nas frações da MOS pode disponibilizar indicações de suas respectivas origens. Conforme os mesmos, alta abundância relativa de determinado composto no solo pode ser proveniente de: (i) grande aporte destes no solo pela adição de material orgânico fresco; (ii) proteção (física ou química) dos mesmos, levando à sua permanência no solo; ou ainda, (iii) recorrência de síntese no solo.

Pela análise no que tange as características químicas das estruturas moleculares identificadas, foi possível observar maior incidência de estruturas de caráter aromático para as amostras referentes à MOPo, inferindo a provável ocorrência de material mais resistente à degradação microbiana; ao passo que notou-se a presença de núcleos ligados a cadeias alifáticas em amostras de MOPl, sugerindo maior suscetibilidade à decomposição microbiana.

Dessa maneira, o perfil obtido ilustra o caráter mais heterogêneo da fração livre em comparação à fração oclusa, sugerindo possível ocorrência de maior disponibilidade de compostos e nutrientes para plantas e comunidade microbiana do solo, aumentando, dessa forma, sua atividade pela adição de esterco aviário, nas áreas sob regime de agricultura orgânica, em detrimento às demais consideradas. A menor variedade de estruturas moleculares observada para a fração oclusa possivelmente é decorrente de material mais biologicamente transformado, acarretando em um montante mais restrito de picos identificados.

\section{2 Área Experimental 2}

\subsubsection{Solo}

\subsubsection{Teor de C}

As amostras provenientes da fazenda Areona apresentaram aumento no teor de $\mathrm{C}$ (cerca de 25\%), no perfil analisado, em áreas sob adição de biossólido em detrimento à área de controle (sem adição), contudo foi observado comportamento inverso nas amostras oriundas da fazenda Entre Rios (decréscimo de, aproximadamente, 20\%).

Segundo Zornoza et al., (2013) a ciclagem correta de resíduos orgânicos nos solos (tais como biossólido) requer a otimização de seu gerenciamento para a minimização da emissão de $\mathrm{CO}_{2}$ e aumento da eficiência do processo de sequestro de C. Para tanto, um 
conhecimento mais detalhado a respeito da dinâmica da mineralização de $\mathrm{C}$ em solos condicionados se faz de intrínseca importância.

A figura 37 e a tabela 19 a seguir ilustram o comportamento observado para as amostras de solo em análise de ambas fazendas.

Fig. 37 - Gráficos de teor de C obtidos para amostras de solo inteiro das áreas analisadas, sendo: AN SEM fazenda Areona sem adição de biossólido; AN LODO - fazenda Areona com adição de biossólido; ER SEM - fazenda Entre Rios sem adição de biossólido; ER LODO - fazenda Entre Rios com adição de biossólido.

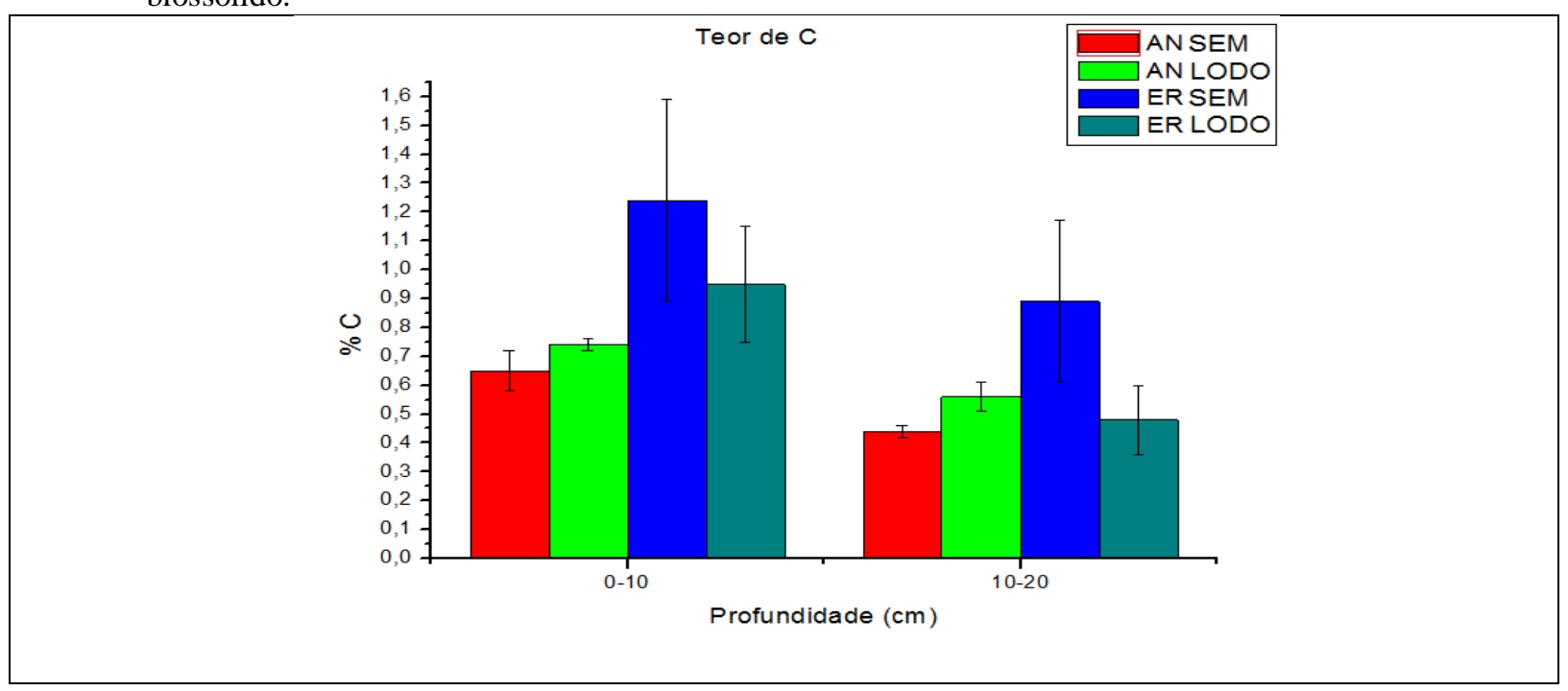

Tabela 19 - Valores de teor de C obtidos para amostras de solo inteiro das áreas analisadas, sendo: AN SEM fazenda Areona sem adição de biossólido; AN LODO - fazenda Areona com adição de biossólido; ER SEM fazenda Entre Rios sem adição de biossólido; ER LODO - fazenda Entre Rios com adição de biossólido.

\begin{tabular}{|c|c|c|c|c|}
\hline Profundidade (cm) & AN SEM & AN LODO & ER SEM & ER LODO \\
\hline $0-10$ & $0,65 \pm 0,07$ & $0,74 \pm 0,02$ & $1,24 \pm 0,35$ & $0,95 \pm 0,20$ \\
\hline $10-20$ & $0,44 \pm 0,02$ & $0,56 \pm 0,05$ & $0,89 \pm 0,28$ & $0,48 \pm 0,12$ \\
\hline
\end{tabular}

O decréscimo no teor de C observado na fazenda Entre Rios nas áreas sob adição de biossólido, em comparação à área de controle, pode ser decorrência de maior atividade microbiana no solo provocado pelo aumento disponibilidade matéria orgânica fresca, pela adição de biossólido, levando a possível degradação da fração mais lábil de $\mathrm{C}$ do solo.

Outro fator, que pode ser considerado como hipótese para tal comportamento, é a diferença do início de atividade nas fazendas (Entre Rios em 2004 e Areona em 2008), o que acarretaria em uma área mais estabilizada para a primeira fazenda, em detrimento à segunda.

Ainda, de acordo com Fontaine et al., (2007) analisando a estabilização de C, controlada pela adição de material orgânico fresco, em diferentes camadas de solo, a maior disponibilidade deste tipo de material, em profundidade, pode levar à perda de $\mathrm{C}$ mais estável no solo pela ação microbiana, causando o chamado efeito priming. 
De acordo com Bastida et al., (2012) a adição de diferentes tipos de condicionadores orgânicos (tais como biossólido) constitui um método de restauração da qualidade de solos degradados, através o aumento de biomassa microbiana do solo, o que implica no aumento da atividade microbiana e enzimática.

Em estudo realizado por Nicolás et al., (2012) verificou-se que a perda C em amostras de solo sob adição de lodo de esgoto foi maior em relação à respectiva área de controle. De acordo com os mesmos, o maior conteúdo de compostos lábeis (facilmente degradáveis) presente no material orgânico adicionado resulta em maior mineralização e perda de $\mathrm{C}$ orgânico.

Os resultados obtidos, para as amostras provenientes da fazenda Areona, apresentam comportamento inverso ao observado para as amostras da fazenda Entre Rios. Observou-se que os valores de conteúdo de $\mathrm{C}$ nas áreas sob adição de biossólido foram maiores em comparação às áreas sem adição. Neste caso, o comportamento observado sugere que o condicionamento do solo com o biossólido leva ao aumento de teor de $\mathrm{C}$, caracterizando, dessa forma, melhor interação entre o material orgânico adicionado e a matéria orgânica neste local, e consequente acúmulo de $\mathrm{C}$.

Tal comportamento pode ser considerado, além de interessante, controverso, uma vez que o solo em questão é caracterizado por apresentar, em sua constituição, uma maior fração de areia, de acordo com o Sistema Brasileiro de Classificação de Solos (Embrapa (1999)). Dessa forma, não era de se esperar interação entre o biossólido e o conteúdo de MOS nesta fazenda, como foi observado, em comparação com a fazenda Entre Rios (perfil de solo mais propício para tal interação).

Em seu estudo avaliando os efeitos, inerentes ao condicionamento do solo com biossólido, juntos às propriedades da MOS e seus constituintes húmicos, Bertoncini et al., (2008) verificaram que amostras de solo de perfil arenoso foram beneficiadas pela adição de biossólido, apresentando maiores teores de $\mathrm{C}, \mathrm{N}, \mathrm{P}$ e Ca, além de maiores valores de $\mathrm{pH}$ e aumento da capacidade de troca catiônica.

Contudo, o decréscimo no teor de $\mathrm{C}$ com aumento de profundidade já havia sido observado na fazenda Entre Rios mesmo sem a adição de biossólido ao solo, podendo, dessa forma, caracterizar um comportamento intrínseco desta área, potencializado pela adição de material orgânico fresco, ratificando o impacto do biossólido junto à comunidade microbiana do solo.

De acordo com Busse et al., (2009) o conteúdo de C em sistemas de floresta é regido, predominantemente, pelo balanço entre o aporte de material orgânico (resíduos de plantas e 
outros) e perda (atividade microbiana, ações antrópicas, erosão, lixiviação), e varia com clima, composição de comunidade microbiana do solo, manejo, textura de solo e tempo. Dessa forma, a identificação de condições de solo e manejo em sistemas de florestas para otimização de sequestro de $\mathrm{C}$ ainda se mostra como um grande desafio, necessitando estudos constantes acerca do assunto.

\subsubsection{Espectroscopia de Fluorescência Induzida por Laser (FIL)}

A figura 38 e a tabela 20 a seguir ilustram os valores de grau de humificação obtidos para as amostras de solo coletadas em áreas com e sem a adição de biossólido, em ambas fazendas consideradas.

Fig. 38 - Gráficos valores de grau de humificação obtidos por Fluorescência Induzida por Laser $\left(\mathrm{H}_{\mathrm{FLL}}\right)$ para amostras de solo inteiro das áreas analisadas, sendo: AN SEM - fazenda Areona sem adição de biossólido; AN LODO - fazenda Areona com adição de biossólido; ER SEM - fazenda Entre Rios sem adição de biossólido; ER LODO - fazenda Entre Rios com adição de biossólido.

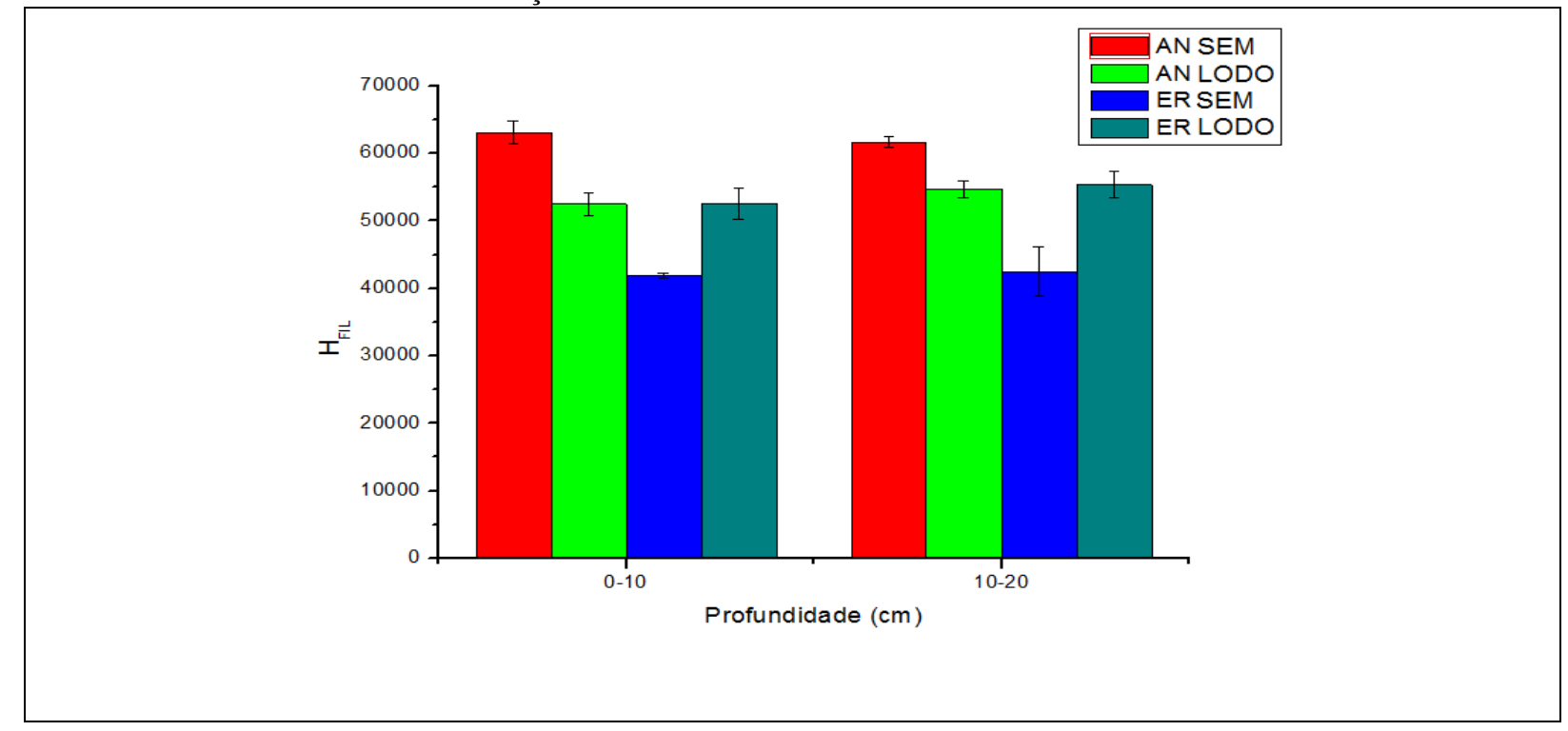

Tabela 20 - Valores de grau de humificação obtidos por Fluorescência Induzida por Laser (H $\left.\mathrm{H}_{\mathrm{FIL}}\right)$ para amostras de solo inteiro das áreas analisadas, sendo: AN SEM - fazenda Areona sem adição de biossólido; AN LODO fazenda Areona com adição de biossólido; ER SEM - fazenda Entre Rios sem adição de biossólido; ER LODO fazenda Entre Rios com adição de biossólido. Valores expressos em notação $\left(x 10^{3}\right)$.

\begin{tabular}{|c|c|c|c|c|}
\hline Profundidade (cm) & AN SEM & AN LODO & ER SEM & ER LODO \\
\hline $0-10$ & $63,10 \pm 1,72$ & $52,49 \pm 1,67$ & $41,88 \pm 0,37$ & $52,60 \pm 2,34$ \\
\hline $10-20$ & $61,67 \pm 0,73$ & $54,69 \pm 1,23$ & $42,49 \pm 3,65$ & $55,33 \pm 1,98$ \\
\hline
\end{tabular}

Assim como observado para os valores de teor de $\mathrm{C}$, os valores de grau de humificação obtidos apresentaram comportamento inverso nas fazendas analisadas. $\mathrm{Na}$ fazenda Areona foi observado maior grau de humificação em amostras de solo referentes às áreas sem adição de biossólido, em detrimento à área submetida a tal condicionamento (decréscimo de cerca de 30\%). Contudo, na fazenda Entre Rios observou-se maior grau de 
humificação (aproximadamente 100\%) nas áreas submetidas à adição de biossólido, em comparação à sua respectiva área de controle.

De acordo com Vergnoux et al., (2011), o processo de humificação leva ao consumo de componentes mais facilmente biodegradáveis, conduzindo à reações de oxidação e condensação, resultando em estruturas macromoleculares mais estáveis.

Ainda em complemento, segundo Birdwell e Engel (2010) compostos orgânicos altamente humificados são, geralmente, mais resistentes à degradação, esperando-se, dessa forma, maior permanência no ambiente em comparação às substâncias menos humificadas.

Dessa forma, uma possível hipótese para o comportamento observado em ambas fazendas, levando-se em consideração os respectivos resultados de teor de $\mathrm{C}$ obtidos para as amostras em análise, é de que o maior conteúdo de $\mathrm{C}$ observado, nas áreas sob adição de biossólido, na fazenda Areona apresenta característica mais lábil, o que justificaria o menor valor de grau de humificação para esta área.

Assim sendo, o perfil de decréscimo de $\mathrm{C}$ na área sob adição de biossólido observado na fazenda Entre Rios, é diretamente relacionado com os maiores valores de humificação para tais áreas, representando as frações mais estáveis de $\mathrm{C}$, após a degradação da fração lábil pela atividade microbiana do solo.

Ainda, em complemento, de acordo com Pacheco et al., (2003) após a aplicação de lodo de esgoto, há possível ocorrência de acúmulo de frações recalcitrantes no solo, tornandose parte integral da MOS. Portanto, levando-se em consideração as características dos perfis de solo das fazendas analisadas, tal acúmulo tende a ser mais pronunciado na fazenda Entre Rios (latossolo) em comparação à fazenda Areona (neossolo quartzarênico), resultando em maiores valores de grau de humificação.

\subsubsection{Respiração do Solo}

A figura 39 e tabela 21 a seguir ilustram os resultados obtidos para medidas de fluxo de $\mathrm{CO}_{2}$ do solo para amostras referentes às áreas sob adição ou não de biossólido consideradas em ambas fazendas analisadas. 
Fig. 39 - Gráficos valores de fluxo de $\mathrm{CO}_{2}$ obtidos para amostras de solo das áreas analisadas, sendo: AN SEM fazenda Areona sem adição de biossólido; AN LODO - fazenda Areona com adição de biossólido; ER SEM fazenda Entre Rios sem adição de biossólido; ER LODO - fazenda Entre Rios com adição de biossólido.

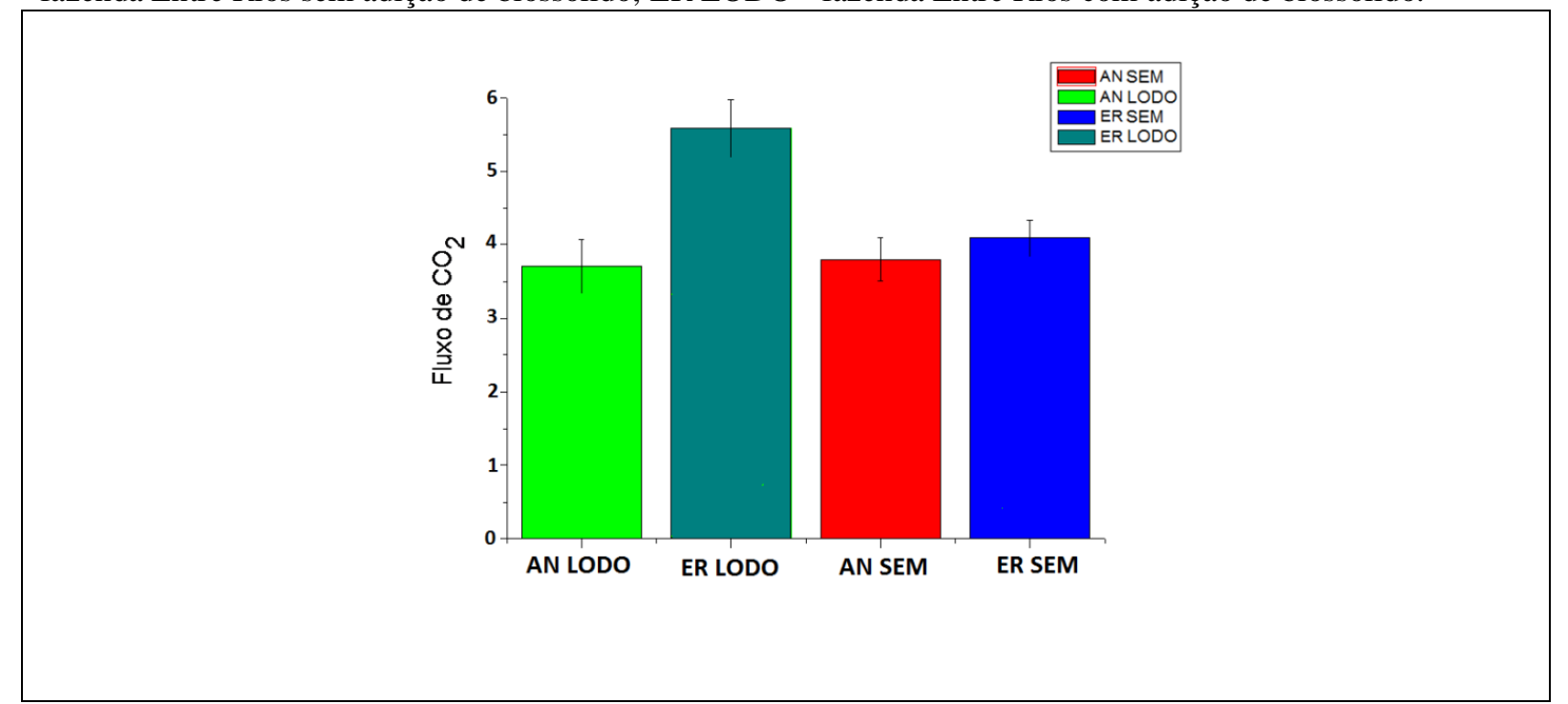

Tabela 21 - Valores de fluxo de $\mathrm{CO}_{2}$ obtido para amostras de solo das áreas analisadas, sendo: AN SEM fazenda Areona sem adição de biossólido; AN LODO - fazenda Areona com adição de biossólido; ER SEM fazenda Entre Rios sem adição de biossólido; ER LODO - fazenda Entre Rios com adição de biossólido.

\begin{tabular}{|c|c|c|}
\hline Fluxo de $\mathrm{CO}_{2}\left(\mu \mathrm{mol} \mathrm{m} \mathrm{m}^{-2} \mathrm{~s}^{-1}\right)$ & Adição de Biossólido & Sem Adição de Biossólido \\
\hline Fazenda Entre Rios (ER) & 5,59 & 4,13 \\
\hline Fazenda Areona (AN) & 3,68 & 3,80 \\
\hline
\end{tabular}

Os resultados obtidos demonstram maior evolução de $\mathrm{CO}_{2}$ (cerca de 35\%) nas áreas sob adição de biossólido para amostras oriundas da fazenda Entre Rios (ER) em detrimento à sua respectiva área de controle, ao passo que, para os dados referentes à fazenda Areona (AN) não foi observada diferença significativa entre os valores obtidos para as áreas com e sem aplicação de biossólido.

O comportamento observado para a primeira fazenda, Entre Rios (latossolo típico), denota a possível influência da disponibilidade material orgânico aplicado junto à comunidade microbiana do solo, levando ao aumento de sua atividade e, consequente, aumento do fluxo de $\mathrm{CO}_{2}$ nas áreas acondicionadas. Contudo, o perfil observado para as amostras referentes à segunda fazenda, Areona (neossolo quartzarênico), manteve-se praticamente inalterado, mesmo após a aplicação de biossólido nas áreas designadas, ratificando a possível falta de afinidade e influência da textura do solo junto à adição de material orgânico fresco e atividade microbiana do solo. Cabe ressaltar que, para a primeira fazenda, mesmo nas áreas sem adição de biossólido, o volume do fluxo de $\mathrm{CO}_{2}$ registrado mostrava-se maior em comparação às áreas analisadas na fazenda Areona, denotando uma possível característica prévia da área, potencializada pela adição de material orgânico fresco. 
Segundo Pontes et al., (2002) os micro-organismos responsáveis pela decomposição e mineralização da MOS utilizam compostos presentes em materiais orgânicos adicionados ao solo como fonte de nutrientes e energia para a formação de sua biomassa.

Contudo, de acordo com Fernandes et al., (2005) o comportamento da população microbiana depende, entre outros fatores, da quantidade e qualidade de resíduo adicionado. Em seu estudo, os mesmos verificaram aumento de 220, 320 e 165\% nas taxas de emissão de $\mathrm{CO}_{2}, \mathrm{~N}_{2} \mathrm{O}$ e $\mathrm{CH}_{4}$, respectivamente, após a aplicação de lodo de esgoto, em comparação à respectiva área de controle.

Em seu estudo, Lopes et al., (2001) verificaram que a respiração do solo foi significativamente maior em áreas sob adição de lodo de esgoto, em comparação às suas respectivas áreas de controle, quando houve aplicação na ordem de 24 e $48 \mathrm{Mg} / \mathrm{ha}$, durante um período de incubação de 2 semanas.

Corroborando, conforme Munier-Lamy e Border (2000) quaisquer mudanças nas características do solo podem levar à alteração de quantidade e atividade de micro-organismos do solo, afetando, consequentemente, processos bioquímicos do solo, e, em casos mais extremos, na fertilidade do solo e crescimento de plantas.

Ainda, de acordo com Leita et al., (1995) o aumento da taxa da respiração do solo após a adição de condicionadores orgânicos pode ser indicativo de maior ciclagem de biomassa microbiana. Em complemento, conforme Islan e Weil (2000) maiores valores da taxa de respiração também podem denotar desequilíbrio ecológico ou aumento de produtividade no ecossistema.

Em sua pesquisa abordando o impacto inerente à aplicação de diferentes tipos de condicionadores orgânicos ao solo em experimentos de longo prazo, Jorge-Mardomingo et al., (2013) verificaram que o uso de lodo de esgoto tratado ocasionou aumento na biomassa microbiana do solo, denotando efeito positivo na atividade microbiana durante o período considerado no experimento. Segundo os mesmos, o comportamento observado deve-se ao aumento das características do solo (formação de agregados, capacidade de retenção de água) e à maior estabilidade de seu conteúdo de matéria orgânica, levando à uma produtividade constantes dos micro-organismos do solo, após a adição do lodo.

Em complemento, de acordo com Silva et al., (2012) a ocorrência de maior biomassa microbiana nos solos é possivelmente relacionada ao conteúdo de argila e matéria orgânica da área em questão.

Dessa forma, o comportamento observado para as fazendas consideradas pode também ser atribuído ao maior conteúdo de argila na fazenda Entre Rios (12 a $16 \%$ ) em detrimento à 
fazenda Areona (5 a $12 \%$ ), fazendo com que a interação entre o conteúdo de matéria orgânica do biossólido adicionado seja maior na primeira fazenda, aumentando a atividade microbiana da área, levando ao maior fluxo de $\mathrm{CO}_{2}$ observado.

Assim sendo, devido ao aumento na produção de lodo de esgoto em território nacional, desde o início das atividades, faz-se de fundamental importância a obtenção de maior conhecimento a respeito dos efeitos da aplicação, em curto e longo prazo, de lodo de esgoto ao solo, principalmente em suas características físicas, químicas e biológicas (Fernandes et al., (2005)).

\subsection{2 Ácidos Húmicos}

\subsubsection{Espectroscopia de Absorção na Região do Infravermelho}

As figuras 40 e 41 ilustram os espectros de infravermelho obtidos para amostras de ácidos húmicos extraídos de solo coletado, em áreas sob adição ou não de biossólido, em ambas fazendas consideradas.

Fig. 40 - Espectros de infravermelho para amostras de AH extraídos de solo proveniente da fazenda Entre Rios, no perfil analisado, sendo: ER LODO - fazenda Entre Rios com adição de biossólido; ER SEM - fazenda Entre Rios sem adição de biossólido.

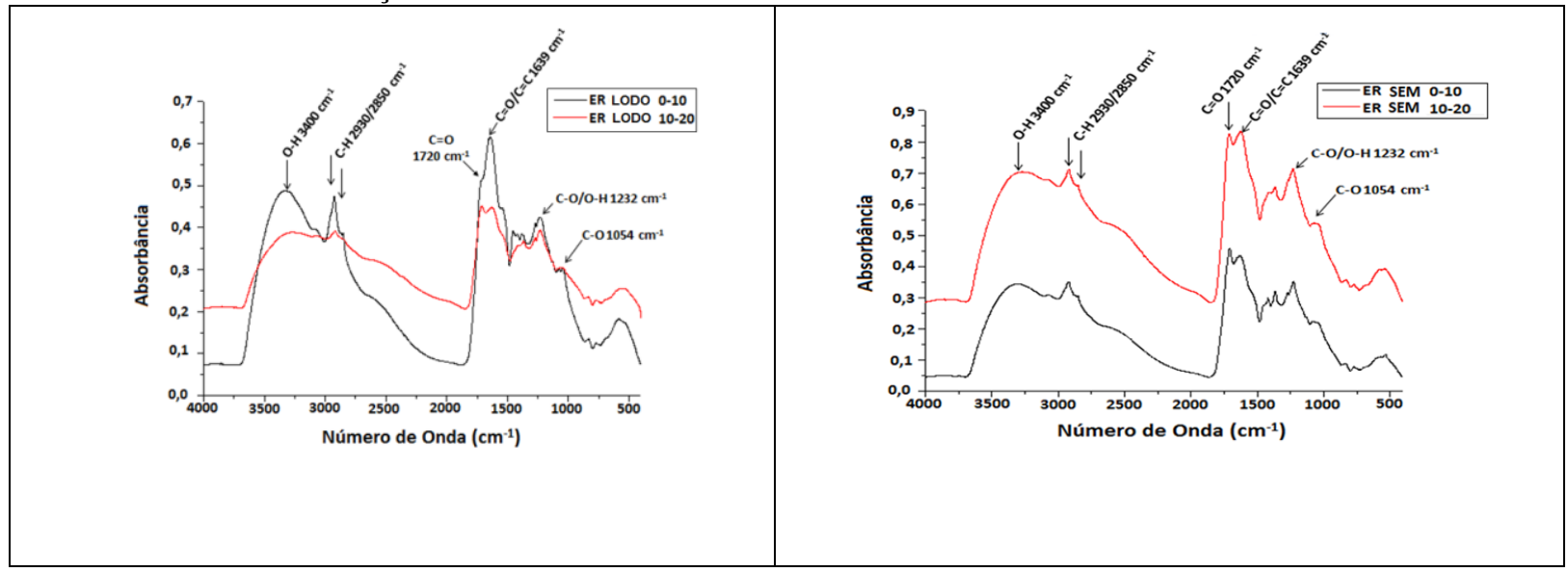

Fig. 41 - Espectros de infravermelho para amostras de AH extraídos de solo proveniente da fazenda Areona, no perfil analisado, sendo: AN LODO - fazenda Areona com adição de biossólido; AN SEM - fazenda Areona sem adição de biossólido.

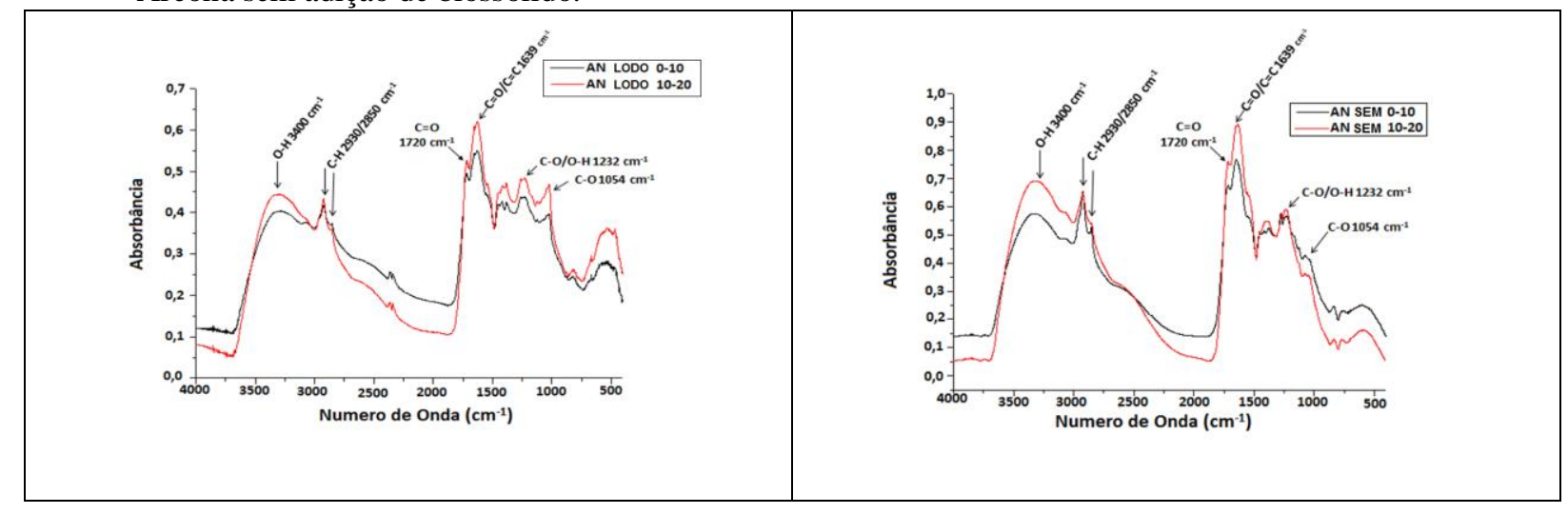


As bandas e picos obtidos apresentaram o perfil esperado em espectros de infravermelho para amostras de ácidos húmicos. Em seu estudo Brunetti et al., (2007) verificaram que os espectros de FTIR, referentes às amostras de ácidos húmicos extraídos de solo sob adição de biossólido, apresentaram modificações, no que tange às características de composição, estruturais e funcionais em detrimento às amostras das áreas de controle.

Segundo os mesmos, os espectros referentes às áreas condicionadas apresentaram aumento de intensidade em bandas atribuídas para compostos alifáticos, amidas e polissacarídeos.

Foi observada, em todos os espectros obtidos, banda larga e intensa na região de 3.400 $\mathrm{cm}^{-1}$, que pode ser atribuída a estiramento de grupos O-H. O mesmo foi observado por Helal et al., (2011) analisando diferentes materiais húmicos.

Em seu estudo, Adani e Tambone (2005) observaram picos mais pronunciados na região de grupamentos $\mathrm{C}$-H alifáticos $\left(2.930 / 2.850 \mathrm{~cm}^{-1}\right)$ em amostras de ácidos húmicos extraídas de solo submetido à adição de lodo, em detrimento as amostras de controle. No entanto, para o presente estudo, tal comportamento foi melhor evidenciado em amostras das areas sem adição de biossolido, em ambas fazendas consideradas.

Observou-se banda menos pronunciada na região de $1.720 \mathrm{~cm}^{-1}$, em todas as amostras analisadas, atribuída a estiramento de grupos $\mathrm{C}=\mathrm{O}$ em grupamentos carboxílicos (FernandezGetino et al., (2010) e Fernandez et al., (2010)).

Foi observada, também, banda na região de $1.639 \mathrm{~cm}^{-1}$, proveniente de superposição de diversos grupos funcionais, tais como aromáticos, quinoides insaturados e carboxilas conjugadas (Fernandez-Getino et al., (2010)), sendo mais pronunciadas em amostras referentes à profundidade de 10-20 para situações analisadas. De acordo com Calderon et al., (2011), apesar da superposição de picos característica desta região, existe predominância de $\mathrm{C}=\mathrm{C}$ aromático. A tabela 22 a seguir lista os picos e bandas mais pronunciadas observadas nas amostras em análise.

Tabela 22 - Identificação dos picos e bandas destacados nos espectros de infravermelho obtidos para as amostras analisadas

\begin{tabular}{|c|c|c|}
\hline Número de Onda $\left(\mathbf{c m}^{-1}\right)$ & Atribuição & Referência \\
\hline 3400 & Estiramento $\mathrm{O}-\mathrm{H}$ & Helal et al., (2011) \\
\hline $2930 / 2850$ & Estiramento C $-\mathrm{H}$ alifático & Fernandez-Getino et al., (2010) \\
\hline 1720 & Agrupamento C = O de acido carboxílico & Calderon et al., (2011) \\
\hline 1639 & $\begin{array}{c}\text { Overlapping de picos com predominância de C }=\mathrm{C} \\
\text { aromático }\end{array}$ & Fernandez-Getino et al., (2010) \\
\hline 1232 & Estiramento grupos C-O de fenóis, aril-esteres e \\
& carboxilas & Fernandes et al., (2010) \\
\hline 1054 & Agrupamento C - O de polissacarídeos & \\
\hline
\end{tabular}


Observou-se banda na região de $1.232 \mathrm{~cm}^{-1}$, que pode ser atribuída a estiramento de grupos C-O e, ainda, deformação O-H em COOH (Helal et al., (2011), Fernandez-Getino et al., (2010) e Fernandes et al., (2010)). Outros autores também atribuem esta banda a materiais com características de lignina (Adani e Tambone (2005)).

Foi observado também, banda na região de $1.054 \mathrm{~cm}^{-1}$, podendo atribuída a estiramento C-O em polissacarídeos e/ou alcoóis (Fernandez-Getino et al., (2010)), bem como impurezas provenientes de silicatos (Helal et al., (2011)).

Da mesma maneira como realizado para as amostras referentes à área experimental 1, foram calculados os índices de condensação e hidrofobicidade (IC e IH, respectivamente) para as amostras de ácidos húmicos analisadas, utilizando-se a razão de intensidade de absorbância em 1.639 e 2.930 para IC e 2.930 e 1.232 para IH. A tabela 23 a seguir lista os valores obtidos para os índices.

Tabela 23 - Índices de condensação (IC) e hidrofobicidade (IH) para amostras de ácidos húmicos extraídos de solo coletado em ambas as fazendas, sendo: ER LODO - fazenda Entre Rios com adição de biossólido; ER SEM - fazenda Entre Rios sem adição de biossólido; AN LODO - fazenda Areona com adição de biossólido; AN SEM - fazenda Areona sem adição de biossólido.

\begin{tabular}{|c|c|c|c|c|c|c|c|c|}
\hline Amostra & \multicolumn{2}{|c|}{ ER LODO } & \multicolumn{2}{c|}{ ER SEM } & \multicolumn{2}{c|}{ AN LODO } & \multicolumn{2}{c|}{ AN SEM } \\
\hline Profundidade (cm) & $\mathbf{0 - 1 0}$ & $\mathbf{1 0 - 2 0}$ & $\mathbf{0 - 1 0}$ & $\mathbf{1 0 - 2 0}$ & $\mathbf{0 - 1 0}$ & $\mathbf{1 0 - 2 0}$ & $\mathbf{0 - 1 0}$ & $\mathbf{1 0 - 2 0}$ \\
\hline IC (1.639/2.930) & 1,30 & 1,15 & 1,23 & 1,19 & 1,23 & 1,38 & 1,15 & 1,38 \\
\hline IH (2.930/1.232) & 1,12 & 1,00 & 1,00 & 0,99 & 0,96 & 0,90 & 1,18 & 1,10 \\
\hline
\end{tabular}

Através dos valores obtidos, pôde-se observar aumento nos índices de condensação, em ambas as fazendas consideradas, nas áreas condicionamento com biossólido em comparação às suas respectivas áreas de controle. Cabe ressaltar ainda que, nos dois locais analisados, foi observado aumento levemente mais pronunciado nas camadas superficiais (010) em detrimento à subsequente (10-20), com maiores valores obtidos para amostras da fazenda Entre Rios.

Conforme discutido anteriormente, tal índice é diretamente relacionado ao grau de humificação, dessa maneira observa-se que as amostras de ácidos húmicos referentes à fazenda Entre Rios apresentam possível característica de maior humificação em comparação às amostras da fazenda Areona. Uma hipótese para explicar tal comportamento, uma vez mais, é o fato de que o perfil de solo característico da primeira fazenda (latossolo) propicia melhor interação entre a carga de material orgânico adicionado e teor de MOS do solo, causando provável aumento na atividade microbiana do solo e consequente consumo da 
fração mais lábil do solo, remanescendo a parcela mais recalcitrante em seus constituintes húmicos (neste caso, o ácido húmico).

Quanto ao índice de hidrofobicidade, nota-se decréscimo em todo o perfil analisado, em ambas as fazendas, mesmo em áreas submetidas à adição de biossólido. De acordo com Freixo et al., (2002) este índice é diretamente proporcional à resistência a atividade microbiana do solo (quanto maior IH, mais resistente).

De acordo com Capriel et al., (1997) a hidrofobicidade da MOS (consequentemente, de seus constituintes húmicos) é causada por unidades alifáticas $\mathrm{C}-\mathrm{H}$ presentes em grupos metil e metileno. Segundo o mesmo, a quantidade de tais unidades controla a afinidade com a água, que, por sua vez, influencia diretamente em propriedades cruciais da MOS, tal como a estabilidade contra degradação pela atividade microbiana.

Dessa maneira, conforme os resultados obtidos, pode-se observar maior vulnerabilidade à degradação pela atividade microbiana, em profundidade, nas áreas sob adição de biossólido, para ambas fazendas. Contudo, este comportamento é contraditório, levando-se em consideração o aumento de IC nas mesmas áreas. Uma possível hipótese explicativa seria o fato de que ainda existiria material de característica lábil em profundidade, além da parcela recalcitrante, mesmo após a ação microbiana, acelerada pelo aporte de material orgânico fresco (biossólido).

Em seu estudo, abordando manejos diferenciados de solo, Simon et al., (2009) verificaram a mesma tendência de decréscimo em profundidade no índice de hidrofobicidade em áreas sob manejo convencional e incorporação de resíduos de culturas.

Entretanto, mais uma vez em se tratando de amostras provenientes de campo experimental, existe a necessidade de resultados complementares através de outras técnicas, para obtenção de dados mais conclusivos.

\subsubsection{Espectroscopia de Absorção na Região do Ultravioleta e Visível (UV-Vis)}

As figuras 42 e 43 ilustram o comportamento dos espectros de absorção de radiação UV-Vis obtidos para amostras de ácidos húmicos extraídos de solo submetidos ou não à adição de biossólido, considerando ambas as fazendas analisadas. 
Fig. 42 - Espectros de absorção de UV Vis, para amostras de AH extraídos de solo proveniente da fazenda Entre Rios, no perfil analisado, sendo: ER LODO- fazenda Entre Rios com adição de biossólido; ER SEM - fazenda Entre Rios sem adição de biossólido

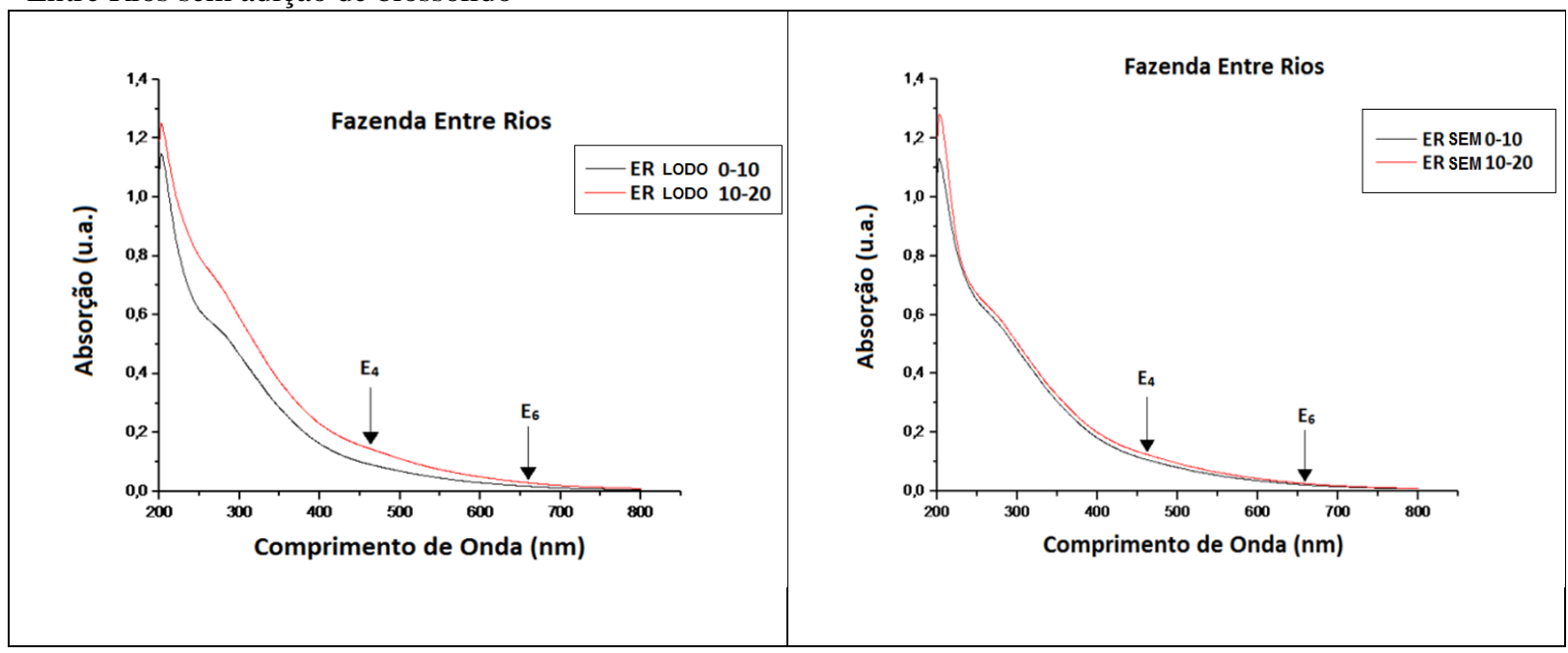

Fig. 43 - Espectros de absorção de UV Vis, para amostras de AH extraídos de solo proveniente da fazenda Areona, no perfil analisado, sendo: AN LODO - fazenda Areona com adição de biossólido; AN SEM fazenda Areona sem adição de biossólido.

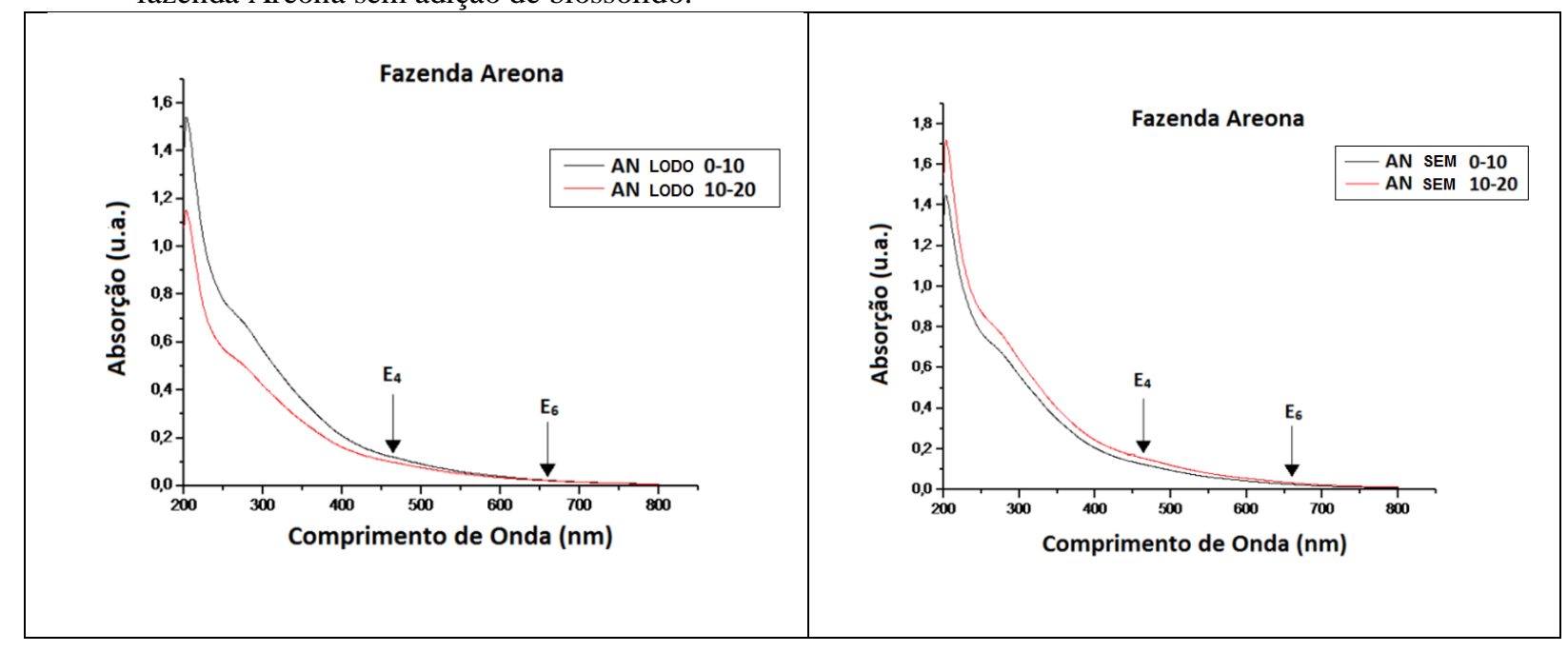

De acordo com Skoog et al., (2002) espectros nesta região obtidos para moléculas orgânicas (como é o caso de $\mathrm{AH}$ ) são, em sua maioria, complexos devido à combinação de linhas superpostas originada pela superposição de transições vibracionais e eletrônicas, observando-se, dessa forma, uma banda larga que geralmente parece ser contínua.

Contudo, para melhor obtenção de informações através desta técnica, a literatura propõe o quociente entre os valores de intensidade de absorção em 465 e $665 \mathrm{~nm}$, dando origem ao índice conhecido por razão $\mathrm{E}_{4} / \mathrm{E}_{6}$, provendo maiores detalhes acerca do grau de condensação (e, consequente humificação) das amostras em análise. 
A seguir, tabela 24 listando os valores de razão $\mathrm{E}_{4} / \mathrm{E}_{6}$ obtidos para as amostras de ácidos húmicos, extraídos do solo de ambas fazendas em análise.

Tabela 24 - Valores de razão $\mathrm{E}_{4} / \mathrm{E}_{6}$ para amostras de ácidos húmicos extraídos de solo coletado em ambas as fazendas, sendo: ER LODO - fazenda Entre Rios com adição de biossólido; ER SEM fazenda Entre Rios sem adição de biossólido; AN LODO - fazenda Areona com adição de biossólido; AN SEM - fazenda Areona sem adição de biossólido.

\begin{tabular}{|c|c|c|c|c|c|c|c|c|}
\hline Amostra & \multicolumn{2}{|c|}{ ER LODO } & \multicolumn{2}{c|}{ ER SEM } & \multicolumn{2}{c|}{ AN LODO } & \multicolumn{2}{c|}{ AN SEM } \\
\hline Profundidade (cm) & $\mathbf{0 - 1 0}$ & $\mathbf{1 0 - 2 0}$ & $\mathbf{0 - 1 0}$ & $\mathbf{1 0 - 2 0}$ & $\mathbf{0 - 1 0}$ & $\mathbf{1 0 - 2 0}$ & $\mathbf{0 - 1 0}$ & $\mathbf{1 0 - 2 0}$ \\
\hline Razão $\mathbf{E}_{\mathbf{4}} / \mathbf{E}_{\mathbf{6}}$ & $5,41 \pm 0,13$ & $5,06 \pm 0,09$ & $5,07 \pm 0,21$ & $4,94 \pm 0,03$ & $5,48 \pm 0,20$ & $4,99 \pm 0,02$ & $5,17 \pm 0,11$ & $4,88 \pm 0,09$ \\
\hline
\end{tabular}

Pôde-se observar, pelos dados obtidos, maiores valores de razão $\mathrm{E}_{4} / \mathrm{E}_{6}$ para amostras submetidas à adição de biossólido em ambas as fazendas analisadas, no perfil considerado, em detrimento às suas respectivas áreas de controle (sem adição de lodo). Cabe ressaltar que não foi observada diferença significativa entre os valores obtidos, considerando as fazendas entre si.

Tal comportamento sugere um maior grau de condensação para as áreas sem adição de biossólido, em ambas fazendas, em comparação às condicionadas. De acordo com MartinNeto e $\mathrm{Saab}$ (2007) a razão $\mathrm{E}_{4} / \mathrm{E}_{6}$ é relacionada à condensação estrutural, sendo indicativo de grau de humificação, aromaticidade e massa molecular, sendo que quanto maior a razão, menor é a quantidade de anéis aromáticos condensados que podem ser associados à MOS.

Ainda, segundo Polak et al., (2009) baixos valores de razão $\mathrm{E}_{4} / \mathrm{E}_{6}$ podem ser atribuídos a absorção por grupos $\mathrm{C}=\mathrm{C}$ de aromáticos. Conforme os mesmos acredita-se que um alto grau de condensação de anéis aromáticos e alto valor de massa molecular de $\mathrm{AH}$ contribuem para tal maior absorção no espectro visível. Por outro lado, um alto valor de razão $\mathrm{E}_{4} / \mathrm{E}_{6}$ leva a uma massa molecular aparente de $\mathrm{AH}$ mais baixa. Além disso, também é indicativo de maiores acidez total e grau de aromatização de substâncias húmicas.

Contudo, por se tratar de uma técnica espectroscópica que apresenta interpretações controversas na literatura, seus dados devem ser analisados em conjunto com resultados fornecidos por outras técnicas, possibilitando a obtenção de informações mais completas.

\subsubsection{Espectroscopia de Fluorescência de Luz UV-Vis}

\subsection{Espectros de Emissão}

Os espectros de emissão, para as amostras de ácidos húmicos em análise, foram obtidos de acordo com as metodologias de Milori et al., (2002) e Zsolnay et al., (1999). As figuras 44 e 45 a seguir ilustram os espectros conforme a primeira, ao passo que as figuras 46 e 47 mostram os espectros obtidos conforme a segunda. 
Conforme constatado por Milori et al., (2002) comprimentos de onda na região do azul (465 nm) apresentam maior eficiência na excitação de estruturas conjugadas, cujas concentrações aumentam durante o processo de humificação. Dessa forma, os autores propuseram a adoção da área obtida sob o espectro de emissão, com excitação em 465 nm, como diretamente proporcional ao grau de humificação da amostra em análise, gerando o índice denominado $A_{465 \mathrm{~nm}}$.

Fig. 44 - Espectros de emissão de fluorescência obtidos pela metodologia de Milori et al., 2002, para amostras de AH extraídos de solo proveniente da fazenda Entre Rios, no perfil analisado, sendo: ER LODO fazenda Entre Rios com adição de biossólido; ER SEM - fazenda Entre Rios sem adição de biossólido.

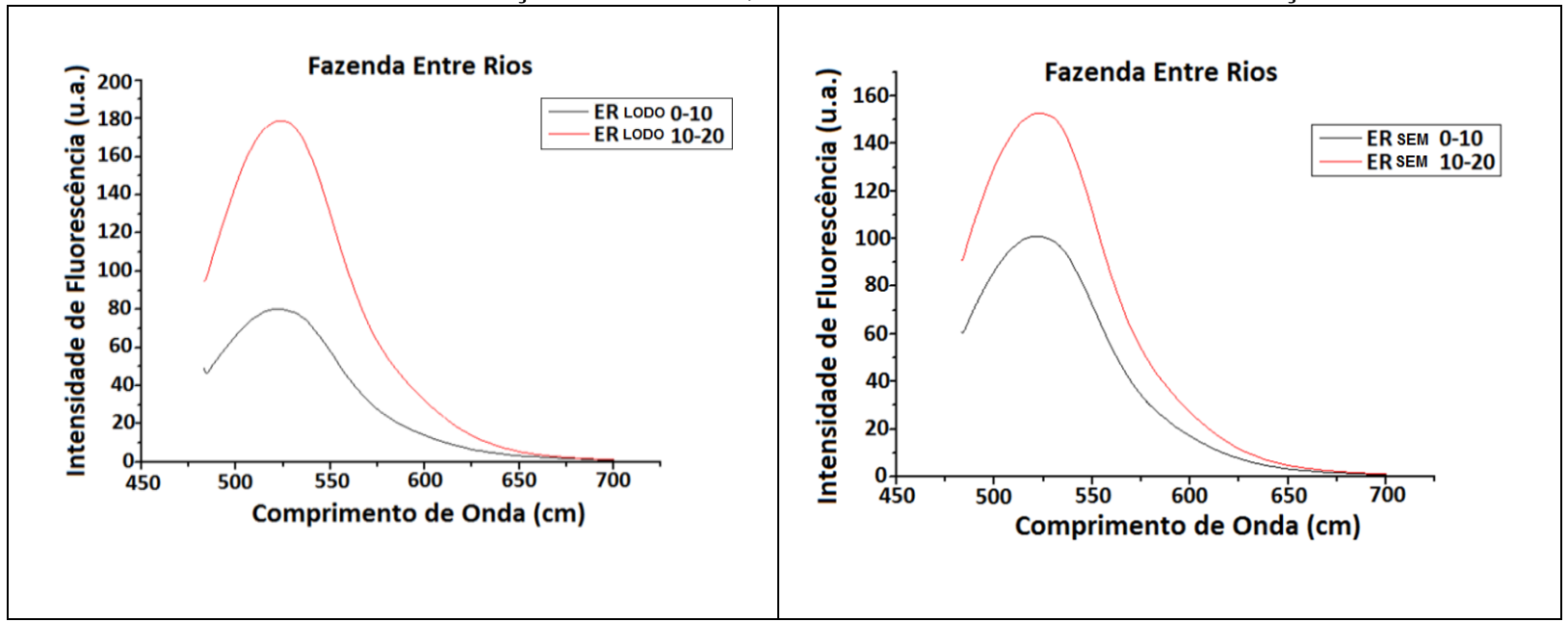

Fig. 45 - Espectros de emissão de fluorescência obtidos pela metodologia de Milori et al., 2002, para amostras de AH extraídos de solo proveniente da fazenda Areona, no perfil analisado, sendo: AN LODO fazenda Areona com adição de biossólido; AN SEM - fazenda Areona sem adição de biossólido.

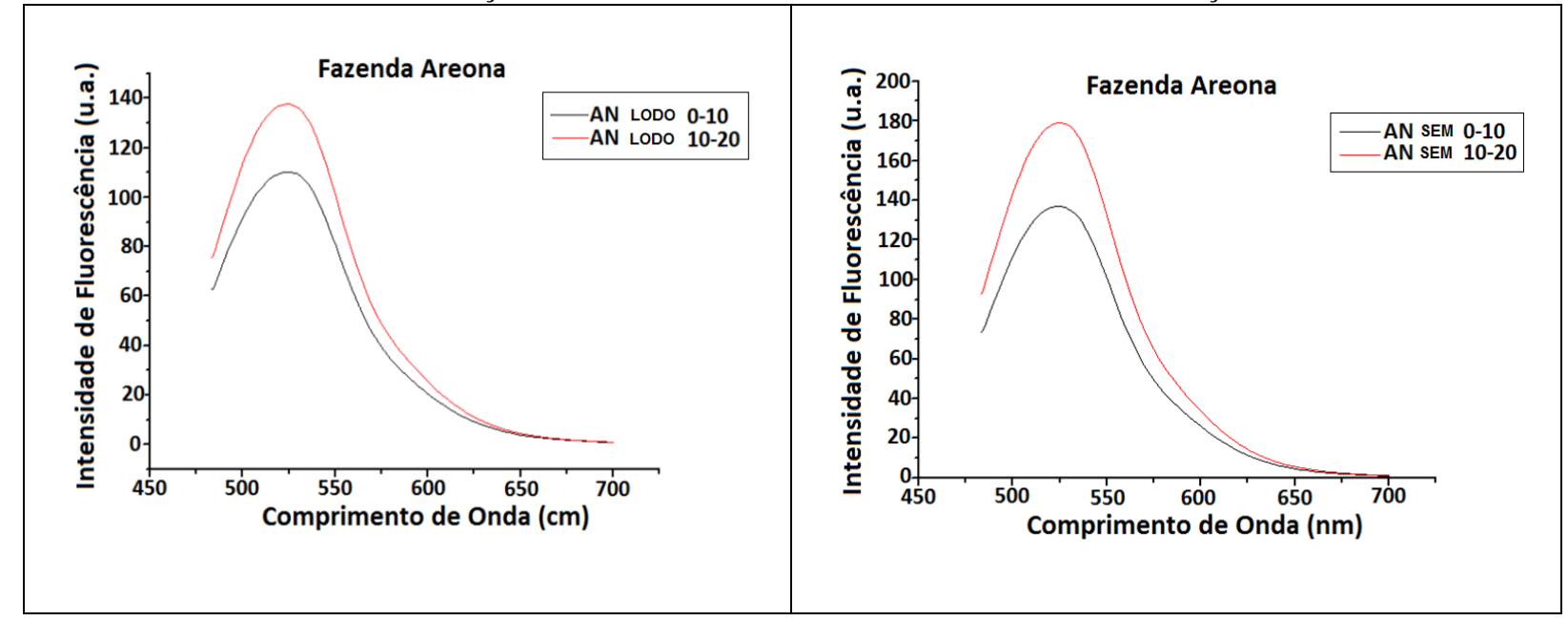

Zsolnay et al., (1999) trabalharam utilizando excitação com radiação ultravioleta, com comprimento de onda em 240 nm, em amostras de matéria orgânica em solução e observaram que o sinal de fluorescência dos espectros de emissão obtido apresentou deslocamento para comprimentos de ondas maiores, caracterizando, dessa forma, uma continuidade no processo de humificação. 
Assim sendo, à medida que moléculas fluorescentes tornam-se mais condensadas, seus espectros de emissão, de acordo com os parâmetros propostos, também tenderão a apresentar deslocamento para comprimento de ondas maiores.

Para esta metodologia, o grau de humificação da amostra em análise é obtido fracionando-se a área sob o espectro em quatro partes e efetuando-se o quociente entre o último quarto (561-640 nm) e o primeiro quarto $(327-405 \mathrm{~nm})$, originando índice denominado $A_{4} / A_{1}$.

Fig. 46 - Espectros de emissão de fluorescência obtidos pela metodologia de Zsolnay et al., 1999, para amostras de AH extraídos de solo proveniente da fazenda Entre Rios, no perfil analisado, sendo: ER LODO fazenda Entre Rios com adição de biossólido; ER SEM - fazenda Entre Rios sem adição de biossólido.

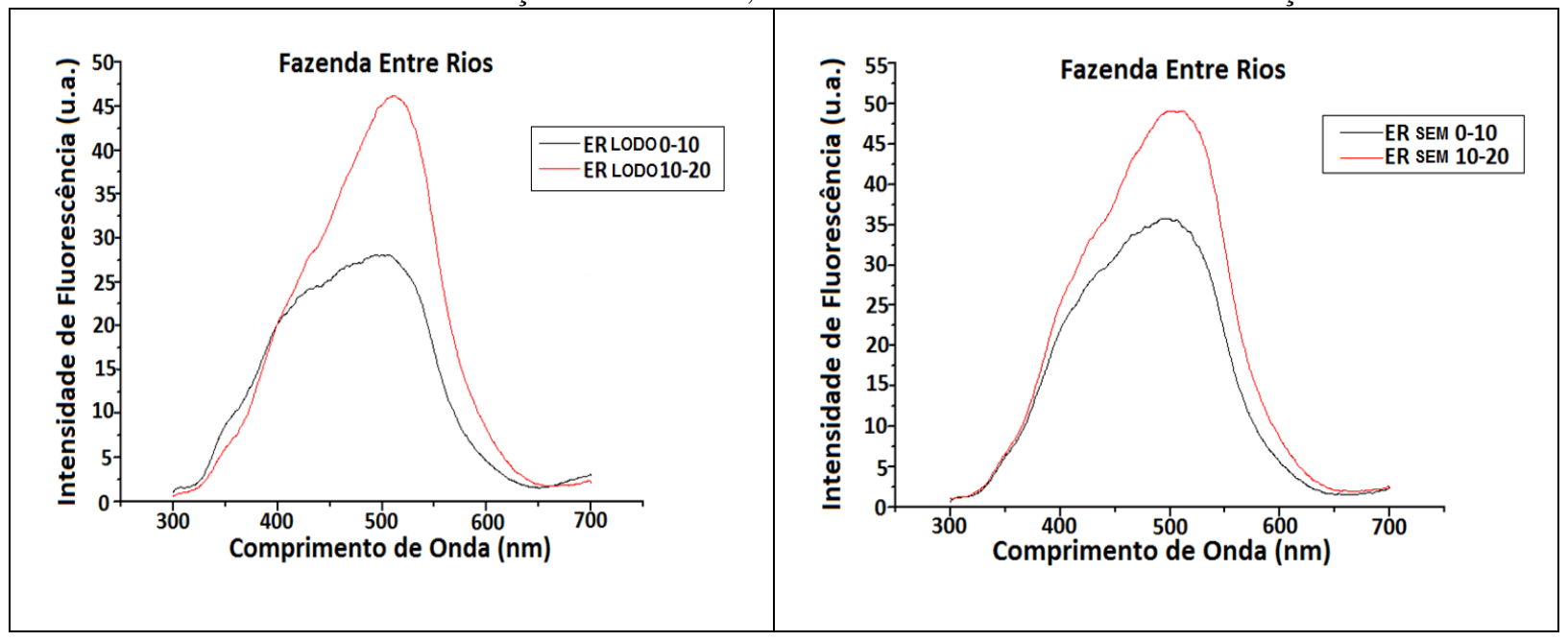

Fig. 47 - Espectros de emissão de fluorescência obtidos pela metodologia de Zsolnay et al., 1999, para amostras de AH extraídos de solo proveniente da fazenda Areona, no perfil analisado, sendo: AN LODO fazenda Areona com adição de biossólido; AN SEM - fazenda Areona sem adição de biossólido.

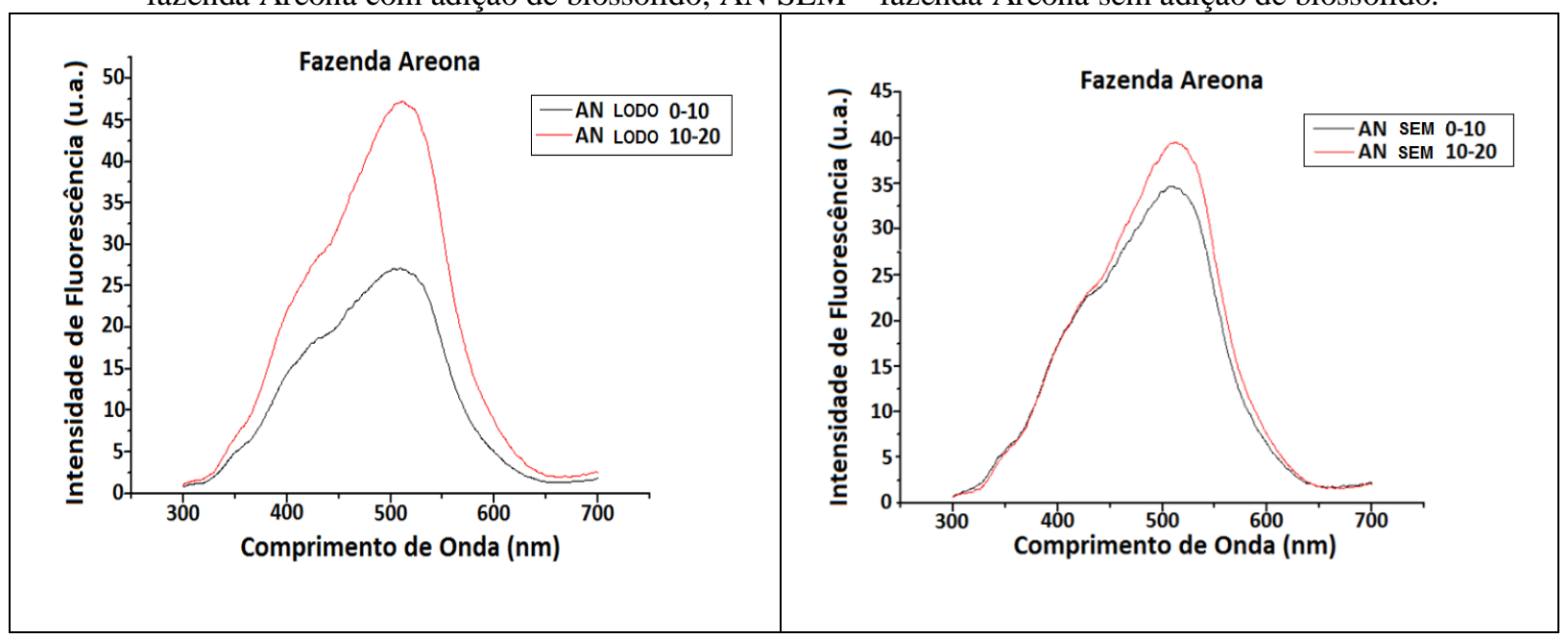

\subsection{Espectros de Varredura Sincronizada}

A metodologia proposta por Kalbitz et al., (1999) obtém espectros através de varredura sincronizada, medidos com diferença de comprimento de onda constante em $55 \mathrm{~nm}$, 
entre emissão e excitação e propõe que espectros de fluorescência sincronizados apresentam dois picos de maior intensidade, evidenciados em, aproximadamente, 360 e $465 \mathrm{~nm}$.

O princípio da técnica baseia-se na suposição do deslocamento do máximo de fluorescência de comprimentos de ondas mais curtos para mais longos, sendo atribuído à presença de sistemas aromáticos condensados. Neste caso, o índice de humificação é obtido pelo quociente entre os valores de maior e menor intensidade observados, em seus respectivos comprimento de onda, neste caso $\mathrm{I}_{472} / \mathrm{I}_{375}$. As figuras 48 e 49 a seguir ilustram os espectros obtidos de acordo com esta metodologia.

Fig. 48 - Espectros de varredura sincronizada de fluorescência obtidos pela metodologia de Kalbitz et al., 1999, para amostras de AH extraídos de solo proveniente da fazenda Entre Rios, no perfil analisado, sendo: ER LODO - fazenda Entre Rios com adição de biossólido; ER SEM - fazenda Entre Rios sem adição de biossólido

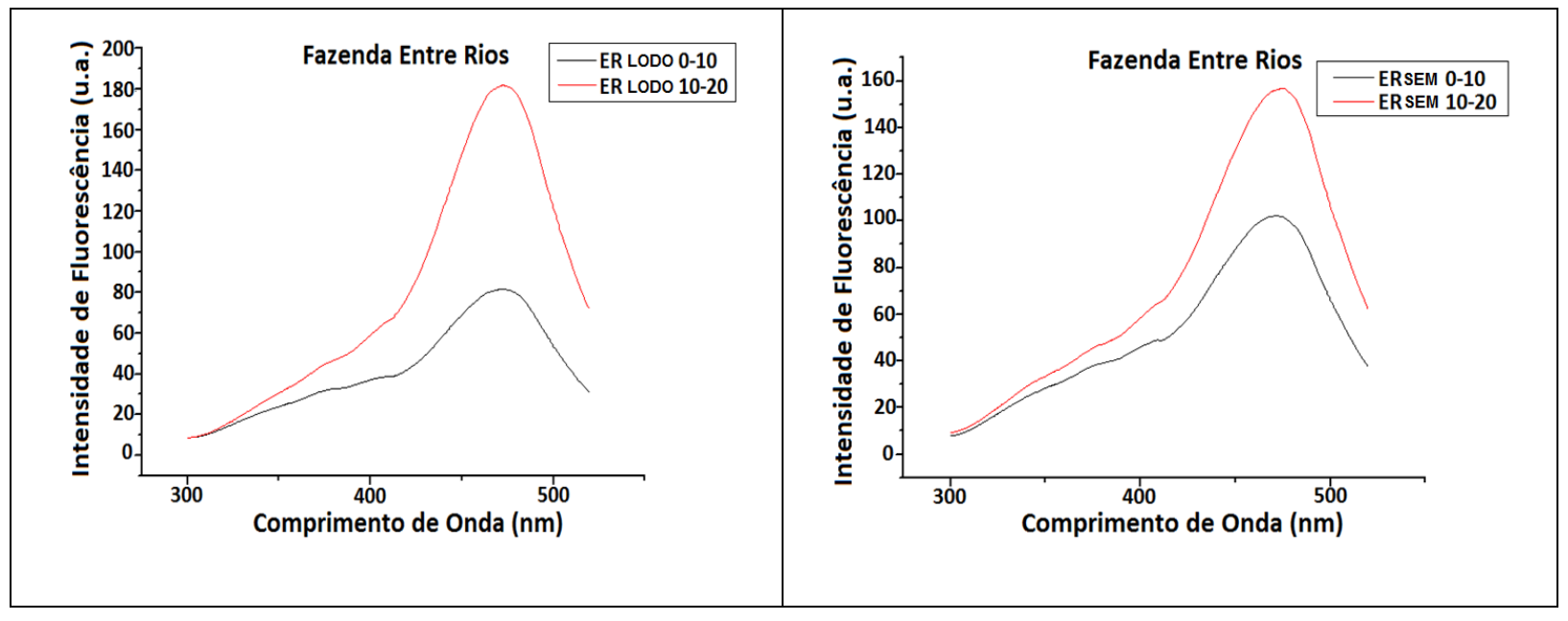

Fig. 49 - Espectros de varredura sincronizada de fluorescência obtidos pela metodologia de Kalbitz et al., 1999, para amostras de AH extraídos de solo proveniente da fazenda Areona, no perfil analisado, sendo: AN LODO - fazenda Areona com adição de biossólido; AN SEM - fazenda Areona sem adição de biossólido

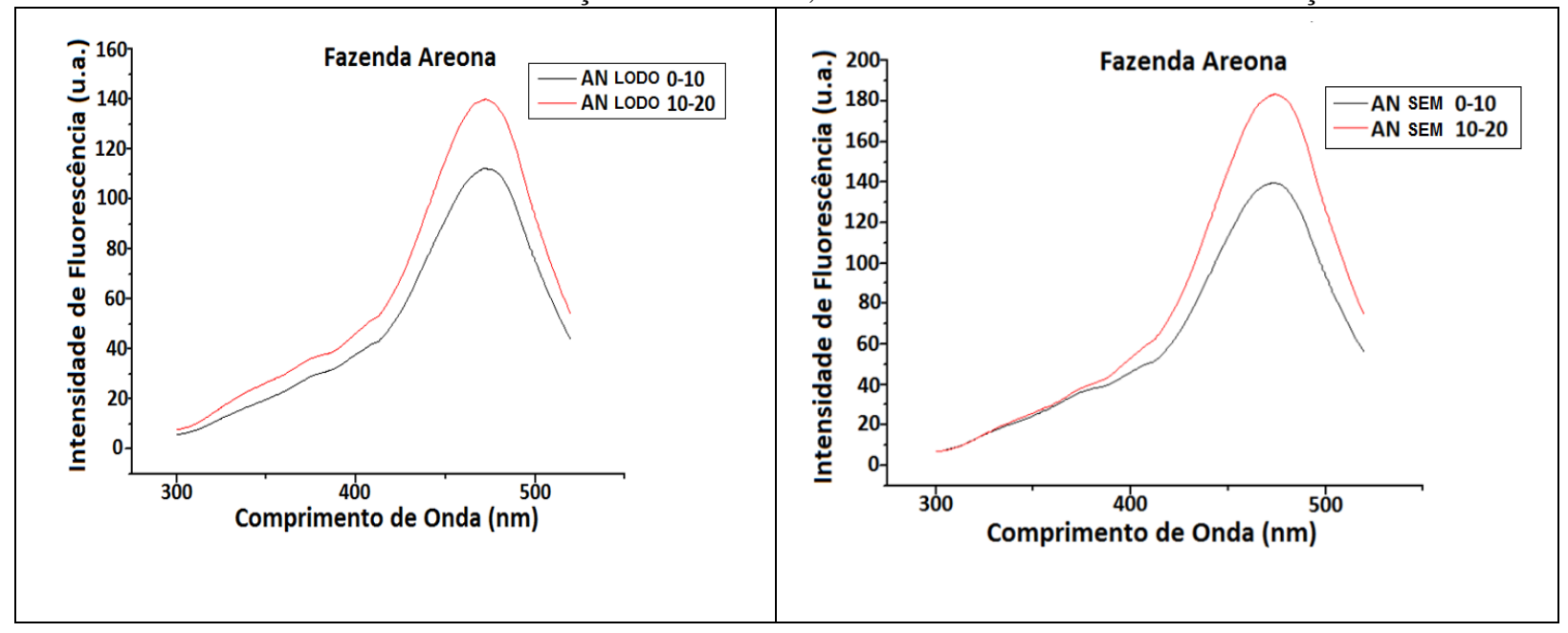

Os resultados obtidos para as amostras de ácidos húmicos, provenientes de solo coletado na fazenda Entre Rios, demonstraram, levando-se em consideração as metodologias 
consideradas, menor grau de humificação na parcela 0-10 cm em área condicionada com lodo, e maior grau de humificação nas parcelas subsequentes, para esta mesma área em comparação à não submetida a adição de lodo. Contudo, o perfil observado para amostras referentes à fazenda Areona foi de maiores valores de grau de humificação, em ambas camadas analisadas, em áreas sem adição de biossólido. A tabela 18 a seguir lista os valores de grau de humificação obtidos para as amostras em análise, de acordo com as metodologias empregadas.

Tabela 25 - Valores de grau de humificação para amostras de ácidos húmicos extraídos de solo coletado em ambas as fazendas, sendo: ER LODO - fazenda Entre Rios com adição de biossólido; ER SEM - fazenda Entre Rios sem adição de biossólido; AN LODO - fazenda Areona com adição de biossólido; AN SEM fazenda Areona sem adição de biossólido. * Valores expressos em notação $\left(x 10^{3}\right)$

\begin{tabular}{|c|c|c|c|c|c|c|c|c|}
\hline Amostra & \multicolumn{2}{|c|}{ ER LODO } & \multicolumn{2}{c|}{ ER SEM } & \multicolumn{2}{c|}{ AN LODO } & \multicolumn{2}{c|}{ AN SEM } \\
\hline Profundidade (cm) & $\mathbf{0 - 1 0}$ & $\mathbf{1 0 - 2 0}$ & $\mathbf{0 - 1 0}$ & $\mathbf{1 0 - 2 0}$ & $\mathbf{0 - 1 0}$ & $\mathbf{1 0 - 2 0}$ & $\mathbf{0 - 1 0}$ & $\mathbf{1 0 - 2 0}$ \\
\hline $\boldsymbol{A}_{\mathbf{4 6 5 n \boldsymbol { m }}}{ }^{*}$ & $6,65 \pm 2,24$ & $14,72 \pm 1,27$ & $8,32 \pm 0,56$ & $12,71 \pm 0,68$ & $9,20 \pm 0,32$ & $11,41 \pm 1,99$ & $11,37 \pm 2,49$ & $14,78 \pm 1,39$ \\
\hline $\boldsymbol{A}_{\boldsymbol{4}} \boldsymbol{A}_{\boldsymbol{I}}$ & $0,45 \pm 0,20$ & $0,94 \pm 0,04$ & $0,59 \pm 0,06$ & $0,81 \pm 0,01$ & $0,75 \pm 0,10$ & $0,89 \pm 0,02$ & $0,81 \pm 0,16$ & $0,98 \pm 0,08$ \\
\hline $\mathbf{I}_{\mathbf{4 7 2}} \mathbf{I}_{\mathbf{3 7 5}}$ & $2,57 \pm 0,67$ & $4,07 \pm 0,04$ & $2,70 \pm 0,54$ & $3,43 \pm 0,60$ & $3,87 \pm 0,63$ & $3,86 \pm 0,17$ & $3,83 \pm 0,59$ & $4,77 \pm 0,74$ \\
\hline
\end{tabular}

Conforme Santos et al., (2010) os índices de humificação indicam a ocorrência de fluoróforos em amostras de $\mathrm{AH}$. Estes fluoróforos estão relacionados à presença de sistemas altamente conjugados, possivelmente em estruturas aromáticas (sistemas policondensados), e à substituição destas estruturas por grupos funcionais contendo oxigênio ou nitrogênio (Milori et al., (2002)).

De acordo com Ikeya et al., (2011) é censo comum o fato de que anéis aromáticos e cadeias alifáticas constituam a base estrutural de substâncias húmicas do solo. O conteúdo de $\mathrm{C}$ aromático em $\mathrm{AH}$ de solo varia, e aumenta de acordo com grau de humificação, alcançando cerca de $70 \%$ do C total. Segundo os mesmos, é esperado que estruturas aromáticas condensadas sejam mais resistentes à degradação, e, assim, contribuam para maiores teores de $\mathrm{C}$ aromático em $\mathrm{AH}$ com maior grau de humificação e/ou maior tempo de residência no solo. Ainda, o conteúdo e grau de condensação anéis aromáticos polinucleares aumenta de acordo com o aumento de grau de humificação, sugerindo que a preservação, incorporação ou formação de compostos aromáticos condensados contribui para o aumento no grau de humificação e aromaticidade de AH de solo.

De acordo com Senesi et al., (2007) amostras de ácidos húmicos de solos sob aplicação de lodo de esgoto apresentaram diferenças notáveis, no que concerne às propriedades de fluorescência, em comparação às suas respectivas áreas de controle, indicando, dessa maneira, alterações na estrutura química e grau de humificação, inerentes à 
adição do material orgânico. Conforme Bastida et al., (2012) a adição de materiais orgânicos frescos, ou maturados, atuam em diferentes níveis na reabilitação do solo ao fornecerem diferentes substratos. Materiais orgânicos frescos são os mais prontamente utilizados pelos micro-organismos do solo, ao passo que os materiais maturados fornecem compostos polimerizados mais recalcitrantes, os mais são facilmente incorporados às $\mathrm{SH}$ do solo.

Assim sendo, de acordo com os dados obtidos, nota-se maior interação entre o material adicionado e os $\mathrm{AH}$, levando ao maior grau de condensação, menor taxa de decomposição, e consequente resistência à degradação microbiana, em camadas mais profundas nas áreas sob adição de lodo na fazenda Entre Rios. Ao passo que na fazenda Areona não foi observada interação tão pronunciada entre o biossólido e o conteúdo de MOS de sua área de estudo, acarretando em menores valores de grau de humificação em áreas condicionadas, comparando-se com sua respectiva área de controle.

Ainda, diversos estudos tem avaliado o impacto da adição de lodo de esgoto junto à MOS e seus constituintes húmicos. Em sua pesquisa, Bertoncini et al., (2005), utilizando espectroscopia de fluorescência, verificaram menor heterogeneidade e menores caráter aromático, policondensação e grau de humificação para amostras de ácidos húmicos extraídos de solo sob adição de lodo de esgoto. De acordo com os mesmos, o perfil observado sugere a possível incorporação de compostos moleculares de baixa massa molecular, previamente presentes no lodo de esgoto, aos ácidos húmicos do solo.

Santos et al., (2010) em sua análise de MOS e AH em áreas sob adição de lodo de esgoto, observaram menores graus de humificação em amostras condicionadas com lodo, inferindo uma possível diferença na constituição química entre lodo e MOS/AH. Ainda assim, notou-se que a adição deste material provocou alteração nas características da MOS. Em pesquisa conduzida por Margherita et al., (2006) resultados obtidos através de análise elementar, FTIR e espectroscopia de fluorescência de amostras de ácidos húmicos isolados de solos condicionados com lodo de esgoto, apontaram a incorporação de material húmico proveniente do próprio lodo aos constituintes húmicos originais da área em questão, proporcionado um aumento significativo na qualidade agronômica e características químicas do solo.

Entretanto, levando-se em consideração a incerteza acerca da estrutura molecular precisa dos $\mathrm{AH}$ e o conhecimento obtido até o presente, a adição de biossólido ao solo é considerada como prática que pode trazer benefícios, pela inclusão de material orgânico fresco ao conteúdo de MOS, apesar da diminuição do grau de humificação em algumas áreas (Santos et al., (2010)). 


\section{CONCLUSÃO}

O objetivo do presente estudo foi avaliar e caracterizar a dinâmica e reatividade da matéria orgânica do solo (MOS) frente a diferentes práticas de uso do solo, no que concerne ao acúmulo e sequestro de carbono, em campos experimentais com condições climáticas diferenciadas.

O entendimento e avaliação da resposta da matéria orgânica e seus constituintes húmicos frente a diferentes situações é de extrema importância para obtenção de sustentabilidade ambiental, no que concerne à mitigação de efeitos inerentes às mudanças climáticas globais. Os resultados obtidos em ambos os campos apresentaram comportamento distinto, no que tange às suas respectivas condições a que os experimentos foram conduzidos.

No que concerne ao conteúdo de carbono em amostras de solo para o campo experimental norte-americano, verificou-se que, em profundidade, os sistemas orgânicos apresentaram maior teor de carbono, quando comparados aos sistemas de plantio direto (PD) e convencional (PC). O comportamento observado sugere maior incorporação de materiais orgânicos em profundidade, além de provável maior disponibilidade de substratos para a comunidade microbiana do solo.

Ainda, nas parcelas superficiais, foi observado maior conteúdo de carbono (cerca de $20 \%$ ) para os sistemas de PD em detrimento aos demais, inferindo menor reflexo dos sistemas orgânicos nas camadas superficiais do solo, ratificando uma vez mais o efeito da incorporação em profundidade de material orgânico adicionado.

Não houve, contudo, diferença significativa entre os sistemas orgânicos analisados. Assim, para este caso, a diferença entre os períodos de rotação de culturas (2,3 e 6 anos) e frequência de aporte de material orgânico fresco (esterco aviário), característicos dos sistemas de agricultura orgânica considerados, não apresentou impacto aparente no que diz respeito ao acúmulo de carbono.

No que tange ao conteúdo de carbono nas frações leve-livre e leve-oclusa da matéria orgânica particulada (MOP), também foi verificado maior teor de carbono em amostras referentes aos sistemas orgânicos, frente aos sistemas de PD e PC, desde as camadas superficiais do perfil considerado, inferindo a característica inerente aos sistemas orgânicos de maior disponibilidade de material orgânico, em detrimento aos demais sistemas abordados.

Logo, pela análise das diferentes situações de campo consideradas, pôde-se observar o efeito inerente às práticas de agricultura orgânica, em detrimento às demais, verificado pelos maiores teores de carbono nas frações de MOP analisadas, o que possivelmente representa maior disponibilidade de material orgânico fresco exógeno, atuando como fonte de nutrientes 
para a biomassa microbiana, e, consequentemente, acarretando em maior oclusão, provavelmente ocasionada pela atividade microbiana do solo, levando à proteção intraagregado de material orgânico.

Os resultados dos índices obtidos pela interpretação dos espectros de infravermelho mostraram maior grau de condensação em profundidade, para amostras de ambas as frações de MOP consideradas referentes aos sistemas orgânicos, apontando, ainda, possível incidência de estruturas suscetíveis à degradação microbiana.

Através dos dados obtidos pela técnica de PY - GC/MS observou-se maior número e variedade de estruturas moleculares para a fração livre em comparação à fração oclusa, especialmente em amostras referentes aos sistemas orgânicos. Ainda, foi verificada maior incidência de estruturas moleculares de caráter aromático na fração oclusa, e maior ocorrência de núcleos ligados a cadeias alifáticas na fração livre.

Assim, pelas características químicas das estruturas moleculares observadas para as frações de MOP consideradas, pôde-se inferir um caráter mais homogêneo, provavelmente mais biologicamente transformado, e, consequentemente, mais recalcitrante, para a fração oclusa, ao passo que, para a fração livre, caráter mais heterogêneo, maior ocorrência de cadeias alifáticas de característica lábil, com maior vulnerabilidade a atividade microbiana do solo.

Dessa forma, os resultados obtidos para o campo experimental norte-americano ilustraram maior impacto dos sistemas de agricultura orgânica, no que tange ao acúmulo de carbono no solo, em área de clima temperado, junto à dinâmica de MOS e suas frações analisadas, em detrimento aos demais sistemas considerados. A análise dos dados obtidos apresentou um enfoque inédito de avaliação e caracterização espectroscópica para amostras coletadas neste campo experimental, na época apresentando 16 anos de atividade.

Os resultados decorrentes da análise das amostras de solo coletadas em campo experimental brasileiro apresentaram comportamento distinto entre si. Os dados referentes ao teor de carbono de solo para a fazenda Areona denotaram aumento de aproximadamente $25 \%$ para as áreas acondicionadas com biossólido, em comparação à sua respectiva área de controle; enquanto as amostras provenientes das áreas sob adição de biossólido para fazenda Entre Rios apresentaram decréscimo de cerca de 20 \%, em relação a sua área de controle.

O comportamento observado aponta para maior incidência de fração mais lábil de carbono junto ao conteúdo de MOS da área em questão para a fazenda Areona, levando-se em consideração o fato de se tratar de solo quartzarênico, com baixo teor de argila, dessa forma 
não sendo esperada maior afinidade entre o material orgânico fresco adicionado e o teor de MOS do solo nativo.

No entanto, o perfil observado para as amostras da fazenda Entre Rios remeteram a provável aumento de atividade microbiana no solo, acelerada pela maior disponibilidade de substrato fresco e condições propícias para maior interação entre solo (latossolo, com teor de argila mediano) e material orgânico adicionado, o que, em segundo plano, pode ser indicativo de ocorrência de efeito priming na área.

Os dados obtidos através da espectroscopia de FIL para as amostras de solo das referidas fazendas foram consistentes aos respectivos resultados de teor de carbono. Foi notado aumento de grau de humificação para as amostras referentes à área condicionada na fazenda Entre Rios, ao passo que para fazenda Areona notou-se decréscimo nos valores de grau de humificação em sua respectiva área condicionada.

Os maiores valores observados para as amostras da fazenda Entre Rios possivelmente indicam maior ocorrência de estruturas mais condensadas e recalcitrantes, provenientes da maior afinidade entre o material orgânico adicionado e o conteúdo de matéria orgânica da área. Da mesma forma, os menores valores de grau de humificação observados para a fazenda Areona indicam a possível presença de estruturas com menor grau de condensação e aromaticidade, com característica mais lábil, inferindo em possível falta de interação química da área com o biossólido adicionado.

A análise dos dados de respiração do solo para as áreas analisadas foram complementares aos resultados prévios obtidos para amostras de solo, apontando aumento de fluxo de $\mathrm{CO}_{2}$, em aproximadamente $35 \%$, em amostras referentes à área condicionada da fazenda Entre Rios, enquanto não foi notada variação significativa entre as áreas condicionadas ou não da fazenda Areona.

O aumento verificado para fazenda Entre Rios incorre em possível maior atividade microbiana na área, relacionando-se com o menor conteúdo de carbono e maior grau de humificação. Da mesma forma, o fato do fluxo de $\mathrm{CO}_{2}$ permanecer praticamente inalterado na fazenda Areona, ratifica a ausência de afinidade entre comunidade microbiana e material orgânico aplicado na área.

Pela análise dos espectros obtidos através da espectroscopia de FTIR para ácidos húmicos $(\mathrm{AH})$ extraídos das respectivas áreas, observou-se maiores índices de condensação e hidrofobicidade para amostras referentes à fazenda Entre Rios, inferindo material de caráter mais humificado e de maior recalcitrância em áreas sob adição de biossólido; amostras de $\mathrm{AH}$ oriundas de área condicionada da fazenda Areona também obtiveram maiores índices de 
condensação, apresentando, contudo, menores índices de hidrofobicidade, sugerindo, dessa maneira, a ocorrência de material ainda sujeito à atividade microbiana do solo, ainda que apresente núcleos condensados em sua estrutura.

Os resultados obtidos através da espectroscopia de absorção na região do UV-VIS mostraram um caráter de menor grau de condensação nas áreas sem adição de biossólido, em ambas fazendas, em relação as suas respectivas áreas condicionadas. Contudo, em se tratando de um índice com interpretações controversas na literatura, não foi possível a obtenção de informações contundentes a respeito das possíveis alterações estruturais decorrentes do condicionamento do solo.

A análise dos espectros de espectroscopia de fluorescência de luz UV-VIS, de acordo com as metodologias empregadas, demonstrou aumento no grau de humificação nas áreas sob adição de biossólido, sobretudo na camada sub superficial, para amostras da fazenda Entre Rios, enquanto que, para a fazenda Areona, os maiores valores de grau de humificação foram notados em sua respectiva área de controle, sem aplicação de biossólido.

O comportamento observado ratificou a diferença de afinidade entre o material orgânico fresco adicionado e conteúdo de matéria orgânica das áreas em estudo, previamente notada quando da análise das amostras dos solos, muito em virtude da disparidade das características dos solos (latossolo e neossolo quartzarênico) em análise.

Através dos resultados obtidos para o campo experimental brasileiro pôde-se observar o maior impacto da aplicação de biossólido em áreas de latossolo em detrimento a área de solo quartzarênico, no que concerne ao efeito do aporte de material orgânico fresco junto à biomassa microbiana e, consequente, acúmulo e sequestro de carbono.

A pesquisa deu origem a resultados interessantes e originais em se tratando de duas áreas experimentais, que apresentavam condições climáticas diferenciadas, além de sistemas de manejo e práticas de solo (agricultura e sistemas florestais). Além do impacto vinculado às diferentes atividades e sistemas de manejo, puderam-se avaliar as diferenças entre a dinâmica e reatividade de $\mathrm{C}$ no solo em situações de condições climáticas diferenciadas.

O condicionamento do solo em áreas de florestas em clima tropical, sobretudo em latossolos, ocasionou decréscimo do teor de carbono, muito em decorrência do aumento de atividade microbiana. Contudo, em áreas agrícolas de clima temperado a prática de condicionamento orgânico levou ao aumento do teor de carbono, no solo e em frações da matéria orgânica. O comportamento observado ratifica a diferença de maior taxa de decomposição de matéria orgânica em áreas de clima tropical em relação a áreas de clima temperado. 


\section{REFERÊNCIAS BIBLIOGRÁFICAS}

ABU-HAMDEH, N. H. Compactation and subsoiling effects of corn growth and soil bulk density. Soil Science Society of America Journal, v. 67, n. 4, p. 1213-1219, 2008.

ADANI, F.; TAMBONE, F. Long-term effect of sewage sludge application on soil humic acids. Chemosphere, v. 60, 1214-1221, 2005.

AERTSENS, J.; NOCKER, L.; GOBIN, A. Valuing the carbon sequestration potential for European agriculture. Land Use Policy, v. 31, p. 584-594, 2013.

AIKEN, G.R.; McKNIGHT, G. R.; WERSHAW, D. M.; MacCARTHY, P. Humic substances in soil, sediment, and water: geochemistry, isolation and characterization. New York: John Wiley, 1985. 692 p.

ALBRETCH, A.; KANDJI, S. T. Carbon sequestration in tropical agroforestry systems. Agriculture, Ecosystems \& Environment, v. 99, n. 1-3, p. 15-27, 2003.

ALIG, R. J.; ADAMS, D. M.; McCARL, B. A. Projecting impacts of global climate change on the US forest and agriculture sectors and carbon budgets. Forest Ecology and Management, v. 169, n 1-2, p. 3-14, 2002.

ALMENDROS, G. Humic substances. In: CHESWORTH, W. (Ed.) Encyclopedia of soil science. Dordrecht: Springer, 2008. p. 315-323.

ANDONOVA, L. B.; HOFFMANN, M. J. From Rio to Rio and beyond: innovation in global environmental governance. Journal of Environment and Development, v. 21, n. 1, p. 57-61, 2012.

ANGERS, D. A.; ERIKSEN-HAMEL, N. S. Full-inversion tillage and organic carbon distribution in soil profiles: a meta-analysis. Soil Science Society of America Journal, v. 72, n. 5, p. 1370-1374, 2008.

ARRAIGADA, C.; SAMPEDRO, I.; GARCIA-ROMERO, I.; OCAMPO, J. Improvement of growth of Eucalyptus globulus and soil biological parameters by amendment with sewage sludge and inoculation with arbuscular mycorrhizal and saprobe fungi. Science of Total Environment, v. 407, p. 4799-4806, 2009.

ASSIS, C. P.; GONZÁLEZ-PEREZ, J. A.; ROSA, J. M.; JUCKSCH, I.; MENDONÇA, E. S.; GONZÁLEZ-VILA, F. J. Analytical pyrolysis of humic substances from a Latosol (Typic Hapludox) under different land uses in Minas Gerais, Brazil. Journal of Analytical and Applied Pyrolysis, vol. 93, p. 120-128, 2012.

AZADI, H; HO, P. Genetically modified and organic crops in developing countries: a review of options for food security. Biotechnology Advances, v. 28, n. 1, p. 160-168, 2010.

AZADI ,H.; SCHOONBEEK, S.; MAHMOUDI, H.; DERUDDER, B.; MAEYER, P.; WITLOX, F. Organic agriculture and sustainable food production system: main potentials. Agriculture, Ecosystems \& Environment, v. 144, n. 1, p. 92-94, 2011. 
BAALOUSHA, M.; MOTELICA-HEINO, M.; LE COUSTUMER, P. Conformation and size of humic substances: effects on major cation concentration and type, $\mathrm{pH}$, salinity, and residence time. Colloids and Surfaces A: Physicochemical and Engineering Aspects, v. 272, p. 48-55, 2006.

BAES, A. U.; BLOOM. P. R. Fulvic acid ultraviolet-visible spectra: influence of solvent and pH. Soil Science Society of America Journal, v. 54, p. 1248-1254, 1990.

BARRAL, M. T.; PARADELO, R.; MOLDEZ, A. B.; DOMINGUEZ, M.; DIAZ-FIERROS, F. Utilization of MSW compost for organic matter conservation in agricultural soils of NW Spain. Resources, Conservation and Recycling, v. 53, p. 529-534, 2009.

BASTIDA, F.; JINDO, K.; MORENO, J. L.; HERNÁNDEZ, T.; GARCÍA, C. Effects of organic amendments on soil carbon fractions, enzyme activity and humus-enzyme complexes under semi-arid conditions. European Journal of Soil Biology, v. 53, p. 94-102, 2012.

BELLON-MAUREL, V.; McBRATNEY, A. Near-infrared (NIR) and mid-infrared (MIR) spectroscopic techniques for assessing the amount of carbon stock in soils: Critical review and research perspectives. Soil Biology \& Biochemistry, p. 1-13, 2011.

BERTONCINI, E. I.; D’ORAZIO, V.; SENESI, N.; MATTIAZZO, M. E. Fluorescence analysis of humic and fulvic acids from two Brazilian oxisols as affected by biosolid amendment. Analytical and Bioanalytical Chemistry, v. 381, p. 1281-1288, 2005.

BERTONCINI, E. I.; D’ORAZIO, V.; SENESI, N.; MATTIAZZO, M. E. Effects of sewage sludge amendment on the properties of two Brazilian oxisols and their humic acids. Bioresource Technology, v. 99, p. 4972-4979, 2008.

BIRDWELL, J. E.; ENGEL, A. S. Characterization of dissolved organic matter in cave and spring waters using UV-Vis absorbance and fluorescence spectroscopy. Organic Geochemistry, v. 41, p. 270-280, 2010.

BLANCO-CANQUI, H.; LAL, R. No-tillage and soil-profile carbon sequestration: an onfarm assessment. Soil Science Society of America Journal, v. 72, p. 693-701, 2008.

BLEVINS, R. L.; FRYE, W. W.; ISMAIL, I. Long-term no-tillage effects on soil properties and continuous corn yields. Soil Science Society of America Journal, v. 58, p. 193-198, 1994.

BOOTH, T. H. Eucalypt plantations and climate change. Forest Ecology and Management, v. 301, p. 28-34, 2012.

BRANCA, G.; HISSA, H.; BENEZ, M. C.; MEDEIROS, K.; LIPPER, L.; TINLOT, M.; BOCKEL, L.; BERNOUX, M. Capturing synergies between rural development and agricultural mitigation in Brazil. Land Use Policy, v. 30, p. 507-518, 2013.

BRITO, L. F.; MARQUES JUNIOR, J.; PEREIRA, G. T.; LA SCALA JUNIOR, N. Spatial variability of soil $\mathrm{CO}_{2}$ emission in different topographic positions. Bragantia, v. 69, p. 19-27, 2010 . 
BRUNETTI, G.; PLAZA, C.; CLAPP, C. E.; SENESI, N. Compositional and functional features of humic acids from organic amendments and amended soils in Minessota, USA. Soil Biology \& Biochemistry, v. 39, p. 1355-1365, 2007.

BURLEY, J.; EBELING, J.; COSTA, P. M. Carbon sequestration as a forestry opportunity in a changing climate. In: FREER-SMITH, P.H.; BROADMEADOW, M. S. J.; LYNCH, J. M. (Ed.) Forestry and climate change. Reading, UK: Cromwell Press, 2007. p. 31-38.

BUSSE, M. D.; SANCHEZ, F. G.; RATCLIFF, A. W.; BUTNOR, J. R.; CARTER, E. A.; POWERS, R. F. Soil carbon sequestration and changes in fungal and bacterial biomass following incorporation of forest residues. Soil Biology \& Biochemistry, v. 41, p. 220-227, 2009.

CALDEIRA, K.; MORGAN, M. G.; BALDOCCHI, D.; BREWER, P. G.; CHEN, C. T. A.; NABUURS, G. J.; NAKICENOVIC, N.; ROBERTSON, G. P. A portfolio of carbon management options. In: FIELD, C. P.; RAUPACH, C. R. (Ed.) The global carbon cycle: integrating humans, climate, and the natural world. Washington, DC: Island Press, 2004. p. 103-129.

CALDERON, F. J.; REEVES, J. B.; COLLINS, H. P.; PAUL, E. A. Chemical differences in soil organic matter fractions determined by diffuse-reflectance mid-infrared spectroscopy.

Soil Science Society of America Journal, v. 75, n. 2, p. 568-579, 2011.

CANELlAS, L. P.; VElloso, A. C. X.; MARCIANO, C. R.; RAMALHO, J. F. G. P.; RUMJANEK, V. M.; REZENDE, C. E.; SANTOS, G. A. Propriedades químicas de um cambissolo cultivado com cana-de-açúcar, com preservação do palhiço e adição de vinhaça por longo tempo. Revista Brasileira de Ciência do Solo, v. 27, p. 935-944, 2003.

CAPRIEL, P. Hydrophobicity of organic matter in arable soils: influence of management. European Journal of Soil Science, v. 48, p. 457-462, 1997.

CARBONELL-BOJOLLO, R.; GONZALEZ-SANCHEZ, E. J.; VEROZ-GONZALEZ, O.; ORDONEZ-FERNANDEZ, R. Soil management systems and short term $\mathrm{CO}_{2}$ emissions in a clayey soil in southern Spain. Science of the Total Environment, v. 409, n. 15, p. 29292935, 2011.

CAVIGELLI, M. A.; LIMA, B. L.; HANSON, J. C.; TEASDALE, J. R.; CONKLIN, A. E.; LU, Y. Long-term economic performance of organic and conventional field crops in the midAtlantic region. Renewable Agriculture and Food Systems, v. 24, n. 2, 102-119, 2009.

CAVIGELLI, M. A.; TEASDALE, J. R.; CONKLIN, A. E. Long-term agronomic performance of organic and conventional field crops in the Mid-Atlantic region. Agronomy Journal, v. 100, n. 3, p. 785-794, 2008.

CELIK, I.; GUNAL, H.; BUDAK, M.; AKPINAR, C. Effects of long-term organic and mineral fertilizers on bulk density and penetration resistance in semi-arid Mediterranean soil conditions. Geoderma, v. 160, n. 2, p. 236-243, 2010. 
CERRI, C. C.; MAIA, S. M. F.; GALDOS, M. V.; CERRI, C. E. P.; FEIGH, B. J.; BERNOUX, M. Brazilian greenhouse gas emissions: the importance of agriculture and livestock. Scientia Agricola, v. 66, p. 831-843, 2009.

CESCHIA, E.; BÉZIAT, P.; DEJOUX, J. F.; AUBINET, M.; BERNHOFER, Ch.; BODSON, B.; BUCHMANN, N.; CARRARA, A.; CELLIER, P.; TOMMASI, P.; ELBERS, J. A.; EUGSTER, W.; GRÜNWALD, T.; JACOBS, C. J. M.; JANS, W. W. P.; JONES, M.; KUTSCH, W.; LANIGAN, G.; MAGLIULO, E.; MARLOIE, O.; MOORS, E. J.; MOUREAUX, C.; OLIOSO, A.; OSBORNE, B.; SANZ, M. J.; SAUNDERS, M.; SMITH, P.; SOEGAARD, H.; WATTENBACH, M. Management effects on net ecosystem carbon and GHG budgets at European crop sites. Agriculture, Ecosystems and Environment, v. 139, p. 363-383, 2010.

CHAN, A. S. K.; PARKIN, T. B. Effect of land use on methane flux from soil. Journal of Environmental Quality, v. 30, p. 786-797, 2001.

CHAVEZ, L. F.; AMADO, T. J. C.; BAYER, C.; LA SCALA JUNIOR, N.; ESCOBAR, L. F.; FIORIN, J. E.; CAMPOS, B. C. Carbon dioxide efflux in a Rhodic Hapludox as affected by tillage systems in southern Brazil. Revista Brasileira de Ciências do Solo, v. 33, p. 325334, 2009.

CHEN, J.; GU, B.; LeBOEUF, E. J.; PAN, H.; DAI, S. Spectroscopic characterization of the structural and functional properties of natural organic matter fractions. Chemosphere, v. 48, p. 59-68, 2002.

CHEN, G.; YANG, Y.; GUO, J.; XIE, J.; YANF, Z. Relationships between carbon allocation and partitioning of soil respiration across world mature forests. Plant Ecology, v. 212, p. 195206, 2011.

CHIRINDA, N.; OLESEN, J. S.; PORTER, J. R.; SCHØNNING, P. Soil properties, crop production and greenhouse gas emissions from organic and inorganic fertilizer-based arable cropping systems. Agriculture, Ecosystems and Environment, v. 139, p. 584-594, 2010.

CHRISTENSEN, B. T. Physical fractionation of soil and structural and functional complexity in organic matter turnover. European Journal of Soil Science, v. 52, p. 345-353, 2001.

CONCEIÇÃO, P. C.; BOENI, M.; DIECKOW, J.; BAYER, C.; MIELNICZUK, J. Fracionamento densimétrico com politungstato de sódio no estudo da proteção física da matéria orgânica em solos. Revista Brasileira de Ciência do Solo, v. 32, n. 2, p. 541-549, 2008.

CROVETTO, C. C. No-till development in Chequén Farm and its influence on some physical, chemical and biological parameters. Journal of Soil and Water Conservation, v. 53, n. 3, p. 194-199, 1998.

DALAL, R. C.; ALLEN, D. E.; WANG, W. J.; REEVES, S.; GIBSON, I. Organic carbon and total nitrogen stocks in a Vertisol following 40 years of no-tillage, crop residue retention and nitrogen fertilization. Soil \& Tillage Research, v. 112, p. 133-139, 2011. 
DAM, R. F.; MEHDI, B. B.; BURGESS, M. S. E.; MADRAMOOTOO, C. A.; MEHUYS, G. R.; CALLUM, I. R. Soil bulk density and crop yield under eleven consecutive years of corn with different tillage and residue practices in a sandy loam soil in Central Canada. Soil \& Tillage Research, v. 84, p. 41-53, 2005.

De LA ROSA, J. M.; FARIA, S. R.; VARELA, M. E.; KNICKER, H.; GONZALEZ-VILA, J. F.; GONZALEZ-PEREZ, J. A.; KEIZER, J. Characterization of wildfire effects on soil organic matter using analytical pyrolysis. Geoderma, v. 191, p. 24-30, 2012.

DeLAUNE, P. B.; SIJ, J. W. Impact of tillage on runoff in long term no-till wheat systems. Soil \& Tillage Research, v. 124, p. 32-35, 2012.

DENDOOVEN, L.; PATIÑO-ZUÑIGA, L.; VERHULST, N.; LUNA-GUIDO, M.; MARSCH, R.; GOVAERTS, B. Global warming potential of agricultural systems with contrasting tillage and residue management in the central highlands of Mexico. Agriculture, Ecosystems and Environment, v. 152, p. 50-58, 2012.

DESSAI, S.; SCHIPPER, E. L. The Marrakesh Accords to the Kyoto Protocol: analysis and future prospects. Global Environmental Change, v. 13, n. 2, p. 149-153, 2003.

DIEKOW, J.; MIELNICZUK, J.; KNIKER, H.; BAYER, C.; DICK, D. P.; KÖGELKNABNER, I. Soil C and N stocks as affected by cropping systems and nitrogen fertilisation in a southern Brazil Acrisol managed under no-tillage for 17 years. Soil \& Tillage Research, v. 81, p. 87-95, 2005.

DIGNAC, M. F.; HOUOT, S.; DERENNE, S. How the polarity of the separation column may influence the characterization of compost organic matter by pyrolysis-GC/MS. Journal of Analytical and Applied Pyrolysis, v. 75, p. 128 - 139, 2006.

DIGNAC, M. F.; HOUOT, S.; FRANCOU, C.; DERENNE, S. Pyrolitic study of compost and waste organic matter. Organic Geochemistry, v. 36, p. 1054-1071, 2005.

DIJKSTRA, J. P. M.; REINDS, G. J.; KROS, H.; BERG, B.; VRIES, W. Modelling soil carbon sequestration of intensively monitored forest plots in Europe by three different approaches. Forest Ecology and Management, v. 258, p. 1780-1793, 2009.

EMBRAPA. Centro Nacional de Pesquisas de Solos. Sistema Brasileiro de classificação de solos. Brasília: Embrapa Produção de Informação, 1999. 412 p.

FALK, M.; U, K .T .P.; WHARTON, S.; SCHROEDER, M. Is soil respiration a major contributor to the carbon budget within a Pacific Northwest old-growth forest? Agricultural and Forest Meteorology, v. 135, p. 269-283, 2005.

FASINMIRIN, J. T.; REICHERT, J. M. Conservation tillage for cassava (Manihot esculenta crantz) production in the tropics. Soil \& Tillage Research, v. 113, p. 1-10, 2011.

FEDERAÇÃO BRASILEIRA DE PLANTIO DIRETO NA PALHA (FEBRAPDP). Área de PD no mundo. Disponível em : <www.febrapdp.org.br>. Acesso em: 14 fev. 2012. 
FERNANDES, S. A. P.; BETTIOL, W.; CERRI, C. C. Effect of sewage sludge on microbial biomass, basal respiration, metabolic quocient and soil enzymatic activity. Applied Soil Ecology, v. 30, p. 65-77, 2005.

FERNANDES, A. N.; GIOVANELA, M.; ESTEVES, V. I.; SIERRA, M. M. S. Elemental and spectral properties of peat and soil samples and their respective humic substances. Journal of Molecular Structure, v. 971, p. 33-38, 2010.

FERNANDEZ-GETINO, V.; HERNANDEZ, Z.; BUENA, A. P.; ALMENDROS, G. Assessment of the effects of environmental factors on humification processes by derivative infrared spectroscopy and discriminant analysis. Geoderma, v. 158, p. 225-232, 2010.

FERREA, C.; ZENONE, T.; COMOLLI, R.; SEUFERT, G. Estimating heterotrophic and autotrophic soil respiration in a semi-natural forest of Lombardy, Italy. Pedobiologia, v. 55, p. 285-294, 2012.

FERRERAS, L. A.; COSTA, J. L.; GARCIA, F. O.; PECORARI, C. Effect of no-tillage on some soil physical properties of a structural degraded Petrocalcic Paleudoll of the southern "Pampa" of Argentina. Soil \&Tillage Research, v. 54, n. 1-2, p. 31-39, 2000.

FIRME, L. P.; BACA, C. M.; ABREU, C. H.; NETO, S. P. M.; MURAOKA, T.; GAVA, J. L. Lodo de esgoto como fonte de nitrogênio e fósforo em floresta de eucalipto. In:

WORKSHOP - REDE AGRORECICLA, 2010, São Carlos. Anais... São Carlos: Embrapa, 2010. CD-ROM.

FONTAINE, S.; BAROT, S.; BARRE, P.; BDIOUI, N.; MARY, B.; RUMPEL, C. Stability of organic carbon in deep soil layers controlled by fresh carbon supply. Nature, v. 450, n. 8 , p. 277-281, 2007.

FOOD AND AGRICULTURAL ORGANIZATION OF THE UNITED NATIONS (FAO). Conservation agriculture when agriculture is profitable and sustainable. Roma: Land and Water Development Division/FAO, 2002. (FAO Land and Digital Media Series, 18) CDROM.

FOOD AND AGRICULTURAL ORGANIZATION OF THE UNITED NATIONS (FAO). Conference on ecological agriculture: mitigating climate change, providing food security and self-reliance for rural livehoods in Africa, 2008. Disponível em: < www.fao.org>. Acesso em: 15 mar. 2012.

FORSTER, P.; RAMASWAMY, V.; ARTAXO, P.; BERNTSEN, T.; BETTS, R.; FAHEY, D. W.; HAYWOOD, J.; LEAN, J.; LOWE, D. C.; MYHRE, G.; NGANGA, J.; PRINN, R.; RAGA, G.; SCHULZ, M.; VAN DOORLAND, R. Changes in atmospheric constituents and in radiative forcing. In: SOLOMON, S.; QIN, D.; MANNING, M.; CHEN, Z.; MARQUIS, M.; AVERYT, K. B.; TIGNOR, M.; MILLER, H. L. (Ed.). Climate change 2007: the physical science basis. Contribution of working group I for the fourth assessment report of the Intergovernmental Panel on Climate Change. Cambrigde: Cambridge University, 2007. p. 129-234. 
FRANZLUEBBERS, A. J.; HONS, F. M.; ZUBERER, D. A. Tillage and crop effects on seasonal $\mathrm{CO}_{2}$ evolution, water content, temperature, and bulk density. Applied Soil Ecology, v. 2, n. 2, p. 95-109, 1995.

FREIXO, A. A.; CANELLAS, L. P.; MACHADO, P. L. O. A. Propriedades espectrais da matéria organica leve-livre e leve intra-agregado de dois latossolos sob plantio direto e preparo convencional. Revista Brasileira de Ciencia do Solo, v. 26, p. 445-456, 2002.

FRONNING, B. E.; THELEN, K. D.; MIN, D. Use of manure, compost, and cover crops to supplant crop residue carbon in corn stover removed cropping systems. Agronomy Journal, v. 100, n. 6, p. 1703-1710, 2008.

FUENTES, M.; GONZALEZ-GAITANO, G.; GARCIA-MINA, J. M. The usefulness of UV - Visible and fluorescence spectroscopies to study the chemical nature of humic substances from soils and composts. Organic Geochemistry, v. 37, p. 1949-1959, 2006.

GAL, A.; VYN, T. J.; MICHÉLI, E.; KLADIVKO, E. J.; McFEE, W. W. Soil carbon and nitrogen accumulation with long-term no-till versus moldboard plowing overestimated with tilled-zone sampling depths. Soil \& Tillage Research, v. 96, n. 1-2, 2007.

GIOVANELA, M.; CRESPO, J .S.; ANTUNES, M.; ADAMATTI, D. S.; FERNANDES, A. N.; BARISON, A.; SILVA, C. W. P.; GUEGAN, R.; MOTELICA-HEINO, M.; SIERRA, M. M. D. Chemical and spectroscopic characterization of humic acids extracted from the bottom sediments of a Brazilian subtropical microbasin. Journal of Molecular Structure, v. 981, p. 111-119, 2010.

GOLCHIN, A.; OADES, J. M.; SKJEMSTAD, J. O.; CLARKE, P. Soil structure and carbon cycling. Australian Journal of Soil Research, v. 32, n. 5, p. 1043-1065, 1994.

GOLCHIN, A.; CLARKE, R.; OADES, J. M.; SKJEMSTAD, J. O. The effects of cultivation on the composition of organic matter and stability of soils. Australian Journal of Soil

Research, v. 33, p. 975-993, 1995.

GONZALEZ-CHAVEZ, M. C. A.; AITKENHEAD-PETERSON, J. A.; GENTRY, T. J.; ZUBERER, D.; HONS, F.; LOEPPERT, R. Soil microbial community, C, N, and P responses to long-term tillage and crop rotation. Soil \& Tillage Research, v. 106, p. 285-293, 2010.

GONZALEZ-PEREZ, M.; MILORI, D. M. B. P.; COLNAGO, L. A.; MARTIN-NETO, L.; MELO, W. J. A laser-induced fluorescence spectroscopic study of organic matter in a Brazilian oxisol under different tillage systems. Geoderma, v. 138, p. 20-24, 2007.

GONZALEZ-VILA, F. J.; GONZALEZ-PEREZ, J. A.; AKDI, K.; GÓMIS, M. D.; PEREZBARRERA, F.; VERDEJO, T. Assessing the efficiency of urban waste biocomposting by analytical pyrolysis (Py-GC/MS). Bioresource Technology, v. 100, n. 3, p. 1304-1309, 2009.

GRANT, C. A.; LAFOND, G. P. The effects of tillage systems and crop sequences on soil bulk density and penetration resistance on a clay soil in southern Saskatchewan. Canadian Journal of Soil Science, v. 73, p. 223-232, 1993. 
GREGORICH, E. G. Fertilization effects on physically protected light fraction organic matter. Soil Science Society of America Journal, v. 61, p. 482-484, 1997.

HAI, L.; LI, X. G.; LI, F. M.; SUO, D. R.; GUGGENBERGER, G. Long-term fertilization and manuring effects on physically-separated soil organic matter pools under a wheat-wheatmaize cropping system in an arid region of China. Soil Biology \& Biochemistry, v. 42, p. 253-259, 2010.

HALL, M.; FRANK, E.; HOLMES, G.; PFAHRINGER, B.; REUTEMANN, P.; WITTEN, I. H. The WEKA data mining software: an update. SIGKDD Explorations, v. 11, n. 1, p. 1018, 2009.

HELAL, A. A.; MURAD, G. A.; HELAL, A. A. Characterization of different humic materials by various analytical techniques. Arabian Journal of Chemistry, v. 4, p. 51-54, 2011

HOLE, G. Research skills Mann-Whitney test handout version 1.0. Disponível em: <www.sussex.ac.uk>. Acesso em: 04 abr. 2013.

HOUGHTON, R. A. Revised estimates of the annual net flux of carbon to the atmosphere from changes in land use and land management. Tellus B, v. 55, n. 2, p. 378-390, 2003.

HOUGHTON, R. A.; HACKLER, J. L.; LAWRENCE, K. T. The US carbon budget: contributions from land-use change. Science, v. 285, p. 574-578, 1999.

HUANG, H.; VON LAMPE, M.; VAN TONGEREN, F. Climate change and trade in agriculture. Food Policy, v. 36, p. S9-S13, 2011.

HUGGINS, D. R.; BUYANOVSKY, G. A.; WAGNER, G. H.; BROWN, J. R.; DARMODY, R. G.; PECK, T. R.; LESOING, G. W.; VANOTTI, M. B.; BUNDY, L. G. Soil organic C in the tallgrass prairie-derived region of the corn belt: effects of long-term crop management. Soil \& Tillage Research, v. 47, n. 3-4, p. 219-234, 1998.

IKEYA, K.; HIKAGE, T.; ARAI, S.; WATANABE, A. Size distribution of condensed aromatic rings in various soil humic acids. Organic Geochemistry, v. 42, p. 55-61, 2011.

ISHWARAN, N. After Rio+20: Translating words in action. Environmental Development, v. 4, p. 184-185, 2012.

ISLAN, K. R.; WEIL, R. R. Soil quality indicator properties in mid-Atlantic soils as influenced by conservation management. Journal of Soil and Water Conservation, v. 55, p. 69-78, 2000.

JABBOUR, J.; KEITA-OUANE, F.; HUNSBERGER, C.; SÁNCHEZ-RODRÍGUEZ, R.; GILRUTH, P.; PATEL, N.; SINGH, A.; LEVY, M. A.; SCHWARZER, S. Internationally agreed environmental goals: a critical evaluation of progress. Environmental Development, v.3, p. 5-24, 2012.

JENKINSON, D. C. The turnover of organic matter in soil. In: WILD, A. (Ed.) Soil conditions and plant growth. Harlow: Longmans, 1988. p. 564-607. 
JOHN, B.; YAMASHITA, T.; LUDWIG, B.; FLESSA, H. Storage of organic carbon in aggregate and density fractions of silty soils under different types of land use. Geoderma, v. 128, p. 63-79, 2005.

JOHNSON, J. M. F.; FRANZLUEBBERS, A. J.; WEYERS, S. L.; REICOVSKY, D. C. Agricultural opportunities to mitigate greenhouse gas emissions. Environmental Pollution, v. 150, p. 107-124, 2007.

JORGE-MARDOMINGO, I.; SOLER-ROVIRA, P.; CASERMEIRO, M. A.; CRUZ, M. T.; POLO, A. Seasonal changes in microbial activity in a semiarid soil after application of a high dose of different organic amendments. Geoderma, v. 206, p. 40-48, 2013.

KALBITZ, K.; GEYER, W.; GEYER, S. Spectroscopic properties of dissolved humic substances - a reflection of land use in a fen area. Biogeochemistry, v. 47, p. 219-238, 1999.

KÖGEL-KNABNER, I. Analytical approaches for characterizing soil organic matter. Organic Geochemistry, v. 31, p. 609-625, 2000.

KONG, A. Y. Y.; SIX, J. Tracing cover crop root versus residue carbon into soils from conventional, low-input, and organic cropping systems. Soil Science Society of America Journal, v. 74, p. 1201-1210, 2010.

KUEPPER, G.; GEGNER, I. Organic crop production overview. Fayetteville: ATTRA, 2004. 28 p. (Boletim de Pesquisa).

KUKAL, S. S.; BENBI, D. K. Soil organic carbon sequestration in relation to organic and inorganic fertilization in rice-wheat and maize-wheat systems. Soil \& Tillage Research, v. 102, p. 87-92, 2009.

KURZ, W. A.; APPS, M. J. Developing Canada's national forest carbon monitoring, accounting and reporting system to meet the reporting requirements of the Kyoto Protocol. Mitigation and Adaptation Strategies for Global Change, v. 11, n.1, p. 33-43, 2006.

KUZYAKOV, Y.; FRIEDEL, J.K.; STAHR, K. Review of mechanisms and quantification of priming effects. Soil Biology \& Biochemistry, v.32, n.11-12, p.1485-1489. 2000.

LAGANIÉRE, J.; PARÉ, D.; BERGERON, Y.; CHEN, H. Y. H. The effect of boreal forest composition on soil respiration is mediated through variations in soil temperature and $\mathrm{C}$ quality. Soil Biology and Biochemistry, v. 53, p. 18-27, 2012.

LAKOWICZ, J. R. Principles of fluorescence spectroscopy. New York: Kluwer Academic/Plenum Publishers, 1999. 698 p.

LAL, R. Soil management and restoration for $\mathrm{C}$ sequestration to mitigate the accelerated greenhouse effect. Progress in Environmental Science, v. 1, p. 307-326, 1999.

LAL, R. Global potential of soil carbon sequestration to mitigate the greenhouse effect.

Critical Reviews in Plant Sciences, v. 22, n. 2, p. 151-184, 2003. 
LAL, R. Soil carbon sequestration to mitigate change. Geoderma, v. 123, n. 1-2, p. 1-22, 2004.

LAL, R. Carbon sequestration. Philosophical Transactions of the Royal Society B, v. 363, n. 1492 , p. 815-830, 2008.

LAMPURLANÉS, J.; CANTERO-MARTÍNEZ, C. Soil bulk density and penetration resistance under different tillage and crop management systems and their relationship with barley root growth. Agronomy Journal, v. 95, n. 3, p. 526-536, 2003.

LEIFELD, J.; KÖGEL-KNABNER, I. Soil organic matter fractions as early indicators for carbon stock changes under different land-use ? Geoderma, v. 154, p. 143-155, 2005.

LEINWEBER, P.; SCHULTEN, H. R. Advances in analytical pyrolysis of soil organic matter. Journal of Analytical and Applied Pyrolysis, v. 49, p. 359-383, 1999.

LEINWEBER, P.; KRUSE, J.; BAUM, C.; ARCAND, M.; KNIGHT, J. D.; FARELL, R.; ECKHARDT, K.; KIERSCH, K.; JANDL, G. Advances in understanding organic nitrogen chemistry in soils using state-of-art analytical techniques. In: SPARKS, D. L. (Ed.) Advances in agronomy. New York: Academic Press, 2013. v. 119, p. 83-151.

LEITA, L.; DENOBILI, M.; MONDINI, C.; MUHLBACHOURA, G.; MARCHINOL, L.; BRAGATO, G.; CONTIN, M. Influence of inorganic and organic fertilization on soil microbial biomass, metabolic quocient and heavy metal bioavailability. Biology and Fertility of Soils, v. 28, p. 371-376, 1995.

LI, L.; YOU, M.; SHI, H.; DING, X.; QIAO, Y.; HAN, X. Soil $\mathrm{CO}_{2}$ emissions from a cultivated Mollisol: effects of organic amendments, soil temperature, and moisture.

European Journal of Soil Biology, v. 55, p. 83-90, 2013.

LIANG, B.; YANG, X.; HE, X.; ZHOU, J. Effects of 17-year fertilization on soil microbial biomass $\mathrm{C}$ and $\mathrm{N}$ and soluble organic $\mathrm{C}$ and $\mathrm{N}$ in loessial soil during maize growth. Biology and Fertility of Soils, v. 41, p. 121-128, 2011.

LOGSDON, S. D.; CAMBARDELLA, C. A. Temporal changes in small depth-incremental soil bulk density. Soil Science Society of America Journal, v. 64, n. 2, p. 710-714, 2000.

LOPES, E. B. M. Diversidade metabólica em solo tratado com biossólidos. 2001. 65 f. Dissertação (Mestrado) - Escola Superior de Agricultura Luiz de Queiróz, Universidade de São Paulo, Piracicaba, 2001.

LORENZ, K.; LAL, R. Biogeochemical cycles of C and N in urban soils. Environment International, v. 35, p. 1-8, 2009.

LOTTER, D.; SEIDEL, R.; LIEBHARDT, W. The performance of organic and conventional cropping systems in an extreme climate year. American Journal of Alternative Agriculture, v. 18, p. 1-9, 2003. 
LOU, Y.; XU, M.; CHEN, X.; HE, X.; ZHAO, K. Stratification of soil organic C, N and C:N ratio as affected by conservation tillage in two maize fields of China. Catena, v. 95, p. 124130, 2012.

LU, Y. C.; WATKINS, K. B.; TEASDALE, J. R.; ABDUL-BAKI, A. A. Cover crops in sustainable food production. Food Reviews International, v. 16, p. 121-157, 2000.

LUO, Z.; WANG, E.; SUN, O. J. Soil carbon change and its responses to agricultural practices in Australian agro-ecosystems: A review and synthesis. Geoderma, v. 155, p. 211223, 2010.

MAHECHA, M. D.; REICHSTEIN, M.; CARVALHAIS, N.; LASSLOP, G.; LANGE, H.; SENEVIRATNE, S. I.; VARGAS, R.; AMMANN, C.; ARAIN, M. A.; CESCATTI, A.; JANSSENS, I. A.; MIGLIAVACCA, M.; MONTAGNANI, L.; RICHARDSON, A. D. Global convergence in the temperature sensitivity of respiration at ecosystem level. Science, v. 329, p. 838-840, 2010.

MAO, J.; CHEN, N.; CAO, X. Characterization of humic substances by advanced solid state NMR spectroscopy: Demonstration of a systematic approach. Organic Chemistry, v. 42, n. 8, p. 891-902, 2011.

MAPANDA, F.; WUTA, M.; NYAMANGARA, J.; REES, R. M. Effects of organic and mineral fertilizer nitrogen on greenhouse gas emissions and plant-captured carbon under maize cropping in Zimbabwe. Plant and Soil, v. 343, n. 1-2, p. 67-81, 2011.

MARGHERITA, E.; BRUNETTI, G.; GARCÍA, C.; CAVALCANTE, F.; FIORE, S.; SENESI, N. Clay minerals and humic substances in organically-amended semiarid soils. Soil Science, v. 171, p. 322-333, 2006.

MARI, G. R.; CHANGYING, J. I. Conservation tillage for the protection of soil quality and sustainability. American-Eurasian Journal of Scientific Research, v.1, n.1, p. 55-60, 2006.

MARRIOTT, E. E.; WANDER, M. M. Total and labile soil organic matter in organic and conventional farming systems. Soil Science Society of America Journal, v. 70, p. 950-959, 2006.

MARTIN-NETO, L.; SAAB, S. C. Anéis aromáticos condensados e relação $\mathrm{E}_{4} / \mathrm{E}_{6}$ : estudo de ácidos húmicos de gleissolos por RMN de ${ }^{13} \mathrm{C}$ no estado sólido utilizando a técnica CP/MAS desacoplamento defasado. Química Nova, v. 30, n. 2, p. 260-263, 2007

McDONALD, S.; BISHOP, A. G.; PRENZLER, P. D.; ROBARDS, K. Analytical chemistry of freshwater humic substances. Analytica Chimica Acta, v. 527, p. 105-124, 2004.

McGRATH, D.; POSTMA, L.; McCORMACK, R. J.; DOWDALL, C. Analysis of Irish sewage sludges: suitability of sludge for use in agriculture. Irish Journal of Agricultural and Food Research, v. 39, p. 73-78, 2000.

McPHIE, P. Enzyme purification and related techniques: dialysis. In: JACOBY, W. B. (Ed.) Methods and enzymology. New York: Academic Press, 1971. v. 22, p. 25-175. 
MIANO, T. M.; SENESI, N. Synchronous excitation fluorescence spectroscopy applied to soil humic substances chemistry. Science of the Total Environment, v. 117, p. 41-51, 1992.

MILLER, C. E. Chemical principles of near-infrared spectroscopy. In: WILLIAMS, P. ; NORRIS, K. (Ed.). Near infrared technology in the agricultural and food industries. Minessota: American Association of Cerial Chemists, 2001. p. 19-37.

MILLER, A. J.; AMUNDSON, R.; BURKE, I. C.; YORKER, C. The effect of climate and cultivation on soil organic C and N. Biogeochemistry, v. 67, p. 57-72, 2004.

MILORI, D. M. B. P.; MARTIN-NETO, L.; BAYER, C.; MIELNICZUK, J.; BAGNATO, V. S. Humification degree of soil humic acids determined by fluorescence spectroscopy. Soil Science, v. 167, n. 11, p. 739-749, 2002.

MILORI, D. M. B. P.; GALETI, H. V. A.; MARTIN-NETO, L.; DIECKOW, J.; GONZÁLEZ-PÉREZ, M.; BAYER, C.; SALTON, J. Organic matter study of whole soil samples using laser-induced fluorescence spectroscopy. Soil Science Society of America Journal, v. 70, p. 57-63, 2006.

MILORI, D. M. B. P.; MARTIN-NETO, L.; BOAS, P. R. V.; FERREIRA, E. C.; SEGNINI, A.; FERREIRA, E. J.; SANTOS, C. H.; ROMANO, R. A.; SILVA, W. T. L.; SIMÕES, M. L; POSADAS, A. Avaliação de um equipamento portátil para determinação do grau de humificação da matéria orgânica de solos. São Carlos: Embrapa, 2012. 5 p. (Boletim de Pesquisa).

MINISTÉRIO DA AGRICULTURA, AGROPECUÁRIA E ABASTECIMENTO (MAPA). Plano ABC. Disponível em <http://www.agricultura.gov.br>. Acesso em: 06 abr. 2013.

MOLDOVEANU, S. C. Pyrolysis GC/MS, present and future (recent past and present needs). Journal of Microcolumn Separations, v. 13, n. 3, p. 102-125, 2001.

MOLDOVEANU, S. C. Review of analytical pyrolysis instrumentation. Analytical Pyrolysis of Sintetic Organic Polymers, v. 25, p. 109-143, 2005.

MONTGOMERY, D. R. Soil erosion and agricultural sustainability. Proceedings of the National Academy of Sciences of the United States of America, v. 104, n. 33, p. 1326813272, 2007.

MOORE, D. S. The basic practice of statistics. New York: W. H. Freeman and Company, 2010. 977 p.

MUNIER-LAMY, C.; BORDER, O. Effect of triazolle fungicide on the cellulose decomposition by the soil microflora. Chemosphere, v. 41, p. 1029-1035, 2000.

MUÑOZ, C.; MONREAL, C. M.; SCHNITZER, M.; ZAGAL, E. Influence of Acacia caven (Mol) coverage on carbon distribution and its chemical composition in soil organic carbon fractions in a Mediterranean-type climate region. Geoderma, v. 144, n. 1, p. 352-360, 2008. 
MUSCOLO, A.; SIDARI, M.; NARDI, S. Humic substance: relationship between structure and activity. Deeper information suggests univocal findings. Journal of Geochemical Exploration, p. 1-7, 2012.

NAIR, P. K. R.; NAIR, V. D.; KUMAR, B. M.; HAILE, S. G. Soil carbon sequestration in tropical agroforestry systems: a feasibility appraisal. Environmental Science and Policy, v. 12, n. 8, p. 1099-1111, 2009.

NAVE, L. E.; VANCE, E. D.; SWANSTON, C. W.; CURTIS, P. S. Harvest impacts on soil carbon storage in temperate forests. Forest Ecology and Management, v. 259, p. 857-866, 2010.

NEBBIOSO, A.; PICCOLO, A. Molecular understanding of a humic acid by "humeomic" fractionation and benefits from preliminary HPSEC separation. In: XU, J.; WU, J.; HE, Y. (Ed.) Functions of natural organic matter in changing environment. Beijing: IHSS, 2012. p. 50-51.

NICOLÁS, C.; MASCIANDARO, G.; HERNÁNDEZ, T.; GARCÍA, C. Chemical-structural changes of organic matter in a semi-arid soil after organic amendment. Pedosphere, v. 22, n. 3, p. 283-293, 2012.

NIEROP, K. G. J.; PULLEMAN, M. M.; MARINISSEN, J. C. Y. Management induced organic matter differentiation in grassland and arable soils: a study using pyrolysis techniques. Soil Biology and Biochemistry, v. 33, n. 6, p. 755-764, 2001.

NIGGLI, U.; FLIEßBACH, A.; HEPPERLY, P.; SCIALABBA, N. Low greenhouse gas agriculture: mitigation and adaptation potential of sustainable farming systems. Roma: FAO, 2009. 21 p. (Boletim de Pesquisa)

NISSEN, T. M.; WANDER, M. M. Management and soil-quality effects on fertilizer use efficiency and leaching. Soil Science Society of America Journal, v. 67, p. 1524-1532, 2003.

OORTS, K.; MERCKX, R.; GREHAN, E.; LABREUCHE, J.; NICOLARDOT, B. Determinants of annual fluxes of $\mathrm{CO}_{2}$ and $\mathrm{NO}_{2}$ in long-term no-tillage and conventional tillage systems in northern France. Soil \& Tillage Research, v. 95, p. 133-148, 2007.

PACHECO, M. L.; PEÑA-MÉNDEZ, E. M.; HAVEL, J. Supramolecular interactions of humic acids with organic and inorganic xenobiotics studied by capillary electrophoresis. Chemosphere, v. 51, p. 95-108, 2003.

PAOLO, N.; ELDOR, P. The chemical and functional characterization of soil $\mathrm{N}$ and its biotic components. Soil Biology \& Biochemistry, p. 1-13, 2009.

PARAT, C.; CHAUSSOD, R.; LÉVÊQUE, J.; ANDREUX, F. Long-term effects of metalcontaining farmyard manure and sewage sludge on soil organic matter in a fluvisol. Soil Biology and Biochemistry, v. 37, n. 4, p. 673-679, 2005. 
PATERSON, E.; MIDWOOD, A. J.; MILLARD, P. Through the eye of the needle: a review of isotope approaches to quantify microbial processes mediating soil carbon balance. New Phytologist, v. 184, p. 19-33, 2009.

PENG, S.; PIAO, S.; WANG, T.; SUN, J.; SHEN, Z. Temperature sensivity of soil respiration in different ecosystems in China. Soil Biology and Biochemistry, v. 41, n. 5, p. 1008-1014, 2009.

PICCOLO, A. The supramolecular structure of humic substances. Soil Science, v. 166, n. 11, p. 810-832, 2001.

PIMENTEL, D.; HEPPERLY, P.; HANSON ,J.; DOUDS, D.; SEIDEL, R. Environmental, energetic, and economic comparisons of organic and conventional farming systems.

BioScience, v. 55, p. 573-582, 2005.

PLAZA, C.; SENESI, N.; POLO, A.; BRUNETTI, G. Acid-base properties of humic and fulvic acids formed during composting. Environmental Science and Technology, v. 39, n. 18, p. 7141-7146, 2005.

PLAZA, C.; COURTIER-MURIAS, D.; FERNÁNDEZ, J. M.; POLO, A.; SIMPSON, A. J. Physical, chemical, and biochemical mechanisms of soil organic matter stabilization under conservation tillage systems: a central role for microbes and microbial by-products in $\mathrm{C}$ sequestration. Soil Biology \& Biochemistry, v. 57, p. 124-134, 2013.

POGNANI, M.; BARRENA, R.; FONT, X.; ADANI, F.; SCAGLIA, B.; SÁNCHEZ, A. Evolution of organic matter in a full-scale composting plant for the treatment of sewage sludge and biowaste by respiration techniques and pyrolysis-GC/MS. Bioresource Technology, v. 102, p. 4536-4543, 2011.

POLAK, J.; BARTOSZEK, M.; SULKOWSKI, W. W. Comparison of some spectroscopic and physico-chemical properties of humic acids extracted from sewage sludge and bottom sediments. Journal of Molecular Structure, v. 924-926, p. 309-312, 2009.

POLL, C.; MARHAN, S.; BACK, F.; NIKLAUS, P. A.; KANDELER, E. Field-scale manipulation of soil temperature and precipitation change soil $\mathrm{CO}_{2}$ flux in a temperate agricultural ecosystem. Agriculture, Ecosystems and Environment, v. 165, p. 88-97, 2013.

PONTES, W. L. Mineralização de um biossólido industrial no solo e efeito desse na biomassa e atividade microbiana. 2002. 73 f. Dissertação (Mestrado) - Departamento de Ciência do Solo, Universidade Federal de Lavras, Lavras, 2002.

PONTI, T.; RIJK, B.; VAN ITTERSUM, M. K. The crop yield gap between organic and conventional agriculture. Agricultural Systems, v. 108, p. 1-9, 2012.

POWLSON, D. S.; GREGORY, P. J.; WHALLEY, W. L.; QUINTON, J.N.; HOPKINS, D. W.; WHITMORE, A. P.; HIRSCH, P. R.; GOULDING, K. W. T. Soil management in relation to sustainable agriculture and ecosystem services. Food Policy, v. 36, p. S72-S87, 2011. 
POWLSON, D. S.; BHOGAL, A.; CHAMBERS, B. J.; COLEMAN, K.; MACDONALD, A. J.; GOULDING, K. W. T.; WHITMORE, A. P. The potential to increase soil carbon stocks through reduced tillage or organic material additions in England and Wales: a case study. Agriculture, Ecosystems and Environment, v. 146, p. 23-33, 2012.

PUGET, P.; DRINKWATER, L. E. Short-term dynamics of root- and shoot-derived carbon from a leguminous green manure. Soil Science Society of America Journal, v. 65, p. 771779, 2001.

PUGET, P.; LAL, R. Soil organic carbon and nitrogen in a Mollisol in central Ohio as affected by tillage and land use. Soil \& Tillage Research, v. 80, p. 201-213, 2005.

PULLEMANN, M. M.; MARINISSEN, J. C. Y. Physical protection of mineralizable C in aggregates from long-term pasture and arable soil. Geoderma, v. 120, p. 273-282, 2004.

QUALLS, R. G. Biodegradability of humic substances and other fractions of decomposing leaf litter. Soil Science Society of America Journal, v. 68, n. 5, p. 1705-1712, 2004.

RAICH, J. W.; POTTER, C. S.; BHAGAWATI, D. Interannual variability in global soil respiration, 1980-94. Global Change Biology, v. 8, n. 8, p. 800-812, 2002.

REICOSKY, D. C. Carbon sequestration and environmental benefits from no-till systems. In: GODDARD, T.; ZOEBISCH, M. A.; GAN, Y.; ELLIS, W.; WATSON, A.;

SOMBATPANIT, S. (Ed.) No-till farming systems - Special publication. Bangkok: World Association of Soil and Water Conservation, 2008. v.3, p. 43-58.

RICHARD, C.; GUYOT, G.; RIVATON, A.; TRUBETSKAYA, O.; TRUBETSKOJ, O.; CAVANI, L.; CIAVATTA, C. Spectroscopic approach for elucidation of structural peculiarities of Andisol soil humic acid fractionated by SEC-PAGE set up. Geoderma, v. 142, p. 210-216, 2007.

ROCHETTE, P.; ANGERS, D. A.; CHANTIGNY, M. H.; GAGNON, B.; BERTRAND, N. $\mathrm{N}_{2} \mathrm{O}$ fluxes in soils of contrasting textures fertilized with liquid and solid dairy cattle manures. Canadian Journal of Soil Science, v. 88, n. 2, p. 175-187, 2008.

ROSSEL, R. A. V.; WALVOORT, D. J. J.; McBRATNEY, A. B.; JANIK, L. J.; SKJEMSTAD, J. O. Visible, near infrared or combined diffuse reflectance spectroscopy for simultaneous assessment of various soil properties. Geoderma, v. 131, p. 59-75, 2006.

ROYAL SOCIETY. The role of land carbon sinks in mitigation global climate change. London: Royal Society, 2001. 2 p. (Boletim de Pesquisa).

RUMPEL, C.; CHABBI, A.; NUNAN, N.; DIGNAC, M. Impact of landuse change on the molecular composition of soil organic matter. Journal of Analytical and Applied Pyrolysis, v. 85 , n. 1-2, p. 431-434, 2009.

SAINJU, U. M.; JABRO, J. D.; STEVENS, W. B. Soil carbon dioxide emission and carbon content as affected by irrigation, tillage, cropping systems, and nitrogen fertilization. Journal of Environmental Quality, v. 36, p. 97 -107, 2008. 
SAINJU, U. M.; LESSEN, A.; CAESAR-THONTHAT, T.; WADDELL, J. Carbon sequestration in dryland soils and plant residue as influenced by tillage and crop rotation. Journal of Environmental Quality, v.35, p 1341-1347, 2006.

SALVO, L.; HERNANDEZ, J; ERNST, O. Distribution of soil organic carbon in different size fractions, under pasture and crop rotations with conventional tillage and no-till systems. Soil \& Tillage Research, v. 109, p. 116-122, 2010

SANTOS, L. M.; SIMOES, M. L.; MELO, W. J.; MARTIN-NETO, L.; PEREIRA-FILHO, E. R. Application of chemometric methods in the evaluation of chemical and spectroscopic data on organic matter from Oxisols in sewage sludge applications. Geoderma, v. 155, p. 121$127,2010$.

SCHAEFER, D. A.; FENG, W.; ZOU, X. Plant carbon inputs and environmental factors strongly affect soil respiration in a subtropical forest of southwestern China. Soil Biology \& Biochemistry, v. 41, p. 1000-1007, 2009.

SCHAHCZENSKI, J.; HILL, H. Agriculture, climate change and carbon sequestration. Butte: ATTRA, 2009. 16 p. (Boletim de Pesquisa).

SCHIMEL, D. S.; HOUSE, J. I.; HIBBARD, K. A.; BOUSQUET, P.; CIAIS, P.; PEYLIN, P.; BRASWELL, B. H.; APPS, M. J.; BAKER, D.; BONDEAU, A.; CANADELL, J.; CHURKINA, G.; CRAMER, W.; DENNING, A. S.; FIELD, C. B.; FRIEDLINGSTEIN, P.; GOODALE, C.; HEIMANN, M.; HOUGHTON, R. A.; MELILLO, J. M.; MOORE III, B.; MURDIYARSO, D.; NOBLE, I.; PACALA, S. W.; PRENTICE, I. C.; RAUPACH, M. R.; RAYNER, P. J.; SCHOLES, R. J.; STEFFEN, W. L.; WIRTH, C. Recent patterns and mechanisms of carbon exchange by terrestrial ecosystems. Nature, v. 414, p. 169-172, 2001.

SCHNITZER, M.; MONREAL, C. M. Quo vadis soil organic matter research? In: SPARKS, D. L. (Ed.) Advances in agronomy. New York: Academic Press, 2011. v. 108, p. 143-217.

SCHULTEN, H. R.; SCHNITZER, M. A state of art structural concept for humic substances. Naturwissenschaften, v. 80, p. 29-30, 1993.

SCIALABBA, E. N.; MÜLLER-LINDENLAUF, M. Organic agriculture and climate change. Renewable Agriculture and Food Systems, v. 25, n.2, p. 158-169, 2010.

SENESI, N.; PLAZA, C.; BRUNETTI, G.; POLO, A. A comparative survey of recent results on humic-like fractions in organic amendments and effects on native soil humic substances.

Soil Biology \& Biochemistry, v. 39, p. 1244-1262, 2007.

SHAVER, G. R.; CANADELL, J.; CHAPIN III, F. S. Global warming and terrestrial ecosystems: a conceptual framework for analysis. Bioscience, v. 50, p. 871-882, 2000.

SHETTO, R. M. Indigenous soil conservation tillage systems and risk of animal traction on land degradation in Eastern and Southern Africa. In: KAUMBUTHO, P. G.; SIMALENGA, T. E. (Ed.) Conservation tillage with animal traction. Harare, Zimbabwe: ATNESA, 1999. p. 67-73. 
SILVA, D. K. A.; FREITAS, N. O.; SOUZA, R. G.; SILVA, F. S. B.; ARAUJO, A. S. F.; MAIA, L. C. Soil microbial biomass and activity under natural and regenerated forests and conventional sugarcane plantations in Brazil. Geoderma, v. 189-190, p. 257-261, 2012.

SIMON, T.; JAVUREK, M.; MIKANOVÁ, O.; VICH, M. The influence of tillage systems in soil organic matter and soil hydrophobicity. Soil \& Tillage Research, v. 105, p. 44-48, 2009.

SIMPSON, A. J.; KINGERY, W. L.; SWAW, D. R.; SPRAUL, M.; HUMPFER, E.; DVORTSAK, P. Molecular structures and associations of humic substances in the terrestrial environment. Naturwissenschaften, v. 89, p. 84-88, 2002.

SINGH, K.P.; GHOSHAL, N.; SINGH, S. Soil carbon dioxide flux, carbon sequestration and crop productivity in a tropical dryland agroecosystem: Influence of organic inputs of varying resource quality. Applied Soil Ecology, v. 42, p. 243-253, 2009.

SIX, J.; ELLIOT, E. T.; PAUSTIAN, K. DORAN, J. W. Aggregation and soil organic matter accumulation in cultivated and native grassland soils. Soil Science Society of America Journal, v. 62, p. 1367-1377, 1998.

SIX, J.; PAUSTIAN, K.; ELLIOT, E. T.; COMBRINK, C. Soil structure and organic matter: I. distribution of aggregate-size classes and aggregate-associate carbon. Soil Science Society of America Journal, v. 64, p. 681-689, 2000.

SIX, J.; FELLER, C.; DENEF, K.; OGLE, S. M.; SÁ, J. C. M.; ALBRETCH, A. Soil organic matter, biota and aggregation in temperate and tropical soils - effect of no-tillage.

Agronomie, v. 22, p. 755-775, 2002.

SIX, J.; BOSSUYT, H.; DEGRYZE, S.; DENEF, K. A history of research on the link between (micro)aggregates, soil biota, and organic matter dynamics. Soil \& Tillage

Research, v. 79, n. 1, p. 7-31, 2004.

SKOOG, D. A.; HOLLER, F. J.; NIEMAN, T. A. Princípios de análise instrumental. Porto Alegre: Bookman, 2002. 836 p.

SMIDT, E.; PARRAVACINI. Effect of sewage sludge treatment and additional aerobic poststabilization revealed by infrared spectroscopy and multivariate data analysis. Bioresource Technology, v. 100, p. 1775-1780, 2009.

SMITH, J.; SMITH, P.; WATTENBACH, M.; ZAEHLE, S.; HIEDERER, R.; JONES, R. J. A.; MONTANARELLA, L.; ROUNSELL, M. D. A.; REGINSTER, I.; EWERT, F. Projected changes in mineral soil carbon of European croplands and grasslands, 1990-2080. Global

Change Biology, v. 11, n. 12, p. 2141-2152, 2005.

SMITH, P. Carbon sequestration in croplands; the potential in Europe and the global context. European Journal of Agronomy, v. 20, p. 229-236, 2004a.

SMITH, P. Engineered biological sinks on land. In: FIELD, C. B.; RAUPACH, M. R. (Ed.) The global carbon cycle: integrating humans, climate, and the natural world. Washington, DC: Island Press, 2004b. p. 479-491. 
SMITH, P. Soils as carbon sinks: the global context. Soil Use and Management, v. 20, p. 212-218, 2004c.

SMITH, P.; MARTINO, D.; CAI, Z.; GWARY, D.; JANSEN, H.; KUMAR, P.; McCARL, B.; OGLE, S.; O’MARA, F.; RICE, C.; SCHOLES, B.; SIROTENKO, O. Agriculture. In: METZ, B.; DAVIDSON, O. R.; BOSCH, P. R.; DAVE, R.; MEYER, L. A. (Ed.) Climate change 2007: mitigation. Contribution of working group III to the fourth assessment report of the Intergovernmental Panel on Climate Change. Cambridge: Cambridge University, 2007. p. 497-541.

SMITH, P.; DAVIES, C. A.; OGLE, S.; ZANCHI, G.; BELLARBY, J.; BIRD, N.; BODDEY, R. M.; McNAMARA, N. P.; POWLSON, D.; COWIE, A.; VAN NOORDWIJK, M.; DAVIS, S. C.; RICHTER, D. B.; KRYZANOVSKI, L.; VAN WIJK, M. T.; STUART, J.; KIRTON, A.; EGGAR, D.; NEWTON-CROSS, G.; ADHYA, T. K.; BRAIMOH, A. K. Towards an integrate global framework to assess the impacts of land use and management change on soil carbon: current capability and future vision. Global Change Biology, v. 18, n. 7, p. 2089-2101, 2012.

SNAPP, S. S.; SWINTON, S. M.; LABARTA, R.; MUTCH, D.; BLACK, J. R.; LEEP, R.; NYIRANEZA, J.; O’NEIL, K. Evaluating cover crops for benefits, costs and performance within cropping systems niches. Agronomy Journal, v. 97, p. 322-332, 2005.

SOTOMAYOR, M. D. P. T.; DIAS, I. L. T.; LANZA, M. R. V.; MOREIRA, A. B.; KUBOTA, L. T. Aplicação e avanços na espectroscopia de luminescência em análises farmacêuticas. Química Nova, v. 31, n. 7, p. 1755-1774, 2008.

SPARGO, J. T.; CAVIGELLI, M. A.; MIRSKY, S. B.; MAUL, J. E.; MEISINGER, J. J. Mineralizable soil nitrogen and labile soil organic matter in diverse long-term cropping systems. Nutrient Cycling in Agroecosystems, v. 90, n. 2, p. 253-266, 2011.

STENBERG, B.; ROSSEL, R. A. V.; MOAUZEN, A. M.; WETTERLIND, J. Visible and near infrared spectroscopy in soil science. In: SPARKS, D. L. (Ed.) Advances in agronomy. Burlington: Academic Press, 2010. v. 107, p. 163-215.

STEVENSON, F.J. Humus chemistry: genesis, composition, reactions. New York: John Wiley, 1994. $496 \mathrm{p}$.

STEWART, C.E. Evaluation of angiosperm and fern contributions to soil organic matter using two methods of pyrolysis-gas chromatography-mass spectroscopy. Plant Soil, v. 351, p. 31-46, 2012.

STOCKMANN, U.; ADAMS, M. A.; CRAWFORD, J. W.; FIELD, D. J.; HENAKAARCHCHI, N.; JENKINS, M.; MINASNY, B.; McBRATNEY, A. B.; COURCELLES, V. R.; SINGH, K.; WHEELER, I.; ABBOTT, L.; ANGERS, D. A.; BALDOCK, J.; BIRD, M.; BROOKES, P. C.; CHENU, C.; JASTROW, J. D.; LAL, R.; LEHMANN, J.; O'DONELL, A. G.; PARTON, W. J.; WHITEHEAD, D.; ZIMMERMANN, M. The knowns, known unknowns and unknowns of sequestration of soil organic carbon. Agriculture, Ecosystems and Environment, v. 164, p. 80-99, 2013. 
SUBKE, J.; VOKE, N. R.; LERONNI, V.; GARNETT, N. H.; INESON, P. Dynamics and pathways of autotrophic and heterotrophic soil $\mathrm{CO}_{2}$ efflux revealed by forest girdling. Journal of Ecology, v. 99, n. 1, p. 186-193, 2011.

SUDDICK, E. C.; SCOW, K. M.; HORWATH, W. R.; JACKSON, L. E.; SAMRT, D. R.; MITCHELL, J.; SIX, J. The potential for California agricultural crop soils to reduce greenhouse gas emissions: a holistic evaluation. In: SPARKS, D. L. (Ed.) Advances in agronomy. Burlington: Academic Press, 2010. v. 107, p. 123-162.

SWIFT, R. S. Macromolecular properties of soil humic substances: fact, fiction, and opinion. Soil Science, v. 164, n. 11, p. 790-802, 1999.

TANDY, S.; HEALEY, J. R.; NASON, N. A.; WILLIAMSON, J. C.; JONES, D. L.; THAIN, S. C. FT-IR as an alternative method for measuring chemical properties during composting. Bioresource Technology, v. 101, p. 5431-5436, 2010.

TEJADA, M.; GONZALEZ, J. L.; GARCÍA-MARTÍNEZ, A. M.; PARRADO, J. Application of a green manure and green manure composted with beet vinasse on soil restoration: effects on soil properties. Bioresource Technology, v. 99, n. 11, p. 4949-4957, 2008.

THANGARAJAN, R.; BOLAN, N. S.; TIAN, G.; NAIDU, R.; KUNHIKRISHNAN, A. Role of organic amendment application on greenhouse gas emission from soil. Science of the Total Environment, p. 1- 25, 2013.

THELEN, K. D.; FRONNING, B. E.; KRAVCHENKO, D. H.; MIN, D. H.; ROBERTSON, G. P. Integrating livestock manure with a corn-soybean bioenergy cropping system improves short-term carbon sequestration rates and net global warming potential. Biomass and Bioenergy, v. 34, n. 7, p. 960-966, 2010.

THERMO SPECTRONIC. Basic UV-VIS theory, concepts, and applications. Disponível em : <www.thermo.com>. Acesso em: 10 maio 2012.

TRIBERTI, L.; NASTRI, A.; GIORDANI, G.; COMELLINI, F.; BALDONI, G.; TODERI, G. Can mineral and organic fertilization help sequestrate carbon dioxide in cropland ?

European Journal of Agronomy, v. 29, p. 13-20, 2008.

TRIPLETT, G. B.; DICK, W. A. No-tillage crop production: a revolution in agriculture ! Agronomy Journal, v. 100, n. S3, p. s153-s165, 2008.

TRUMBORE, S. E. Potential responses of soil organic carbon to global environmental change. Proceedings of the National Academy of Sciences of the United States of America, v. 94, n. 16, p. 8284-8291, 1997.

UNGER, P. W.; JONES, O. R. Long-term tillage and cropping systems affect bulk density and penetration resistance of soil cropped to dryland wheat and grain sorghum. Soil \& Tillage Research, v. 45, n. 1-2, p. 39-57, 1998.

VAN ES, H. M.; GOMES, C. P.; SELLMAN, M.; VAN ES, C. L. Spatially-balanced complete block designs for field experiments. Geoderma, v. 140, p. 346-352, 2007. 
VANCAMPENHOUT, K.; VOS, B.; VAUTERS, K.; CALSTER, H. V.; SWENNEN, R.; BUURMAN, P.; DECKERS, J. Determinants of soil organic matter chemistry in maritime temperate forest ecosystems. Soil Biology \& Biochemistry, v. 42, p. 220 - 233, 2010.

VANDENBYGAART, A. J.; ANGERS, D. A. Towards accurate measurements of soil organic carbon stock change in agroecosystems. Canadian Journal of Soil Science, v. 86, p. 465-471, 2006.

VERCHOT, L. V.; DUTAUR, L.; SHEPHERD, K. D.; ALBRECHT, A. Organic matter stabilization in soil aggregates: Understanding the biogeochemical mechanisms that determine the fate of carbon inputs in soils. Geoderma, v. 161, p. 182-193, 2011.

VERGNOUX, A.; GIULIANO, M.; ROCCO, R.; DOMEIZEL, M.; THERAULAZ, F.; DOUMENQ, P. Quantitative and mid-infrared changes of humic substances from burned soils. Environmental Research, v. 111, n. 2, p. 205-214, 2011.

VIJAYAVENGATARAMAN, S.; INIYAN, S.; GOIC, R. A review of climate change, mitigation and adaptation. Renewable and Sustainable Energy Reviews, v. 16, p. 878 897, 2012.

VRIES, W.; POSCH, M. Modelling the impact of nitrogen deposition, climate change and nutrient limitations on tree carbon sequestration in Europe for the period 1900-2050.

Environmental Pollution, p. 1-11, 2010.

WANDER, M. M.; BOLLERO, G. A. Soil quality assessment of tillage impacts in Illinois. Soil Science Society of America Journal, v. 63, n. 4, p. 961-971, 1999.

WANDER, M. M.; YANG, X. Influence of tillage on the dynamics of loose- and occludedparticulate and humified organic matter fractions. Soil Biology \& Biochemistry, v. 72, p. 1151-1160, 2000.

WANG, Q.; WANG, S. Response of labile soil organic matter to changes in forest vegetation in subtropical regions. Applied Soil Ecology, v. 47, p. 210-216, 2011.

WATSON, C. A.; ATKINSON, D.; GOSLING, P.; JACKSON, L. R.; RAYNS, F. W. Managing soil fertility in organic farming systems. Soil Use Management, v. 18, p. 239-247, 2002.

WELLS, T.; HANCOCK, G. R.; DEVER, C.; MURPHY, D. Prediction of vertical soil organic carbon profiles using soil properties and environmental tracer data at an untilled site. Geoderma, v. 170, p. 337-346, 2012.

WENDE, W.; WOJTKIEWICZ, W.; MARSCHALL, I.; HEILAND, S.; LIPP, T.; REINKE, M.; SCHAAL, P.; SCHMIDT, C. Putting the plan into practice: implementation of proposals for measures of local landscape plans. Landscape Research, v. 37, n. 4, p. 483-500, 2012.

WERSHAW, R. L. Evaluation of conceptual models of natural organic matter (humus) from a consideration of the chemical and biochemical process of humification. Reston: US Geological Survey, 2004. 49 p. (Boletim de Pesquisa). 
WEST, T. O.; POST, W. M. Soil organic carbon sequestration rates by tillage and crop rotation: a global data analysis. Soil Science Society of America Journal, v. 66, p. 19301946, 2002.

WILLSON, T. C.; PAUL, E. A.; HARWOOD, R. R. Biologically active soil organic matter fractions in sustainable cropping systems. Applied Soil Ecology, v. 16, p. 63-76, 2001.

WILSON, K. B.; MEYERS, T. P. The spatial variability of energy and carbon dioxide fluxes at the floor of a deciduous forest. Boundary-Layer Meteorology, v. 98, n. 3, p. 443-473, 2001.

YAN, Y.; TIAN, J.; FAN, M.; ZHANG, F.; LI, X.; CHRISTIE, P.; CHEN, H.; LEE, J.; KUZYAKOV, Y.; SIX, J. Soil organic carbon and total nitrogen in intensively managed arable soils. Agriculture, Ecosystems and Environment, v. 150, p. 102-110, 2012.

ZANG, X.; HATCHER, P. G. A Py-GC-MS and NMR spectroscopic study of organic nitrogen in Mangrove Lake sediments. Organic Geochemistry, v. 33, n. 3, p. 201-211, 2002.

ZHOU, Z.; ZHANG, Z.; ZHA, T.; LUO, Z.; ZHENG, J.; SUN, O. J. Predicting soil respiration using carbon stock in roots, litter and soil organic matter in forests in Loess Plateau in China. Soil Biology and Biochemistry, v. 57, p. 135-143, 2013.

ZIMMERMAN, A. R.; GAO, B.; AHN, M. Positive and negative carbon mineralization priming effects among a variety of biochar-amended soils. Soil Biology and Biochemistry, v. 43, n. 6, p. 1169-1179, 2011.

ZORNOZA, R.; FAZ, A.; CARMONA, D. M.; ACOSTA, J. A.; MARTÍNEZ-MARTÍNEZ, S. Carbon mineralization, microbial activity and metal dynamics in tailing ponds amended with pig slurry and marble waste. Chemosphere, v. 90, p. 2606-2613, 2013.

ZOTARELLI, I.; ALVES, B. J. R.; URQUIAGA, S.; BODDEY, R. M.; SIX, J. Impact of tillage and crop rotation on light fraction and intra-aggregate soil organic matter in two Oxisols. Soil \& Tillage Research, v. 95, p. 196-206, 2007.

ZSOLNAY, A.; BAIGAR, E.; JIMENEZ, M.; STEINBERG, B.; SACCOMANDI, F. Differentiating with fluorescence spectroscopy the sources of dissolved organic matter in soils subjected to drying. Chemosphere, v. 38, n. 1, p. 45-50, 1999. 